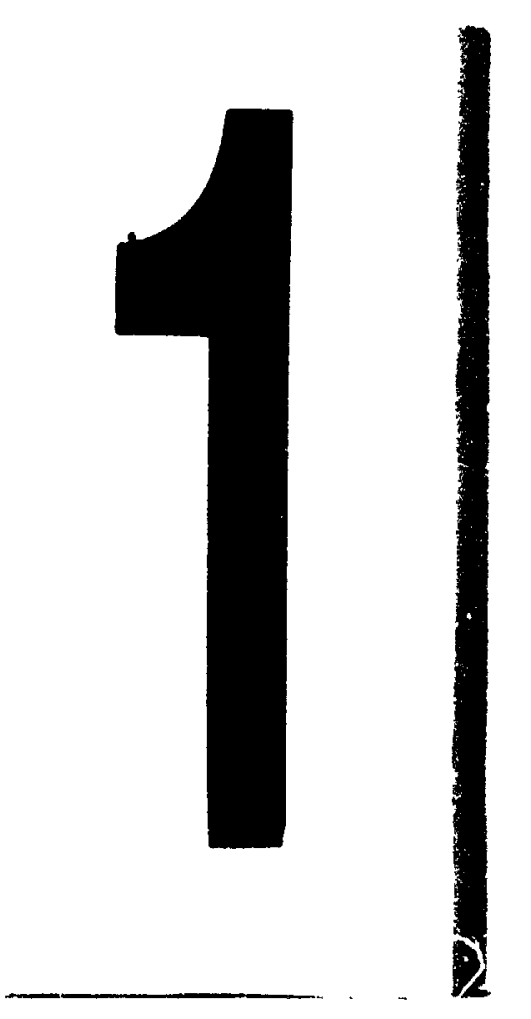

PM-1 3\%" "X4" PHOTOGRAPHIC MICROCOPY TARGET NAS 1010 ANSIISO "2 EOUTUALET

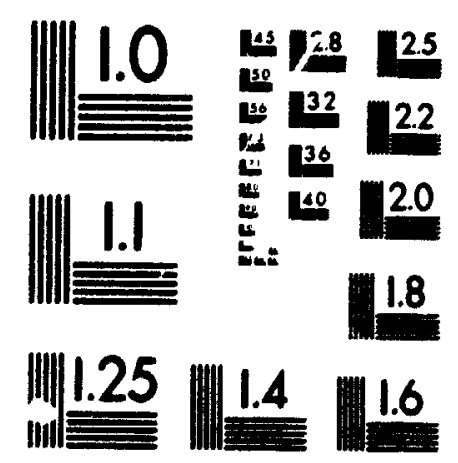

PRECISHONEM RESOUTION TARGETS

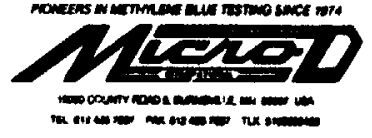


National Library

of Canada

Acquisitions and

Bibliographic Services Branch

395 Wellington Street

Ottawa, Ontario

K1A ON4
Bibliotheque nationale

du Canada

Direct:un des acquisitions et

des services bibliographiques

395, rue Wellington

Ottawa (Onlano)

KIA ON4

NOTICE

AVIS

The quality of this microform is heavily dependent upon the quality of the original thesis submitted for microfilming. Every effort has been made to ensure the highest quality of reproduction possible.

If pages are missing, contact the university which granted the degree.

Some pages may have indistinct print especially if the original pages were typed with a poor typewriter ribbon or if the university sent us an inferior photocopy.
La qualité de cette microforme dépend grandement de la qualité de la thèse soumise au microfilmage. Nous avons tout fait pour assurer une qualité supérieure de reproduction.

S'il manque des pages, veuillez communiquer avec l'université qui a conféré le grade.

La qualité d'impression de certaines pages peut laisser à désirer, surtout si les pages originales ont été dactylographiées à l'aide d'un ruban usé ou si l'université nous a fait parvenir une photocopie de qualité inférieure.

La reproduction, même partielle, de cette microforme est soumise à la Loi canadienne sur le droit d'auteur, SRC 1970, c. C-30, et ses amendements subséquents.
Reproduction in full or in part of this microform is governed by the Canadian Copyright Act, R.S.C. 1970, c. C-30, and subsequent amendments.

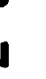

.




\title{
Experimental Investigation of the Ventilation Air Flow Properties in an Office Space
}

\author{
by \\ Jouini Dhafer B. \\ B. Sc. (Mechanical Engineering), University of Ottawa \\ A thesis submitted to \\ the Faculty of Graduate Studies and Research \\ in partial fulfillment of \\ the requirements for the degree of \\ Master of Engineering \\ Department of Mechanical \\ and Aerospace Engineering \\ Carleton University \\ Ottawa, Ontario \\ June 1992 \\ () Copyright \\ 1992, Jouini Dhafer B.
}


National Library

of Canada

Acquisitions and

Bibliographic Services Branch

395 Wellinglon Street

Onawa. Ontarıo

KIA ON4
Bibliotreque nationale

du Canacia

Direction des acquisitions et

des services bibliographiques

395. ruf: Wellington

Ottawa (Ontario)

KIACN4
The author has granted an irrevocable non-exclusive licence allowing the National Library of Canada to reproduce, loan, distribute or sell copies of his/her thesis by any means and in any form or format, making this thesis available to interested persons.

The author retains ownership of the copyright in his/her thesis. Neither the thesis nor substantial extracts from it may be printed or otherwise reproduced without his/her permission.
L'auteur a accordé une licence irrévocable et non exclusive permettant à la Bibliothéque nationale du Canada de reproduire, prêter, distribuer ou vendre des copies de sa thèse de quelque manière et sous quelque forme que ce soit pour mettre des exemplaires de cette thèse à la disposition des personnes intéressées.

L'auteur conserve la propriété du droit d'auteur qui protège sa thèse. Ni la thèsé ni des extraits substantiels de celle-ci ne doivent être imprimés ou autrement reproduits sans son autorisation. 
The undersigned hereby recommend to the Faculty of Graduate Studies and Research acceptance of the thesis,

\section{Experimental Investigation of the Ventilation Air Flow Properties in an Omce Space}

Submitted by

Jouini Dhafer B., B. Sc. (Mechanical Engineering),

in partial fulfillment of the requirements

for the degree of Master of Engineering

$732-1$

Chair, Departrnent of Mechanical and Aerospace Engineering

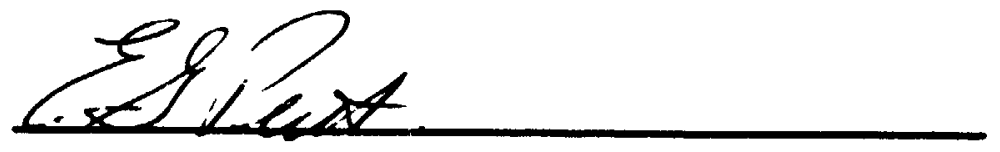

Thesis Supervisor

\section{Carleton University}

June 1992 


\section{ABSTRACT}

Results of measurements of the flow properties in the mid-plane of an office space $(4.75 \mathrm{~m} \times 4.87 \mathrm{~m} \times 2.87 \mathrm{~m})$ are presented. The flow properties are presented in terms of the spatial distributions of the air flow velocity, turbulence intensity, turbulent kinetic energy, temperature, and contaminant concentration. Flow visualization using a helium filled soap bubble technique and smoke filaments were used to visualize room air flow patterns. The effect of the air flow rate and the presence of partitions on the air flow distribution are examined experimentally. The EXACT3 code is used to predict some of the experimental tests. The discrepancy between the numerical and the experimental results is attributed to the numerical scheme, and to false diffusion at the supply diffuser.

The measurements conducted are intended for use in the evaluation of the existing numerical and scale models, and to aid in furthering the understanding of the behavior of room ventilation air flows. 


\section{ACKNOWLEDGMENTS}

I express gratitude and appreciation to my thesis supervisor Professor E. G. Plett for his suggestions, guidance and support through this research. I am deeply indebted to Dr. Mohammed Nady Said (Research Officer at the National Research Council of Canada (NRC)) for his availability for discussions, and his encouragement, and guidance throughout this research. Also, I am indebted to the Building Performance Section (NRC) for providing the facilities and the instruments needed in this study. Thanks to Mr. Cabot Broughton for his help with the experimental set-up. Thanks also to my friend Dr. Achilles Karagiozis (Research Officer at the National Research Council of Canada (NRC)) for his encouragement and help with the computer system of the Building Performance Section.

The financial support, provided by the Scientific mission of Tunisia and the Department of Mechanical and Aerospace Engineering, Carleton University, is greatly appreciated.

Finally, I wish to express my gratitude to my family for their encouragement and guidance, and 1 dedicate this thesis to them. 


\section{TABLE OF CONTENTS}

ABSTRACT

ACKNOWLEDGMENTS.......................................................................................... II

TABLE OF CONTENTS ..................................................................................................... Iif

LIST OF TABLES ................................................................................................................... vi

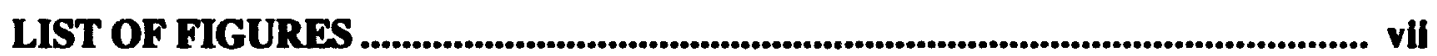

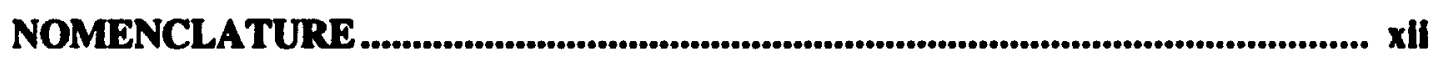

1 INTRODUCTION 1

$1.1 \quad$ Problem Outline ........................................................................... I

$1.2 \quad$ Thesis Outline and Objective ............................................................. 3

2 LITERATURE REVIEW 6

$2.1 \quad$ Numerical Investigation................................................................ 6

$2.2 \quad$ Experimental Investigation ............................................................ 15

3 The NUMERICAL MODEL 23

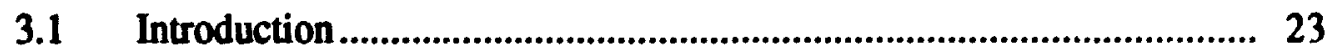

3.2 Calculation Procedure................................................................... 24

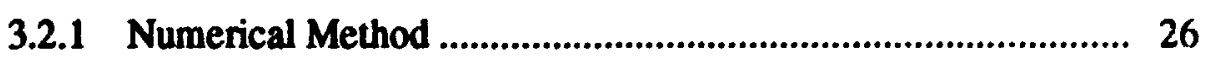

3.2.2 Boundary Conditions................................................................ 28

3.2.2.1 Inflow conditions................................................... 29

3.2.2.2 Outflow conditions .................................................. 29

3.2.2.3 Wall boundary conditions ......................................... 30

3.2.2.4 Energy wall boundary conditions............................ 30

4 EXPERIMENTAL FACILITIES AND INSTRUMENTATION 31

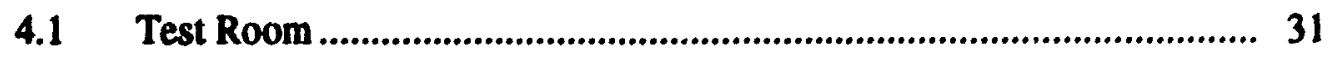

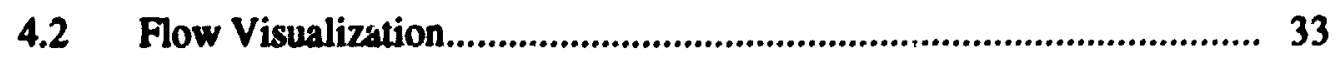


4.2.1 Lighting Unit ................................................................................ 33

4.2.2 Helium-Filled Soap Bubbles...................................................... 34

4.2.3 Smoke Filament Technique .................................................... 34

4.3 Flow Rate Measurements................................................................ 35

4.4 Velocity and Temperature Measurements ............................................. 36

4.4.1 Description of the Multiflow Analyzer DANTEC 54N10 ......... 36

4.4.2 Description of the 54R10 Low Velocity Transducers ............... 37

4.5 Traversing Mechanism....................................................................... 37

4.6 Contaminant Measurement System ......................................................... 38

4.7 The Tracer Gas ......................................................................................... 39

5 TEST PROCEDURE AND ACCURACY 40

5.1 Experimental Procedure................................................................... 40

5.1.1 Determination of the Steady State Conditions ............................ 40

5.1.2 Methodology of Flow Visualization ........................................... 41

5.1.3 Methodology of Velocity, Temperature, and Turbulence Intensity Measurements............................................................. 42

5.1.3.1 Directional sensitivity ............................................. 42

5.1.3.2 Frequency response..................................................... 43

5.1.3.3 Influence of changing temperature.............................. 43

5.1.3.4 Measurements of air temperature ............................. 43

5.1.3.5 Influence of natural convection................................. 44

5.1.4 Methodology of Contaminant Measurements............................ 44

$5.2 \quad$ Numerical Computations .................................................................... 45

6 RESULTS AND DISCUSSION 49

6.1 Test Conditions..................................................................................49 49

6.1.1 Flow Visualization Test Conditions............................................ 50 
6.1.2 Velocity, Temperature and Turbulence Intensity Test

Conditions................................................................................ 50

6.1.3 Contaminant Concentration Measurements Test Conditions ..... 51

$6.2 \quad$ Experimental Results ................................................................................ 52

6.2.1 Flow Visualization Results ................................................... 52

6.2.2 Velocity, Temperature, Turbulence Intensity, and

Turbulence Kinetic Energy Distributions ................................... 56

6.2.2.1 Velocity distribution ................................................ 56

6.2.2.2 Spatial distribution of turbulence intensity ............... 57

6.2.2.3 Spatial distribution of turbulence kinetic energy ...... 58

6.2.2.4 Spatial temperature distribution ................................ 59

6.2.3 Contaminant Concentration Distribution ................................. 59

6.2.4 Uncertainty in the measurements.............................................61 61

6.2.4.1 Repeatability.............................................................61 61

6.2.4.2 Low velocity transducers readings ............................61 61

6.2.4.3 Variation of the velocity readings with the sampling location .................................................. 62

6.3 Numerical Results.................................................................................. 62

7 CONCLUSIONS AND RECOMMENDATIONS 65

REFERENCES................................................................................................................68

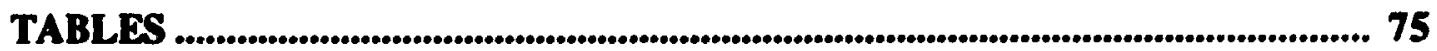

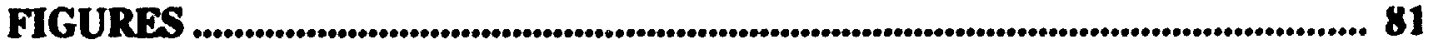

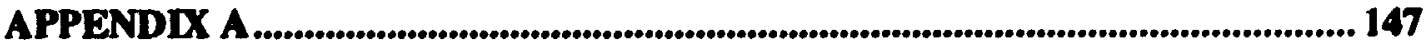




\section{LIST OF TABLES}

5.1 Summary of the experimental tests conducted ............................................. 75

5.2 Some of the various correlations used to specify the dissipation rate of the turbulence kinetic energy $(\varepsilon)$ at the supply diffuser ....................................... 76

6.1.a Flow visualization test conditions ................................................................ 77

6.1.b Comparison between the set point and the measured flow rates through the supply and return orifice plates during the flow visualization .................. 77

6.1.c Velocity, temperature, and turbulence intensity measurements test conditions

6.1.d Comparison between the set point and the measured flow rates throught the supply and return orifice plates during the measurements of the velocity, the temperature, and the turbulence intensity ................................ 78

6.1.e Contaminant concentration measurements test conditions.............................. 79

6.1.f Comparison between the set point and the measured flow rates through the supply and retum orifice plates during the contaminant concentration measurements.

6.2 Average non-dimensional velocity in the test room ...................................... 80

6.3 Vertical temperature distribution in the test room ............................................ 80

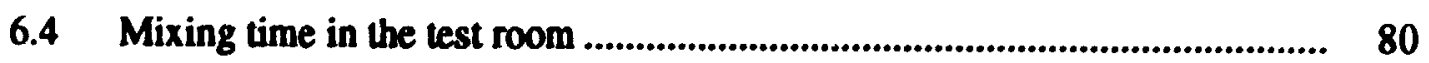




\section{LIST OF FIGURES}

3.1 Staggered mesh system (Reference 3) ............................................................

3.2 Solution procedure for the momentum equations (Reference 3)....................... 82

3.3 Solution procedure for the scalar equations (Reference 3) ................................ 83

3.4 Mesh layout near boundary (Reference 3) ................................................. 83

4.1 Test room facility and c̈imensions, $L=4.75 \mathrm{~m}, \mathrm{H}=2.87 \mathrm{~m}, \mathrm{~W}=4.87 \mathrm{~m}$, $w=1.016 \mathrm{~m}, \mathrm{~h}=0.0127 \mathrm{~m}$.......................................................................... 84

4.2 Locations of the ceiling-mounted diffusers ..................................................... 85

4.3 Sampling locations for the velocity, temperature, and contaminant

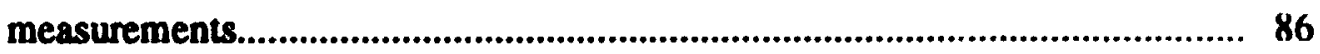

$4.4 \quad$ Light sheet system....................................................................................... 87

4.5 SAI bubble generator .............................................................................. 88

4.6 Schematic diagram of the helium-filled soap bubble technique......................... 89

4.7 Schematic diagram of the smoke filament technique ........................................ 90

4.8 Test room HVAC system ........................................................................... 91

4.9 Velocity, temperature, turbulence intensity measuring system ......................... 92

4.10 Low Velocity Transducer 54R10................................................................... 93

4.11 Traversing mechanism................................................................................... 94

4.12 Schematic diagram of a sampling system with backflushing (Reference 2)..... 95

4.13.a System I for contaminant concentration measurements................................... 96

4.13.b System II for contaminant concentration measurements .................................. 97

4.14 Vertical distribution of the contaminant concentration sampling tubes............. 98

5.1 Smoke tube, bubble generator heads, and sampling tree positions .................... 99

5.2 Experimental grid $(9 \times 21)$ points ................................................................... 100

5.3.a Effect of the integration time on the measured mean velocity, IT $=20$ 
minutes 101

5.3.b Efrect of the integration time on the measured mean velocity, $\mathrm{IT}=2$

minutes 102

5.4 Variation of the velocity with a) the roll angle, and b) the yaw angle (Reference 1) 103

5.5 Influence of natural convection at low velocities (Reference 1) ..................... 103

5.6 Contaminant source location ............................................................................... 104

5.7 Ceumetry and dimensions of the test model used by Nielsen [26]. $\mathrm{H}=3.0$

$m, L=9.0 \mathrm{~m}, \mathrm{~h}=0.168 \mathrm{~m}$, and $\mathrm{t}=0.48 \mathrm{~m}$ 105

5.8 Velocity and turbulence kinetic energy distribution at an early stage (4000 time step itentions), a) and c) at $\mathrm{Y} / \mathrm{H}=1.0, \mathrm{~b}$ ) and e) at $\mathrm{Y} / \mathrm{H}=\mathbf{2 . 0}$ 106

5.9 Velocity and turbulence kinetic energy distribution at an intermediate stage (8000 time step iterations), a) and c) at $Y / H=1.0, b)$ and $e$ ) at $\mathbf{Y} / \mathbf{H}=\mathbf{2 . 0}$ 107

5.10 Velocity and turbulence kinetic energy distribution at the steady state stage (13000 time step iterations), a) and c) at $Y / A=1.0, b)$ and e) at $\mathbf{Y} / \mathbf{H}=\mathbf{2 . 0}$ 108

5.11.a Velocity (Ud), Turbulence kinetic energy (2k/(Ud)2), and Turbulence intensity $\left(T I=\left(u^{\prime} / U\right)\right)$ along the supply diffuser for a) $1.5 \mathrm{ACH}$, and b) 3 ACH 109

5.11.b Velocity (Ud), Turbulence kinetic energy (2kJ(Ud)2), and Turbulence intensity (TI=(u'/U)) across the supply diffuser for $3 \mathrm{ACH}(\mathrm{a}), \mathrm{b})$, and c)), and for $1.5 \mathrm{ACH}(\mathrm{d}), \mathrm{e})$, and $\mathrm{f}$ ) 110

6.1.a Flow visualization using bubbles in the mid-plane of the test mom, T01 112

6.1.b Flow visualization using emoke in the mid-plane of the test room, T01 113

6. 1.c Flow visualization using bubbles in the mid-plane of the test room, T05, 
partition height $=5.5 \mathrm{ft}$, gap $=6.0$ inches, partition located in the center of the room 114

6.1.d Flow visualization using bubbles in the mid-plane of the test room, T04, partition height $=6.5 \mathrm{ft}$, gap $=0.0$ inches, partition located in the center of the room

6.1.e Qualitative sketches of observations of the air flow pattem in the midplane of the test room, for test T01, test T04, and test T05

6.2 Spatial distribution of a) the velocity, and b) the turbulence intensity in the mid plane of the test room, for test T01

6.3 Spatial distribution of a) the velocity, and b) the turbulence intensity in the mid plane of the test room, for test T02

6.4 Spatial distribution of a) the velocity, ard b) the turbulence intensity in the mid plane of the test room, for test T03

6.5 Spatial distribution of a) the velocity, and b) the turbulence intensity in the mid plane of the test room, for test T04

6.6 Spatial distribution of a) the velocity, and b) the turbulence intensity in the mid plane of the test room, for test T05.

6.7 Spatial distribution of a) the velocity, and b) the turbulence intensity in the mid plane of the test room, for lest T06

6.8 Spatial distribution of the turbulence kinetic energy in the mid-plane of the test room for the tests a) T01, b) T02, c) T03, d) T04, e) T05, and f) T06

6.9 Spatial distribution of the temperature in the mid-plane of the test room for the tesis a) T01, b) T02, c) T03, d) T04, e) T05, and f) T06 126

6.10 Vertical distribution of the average temperature, measured on a horizontal line in the mid-plane of the test room for the tests a) T01, 
b) $\mathrm{T} 02$, c) $\mathrm{T} 03$, d) $\mathrm{T} 04, \mathrm{e}) \mathrm{T} 05$, and f) $\mathrm{T} 06$.

6.11 Contaminant concentration distribution in the test room for test T01

(3 ACH)

6.12 Contaminant concentration distribution in the test room for test T02

(1.5 ACH)

6.13 Contaminant concentration dL.tribution in the test room for test $\mathrm{T} 03$,

partition height $=6.5 \mathrm{ft}$, gap $=6.0$ inches, partition located in the center

of the room

131

6.14 Contaminant concentration distribution in the test room for test T04,

partition height $=6.5 \mathrm{ft}$, gap $=0.0$ inches, partition located in the center

of the room

6.15.a Contaminant concentration distribution in the test room for test T05, position $\mathrm{Cl}$, partition height $=5.5 \mathrm{ft}$, gap $=6.0$ inches, partition located in the center of the room

6.15.b Contaminant concentration distribution in the test room for test $\mathrm{T} 05$, position C2, partition height $=5.5 \mathrm{ft}$, gap $=6.0$ inches, partition located in the center of the room

6.16 Contaminant concentration distribution in the test room for test T06, partition height $=5.5 \mathrm{ft}$, gap $=0.0$ inches, partition located in the center of the room 133

6.17 Initial and final readings of the velocity and the temperature in the midplane of the test room 134

6.18 Typical horizontal velocity distribution in the mid-plane of the test room ........ 137

6.19 Predicted a) velocity contour, and b) velocity vector distributions in the mid-plane of the test room, for test T01, inflow angle $=16^{\circ}$ 138

6.20 Predicted a) velocity contour, and b) velocity vector distributions in the 
mid-plane of the test room, for test T04. inflow angle $=16^{\circ}$.

6.21 Predicted a) velocity contour, and b) velocity vector distributions in the mid-plane of the test room, for test TOS, inflow angle $=16^{\circ}$.

6.22 Comparison between the predicted and the measured velocity, turbulence kinetic energy at some locations in the mid-plane of the test room, for test T01

6.23 Comparison betwean the predicted and the measured velocity, turbulence kinetic energy at some locations in the mid-plane of the test room, for iest T04 142

6.24 Comparison between the predicted and the measured velocity, turbulence kinetic energy at some locations in the mid-plane of the test room, for test T05

6.25 Predicted a) velocity contour, and b) velocity vector distributions in the mid-plane of the test room, for test TO1, inflow angle $=11^{\circ}$

6.26 Predicted a) velocity contour, and b) velocity vector distributions in the mid-plane of the test room, for test T01, inflow angle $=22^{\circ}$ 145

6.27 Predicted air flow pattern for test T01 in a) a plane containing the supply diffuser $(Y / L=0.452)$, and $b)$ plane parallel to the supply diffuser $(X / H=$ 0.856) 146 


\section{NOMENCLATURE}

\begin{tabular}{|c|c|}
\hline $\mathbf{A}$ & Area of the supply and the return orifice plate $\left(A=0.08727 \mathrm{ft}^{2}\right)$ \\
\hline Area & Area of the supply diffuser \\
\hline Ar & Archimedes number $\left(\beta g_{i} L_{0} \theta_{0}\left(U_{0}\right)^{2}\right)$ \\
\hline c & Mean volumetric concentration of passive contaminants \\
\hline$C_{1}, C_{2}, C_{3}, C_{\mu}$ & Empirical constants in the turbulence model \\
\hline$C_{p}$ & Specific heat \\
\hline D & Molecular diffusivity for passive contaminants \\
\hline$D_{h}$ & Hydraulic diameter (4 Area/WP) \\
\hline G & Buoyancy production term \\
\hline $\mathrm{g}_{\mathrm{c}}$ & Gravitational acceleration \\
\hline $\mathbf{g}_{\mathbf{i}}$ & Gravitational acceleration in the $\mathbf{x}_{\mathbf{j}}$ direction \\
\hline h & Mean volume heat generation rate \\
\hline $\mathbf{H}_{\mathbf{w}}$ & Wall heat flux \\
\hline lu & Turbulence intensity \\
\hline $\mathbf{K}$ & Orifice plate constant \\
\hline k & Turbulence kinetic energy \\
\hline $\mathbf{L}_{\mathbf{0}}$ & Representative length scale \\
\hline$\ell$ & Turbulence length scale \\
\hline$\dot{\mathbf{m}}$ & Mass flow rate through the orifice plate \\
\hline $\mathbf{P}$ & Pressure \\
\hline$p$ & Mean static pressure \\
\hline $\mathrm{Pe}$ & Peclet number $\left(u \Delta x / \Gamma\right.$, where $\left.\Gamma=v+v_{t}\right)$ \\
\hline $\mathrm{Pr}$ & Prandtl number $(v / \alpha)$ \\
\hline$\Delta \mathrm{P}_{\text {crifice }}$ & Pressure difference across the orifice plate \\
\hline
\end{tabular}




\begin{tabular}{|c|c|}
\hline$q_{w}$ & Wall thermal flux \\
\hline $\mathbf{R}_{\mathbf{e}}$ & Reynolds number $\left(U_{d} L_{d} / v\right)$ \\
\hline $\mathbf{s}$ & Mean volume contaminant source generation rate \\
\hline $\mathbf{S}$ & Source term for the shear stress production \\
\hline $\mathbf{S}_{\boldsymbol{\theta}}$ & Dimensionless heat generation rate $\left(\mathrm{hL}_{\mathrm{d}}\left(\mathrm{pC}_{\mathrm{p}} \mathrm{U}_{\mathrm{o}} \boldsymbol{\theta}_{0}\right)\right)$ \\
\hline t & Time \\
\hline$U_{d}$ & Mean velocity at the diffuser \\
\hline $\mathbf{u}_{\mathbf{i}}$ & Mean velocity component in the $\boldsymbol{x}_{\mathbf{i}}$ direction \\
\hline$u_{t}$ & Velocity component parallel to the wall \\
\hline$u_{\delta}$ & Velocity at the wall boundary \\
\hline WP & Wetted perimeter of the supply diffuser \\
\hline $\mathbf{x}_{\mathbf{i}}$ & Cartesian coordinates \\
\hline$\Delta x, \Delta y$ & Step size in the $\mathrm{x}$ and $\mathrm{y}$ directions respectively \\
\hline y & distance normal to the wall \\
\hline
\end{tabular}

\section{Greek Symbol}

$\Gamma \quad$ Diffusion coefficient

$\alpha, \alpha_{\text {eff }} \quad$ Thermal diffusivity, and effective thermal diffusivity of air respectively

$\beta \quad$ Volumetric coefficient of expansion

$\delta \quad$ Wall boundary layer thickness

$\varepsilon \quad$ Turbulence energy dissipation rate

$v \quad$ Kinematic viscosity of air $\left(1.5 \times 10^{-5} \mathrm{~m}^{2} / \mathrm{s}\right)$

$v_{1}, v_{\text {eff }} \quad$ Eddy viscosity, and effective eddy viscosity respectively

$\sigma_{k}, \sigma_{\varepsilon}, \sigma_{\theta}, \sigma_{c}$ Turbulent PrandtllSchmidt number for $k, \varepsilon, \theta$, and $c$

$\theta \quad$ Mean temperature differcnce

$\theta_{0}$ Temperature difference between the supply air and the room 
$\Delta \theta$

$\rho$

$\xi$

\section{Circumflex}

$\wedge$

\section{Subscripts}

A

amb

d

i, $\mathbf{j}$

in

out

t

std

$\mathbf{w}$

$\mathbf{x}$

y

$\mathbf{z}$
Temperature difference between the wall and the adjacent fluid

Density

Correction factor

Dimensionless number

Diffuser

i j Vector directions

in Inlet

out Outlet

Turbulent

Standard

To designate water in the case of density, and wall in the other cases

$\mathrm{X}$ axis direction

$\mathrm{Y}$ axis direction

$\mathrm{Z}$ axis direction 


\section{Chapter 1}

\section{INTRODUCTION}

\subsection{Problem Outline}

Room air flow is a complex phenomenon. It is turbulent and three dimensional with both low and high turbulence levels existing in the flow. It also involves flow regimes with forced convection where high velocities play a major role, and natural convection where low velocities are predominant. Within an occupied space the air velocity distribution affects both the air quality and the thermal comfort of the occupants. Understanding such flows is essential to the design of ventilation systems capable of providing acceptable indoor air quality with a proper air distribution, and the control of thermal conditions.

The room air distribution is influenced by many factors such as the room geometry, the ventilation system (the way it is operated and maintained), the geomctry of the supply diffuser, the presence of furniture and obstacles, and the supply and return diffuser 
location. With proper room air distribution, draft, contaminants, and moisture can be controlled and eliminated. In addition, by using low flow rates, the building energy consumption can be kept within reasonable bounds.

During the last two decades, considerable effort has been directed toward the study of room air distribution in many applications and areas including residential and business space, hospital operation and recovery rooms, clean room manufacturng, and even in agriculture. Several techniques and methods have been used for that purpose. These techniques and methods include similitude or scale models, numerical computer programs, and prototype or full scale models. So far, the studies conducted dealt mostly with very simple room geometries under isothermal and non-isothermal conditions with no presence of obstacles or furniture. In these studies the supply air jet was assumed normal to the flow domain.

An experimental investigation of the indoor air movement for different air supply parameters and different supply and return configurations is made easier in a full-scale climate room, where air velocity, temperature, turbulence intensity, and pollutant concentration distribution can be measured. Such full-scale tests are, in most cases, expensive and major challenges can be encountered in such an experimental investigation. These include the measurement of the flow direction at low velocity and the lcw turbulence intensity. In spite of their cost and the time required, the full-scale model studies are essential to provide data for the evaluation of numerical and the similitude models.

Similitude or scale model studies involve the measurement of the characteristics of room airflows in a reduced scale model room, from which the findings are extrapolated to geometrically similar or corresponding prototypes. These models are very convenient and economical to provide better understanding of the different regional characteristics 
and physics of room airflows. High technology instruments, which cannot as easily be used in full scale experiments, are used in these studies for flow visualization and scalar quantity measurements. When using non-isothermal conditions, the scale model studies present a serious difficulty. This difficulty is mainly due to the lack of proper scaling factors to extrapolate from the scale model results to its prototype. The Reynolds number (ratio of inertial force to viscous force) and the Archimedes number (ratio of thermal buoyancy force to inertial force) are important non-dimensional terms in determining room air distribution, and should be duplicated in the simulation when a numerical solution is involved. However, these two terms lead to contradictory scaling factors, which in some cases do not reflect the real flow conditions.

The numerical studies are based on the mathematical modeling of room air flows. Although complicated, they are the most efficient and adequate methods to reveal a detailed study of the dependence of room air distribution on various parameters. To date, the assumptions used in the numerical models did not fully account for all of the complexity of the physics. In order to allow further advances in simulating room airflows, more detailed full-scale measurements of the different characteristics of roxm airflows is needed. When the more sophisticated models have been validated, it should be possible and economical to solve ventilation problems by making more use of numerical calculation procedures.

\subsection{Thesis Outline and Objective}

In the present study, a detailed experimental investigation is conducted in a full-scale room equipped with two commercial slot diffusers of dimensions $40^{\prime \prime}(1.016 \mathrm{~m})$ long by $0.5^{\prime \prime}(0.0127 \mathrm{~m})$ width for each of the supply and the return air. Experimental facilities 
of the Building Performance Laboratory IRC (NRCC) for studying three-dimensional air flows were used. Isothermal conditions are assumed in all experimental tests conducted. Low Velocity Transducers are used to obtain detailed measurements of the mean velocity, the temperature, and the turbulence intensity in the mid-plane (symmetric plane) of the test room. Bubbles and smoke are used to visualize and reveal the flow pattern in the plane of interest. Spatial contaminant concentration distributions are also measured in the room.

The ability of a state-of-the-art computer code to predict the room air motion is examined. The EXACT3 [3] code is used to simulate some of the conditions used in the experimental tests conducted, and comparisons with the experimental results obtained in this study are made. In addition, various input parameters to the EXACT3 code are varied to evaluate the effect of these parameters on the accuracy of the solution obtained. Such parameters as the grid size and the supply air jet orientation were varied.

The objectives of the present study can be summarized as follows:

1. To investigate the different characteristics of the flow in a typical three-dimensional room, and to study the effect of obstacles on the flow pattern.

2. To provide detailed measured data that can augment the data base available in the literature, and that can be used for numerical and scale models evaluations and validations.

3. To provide full-scale measurements in a three-dimensional room and assist the understanding of room air flow physics, and to help achieve better design of ventilation systems.

4. To evaluate the EXACT3 code by comparing the numerical results to the experimental ones. 


\section{Chapter I Introduction}

5. To investigate the effect of various parameters on the accuracy of the numerical solution. 


\section{Chapter 2}

\section{LITERATURE REVIEW}

During the last two decades, a large number of experimental and numerical studies have been conducted relating to room air motion. In this chapter, a brief description is given of previously published numerical, as well experimental work applied to room ventilation problems.

\subsection{Numerical Investigation}

In 1949, John Rydberg and Per Norbä ck [35] were among the first researchers to give concern to thermal comfort in occupied spaces. They developed a method to evaluate the performance of air streams issuing from grills and similar openings. The method proposed consisted of predicting the draft from such jets. They expressed the draft as a function of the jet velocity and the temperature difference between the room and the jet. 
The relation obtained has very limited design applications in heating and air-conditioning systems, because the assumptions made in the derivations exclude important factors that have great influence on the draft. These factors are the Reynolds number, the deflection or guide vanes, and the disturbance of the jet by the surroundings.

In 1974, Launder and Spalding [30] proposed the $k-\varepsilon$ turbulence model. which consisted of two transport equations for the turbulence kinetic energy (k), and the dissipation rate of the turbulence kinetic energy $(\varepsilon)$ respectively, and an equation for the turbulent viscosity $\mu_{\mathrm{t}}$. This seven-constant model is suitable for high Reynolds number turbulent flows, and constitutes the basis of almost all the computer programs used these days. In 1975, Nielsen [31] was the first to use this $k-\varepsilon$ model to develop a numerical procedure to solve for two-dimensional room air flow. He based his numerical solution on the work of Gosman et al. [37]. The code developed solves the conservation of mass, momentum, energy, and the two transport equations $k$ and $\varepsilon$. The agreement was satisfactory between the numerical and the experimental results. Consequently, this code may be suitable for describing steady-state two-dimensional room air flow. In 1978 , Nielsen et al. [21] conducted a numerical and an experimental investigation of the flow characteristics in a scale model room under isothermal conditions. In their experiment. they used Laser Doppler Anemometry (LDA) to obtain both the direction and the magnitude of the velocity in the flow domain. The calculation procedure made use of the TEACH computer program devised by Gosman and Pun [22], to solve the equations of motion plus the two transport equations by expressing them in finite difference form and making use of a line by line iteration method. The code also includes a pressure correction approach to obtain solutions that satisfy mass conservation, and wall functions at the walls. By varying the width of the inlet slot diffuser, they also determined the influence of a three-dimensional inlet flow on the velocity characteristics in the room. 
The results demonstrate that the precision of the calculation is adequate for design purposes although, for slots much smaller than the width of the room, three-dimensional effects become important. That contribution was extended by Nielsen et al. [14] to allow the calculation of two dimensional temperature distributions in ventilated rooms with buoyancy effects. A comparison between the experimental and the numerical results gave a discrepancy of $10 \%$, but no difference in the overall flow pattem. The predicted results quantify the effect of buoyancy and their dependence on the geometric ratios $\mathrm{h} / \mathrm{H}$ and $L / H$, where $h, H$, and $L$ are the height of the diffuser, the height of the room, and the length of the room respectively. In 1980, Gosman et al. [23] extended the work of Nielsen et al. [21], with the computer code to find properties in ventilated rooms, to include the third dimension. They used LDA to measure the flow properties in a small scale room fabricated from perspex. The supply air arrangement used produced results within a typical precision of 5\%. A comparison between the computed results and the data measured by Blum [24], who used a pitot tube for his measurements, was very satisfactory. In 1989, Lamers and van de Velde [43] used the finite volume package PHOENICS to compute the flow field distribution for two cases as suggested by Nielsen et al. [21]; a nearly two-dimensional turbulent flow, and a fully developed threedimensional flow. The study was a contribution to the numerical simulation of threedimensional flow patterns in ventilated rooms. They compared their results to the experimental data obtained by Nielsen et al. [21]. For the two-dimensional case the comparison showed that the accuracy of the computed results depends on the grid layout. For the three-dimensional case, they concluded that the discrepancies between the experimental and the predicted results will always be present due to the very nature of the numerical simulation method (physical reality is represented by hypothetical discontinua). 
In 1989, Awbi [18] developed a 3-D computational code to study the effect of various factors such as Archimedes number, heat load, and ceiling mounted obstacles on the air flow field in a room. He based his numerical solution on the SIMPLE, algorithm described by Patankar [5], and adopted the pressure correction method described by Markatos et al.[44]. To enhance stability in his numerical solution, he used a staggered grid with the hybrid scheme depending on a Peclet number value of 2 . He used the tridiagonal matrix algorithm (TDMA) to solve the full Navier-Stokes equations, as well the two transport equations for $k$ and $\varepsilon$. In his numerical study, he used measured values of the velocity and turbulence intensity at the inlet conditions. The study was carried out for a range of diffuser Reynolds numbers between 2400 and 4000 . He used the expirimental measurements of Jackman [45] for comparison. As noticed by Awbi, the Archimedes number has a very significant effect on the velocity in the room. He also found that for isothermal flows the mean velocity in the occupied space is strongly affected by the momentum of the supply jet, and that the presence of obstacles in front of the jet supply may affect the flow distribution in the room.

In 1990, Andreas Schachenmann et al. [16] used the AIRCOND code of the AVL company to study room air distribution under free and forced convection. Since in the case of mixed convection, the buoyancy forces at the heated and the cooled walls influence the flow and the heat transfer, they used a corrected formula for the Nusselt number in the heat transfer calculations. The correction used combines experimentally determined correlations for forced and free convection in a weighted mixed formula $\left(\mathrm{Nu}_{\infty}=\left(\mathrm{Nu}^{*}+\mathrm{Nu}^{*}\right)^{v_{0}}\right)$. With this modification, the discrepancy between the numerical results and the measured values using the LDA was around 5\%. They also obtained the same results as for AIRCOND with two new codes, the STAR_CD and the ASCONA, that use a non-orthogonal contour-matched grid for the forced convection case. 
In 1990, J.B. Fang et al. [28] used the EXACT3 code to study buoyancy-affected flows in a ventilated room. They performed the calculations for three-dimensional turbulent buoyant flows emerging from an air diffuser in an air-conditioned, ventilated room subject to diverse supply air velocities and heat loads. The EXACT3 code was also used to evaluate the performance of the ventilation system by calculating the Air Diffusion Performance Index (ADPI) (Appendix A). At low flow rates (ranging between $10.97 \mathrm{~m} 3 / \mathrm{h} \cdot \mathrm{m}^{2}$ and $54.86 \mathrm{~m}^{3} / \mathrm{h} \cdot \mathrm{m}^{2}$ ), the predicted results were found to agree within $8 \%$ of the corresponding experimental values. At high flow rates (ranging between 73.15 $\mathrm{m}^{3} / \mathrm{h} \cdot \mathrm{m}^{2}$ and $91.44 \mathrm{~m}^{3} / \mathrm{h} \cdot \mathrm{m}^{2}$ ), there were slight discrepancies between the predicted and the experimental results. The agreement obtained at low flow rates, was for both the scalar quantities and the flow pattern in the room.

In 1990. Awbi et al. [19] studied the effect of using scale models in room air flow studies. The study included both isothermal and non-isothermal cases. The results from this study show that when modeling isothermal flows in a room, it is important to perform the model test at the same Reynolds number as in the prototype, since the Reynolds number has an influence on the velocity in the occupied zone. In the case of non-isothermal flow, both the Reynolds number and the Archimedes number affect the velocity distribution in the occupied zone. He found that these dimensionless parameters, when used in determining room air distribution in scale model studies, lead to contradictory scaling factors.

Extensive work using numerical solutions of room air flows in connection with contaminant concentration distributions have been carried out for the past few years, to study the performance of different ventilation systems. In 1983, Sandberg and Sjöberg [46] introduced a new concept to describe the ventilation efficiency in ventilated rooms. This concept is based on two parameters: the local purging flow rate (Appendix A) and 
the local age (Appendix A) distribution. In 1987, Lars Davidson et al. [47] calculated both these two quantities in an isothermal two-dimensional room. They also calculated the local age in two rooms which had three-dimensional flows which were influenced by buoyancy effects in conditions representing both summer and winter. Both the age and the local purging flow rate fields were simulated using i jnamically passive contaminants. They used the PHOENICS computer program [48] for the three dimensional calculations, and a slightly modified version of TEACH-T [49] for the twodimensional calculations. For the two dimensional cases, they adopted the new one equation turbulence model by Lars Davidson [50]. Comparison of the predicted values in the three-dimensional cases to the experimerital results gave discrepancies of around 25\%. These discrepancies were attributed to errors in the predictions of the flow field as well as uncertainty in the experimental results. They also showed that from a calculated velocity field the age distribution can be calculated. For the 2-D cases, they showed that the main features of the ventilation situation are readily obtained from either field quantity (the age field or the local purging flow rate field).

In 1991, Lage et al. [6] studied the transient removal of a contaminant from a twodimensional enclosure with one inlet and one outlet. They computed the flow field distribution as well the concentration distribution in the enclesure using Jones and Launder's low Reynolds number $k-\varepsilon$ model [7]. They adopted the SIMPLE algorithm described by Patankar [5] to solve the conservation equations as well the transport equations for $k, \varepsilon$, and $C$. They reported quantitative data for the displacement ventilation efficiency and the critical concentration decay time. They also studied the dependence of displacement ventilation efficiency upon jet orientation, and inlet and outlet configuration. The study was for a wide range of the Reynolds number (above 2000) from 5 to 5000 , where $R e$ is based on the jet inlet width. As noted in this study, 
geometric arrangerrents where the path of the jet is the longest and the short circuiting is the smallest, gave the highest efficiencies. These geometric arrangements are obtained by varying the location of the retum opening (diffuser) with respect to the supply one.

The precision of the numerical solution depends on various factors. Among these factors are the inlet boundary conditions. In 1991, Chen et al. [11] adopted the low Reynolds number $k-\varepsilon$ model developed by Lam and Bremhorst [13] with buoyancy production terms in the $\mathbf{k}$ and $e$ equations introduced by Nielsen et al. [14], to study the influence of the variation of air supply parameters on air diffusion, indoor air quality, and thermal comfort. As noted by Chen [15], the model applies to the whole domain of calculation and permits satisfactory calculation at the wall boundary layer. They conducted the study in an office equipped with a displacement ventilation system. They used the air flow program developed by Rosten and Spalding [12], to calculate the air distribution. The computations involve the solution of the continuity, momentum, energy, and contaminant concentration equations, together with the two transport equations for $\mathbf{k}$ and $\varepsilon$. They found that the effective area, shape and dimensions of the diffuser, and the turbulence intensity of the air supplied have little effect on the air diffusion, which is not the case for the airflow rate and temperature.

In 1991, Heikkinen [40] discussed different methods and models to set the boundary conditions at the supply arr opening. His idea was to define a simple method to set the inlet boundary conditions when using air supply terminals with impinging jets. He used the FLUENT [41], and the WISH [42] codes to compute the flow in the test room and close to the supply opening. The two codes use the finite volume method with a staggered grid for the velocity components, the high Reynolds number k- $\varepsilon$ turbulence model, and the logarithmic wall functions. Each code uses a different numerical scheme in the calculations. In his experiment, he also used smoke to detect the flow direction. 
He compared the computed results from all the models to the measured values around the impinging diffuser which were obtained using a TSI 1640 omnidirectional hot film anemometer. He found that not only the diffuser model affects the maximum velocity, but also the number of grid points, the differencing scheme, and even the code used has an effect. Jorma also noted that the supply air opening has the most direct influence on the decay of the jet velocity and the shape of the jet. For the inlet boundary conditions, the momentum method is a more general method, but the prescribed velocity method has the possibility of making best predictions, when combined with the momentum method. In 1991, Ewert et al. [29], also conducted an experimental and a numerical investigation to study the effect of the inlet boundary conditions on the flow field in the occupied zone. They used LDA for measurements and the FLUENT [41] code to solve the conservation equations for mass, momentum, energy, and the two transport equations for $k$ and $\varepsilon$. They compared results obtained by four methods used to specify the inlet conditions to the experimental results. They found that there is over-prediction of the flow field in the room when using the box method (Appendix A) or the simplified slit (Appendix A).

Due to the variety of the problems and situations that are present in room air ventilation, Chen et al. [9] tried to develop a concept for a design tool that allows the design engineer to assess air flow pattem, comfort, and indoor air quality without performing a full scale experiment or running a complex flow field simulation code. They used the low Reynolds number k- $\varepsilon$ model [15] to interpolate between known cases to derive as much information as possible for the designer for a particular design case. They also discussed the influence on the interpolated results of the heat load due to solar radiation through windows, the window size, the heat source location due to the lighting, the surface temperatures of the interior walls, and the furniture location and its size. Two 
different levels of approximation were discussed: 1) the design case and existing case are not absolutely geometrically similar but the important non-dimensional parameters are the same or only slightly different, and 2) the cases are geometrically similar but the nondimensional input parameters are slightly different. They found that the interpolation error caused by the variation of the space load due to solar radiation through windows, the window size, the heat source location due to lighting and the surface temperature of interior walls is small, and can be quantitatively determined. They also concluded that the errors introduced by the variations of furniture locations and size, were difficult to estimate.

Soultogiannis [64], developed two numerical models, the COMP code and the INCOMP code, to predict the air flow pattern in two-dimensional spaces. The two models were based on two different approaches: one assuming the flow as compressible (COMP code), while the second one as incompressible (INCOMP code). He also used a different numerical scheme for each model. For the COMP code, he used a two-step explicit and time marching finite difference scheme to solve the governing partial differential equations, while in the INCOMP code he used the Gauss-Seidel point-bypoint and line-by-line methods to solve the discretized form of the continuity, momentum and energy equations. He compared the numerical results obtained by the two codes with the results provided in the literature by Awbi [18], Nielsen [21, 31] and Murakami et al. [32]. He found that the results by the INCOMP code are in agreement, and the general trend of the airflow is reproduced to satisfactory tolerance. The results from the COMP code did not yield useful information probably because of numerical diffusion, and consequently it was recommended that the compressible approach using that approach should be abandoned. The results of Soultogiannis also indicated that for the practical 
understanding of the physics in room airflows, the use of sophisticated models may not be justified.

\subsection{Experimental Investigation}

Understanding air flow movement in ventilated rooms is very important for the development of any numerical solution. Extensive work has been done on this subject to develop high quality experiments, and new techniques to help understand the physics of such flows, and validate the existing numerical codes. This section describes some of these experiments and techniques.

The first flow visualization technique used for the experimental research in room air distribution was introduced in 1952 by Nottage et al. [10]. They used smoke filaments to trace the flow directions. They used ammonium chloride to generate smoke. As found, this technique is satisfactory for obtaining approximate velocity vector direction data in the low velocity regime of room air distribution. Attempts to visualize flows using smoke in large enclosures were not successful. In 1972, Carpenter and Moulsley [51] used bubbles generated by several bubble generators [52], to visualize flow and investigate the flow pattern in a section of a livestock building. This technique of using bubbles for flow visualization was first reported in 1969 [53]. To enhance visibility and to obtain a permanent picture of the flow pattern, they used a special lighting system to produce a light sheet, and a special photographic unit. Interrupted exposures of the bubble tracings were used to calculate the velocity in the flow field. This technique was adequate for describing flows in an enclosure where fairly high flow rates are used. In 1990, Skovgaard et al. [20] conducted full scale measurements in a room with isothermal mixing ventilation. The measurements included the change in the effective inlet area, 
wall jet measurements (both cartesian and radial approach), measurements of mean velocities and rms values in the occupied zone and measurements of the effect of low Reynolds number (Re) on the flow. The experiment was carried out for the Reynolds number range between 1000 and 7000 , for which the Re was based on inlet dimensions. They used smoke to establish the flow field, ball probes (DANTEC 54N10) and hot wires (DISA 56N24) to quantify the flow at the inlet and in the occupied zone. They used these measurements to evaluate a new kind of 'simplified' approach for describing the flow field by means of an impinging turbulent jet, and to detect the isothermal flow dependencies on the Reynolds number. The study concluded that low Reynolds number effects dominate the velocity field especially in the occupied zone, where the measured velocity showed dependency on the inlet momentum and the room geometry.

In 1991, Anderson et al. [4], developed a new method to visualize the air flow from a cold air ceiling jet. The method uses an infrared (IR) thermal imaging system and a fiber glass screen mesh. Using this method, an overall picture of the temperature distribution and flow pattern in the room were obtained instantaneously. Together with this technique, they also used hot-wire anemometry to scan the inlet conditions. Cornputing the flow with the EXACT3 code showed that the predicted decay rate of the velocity and the temperature were $20 \%$ larger than in the case of the experiment.

Cooling and heating affect significantly the air flow pattem in ventilated rooms. Experimental studies have been carried out to study this effect by several researchers. In 1955, Kostel and Tuve [36] investigated the effect of buoyancy on the flow properties in the occupied zone. In their experiment, they used four air distribution systems with different supply and return configurations. They measured the velocity and the temperature in the occupied zone for different flow rates and under different values of the temperature difference between the room and the surroundings. Several instruments 
using different techniques were used for this purpose (see [36] for details). From the results obtained, they found that a system of air distribution can be evaluated on the basis of three factors, namely the vertical air temperature differences, the air velocity, and the objectionability or tolerability to draft by the occupants of the zone. They also concluded that the flow pattern in the room is mainly a function of the geometry of the room, the type and the geometry of the air distribution device, and the location of the retum air register, which has a slight influence on the critical draft velocities.

In 1969. Miller and Nevins [38] studied room air distribution with two different air distributing ceiling panels. They conducted the study under non-isothermal conditions with uniform and concentrated heat loads. They used the Air Distribution Performance Index (ADPI) to evaluate the performance of the two air distributing devices. They defined the ADPI as the percentage of the positions satisfying the criteria of the effective draft temperature between $-3^{\circ} \mathrm{F}$ and $+2^{\circ} \mathrm{F}$, and a velocity less than $70 \mathrm{fpm}$. They found that the ADPI is affected by the heat load in the room, but is not strongly affected by either the type of ceiling panels or the flow rate.

In 1988, Heiselberg and Nielsen [17] studied the flow conditions in a mechanically ventilated room with a convective heat source consisting of an electrically heated radiator. They conducted the experiment at different heat loads using two supply openings, a nozzle, and a PVD_10 diffuser. They concluded that the presence of the convective heat source led to a large internal volume flow rate in the occupied space.

Measurements on buoyant jet flows from ceiling mounted diffusers were conducted by Nielsen and Möller [25] using a hot wire instrument. The study dealt with a twodimensional flow from a slot diffuser, and the transition to three-dimensional flow in the case of a slot diffuser with a small width. The study revealed that the flow along the ceiling can be described as a wall jet although the flow is dependent on the Reynolds 
number. They also concluded that the "wall jet" from a diffuser with a short width shows a tendency towards three-dimensional flow over a long distance from the diffuser, and that the penetration depth of the jet is proportional to the Archimedes number (Ar) to the power $(-2 / 3)$.

In 1989, Zhang et al. [55] conducted several experimental tests in a 1/12 scale model building, and in full scale rooms established for swine production. Non-isothermal conditions were imposed in all the tests, to investigate the regional flo:; characteristics within the test rooms with heat production, and to evaluate the effects of thermal buoyancy, the diffuser opening size, and the ventilation rate on the flow velocities in the occupied zone. The measurements were taking using an omnidirectional temperature compensated hot wire anemometer, and a copper constantan thermocouple. The smoke wire method was also used to visualize the flow pattern in each test room. They found that the flow field in the room may be divided into regional subfields that can be computed separately under different assumptions to give the whole flow domain. Increasing the thermal buoyancy in the room was found to increase the decay of the maximum velocity in the jet, and to decrease the average mean velocity in the reverse flow region. This reverse velocity was also influenced by the supply opening. They also found that an increase in the Reynolds number causes the velocity in the occupied zone to increase, and the ratio of the local velocity to the diffuser velocity to decrease (dependency of the air distribution on the Reynolds number). The maximum velocity in the occupied zone was also found to depend on the Archimedes number. When comparing the results obtained from the full scale and the 1/12 scale model rooms, contradictory results were obtained on the effect of the thermal buoyancy in the low velocity regimes. Misleading results were obtained in the scale model case, since 
thermal buoyancy seems to balance part of the inertial effect, resulting in lower velocities in the reverse flow region.

Examining the accuracy of the numerical programs to describe room air distribution is one of the important issues in ventilation. There is a tremendous need for experimental data to aid in evaluating these codes. In 1987, Murakami et al. [32] examined the accuracy of using a three-dimensional code based on the $k-\varepsilon$ two equation turbulence model [39], by comparing simulated test results to the experimental ones. The code uses a staggered grid with the QUICK scheme to solve for the transport equations of the scalar quantities $(k, \varepsilon$, and $C)$. The Measurements of the velocity were conducted by means of a tandem type parallel hot-wire anemometer. A laser light sheet system with magnesium carbonate $\left(\mathrm{MgCO}_{3}\right)$ powder as a tracer gas, was used for flow visualization. Spatial distributions of contaminants in the room were also measured by means of a gas chromatograph. They concluded from this investigation that numerical prediction of room airflow is a very promising technique. In 1991, Zhang et al. [56] conducted full scale experiments in a ventilated room under isothermal and non-isothermal conditions. The reported results were believed valuable for evaluating numerical simulation models, as well as to help provide understanding of the behavior of room airflows.

In 1989, James et al. [57] designed a measuring system to evaluate the environment within a workstation in terms of a numerical value for occupant comfort. The system can measure air velocity and temperature within different configurations in which workstations exist, it has the flexibility to evaluate various environments and needs, it is simple to operate and to use the state of the art technology. Following James, Nielsen [26] introduced a new test model with large supply opening dimensions compared with the practical diffusers. This model was introduced to allow direct specification of the inlet boundary conditions rather than using the box method or the prescribed velocity 
method, and to avoid as much as possible the boundary region of the ceiling where different boundary conditions are used in Computational Fluid Dynamics (CFD). Isothermal as well non-isothermal cases were described, so they can be used to test different two-dimensional CFD codes in the IEA Annex 20 work [26].

Experimental investigations on room airflows in connection with contaminant concentration distribution have been conducted by several researchers. In 1988, Kato et al. [33] defined three ventilation efficiency scales to evaluate the performance of the ventilation systems. These scales are based on the spatial distribution of passive contaminants in the occupied space. This study was aided by a numerical simulation on different test cases with different configurations. They concluded that these scales are able to represent the differences of ventilation efficiency caused by changing the ventilation system configuration.

In a study conducted by Murakami et al. [34] on turbulent diffusion fields in conventional flow type clean rooms, it was concluded that the flow in such rooms can be very well modeled as serial combinations of flow units consisting of a supply jet and a rising streams around it. They also concluded that the structure of the diffusion field is quantitatively assessed by means of the new scales of ventilation efficiency.

In 1988, Anderson [59] developed a short term testing methodology to evaluate the performance of ventilation systems with respect to control of indoor air pollutants. For this purpose two new parameters were used, the displacement ventilation efficiency, and the removal efficiency. In his experiment, he applied these new efficiency measures to the analysis of a ceiling based ventilation system. He also compared these new efficiency measures to the mean age of air (Appendix A) and pollutant removal effectiveness concepts. He found that the new ventilation concepts have a number of advantages over the previous methods including being based on short term 
measurements. As Anderson noted, the ventilation efficiency definitions are suitable for both laboratory and field studies.

In 1988, Carlton-Foss [58], conducted an experiment to define the Ventilation Effectiveness Performance Index (VEPI) (Appendix A), combined with the Air Diffusion Performance Index (ADPI), to define the Combined Air Motion Index (CAMI). Velocity, temperature, and contaminant concentrations were measured in the test room to provide the flow field distribution. He used smoke to visualize the flow pattern in the room. He found that the tracer gas is very useful in understanding the ability of the room ventilation to clear the air in specific locations.

In 1990, Cox et al. [54] conducted measurements in a typical office space to find the temperature efficiency (TE), the air change efficiency (ACE), and the ventilation efficiency (VE). The room was equipped with a displacement ventilation system. They used thermo-couples to measure the temperature in the room and the surroundings, an omnidirectional thermo-anemometer to measure the velocity and turbulence intensity in the occupied zone, a tracer gas $\left(\mathrm{NO}_{2}\right)$ technique to measure the concentration in the room, and a pyranometer to measure the solar radiation to the room. The tracer gas measurements were used to evaluate the ACE, and the VE. A different injection method was used for each parameter, in the case of the ACE the tracer gas was mixed at the supply prior to injection into the room, but in the case of the VE a constant injection rate into the room was used. They measured the contaminant concentration change with time in the room. The experimental tests were conducted under non-isothermal conditions with different flow rates. They found that for this type of ventilation system, the temperature efficiency is higher than in the case of dilution ventilation systems. The air change efficiency was very much dependent on the balance between supply and retum air flow rates. The measured values of the ventilation efficiency were very much dependent 
on the position of the contaminant source in the room. They also concluded that when using displacement ventilation systems, careful attention should be given to avoid exfiltration near floor levels, because it affects the performance of the ventilation system. In 1991, Heiselberg [8] reported the results of full-scale experiments of contaminant distribution in a test room. He used different contaminant densities under isothermal steady state conditions. The room average concentration was determined by measuring the concentration in the roorn after a final mixing of the room air, after air and contaminant supplies were shut off. He concluded that with contaminants of higher density, higher velocities are needed to remove the contaminant, especially from the occupied zone. This was, of course dependent on the geometry used. He also mentioned that a ventilation system with an exhaust opening only at ceiling level will not always be able to remove heavy contaminants in a satisfactory way.

In 1990, Enai et al. [60,61] used the multiple tracer gas technique developed by Evans et al. [2], to measure interzonal airflows, between two and three interconnected rooms respectively. The calculations performed were based on the measured concentration profile of the contaminants. They used different tracer gases with different injection methods for each of the tests conducted. The calculated values (by a simple model) for the interzonal airflows were compared with the measured ones. They found that there is a certain range of contaminant concentration that can be used for interzonal airflow predictions. They also found that the error involved in this appropriate range of the concentration of contaminants is around $20 \%$ between the calculated values and the measured ones, and outside that range the error is much larger. Their results did not give any indication of the effect of the method of injection on the calculated results, but did indicate that for the same test, the calculated airflow rates based on different sets of concentration measurements were not always the same. 


\section{Chapter 3}

\section{The Numerical Model}

In this chapter a brief description of the computer code used in this study is given. For more details about the numerical scheme as well the solution procedure used in the calculations, the reader is advised to refer to reference [3] where more details are given by Kurabuchi.

\subsection{Introduction}

The EXACT3 code, used in this study, was developed at the U. S. National Institute of Standards and Technology. The code is a public domain code, and has an international user base; it is extensively used in building energy calculations [3].

The model has a wide range of applicability because it can handle a variety of flow, pressure, temperature and heat flux boundary conditions. The inflows and outflows are 
specified by either prescribing the flow or pressure. Wall boundary conditions together with heat flux, temperature and/or heat transfer coefficients on the boundary need to be prescribed. Volumetric heat sources may also be included, and it has the ability of treating an arbitrary number of obstacles in the flow region, which permits the modeling of the effect of furniture and partitions on the flow field. It also provides means for modeling multi-room airflow.

Many applications of the EXACT3 code $[3,4,28]$, showed the ability of the code to predict room air motion and contaminant distribution with satisfactory accuracy, and within an acceptable range of computational time effort. Nevertheless, it is important to recognize the following inherent limitations in the present calculation method.

- The calculation domain including the inlet and the outlet must be rectangular (cartesian grid).

- The reference Reynolds number must be large enough so that the viscous effect can be negligible except near the wall region.

- The temperature gradient in the flow regime must be small enough that buoyancy exerts little influence on the turbulence model.

\subsection{Calculation Procedure}

In an air conditioned room, there is a strong possibility that turbulent and non turbulent flow portions coexist. Therefore, assumptions relative to the nature of the flow field in such a room are necessary when adapting a numerical model to solve for such flows. Since in most cases the air conditioned rooms use forced air systems, the flow ficld in these conditions is considered to be fully turbulent. 
To predict the flow field in the test room, the mass conservation, the averaged NavicrStokes equations, as well the two transport equations for turbulent kinetic energy and dissipation rate of the turbulent kinetic energy were solved. A complete derivation of the equations as well the empirical correlations used in this program are described by Kurabuchi et al. [3]. The equations used with the complete $k-\varepsilon$ turbulence model together with the recommended empirical constants used in the program, are summarized as follows.

\section{Conservation equations (tensor notation):}

$$
\begin{aligned}
& \frac{\partial u_{j}}{\partial x_{j}}=0 \\
& \frac{\partial u_{i}}{\partial t}+\frac{\partial u_{i} u_{j}}{\partial x_{j}}=-\frac{1}{\rho} \frac{\partial \Pi}{\partial x_{i}}+\frac{\partial}{\partial x_{j}}\left\{\left(v+v_{i}\right)\left[\frac{\partial u_{i}}{\partial x_{j}}+\frac{\partial u_{j}}{\partial x_{i}}\right]\right\}-\beta g_{i} \theta \\
& \text { where } \Pi=p+\frac{2}{3} \rho k, \text { and the eddy viscosity } v_{t}=C_{\mu} \frac{k^{2}}{\varepsilon} . \\
& \frac{\partial \theta}{\partial t}+\frac{\partial \theta u_{j}}{\partial x_{j}}=\frac{\partial}{\partial x_{j}}\left\{\left(\alpha+\frac{v_{i}}{\sigma_{\theta}}\right) \frac{\partial \theta}{\partial x_{j}}\right\}+h\left(x_{i}, t\right) \\
& \frac{\partial c}{\partial t}+\frac{\partial c u_{j}}{\partial x_{j}}=\frac{\partial}{\partial x_{j}}\left\{\left(D+\frac{v_{i}}{\sigma_{c}}\right) \frac{\partial c}{\partial x_{j}}\right\}+s\left(x_{i}, t\right)
\end{aligned}
$$

Conservation equations for turbulent kinetic energy and its dissipation rate (tensor notution):

$$
\begin{aligned}
& \frac{D k}{D t}=\frac{\partial}{\partial x_{j}}\left\{\left(v+\frac{v_{t}}{\sigma_{k}}\right) \frac{\partial k}{\partial x_{j}}\right\}+v_{t}\left(\frac{\partial u_{j}}{\partial x_{i}}+\frac{\partial u_{i}}{\partial x_{j}}\right) \frac{\partial u_{i}}{\partial x_{j}}+\beta g_{i} \frac{v_{t}}{\sigma_{\theta}} \frac{\partial \theta}{\partial x_{i}}-\varepsilon \\
& \frac{D \varepsilon}{D_{l}}=\frac{\partial}{\partial x_{j}}\left\{\left(v+\frac{v_{t}}{\sigma_{e}}\right) \frac{\partial \varepsilon}{\partial x_{j}}\right\}+\frac{\varepsilon}{k}\left\{C_{i} v_{l}\left(\frac{\partial u_{j}}{\partial x_{i}}+\frac{\partial u_{i}}{\partial x_{j}}\right) \frac{\partial u_{i}}{\partial x_{j}}-C_{2} \varepsilon+C_{3} \beta g_{i} \frac{v_{l}}{\sigma_{\theta}} \frac{\partial \theta}{\partial x_{i}}\right\}
\end{aligned}
$$


The partial differential equations mentioned above are all coupled with each other, with the exception of the transport equation for the passive contaminants. This equation is solved independently after the flow field distribution is computed.

\subsubsection{Numerical Method}

The code uses a finite difference approximation to solve the non-dimensional form of the turbulence $k-\varepsilon$ model equations mentioned above. All the variables in the equations are normalized with respect to the inlet velocity $U_{d}$, the width of the slot diffuser $L_{o}$, the average density of the air $p_{0}$, and the temperature difference between the supply air and the average room air $\theta_{0}$. A summary of the non-dimensional form of the equations, the normalized parameters and the empirical constants used in the program are listed below.

Continuity equation (tensor notation):

$\frac{\partial \hat{u}_{j}}{\partial \hat{x}_{j}}=0$

Momentum equation (tensor notation):

$$
\frac{\partial \hat{u}_{i}}{\partial \hat{t}}+\frac{\partial \hat{u}_{i} \hat{u}_{j}}{\partial \hat{x}_{j}}=-\frac{1}{\hat{p}} \frac{\partial \hat{P}}{\partial \hat{x}_{i}}+\frac{\partial}{\partial \hat{x}_{j}}\left\{\hat{v}_{\text {off }}\left(\frac{\partial \hat{u}_{i}}{\partial \hat{x}_{j}}+\frac{\partial \hat{u}_{j}}{\partial \hat{x}_{i}}\right)\right\}-A_{i} \hat{\theta}
$$

Energy equation (tensor notation):

$$
\frac{\partial \hat{\theta}}{\partial \hat{\imath}}+\frac{\partial \hat{\theta} \hat{u}_{j}}{\partial \hat{x}_{j}}=\frac{\partial}{\partial \hat{x}_{j}}\left(\hat{\alpha}_{\text {eff }} \frac{\partial \hat{\theta}}{\partial \hat{x}_{j}}\right)+S_{\theta}
$$

Transport equations for $k$ and $\varepsilon$ (tensor notation):

$$
\frac{\partial \hat{k}}{\partial \hat{\imath}}+\frac{\partial \hat{k} \hat{u}_{j}}{\partial \hat{x}_{j}}=\frac{\partial}{\partial \hat{x}_{j}}\left(\Gamma_{k} \frac{\partial \hat{k}}{\partial \hat{x}_{j}}\right)+\hat{v} S+G-\hat{\varepsilon}
$$


$\frac{\partial \hat{\varepsilon}}{\partial \hat{\mathrm{t}}}+\frac{\partial \hat{\varepsilon} \hat{\mathrm{u}}_{j}}{\partial \hat{\mathrm{x}}_{j}}=\frac{\partial}{\partial \hat{\mathrm{x}}_{j}}\left(\Gamma_{\varepsilon} \frac{\partial \hat{\varepsilon}}{\partial \dot{\mathrm{x}}_{j}}\right)+\frac{\hat{\varepsilon}}{\hat{\mathrm{k}}}\left(C_{1} \hat{\hat{v}_{i} S}-C_{2} \hat{\varepsilon}+C_{3} G\right)$

where,

$\hat{\mathbf{x}}_{j}=\mathrm{x}_{j} / \mathrm{L}_{0}, \quad \hat{\mathrm{t}}=\mathrm{t} U_{d} / \mathrm{L}_{0}, \quad \hat{\mathrm{u}}_{j}=\mathrm{U}_{j} / U_{d}, \hat{\mathrm{P}}=\mathrm{p} / \rho_{0}\left(U_{d}\right)^{2}$

$\hat{\rho}=\rho / \rho_{0}, \hat{\theta}=\theta / \theta_{0} \quad, \quad \hat{\mathbf{k}}=K /\left(U_{d}\right)^{2}, \hat{\varepsilon}=\varepsilon L_{0} /\left(U_{d}\right)^{3}$

$\hat{v}_{t}=\frac{v_{t}}{U_{d} L_{0}} \quad:$ dimensionless eddy viscosity

$\hat{v}_{\text {eff }}=\frac{1}{R_{e}}+\hat{v}_{t} \quad:$ effective eddy viscosity

$\hat{\alpha}_{e f f}=\frac{1}{R_{e} P_{r}}+\frac{\hat{v}_{t}}{\sigma_{\theta}} \quad:$ effective thermal diffusivity

$S=\left(\frac{\partial \hat{v}_{i}}{\partial \hat{x}_{j}}+\frac{\partial \hat{u}_{j}}{\partial \hat{x}_{i}}\right) \frac{\partial \hat{v}_{i}}{\partial \hat{x}_{j}} \quad:$ sou $=$ term for the shear production

$G=\beta g_{i} \frac{\hat{v}_{t}}{\sigma_{\theta}} \frac{\partial \hat{\theta}}{\partial \hat{x}_{j}} \quad$ : buoyancy production term

$\Gamma_{\mathrm{k}}=\frac{1}{\mathrm{R}_{\mathrm{e}}}+\frac{\hat{\mathrm{v}}_{\mathrm{t}}}{\sigma_{\mathrm{k}}} \quad$ : diffusion coefficient for $\mathrm{k}$

$\Gamma_{\varepsilon}=\frac{1}{R_{e}}+\frac{\hat{v}_{t}}{\sigma_{e}} \quad:$ diffusion coefficient for $\varepsilon$

$R_{e}=\frac{L_{0} U_{d}}{v} \quad:$ the Reynolds number

$P_{t}=\frac{v}{\alpha} \quad:$ the Prandtl number

$A r_{i}=\beta g_{i} L_{0} \theta_{0} /\left(U_{d}\right)^{2} \quad:$ the Archimedes number

$S_{\theta}=h \frac{L}{\rho C_{P} U_{S} \theta_{0}} \quad$ : the dimensionless heat generation rate 
Chapter 3 The Numerical model

$h$ is the volumetric heat generation rate, and $\alpha$ is the thermal diffusivity of air. The empirical coefficients are as follows:

$$
C_{\mu}=0.09, C_{1}=1.44, C_{2}=1.92, C_{3}=1.0, \sigma_{k}=1.0, \sigma_{\varepsilon}=1.3, \sigma_{\theta}=\sigma_{c}=0.9
$$

The code uses an Explicit Marching Algorithm for Continuous Thermal fluid flow (EXACT), with a staggered grid in which velocity components are defined on the cell boundary normal to its cell surface, and scalar quantities such as pressure, temperature and turbulent kinetic energy are defined at the cell center as shown in figure (3-1). The computer code employs a hybrid scheme [5], which utilizes either centered differencing or upwind differencing schemes depending on the local value of the cell Peclet number $P_{e}\left(P_{c}=u \Delta x / \Gamma\right.$, where $\left.\Gamma=v+v_{c}\right)$ for the partial derivatives in space, and an explicit scheme for the partial derivatives with respect to time, thereby minimizing the disadvantages of each scheme. It also uses the pressure relaxation technique [3] to correct for the pressure and the velocity components simultaneously in order to obtain solutions that satisfy the continuity equation. Figures (3-2)and (3-3) show the solution procedure for both the momentum and the scalar transport equations respectively.

\subsubsection{Boundary Conditions}

The $k-\varepsilon$ turbulence model consists of a system of elliptic partial differential equations. The dependent variables in them require appropriate boundary conditions. These are usually expressed as conditions on the primitive variables except for the pressure. The pressure boundary condition is required only when the velocity component normal to the boundary is unknown and has to be determined through calculation.

In the staggered approach, the boundary location is designed so as to coincide with the end face of a real cell. One or two cells with the same cell interval as that of the terminal 
real cell are added just outside it to handle the boundary conditions. The velocity component normal to the boundary is therefore located just on the boundary while the lateral component and other scalar variables are defined at a half cell interval detached from the boundary as shown in figure(3-4). The values of the variables in the added cells are set to the values of the terminal real cells.

\subsubsection{Inflow conditions}

The velocity normal and tangential to the flow domain, as well the turbulence kinetic energy $k$, the dissipation rate of the turbulence kinetic energy $\varepsilon$, and the temperature were specified. Values of the mean velocity and fluctuating velocity measured by means of a precalibrated hot-wire anemometer at the supply diffuser were used to specify these conditions. The turbulence kinetic energy and the dissipation rate of the turbulence kinetic energy are given by the following equations.

$k=\frac{3}{2} \mathrm{I}^{2}\left(U_{d}\right)^{2} \quad$, and $\quad \varepsilon=C_{\mu}^{\frac{3}{4}} \frac{k^{\frac{3}{2}}}{\ell} \quad$, where $I_{\mu}$ is the turbulence intensity, $U_{d}$ is the mean inlet velocity, $\ell$ is the turbulence length scale $\left(\ell=0.03 \mathrm{D}_{\mathrm{h}}, \mathrm{D}_{\mathrm{h}}=\frac{4 \text { Area }}{\text { WP }}\right.$, Area and WP are the area and the wetted perimeter of the supply opening respectively).

\subsubsection{Outflow conditions}

Since the outlet conditions are unknown, an approximate condition was imposed using engineering judgment on the velocity, temperature, dissipation and turbulence energy. These conditions are as follows. 
- Outlet normal velocity equal and opposite in sign to the inlet normal velocity.

- Zero tangential velocity, and tangential gradient of temperature, kinetic energy and dissipation.

\subsubsection{Wall boundary conditions}

The EXACT3 code uses the "Power Law" type of boundary condition at the wall. It uses the assumption of the velocity profile in the vicinity of the wall as given by:

$$
u_{t}=u_{s}\left(\frac{y}{\delta}\right)^{n}
$$

where $n=1 / 7$ for fully developed wall boundary, and $\delta=h / 2$ (where $h / 2$ is the distance of the first grid point from the wall).

\subsubsection{Energy wall boundary conditions}

The wall boundary condition for the energy equation is given by:

$$
q_{w}=\frac{H_{w}}{C_{p p}}=\alpha \Delta \theta
$$

where $\alpha$ is local thermal transfer coefficient, and $\Delta \theta$ is the temperature difference between the wall and the adjacent fluid. This condition is very important to the entire accuracy of huoyant flow calculations, because it exerts a significant effect on the total heat loss/gain at the wall and also on the buoyancy driving force in the momentum equations. Since in the present experiment, isothermal conditions are used, zero heat flux was assumed through the walls. 


\section{Chapter 4}

\section{EXPERIMENTAL FACILITIES AND INSTRUMENTATION}

\subsection{Test Room}

The ventilation test room shown in figure (4-1), is located at the Institute for Research in Construction of the National Research Council of Canada, and is one of the test facilities of the Building Performarse Laboratory for buildings and indoor air quality studies. The test room corresponds to a typical office that can fit up to two work stations separated by a partition. It is $2.87 \mathrm{~m}(9.4 \mathrm{ft})$ high, $4.75 \mathrm{~m}$ (15.6 ft) long, and $4.87 \mathrm{~m}$ (16 $\mathrm{ft}$ ) wide. The room can be extended to $9.5 \mathrm{~m}$ in length by removing a temporary wall.

A dedicated ventilation system provides a range of air conditions to the room. The test room was painted with black paint, and half of the floor was covered by black felt for photography purposes. As shown in figure (4-2), the room is equipped with commercial slot ceiling mounted diffusers for supply and return air. Only two of these diffusers were 
used for the supply and the return as shown in figure (4-1), the others were sealed. This configuration was chosen following some preliminary calculations with the EXACT3 code, as well as based on observations when conducting preliminary flow visualization tests. The temporary wall consists of four identical vertical panels. One of these panels, close to the mid-plane of the room, was replaced by a plywood sheet for flow visualization purposes.

A window of dimensions $36.25^{\prime \prime} \times 36^{\prime \prime}$ located at $6^{\prime \prime}$ from the floor and at $11^{\prime \prime}$ from the north east wall was installed in the woll separating the test room from the mechanical room. This window was used to view the position of the mobile tree when measuring the flow characteristics, and for flow visualization purposes. The locations of the tree were marked on the floor by $1.5^{\prime \prime}$ wide tape.

"T" Thermocouples were installed in 14 locations in the room as shown in figure (43). These thermocouples were used to check isothermal conditions, and to check the heat fluxes through the walls and the ceiling. Pressure taps in locations surrounding the test room were placed at a height of $57^{\prime \prime}$ as shown in figure (4-3). These pressure taps were connected to precalibrated micromanometers (MP6KD) to measure the pressure difference between the room and the surroundings. The measured pressure differences were used to check for air leakage from/or to the room. The test room was also equipped with four stands (marked by B) as shown in figure (4-3), placed in the center of each quadrant of the room. On these stands, low velocity transducers as well sampling tubes for contaminant measurements were installed. The transducers mounted on the stands were only for temperature measurements.

As shown in figure (4.3), two camera supports were installed at mid-height of the north-west wall and in the center of the two halves of the wall for photography purposes. 


\subsection{Flow Visualization}

Two techniques were used to visualize the flow in the test room, the helium filled soap bubble technique and the smoke filament technique. A CANON T-70 camera was used, with two types of KODAK 400 films, to obtain a permanent picture of the flow pattern in the s.om as evidenced by smoke or bubble movement. The camera was equipped with a $24 \mathrm{~mm}$ lens, and a $32 \mathrm{ft}$ long remote control cable, so pictures can be taking from the outside of the room.

\subsubsection{Lighting Unit}

Four slide projectors were modified to illuminate a narrow slice along the mid-plane of the room. This modification consists of removing the focusing lens and placing a narrow slit at the focal point of the condensing lens. A plano-convex cylindrical lens (made of plexiglass of focal length $300 \mathrm{~mm}$ ) was placed in front of the slit to project the beam across the full length of the room. The system was designed to produce a light sheet of about $100 \mathrm{~mm}$ width. This width was chosen as suggested by Carpenter and Moulsley [51], to be sufficient to permit efficient collection of light by the objective lens. and yet sufficiently narrow for particle tracks to represent flow in the mid-plane (see figure (4-4)). Opposite to the lenses, a narrow mirror scanning the height of the room was used to reflect back the light from the projectors to illuminate the whole plane of interest. The lenses were mounted on the plywood sheet in front of the projectors, at $28^{\prime \prime}$ from each other, to obtain a uniform distribution of the light intensity across the height of the room. 


\subsubsection{Helium-Filled Soap Bubbles}

The model 3 SAI bubble generator shown in figure(4-5) was used for flow visualization. It produces helium-filled, neutrally-buoyant bubbles of controlled uniform

size from $1 / 32 " 103 / 16$ in diameter. Helium, air and commercial bubble film solution were used by two units as shown in figure(4-6) to produce about 500 to 600 bubbles per second. The helium and air supplies to the generators were adjusted to $20 \mathrm{psi}$ (137.9 kpa) and 25 psi (172.4 kpa) respectively [62]. The volume flow rates of the helium, air and soap solution were independently controlled by three micro metering control valves set at $1.35,0.8$ and 2.5 respectively.

This set up provides neutrally-buoyant bubbles of approximately $1 / 8(3 \mathrm{~mm})$ in diameter [62]. Once generated, these bubbles will trace the flow pattern in the room. These bubbles last about 1 to 5 minutes depending on the relative humidity, obstacles present in the room, and their weight.

\subsubsection{Smoke Filament Technique}

The system shown in figure(4-7), uses smoke generated by vaporizing mineral oil by a smoke generator. The smoke is driven from the supply tank by a pump at low flow rate. The smoke then escapes from a tube through 18 holes of $2 \mathrm{~mm}$ in diameter evenly distributed, to scan the whole height of the room. The tube was mounted vertically on the traversing mechanism to facilitate scanning the mid-plane of the room. The flow rate of the smoke through the holes was adjusted to provide sufficient smoke to trace, and to 
minimize the effect of the smoke jet on the flow pattern in the room. Each hole in the tube provided a smoke filament.

\subsection{Flow Rate Measurements}

A dedicated ventilation system was used to set the flow conditions in the test room. Two precalibrated micromanometers (MP6KD) were used to measure the pressure drop across the supply and retum precalibrated orifice plates, installed in the supply and return ducts respectively, as shown in figure(4-8). The pressure drops across the orifice plates (supply and return) were set to the test values by adjusting the supply and return fan speeds from the control panel of the HVAC system.

From the calibration data of the orifice plates, a $\mathrm{K}$ value of 0.622 was used for the supply and 0.633 for the return. Knowing the desired mass flow rate to the room, the pressure drop across each orifice plate was calculated by rearranging the equation :

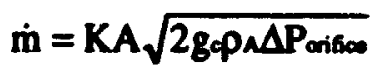

in the following form:

$$
\Delta P_{\text {antice }}=\frac{12}{2 \rho_{A p} g_{c}}\left(\frac{\dot{m}}{K A}\right)^{2} \quad \text { in inches of } \mathrm{H}_{2} \mathrm{O} \text {. }
$$

where $\rho_{A}, \rho_{w}$ are the densities of air and water respectively, and $A=0.08727 \mathrm{ft}^{2}$ is the area of the orifice plate used in both the return and the supply ducts.

These calculated values of the pressure drop across each orifice plate were then set using the control panel to give the wanted mass flow rate. 


\subsection{Velocity and Temperature Measurements}

To have a complete survey of the flow conditions in the test room, 13 precalibrated DANTEC 54R10 Low Velocity Transducers (LVT) were used. Nine of these transducers were mounted on the mobile tree of the traversing mechanism spanning the height of the room and the whole plane of interest. The other four were stationary, each at the center of the four quadrants of the room at a height of about $48.25^{\circ}$. As shown in figure(4-9), the transducers were connected to the Multiflow Analyzer (M.F.A.) unit (DANTEC 54N10), by long cables and via the 54N21 Input Module. The Multiflow Analyzer was connected to an XT computer for data storage via an IEEE-488 interface card.

\subsubsection{Description of the Multiflow Analyzer DANTEC 54N10}

The 54N10 Multiflow Analyzer is based on a spherical probe with near-perfect omnidirectional characteristics for measurements of air flows, and a thermistor for measuring temperatures. The instrument is equipped with 8 plug-in units 54N21; each unit contains 3 CTA and temperature circuits, allowing simultaneous measurement of air flow and temperature from 24 channels. The instrument works on the basis of a hotsensor anemometer principle, which utilizes the relationship between heat transfer and flow velocity. The 54 N10 Multiflow Analyzer is also equipped with a standard IEEE488 parallel interface for data transfer to the computer.

This instrument was operated from the computer using the 546301 software package provided by DANTEC. 


\subsubsection{Description of the 54R10 Low Velocity Transducer}

As shown in figure(4-10.a), the probe for the 54N10 Multiflow Analyzer consists of two spherical sensors mounted in a cage close to each other, and a small thernistor. The velocity sensor [1] consists of a thin-film of Nickel deposited, by sputtering, on the surface of a $3 \mathrm{~mm}$ glass sphere and protected against corrosion by means of $5 \mu \mathrm{m}$ thick quartz coating (see figure(4-10.b)). It is connected to one arm of a Wheatstone bridge, whose oppusite arm contains an identical non-heated sphere for automatic temperature compensation. A servo-loop controls the heating current through the velocity sphere, so that it is always kept $30^{\circ} \mathrm{C}$ above the surrounding air temperature, independent of variations in flow velocity or temperature. The temperature sensor is an NTC thermistor approximately $0.5 \mathrm{~mm}$ in diameter, and suspended on a thin wire. It is operated as a resistance thermometer in a constant current set-up.

In addition to the three sensors, the transducer contains the anemometer bridge, part of the temperature circuit and components for normalization of the velocity ard temperature signals.

\subsection{Traversing Mechanism}

The traversing mechanism shown in figure(4-11), consists of a traversing gear and a guide rail. The traversing gear consists of a base plate $1 / 4$ thick and $2 \mathrm{ft} \times 2 \mathrm{ft}(61.0 \mathrm{~cm}$ $\times 61.0 \mathrm{~cm}$ ) in dimensions. On the center of this plate, a "tree" for scanning the height of the room was mounted insicle a support strut, bolted to the plate. The base plate is equipped with two sets of guide bearing mechanisms for easy and precise movement. 
The traversing gear can be moved along the rail which is fixed to the walls at the ends by means of two cables fixed to each end of the plate. The cables slide on two pulleys fixed to the two ends of the guide rail.

\subsection{Contaminant Measurement System}

For tracer gas measurements, two Gas Chromatography (GC) units were used, model Varian 3400 and Varian 3300.

Each unit consists of a carrier gas supply unit, a sample selection unit, a dual column sampling unit with back-flushing and detection unit (see figure(4-12)). The carrier supply unit consists of a carrier gas supply tank (NTROGEN), a pressure regulator, a water scrubber, an oxygen scrubber, and a unit for both the oxygen and water traps. This was suggested by Evans and Shaw [2] because the presence of the oxygen in the carrier gas will reduce the sensitivity of the detector, and to decrease the deterioration of the column due to moisture accumulation.

The sampling selection unit consists of a 16 port multiposition valve, a multiposition control module, a sampling pump, and a by-pass valve. The multiposition control module controls the valve to allow one sample at a time to be supplied by the sampling unit.

The sampling unit consists of a ten-port sampling valve, a digital valve sequence programmer, a flow meter, a sampling loop, and two molecular sieve columns. The digital valve sequence programmer controls the sampling valve to switch from the loading/backflushing mode to the injection mode or vice versa in a timed sequence.

Each of the GC's used was connected to a computer via a Labmate (an A to D converter) equipped with an RS232 interface for data acquisition, and operated by the 
Maximon Plus software. Figures(4-13.a) ard (4-13.b) show a schematic diagram of the two systems used for tracer gas measurements. One of the systems (system I) was used for tracer gas measurements from 15 locations in the test room. Nine of these locations were on the mobile tree of the traversing mechanism as shown in figure( $(-14)$, four in the center of the four quadrants of the room at a height of $48.25^{\prime \prime}$, one at the supply diffuser, and one at the return diffusc: From these 15 locations, 15 more tygon tubes were run to a manifold connected to the sampling valve of the second system. Other sampling tubes were run from the mechanical room, and the corridor. The tubes in the corridor and the mechanical roum were at a height of $\mathbf{5 7}$ inches, and were used to check for leakage from the test room.

In system I, the data measured by the GC were first stored using an HP integrator, and then transferred to the computer at the end of the test using Cross-Talk sofiware. This is different from system II, where the measured values are stored continuously in the computer using Desk-View software.

\subsection{The Tracer Gas}

Sulfur hexafluoride (SF) was used as a tracer gas. It has been used for several years [2] to measure air change rates in buildings. It is stable, inert, non-flammable, not considered toxic in the parts per billion range, not normally present in the atmosphere and can be detected in the ppb range using an electron capture detector. In the gas state, and at a temperature of $25^{\circ} \mathrm{C}$ and a pressure of $101.325 \mathrm{kpa}$, the density of $\mathrm{SF}_{6}$ is $6.602 \mathrm{~g} / 1[63]$. 


\section{Chapter 5}

\section{TEST PROCEDURE AND ACCURACY}

\subsection{Experimental Procedure}

In the present investigation, a total of six test runs were performed under steady state conditions in the test room described earlier in chapter 4. Each test consisted of flow visualization, and measurements of velocity, temperature, turbulence intensity, and contaminant concentration. A summary of these tests is listed in table (5-1).

\subsubsection{Determination of the Steady State Conditions}

Preliminary tests were conducted to determine the time required for the test room to reach steady state conditions. Steady state conditions were specified according to the degree of variation in temperature and velocity readings during the measiurements. When 
these were found to vary less than approximately $3 \%$, steady state was considered to have been attained.

From these tests, it was found that a period of $\mathbf{4 5}$ minutes to one hour was necessary for the room to reach the steady state conditions.

\subsubsection{Methodology of Flow Visualization}

Prior to measurements of the scalar quantities in the test room, flow visualization of the flow pattern in each test case was conducted in the mid-plane of the room, for the following reasons:

- to check the two dimensionality assumption in the mid-plane of the test room for the numerical computations,

- to determine the flow orientation for the Low Velocity Transducers, and

- to visualize the flow in that particular plane.

Since it was difficult to get the whole plane with the camera at once, the mid-plane of the room was divided into two frames, frame A containing the supply diffuser, and frame B containing the return diffuser.

Both techniques of flow visualization introduced earlier in chapter 4 were used in this study. When using the Helium-Filled Soap Bubble technique, the bubbles were released continuously in the room for 15 minutes from the two heads of the two bubble generators. As shown in figure (5-1), the two heads were located on each side of the plane to provide enough bubbles in each frame. For this technique, a total of two pictures was sufficient to describe the whole flow domain in the mid-plane. In the case of the Smoke Filament technique, two locations were used for the smoke tube (see figure 
(5-1)) to trace the flow pattern in each frame. To describe the flow pattern in the plane using smoke, a total of four pictures were needed.

The pictures were taken using a remote control, whenever bubbles or smoke present in the plane were believed to be enough to describe the flow. For each picture taken, the shutter was open for 20 seconds. This time was determined from repeated testing with different shutter periods raging from 10 to 30 seconds.

\subsubsection{Methodology of Velocity, Temperature and Turbulence Ii tensity Measurements}

A grid of $9 \times 21$ points was used to describe the flow field in the mid-plane of the room (see figure(5-2)). At each position of the tree, measurements in 9 vertical locations were taken over a 20 minute time period. The 20 minute period, defined as the integration time (IT) was determined according to several preliminary tests conducted with different values of IT. As shown in figures (5-3.a) and (5-3.b), more stable results of the mean velocity in the occupied space were obtained with the 20 minutes time period of IT than with 2 minutes.

Since an induced vibration of the tree was noticed when moving it from one location to another, a period of 5 minutes was allowed between each set of measurements, to restore the steady state conditions in the room. Each test took approximately 10 hours.

\subsubsection{Directional sensitivity}

Figure(5-4.a), and figure(5-4.b) sho'v the variation of the velocity readings by the sensor with both the roll, and the yaw angle respectively. 
Chapter 5 Test Procedure and Accuracy

A previous error analysis of the instrument[1], showed that errors of $5 \%$ were present if the flow rotates in a plane perpendicular to the transducer axis, and smaller than $10 \%$ if the flow rotates in the plane containing the transducer house within an angle of $90^{\circ} \pm 30^{\circ}$.

\subsubsection{Frequency response}

Using the Low Velocity Transducer, the velocities are measured correctly at frequencies up to $0.1 \mathrm{~Hz}$, after which a damping occurs due to the interaction between the sensor film and the glass sphere (see reference[1] for more details).

\subsubsection{Infuence of changing temperature}

Air temperature variations are automatically compensated for by means of the lower sphere. The electrical parameters are chosen close enough to those of the velocity sphere that errors in the velocity reading are less than $+2 \%$ per ${ }^{\circ} \mathrm{C}$. In this way the induced errors in the velocity measurements in the comfort zone were smaller than $1 \%$. However, rapid temperature changes may cause large errors in velocity readings[1].

\subsubsection{Measurements of air temperature}

The accuracy of the temperature measurements with the NTC thermistor is a function of both the velocity magnitude and the velocity direction. At very low velocities, the heat dissipated from the transducer housing may cause too high temperature readings; varying from $0.2^{\circ} \mathrm{C}$ at $5 \mathrm{~cm} / \mathrm{s}$ up to $0.6^{\circ} \mathrm{C}$ at zero flow. If the flow direction changes, so that the thermistor enters the hot wake of the velocity sphere or the transducer 
housing, the reading will be approximately $1-2{ }^{\circ} \mathrm{C}$ too high, but as long as the velocity vector is maintained within $90^{\circ} \pm 45^{\circ}$ with respect to the transducer axis, the errors are below $0.3^{\circ} \mathrm{C}$.

\subsubsection{Infuence of natural convection}

At very low velocities the heated velocity sensor creates an upward directed natural convection flow. Its influence on the measuring accuracy depends on the direction of the flow with respect to the gravity field. The worst case occurs in a downward direction flow, which is opposed by the natural convection. Figure(5.5) shows the effect of natural convection on the measured velocity for the different flow orientations. An upward directed flow of $5 \mathrm{~cm} / \mathrm{s}$ is measured $2 \mathrm{~cm} / \mathrm{s}$ too big. As the transducers are calibrated in a horizontal flow, the natural convection does not cause measuring error in this situation above $5 \mathrm{~cm} / \mathrm{s}$. The Figure shows that at $15 \mathrm{~cm} / \mathrm{s}$ the influence of natural convection is less than $\pm 5 \%$ of reading independent of flow direction.

\subsubsection{Methodology of Contaminant Measurements}

For contaminant measurements, as well as methods of injection into the occupied space, several techniques were introduced in the literature $[6,8,59,60,61]$.

In this experimental investigation, the injection technique of Heiselberg [8] was followed. This technique presents a more realistic condition for the release of air borne contaminants in ventilated spaces, since in realistic situations, contaminants are usually released while the ventilation system is on. In addition, in these situations no fans are used for mixing of the contaminants with the room air. The technique in each test case 
Chapter 5 Test Procedure and Accuracy

was first to inject the $\mathrm{SF}_{6}$ at the center of the quadrant of the room shown in figure(5-6) at a height of $48.25^{\prime \prime}$, and then to stan the measurement right after the injection at the 15 locations in the test room. In each test, a pump was used to inject a volume of $5 \mathrm{ml}$ of $\mathrm{SF}_{6}$ over a period of 2 minutes. For test $\mathrm{T} 01$ and test $\mathrm{T} 02$, the sampling location of the mobile tree was in the center of the room. For the other tests with the partition, the samples were taken from two locations of the mobile tree on each side of the partition as shown in figure(5-1).

\subsection{Numerical Computations}

The numerical computations were carried out for the experimental test cases T01. T04, and T05 described earlier, using the EXACT3 code. As mentioned earlier, the purpose of the numerical computations was to obiain numerical results of the flow distribution in the test room that can be compared with the experimental findings. Consequently an evaluation of the EXACT3 code can be obtained. Prior to the prediction of the air flow distribution in the test room, the EXACT3 code was used in some preliminary studies to determine the inlet boundary condition value of the dissipation rate of the turbulent kinetic energy $\left(\varepsilon_{i n}\right)$, since the later is one of the parameters specified at the inlet boundary conditions.

\section{Preliminary Studies}

The dissipation rate of the turbulence kinetic energy $\left(\varepsilon_{i n}\right)$ is one of the parameters specified at the inlet boundary conditions. This parameter is theoretically a function of 
the turbulent length scale $\ell$, which sannot be measured directly, and is found to dependent on the inlet geometry.

Various correlations defining the inlet dissipation rate were provided in the literature. These correlations varied significantly from one author to another according to the geometry of the supply opening and the geometry of the room. A summary of these correlations is listed in table (5-2).

None of the configurations used in the literature was similar to the one used in the present study, and no measured values of the dissipation rate at the supply diffuser were available. Thus, it was difficult to specify the appropriate value of $\left(\varepsilon_{1}\right)$ at the inlet conditions.

An investigation was necessary to study the effect of $\left(\varepsilon_{i}\right)$ on the development of the solution and the steady state solution of the flow field in the occupied zone. For this purpose, published data by Nielsen [26] were used for comparison with the numerical results obtained by the EXACT3 code for the same geometry of the room and under the same conditions. Figure (5-7) shows the geometry as well the dimensions of the test room used in this investigation. Three values of $\varepsilon$ were used for this investigation. These three values were based on three different correlations, by Nielsen [26] giving a non-dimensional value of $\hat{\varepsilon}_{n}=0.00118$, by Skovgaard [65] (hydraulic diameter) giving a non-dimensional value of $\hat{\varepsilon}_{i}=0.00034$, and by Lamers et al. [43] giving a nondimensionai value of $\hat{\varepsilon}_{i}=0.00021$. The choice of these values was based on selecting a maximum, a minimum, and an intermediate value of $\varepsilon$ from the preliminary calculated values using all the correlations given in table (5-2). The numerical results were compared in two locations in the test room, at $\mathrm{Y} / \mathrm{H}=1.0$ and $\mathrm{Y} / \mathrm{H}=2.0$ respectively, at three stages of the solution. These stages include an early stage of the solution at $\mathbf{4 0 0 0}$ 
time step iterations, an intermediate stage at $\mathbf{8 0 0 0}$ time step iterations, and a final stage when reaching steady state (around 13000 time step iterations).

In the early stage of the solution, figure(5-8) shows that the progress of the solution is the same for the three different values of $\varepsilon$. Indeed the same converged solution was obtained with the three correlations. In contrast to figure(5-8), figure (5-9) shows that, depending on the chosen initial value of $\varepsilon$, different results may be obtained. This is especiaily so downstream of the supply diffuser $(\mathrm{Y} / \mathrm{H}=2.0)$ were higher values of $\varepsilon$ gave results closer to the experimental ones. Close to the supply, the difference between the numerical results obtained using the three different values of $\varepsilon$ and the experimental data was very small and almost negligible. As shown in figure (5-10), the steady state solution did not vary with the initial value of $\varepsilon$.

From this investigation, it was concluded that the steady state solution does not depend on the initial value of the dissipation rate of the turbulence kinetic energy. However, the solution developed faster downstream of the supply diffuser for higher values of ( $\left.\varepsilon_{i n}\right)$.

As shown in figures (5.11.a) and (5.11.b), measurements of the flow characteristics along and across the supply diffuser show almost uniform velocity as well as turbulence intensity distributions. A precalibrated hot-wire anemometer for the velocity range 1.4 $\mathrm{m} / \mathrm{s}(4.6 \mathrm{f} / \mathrm{s})$ to $6.0 \mathrm{~m} / \mathrm{s}(19.7 \mathrm{ft} / \mathrm{s})$ was used in these measurements. The average velocity at the supply diffuser was found to be $4.302 \mathrm{~m} / \mathrm{s}$ (14.1 f $\mathrm{fs}$ ) for the air flow rate of $3 \mathrm{ACH}$, and $2.291 \mathrm{~m} / \mathrm{s}(7.5 \mathrm{fU} / \mathrm{s})$ for the air flow rate of $1.5 \mathrm{ACH}$. In addition, the supply air jet orientation (inlet flow angle) with respect to the vertical direction ( $x$ axis) was found to be $16^{\circ}$. These values of the average velocities and the inlet flow angle were used for the inlet boundary conditions at the supply diffuser in the numerical simulation. 
Moreover, a value of $4 \%$ was used for the turbulence intensity at the supply inlet boundary conditions. It is noted in previously published numerical work [18] applied to room air distribution, that the value of the turbulence intensity at the supply inlet condition has little effect on the accuracy of the numerical solution.

A summary of the input data used in the computations is given below:

- time step

- inlet $\mathrm{x}$ direction velocity

- inlel y direction velocity

- inlet $\mathrm{z}$ direction velocity

- outlet $x$ direction velocity

- outlet y direction velocity

- outiet z direction velocity

- inlet turbulence energy

- inlet turbulence dissipation rate

- inlet length scale

- wall boundary conditions

- switching parameter for convection term.

$$
0.01 L_{0} / U_{d}
$$

$\left(U_{i m}\right)_{x}=U_{d} \cos \left(16^{\circ}\right)$ (uniform),

$\left(U_{i n}\right)_{y}=-U_{d} \sin \left(16^{\circ}\right)$ (uniform),

$\left(U_{i a}\right)_{2}=0$ (uniform),

$\left(U_{\infty}\right)_{x}=-\left(U_{i=}\right)_{z}$ (uniform),

$\left(U_{c a x}\right)_{y}=0$ (uniform),

$\left(U_{\text {oun }}\right)_{2}=0$ (uniform),

$k_{i=}=\frac{3}{2}(0.04)^{2} U_{d}^{2}$,

$\varepsilon_{n}=C_{\mu}^{\frac{3}{4}} \frac{\mathrm{k}_{\mathrm{i}}^{\frac{3}{2}}}{0.03 \mathrm{Dh}_{\mathrm{h}}}$.

$L_{0}=w$, where $w=40^{n}(1.016 \mathrm{~m})$,

$1 / 7$ th power profile,

2 for whole domain. 


\section{Chapter 6}

\section{RESULTS AND DISCUSSION}

\subsection{Test conditions}

The primary objective in this study was to conduct an experimental investigation to obtain the flow characteristics and properties in a typical office space under isothermal ventilation conditions. To satisfy this condition, the issuing air temperature from the supply diffuser was set to the test room temperature using the ventilation system control panel. Moreover, no heat loads or heat sources were added to the room, and the surface temperatures of the surrounding walls, the ceiling, the plenum, and the room were recorded continuously at the thermocouple locations as well as at the LVT locations. In addition, the air mass flow rates through the supply and the return orifice plates were recorded continuously, together with the pressure difference between the room and the surroundings. 


\subsubsection{Flow Visualization Test Conditions}

As mentioned earlier, the temperature in the test room, the temperature of the surroundings, the pressure difference across the supply and the return orifice plates, as well as the pressure difference between the room and the surroundings, were recorded continuously throughout each test. A summary of these test conditions, when visualizing the flow pattern in the mid-plane of the test room, is listed in tables (6.1.a) and (6.1.b). As shown in table (6.1.a), the Archimedes number in each test was less than $10^{-3}$, except for test $\mathrm{T02}\left(\mathrm{Ar}=-8.582 \times 10^{-3}\right)$. In addition, the temperature difference between the supply and the return air was less than $0.18 \Omega^{2}$, and the temperature difference between the supply and the room air was less than $0.65{ }^{\circ} \mathrm{C}$.

During each experimental test, the temperature of the temporary wall in all the test cases was higher by almost $1^{\circ} \mathrm{C}$ than the other walls, because the plywood panel used for mounting the plano-convex lenses wasn't insulated, and its temperature was affected by the change in temperature in the control room where the data acquisition systems were located. This temperature showed no apparent effect on the temperature distribution in the test room.

Table (6.1.b) shows a comparison between the set point values of the pressure drop (the value of $\Delta P_{\text {cifice }}$ calculated for the desired volume flow rate) and the measured ones across the supply and return orifice plates. With both volume flow rates used in this study, the differences involved at the supply and return orifice plates were less than $3 \%$.

\subsubsection{Velocity, Temperature and Turbulence Intensity Test Conditions}

Tables (6.1.c) and (6.1.d) list all the test conditions present during the measurements of the spatial distribution, in the mid-plane (symmetric plane) of the test room, of the 
mean velocity, the temperature, and the turbulence intensity. During these measurements, the temperature difference between the supply diffuser, and the room was around $0.5^{\circ} \mathrm{C}$, giving a value of Archimedes number (Ar) less than $10^{-3}$ in all test cases, except for test case $\mathrm{T02}$, where Ar was around 0.003 . The temperature difference between the supply and the return air was less than $0.18{ }^{\circ} \mathrm{C}$.

The errors involved between the measured values, and the set point values (calculated) of the pressure drop across the supply and return orifice plates, show the samc results encountered in the flow visualization tests. Table (6.1.d) shows a summary of these errors.

\subsubsection{Contaminant Concentration Measurements Test Conditions}

The test conditions present during the contaminant concentration measurements are similar to the flow visualization and the scalar quantity measurement test conditions.

As shown in tables (6.1.e) and (6.1.f), the temperature differences between the roxm and the supply air diffuser, and between the supply and return air, were less than $0.38{ }^{\circ} \mathrm{C}$. In addition, the Archimedes number in all test cases was less than 10 $0^{3}$. Table (6.1.e) shows that the errors between the set point values and the measured values of the pressure drop across the supply and retum orifice plates were around $0-3 \%$, and $0-2$ \% respectively.

In all the experimental tests conducted in this study, the measured pressure difference between the room and the surroundings was negligible, imp'ying no air leakages from/or to the room were present. The density was also assumed constant during the experiment, and was calculated from the standard conditions using a correction factor $\xi$ defined as follows: 


$$
\xi=\left(\frac{P_{\text {mam }}}{P_{m d}}\right)\left(\frac{T_{m d}}{T_{m m d}}\right) .
$$

From the summary of the test conditions mentioned above, isothermal conditions may be assumed for all the test cases.

\subsection{Experimental results}

The Correction factor $(\xi)$ defined above was used to present alı the experimental results with respect to the standard conditions.

\subsubsection{Flow Visualization Results}

Bubbles were used to visualize the flow pattern for all the test cases described earlier in chapter 5. For test case T01, smoke was also used, to permit comparisons between the two flow visualization techniques to be made. In all the test cases, photographs in the mid plane of the room were taking occasionally when bubbles or smoke injected in the room were believed to be enough to trace the flow pattern. Moreover, observations of the flow pattern were recorded in each test case. Figures (6.1.a) through (6.1.e) show typical results obtained from the flow visualization and the observations recorded in each test case of the air flow distributicins in the mid-plane of the test room. These figures present the different situations used in this study.

In the case of the empty room (T01 and T02), figures (6.1.a) and (6.1.e) show a typical air distribution in the mid-plane of the test room. In these cases (T01 and T02), the incoming air from the supply diffuser divides at the floor producing two recirculation eddies, a small one with high velocities located in frame $\mathbf{A}$, and a large one with low velocities located in frame B. As shown in figure (6.1.a) and (6.1.e), the large recirculation eddy is located under the return diffuser, and I think all of the flow in that 
frame (frame B) is induced by the supply air jet. In addition, there was no perceived disturbance of the supply air jet by the surrounding room air. A shear layer with relatively high levels of turbulence was present between the two flows. For both tests (T01 and T02), the flow pattem in the mid plane of the test room was reproducible. The only difference present between the two cases is that the supply air jet penetrates deeper for the high flow rate (T01 (3 ACH)) than for the low flow rate (T02 (1.5 ACH)).

When using the smoke filament technique, figures (6.1.b) and (6.1.e) show the air flow distribution for test T01. As it can be seen, the flow pattern could only be observed at several locations very near the smoke tube. With this technique, as for the bubbles, the same flow pattern was reproduced in areas that were visible. The two techniques used for flow visualization each present advantages and disadvantages over each other. The helium-filled soap bubble technique is more convenient than the smoke filament technique when visualizing air flow distributions in large enclosures such as our test room, and the whole plane of the room can be described at once rather than using several locations as required when using smoke. Flow direction can also be obtained with the bubble technique when recording the flow motion with a video camera. This flow direction cannot be observed in a photograph taken with a fast shutter speed. In contrast to the bubble technique, the smoke filament technique is slow (this technique requires more time to visualize the flow pattem in the whole plane rather than in few locations), and once in the room, the smoke diffuses quickly, and the flow direction can no longer be detected. Thus the smoke filament technique presents a rnajor disedvantage over the bubble technique where high velocities are present.

In spite of the quick diffusion of the smoke in the occupied space, the smoke technique can provide satisfactory results in small areas where detailed flow characteristics are of interest, and the flow direction can eisily be obtained without any ambiguity. 
Figures (6.1.c) and (6.1.e), show a typical airflow distribution in the ruid-plane of the room when using the partitions with the $6.0^{\mathrm{m}}(15.24 \mathrm{~cm})$ gap between the bottom of the partition and the floor (T03 and T05). In these cases, the effect of the partition height on the air flow distribution in the room while keeping the same gap (6.0") is studied.

Two partitions with different heights, but having the same clearance were used. These partitions were positioned in the center of the room. In both cases, the flow rate was the same. As shown in figures (6.1.c) and (6.1.e), the supply air jet divides into three air streams, two producing eddies on each side of the supply air jet (vortices), and one stream traveling through the clearance. The recirculation eddy located on the right of the jet extends from the floor to the top of the partition. The air stream flowing under the partition, and producing a recirculation eddy behind the partition (in frame $B$ ) also extends from the floor to the top of the partition. From the flow visualization results of both tests T03 and T05, it was found that the flow pattern in the mid-plane of the room was reproducible for both test cases. Moreover, it was found, that the height of the partition affects the size of the recirculation eddies produced on each side of the partition, and that the higher the partition the weaker is the recirculation in the half of the plane containing the retum diffuser.

Figures (6.1.d) and (6.1.e), show a typical air flow distribution in the mid-plane of the test room when using the two partitions with no clearance (T04 and T06). In these cases, the supply air jet separates into two streams forming two recirculation eddies on each side of the supply air jet (frame A), and hardly no flow in the second half of the plane (frame B). For both these two cases, the same flow pattem was reproducible.

The flow visualization results for test cases T03, T04, T05, and T06, show that the presence of the partitions in the test room seem to create two zones in the mid-plane of the test room, one zone with high recirculation flows and high velocities, and another zone with hardly any air flow circulation and with low velocities. It was also shown from the flow visualization results, that closing the gap between the bottom of the 
partition and the floor minimizes the air flow circulation in the part of the plane containing the return air opening (return diffuser), hence creating an almost stagnant region. In addition, increasing the partition height while keeping the gap closed also seems to reduce the circulation in the region shown in frame $B$. The presence of the clearance between the floor and the bottom of the partition increases the air flow circulation in frame B, allowing ventilation air to circulate in that part of the plane (frame B). While keeping the clearance open, increasing the partition height reduces the amount of air circulating from frame B to frame A, causing "bigger" regions of stagnant recirculation flows.

The effect of the partitions shown in this study was affected by the three-dimensional flow present in the room, since air was allowed to flow around the partition and circulate between the two frames (frame $A$ and frame B) at the mid-plane. Otherwise, it may be expected that the gap height and the overall height of the partitions in the lest room would have had a greater effect on the flow patterns in zone B. if the width of the partitions were equal to the width of the room (two-dimensional situation).

The flow visualization results suggested that the flow in the mid-plane of the test room is predominantly two-dimensional, except at the corners where the third dimensional effect is significant. Thus, the mid-plane of the test room may be assumed to be the symmetric plane. In addition, it was found that the presence of obstacles clearly affects the flow pattem in the test room, by interfering with the flow, thereby possibly creating zones with thermal discomfort. This effect was not as apparent in the room studied as if the flow in the test room had been more fully two-dimensional. 


\subsubsection{Velocity, Temperature, Turbulence Intensity, and Turbulence Kinetic Energy Distributions}

\subsubsection{Velocity distribution}

Figures (6.2.a) through (6.7.a) show the spatial distribution of the non-dimensional velocity in the mid-plane (symmetric) of the test room for the test cases described earlier.

For the tests T01 and T02, figures (6.2.a) and (6.3.a) show that the supply diffuser air jet penetrates much deeper in the case of the high flow rate $(3 \mathrm{ACH})$ than in the case of the low flow rate (1.5 $\mathrm{ACH}$ ), because the high air inflow rate has more momentum to penetrate longer distance without being dispersed by the room air. Moreover, the two figures show that the higher momentum inflow has more momentum to impart to the recirculation flow. Table (6.2) lists the calculated average non-dimensional velocity for all tests, in both frames $\mathbf{A}$ and $B$. This average non-dimensional velocity was obtained by calculating the a 'erage of all the velocity readings on each frame. Since the velocities in test T02 are non-dimensionalized with respect to a lower diffuser velocity, the average non-dimensional velocity in both frames was higher than in the test T01.

The same jet behavior as in test T01, was observed in tests T03 through T06. Figures (6.4.a) and (6.6.a) show the spatial distribution of the non-dimensional velocity for both tests T03 and T05 respectively. In these tests, two partitions having the same clearance $6.0^{\prime \prime}(15.24 \mathrm{~cm})$ but different heights are used to study their effect on the velocity magnitude in both frames of the plane. The two figures show nearly the same velocity distribution for both cases. Table (6.2) shows almost no variation of the average nondimensional velocity for the test cases in both frames $A$ and $B$, since the threedimensional effect allows air to get around the partition. If there was no threedimensional effect, the average non-dimensional velocity in frame $B$ would be expected to have been higher in test case TOS than in test case T03. 
Figures (6.5.a) and (6.7.a) show the velocity distribution when using the partitions with no clearance. As shown in table (6.2), blocking the clearance did not greatly affect the magnitudes of the velocities in both frames of the plane. In addition, almost the same spatial velocity distribution is obtainsd with the two different height partitions.

For all the test cases conducted, the spatial distribution of the velocity in the midplane (symmetric) of the test room show the same trend as in the flow visualization of the flow pattern.

It can be concluded from the spatial velocity distribution that for the particular configuration of the supply and retum diffusers, and for the particular room geometry used in this study, and with high supply diffuser air velocities, high velocities are present in the recirculation eddies. In addition, due to the three-dimensional effect, the use of the partitions with different heights and having the same clearance did not affect the nondimensional velocity in both sides of the plane. Moreover, the use of the partitions with no clearance, shows a little variation in the non dimensional velocity in frame $B(U / U d=$ 0.015 versus 0.017 when using the clearance). The effect of closing the clearance would have been more apparent if the three-dimensional effect was minimum. Also the use of the partitions seem to have little effect on the velocity magnitudes in frame $B$.

In all the experimental tests conducted, the supply air jet seem to penetrate deeper in the occupied zone without been mixed with, or disturbed by the surrounding room air. This type of jet may present thermal discomfort in the regions where it is oriented, and should be avoided in design.

\subsubsection{Spatial distribution of turbulence intensity}

The turbulence intensity is defined as the ratio between the standard deviation $\left(u^{\prime}\right)$ of

the velocity fluctuations and the mean velocity (U). It represents the degree of 
turbulence at a local point. Using the Low Velocity Transducers, the velocity fluctuations are measured correctly at frequencies up to $0.1 \mathrm{~Hz}$.

Figures (6.2.b) through (6.7.b), show the distribution pattern of the measured turbulence intensity in the mid-plane (symmetric) of the test room for the six test cases conducted in this study.

In all test cases, relatively high values of the turbulence intensity were distributed at the central regions of the recirculation eddies. The turbulence intensity at the intermittent region at the edge of the diffuser air jet was found to be in the range of $24 \%$ to $32 \%$.

The spatial distribution of the turbulence intensity show where the high values of the local turbulence intensity are in the test room. These generally occur at the central regions of the recirculation eddies. Their values range from $20 \%$ to $60 \%$.

\subsubsection{Spatial distribution of turbulence linetic energy}

Figures (6.8.a) through (6.8.f) show the distribution pattern of the turbulent kinetic energy ( $k$ ) in the symmetric plane of the test room, for the test cases T01 through T06. It is defined as $0.5 \mathrm{u}^{\prime 2}$, and is a more convenient term than the turbulence intensity to characterize the significance of turbulence effect on the room air distribution because the latter only describes the degree of turbulence locally. These figures show that the turbulence kinetic energy in the test room is almost negligible everywhere except in the diffuser jet region. Mrreover, the turbulence kinetic energy in the test room is mainly generated in the diffuser jet region, due to the strong interaction between the incoming air and the room air. This turbulence energy is then transported to the other regions of the room to contribute to the turbulence kinetic energy generated locally within each region. During the transport process, the velocity fluctuations are damped by the viscous 
effects, resulting in low values of the turbulent kinetic energy elsewhere in the test room. These results are in agreement with the findings of Zang [56].

\subsubsection{Spatial temperature distribution}

Within the test room, heat diffuses slightly faster than the momentum. This is explained by the Prandtl number of air (0.71), which represents the ratio between the momentum and the thermal diffusion coefficients. The heat in the test room is generated by the shear work of the entering air jet. Since the energy thereby converted is a small amount, one would not expect large temperature changes as a result.

Figures (6.9.a) through (6.9.1) show the spatial temperature distribution in the midplane (symmetric) of the test room for the six experimental test cases conducted. These results are not statistically significant, but they are used to show that the temperature distribution in the test room is almost uniform. Actually, the average room temperature in each test case was within $\pm 0.33{ }^{\circ} \mathrm{C}$. Figure (6.10) and table (6.3), show the vertical distribution of the average horizontal temperature in the test room. This vertical distribution shows no thermal stratification occurring in the test room. In addition it can be concluded that buoyancy effects on the airflow distribution within the test room can be neglected.

\subsubsection{Contaminant Concentration Distribution}

Figures (6.11) and (6.12), sho $w$ the $\mathrm{SF}_{6}$ concentration distribution in the test room for both test cases T01 and T02 respectuvely A typical concentration distribution of the air borne contaminants ( $\mathrm{SF}_{6}$ ) from the manifold, the sampling tube located in the corridor, and the sampling tube located in the mechanical room, are shown in figure (6.11). This figure shows that the $\mathrm{SF}_{6}$ concentration in the mechanical room and the corridor is 
negligible by comparison with the concentration in the test room. This is further evidence that there was no significant air leakage from the test room. Moreover, the readings recorded from the manifold were in good agreement with the individual sampling ube readings. This was expected since the $\mathrm{SF}_{6}$ was very well mixed with the room air.

When using the partitions, figures (6.15.a) and (6.15.b) show that the $\mathrm{SF}_{6}$ distribution in the test room does not depend on the sampling location, since the $\mathrm{SF}_{6}$ is very well mixed with the room air. The same behavior of the $\mathrm{SF}_{6}$ distribution as in figures (6.15.a) and (6.15.b) was found for the test cases T03, T04, and T06. Figures (6.13), (6.14), and (6.16) show typical contaminant concentration distributions for these tests respectively.

The results from the contaminant concentration distribution in the test room show that regardless of the presence of obstacles, very well mixed flow is obtained under the test conditions. Table (6.4) shows the mixing time for all lest cases. The mixing time was defined as the time from the injection of the $\mathrm{SF}_{6}$ in the test room, to the time when less than 5\% standard deviation is obtained from the 15 sampling locations (almost uniform contaminant concentration from the 15 sampling locations). It was found that the higher the flow rate, the faster the mixing occurs in the test room, and the faster the contaminant concentration decays. In addition, it was found that the use of the partitions (with and without the gap) in the test room delay the mixing time by a few minutes.

The contaminant concentration results presented in this study represent valuable data for scale and numerical models evaluations. Besides, they can be used for the evaluation of the performance of ventilation systems. The contaminant concentration results should not be used to calculate the number of air changes per hour, since they represent results of a dilution ventilation system where some of the return air mixes with the 'fresh' air from the lab prior entering the test room. Figure (6.11) shows a typical contaminant concentration distribution in the supply duct. This figure shows that the readings from the sampling tube located before the supply fan are equal to the individual sampling tube 
readings in the test room. From these results, one would expect that the contaminant distribution in the test room stays uniform. This is not the case, since the results show almost an exponential decay of the contaminant concentration in the test room. This decay may be explained by the fact that the contaminant concentration in the supply duct is much lower downstream than upstream of the supply fan.

\subsubsection{Uncertainty in the Measurements}

\subsubsection{Repeatability}

For every test case, a repeatability test was conducted to check the variation of the test conditions during each test, and to check the repeatability of the Low Velocity Transducer readings. For these purposes, readings at the first location where measurements started were recorded at the beginning and the end of each test.

As shown in figures (6.17.a) through (6.17.1), good repeatability of the measurements was obtained for all the experimental tests conducted. In addition, these figures support the assumption that the steady state conditions were maintained in each test case.

\subsubsection{Low velocity transducers readings}

The Low Velocity Transducers were calibrated by the manufacturer, and the calibration data show an error ranging from $0 \%$ to $1.7 \%$ for the temperature measurements, and an error ranging from $0.5 \%$ to $5 \%$ for the velocity measurements. These errors were transducer dependent. Also, the zero point (zero flow) readings of the transducers were found to range from $0.8 \mathrm{~cm} / \mathrm{s}$ to $1.6 \mathrm{~cm} / \mathrm{s}$, giving an error ranging from $1.5 \%$ to $20 \%$ in the velocity readings. These errors were also transducer dependent. 


\subsubsection{Variation of the velocity readings with the sampling location}

Figure (6.18) shows a series of typical horizontal distributions of the velocity in the test room. This figure reveals that high velocity gradients are present around the jet, and a change of $10 \%$ may result in the Low Velocity Transducers readings if the offset in the tree position is around 1 inch $(2.54 \mathrm{~cm})$.

\subsection{Numerical Results}

As mentioned earlier, numerical computations were carried out for the test cases T01, T04, and T05. Measured values of the velocity and the jet orientation were used for the inlet flow conditions at the supply diffuser. Each test run took approximately 70 hrs on a Silicon Graphics machine (INDIGO).

Figures (6.19.a) and (6.19.b), show the velocity contour and the velocity vector distribution in the symmetric plane of the test room for test T01. The predicted air flow pattern for the test case TO4 is shown in both figures (6.20.a) and (6.20.b). For the test case T05, the predicted air flow pattern is shown in figures (6.21.a) and (6.21.b).

A comparison between the predicted and the visualized air flow pattem in the symmetric plane of the test room showed some similarities between the two flows, especially in the part of the plane (frame A) containing the supply air opening (supply diffuser). However, the predicted results show that the supply air jet seems to be directed at a different angle than the one specified at the supply boundary conditions. An investigation of the predicted air flow pattern in planes perpendicular to the symmetric plane show that most of the flow circulation is happening in those planes (ivee figure (6.27)). The predicted total velocity and the turbulence kinetic energy at the symuisic plane was in agreement with the measured ones at some locations away from the supply 
air jet where high gradients of the velocities are present. Figures (6.22), (6.23), and (6.24) summarize these results.

To study the effect of the grid size and its distribution on the accuracy of the numerical solutions and the air flow pattern in the mid-plane of the test room (especially in frame A), tests T01 and T04 were simulated with two different grid sizes. A finer grid was used for test T04 $(26 \times 62 \times 18)$ than for test T01 $(19 \times 56 \times 32)$. In both cases the grid was finer around the supply diffuser where high velocity gradients are expected, and coarser elsewhere. As shown in figures (6.19.b) and (6.20.b), this range of grid size variation had no noticeable effect on the accuracy of the numerical solution, especially in the part of the plane (frame A) containing the supply air diffuser.

A numerical investigation of the effect of the supply air jet orientation unit the air flow pattern in the test room was also conducted. This investigation was carried out for three values of the jet orientation; $11^{\circ}, 16^{\circ}$, and $22^{\circ}$. Figures (6.19.b), (6.25.b), and (6.26.b) show that the supply jet orientation has a significant effect on the air flow distribution in the test room. Again, some similarities were found between the predicted and the visualized air flow pattern in the symmetric plane of the test room. Moreover, at some distance from the supply air opening, the jet was found to be directed in a direction different from the one specified at the supply opening.

This phenomena might be attributed to the following:

- The numerical scheme used in the code.

- False diffusion, which is caused by the practice of treating multi-dimensional flows across each control volume face as locally one-dimensional, and occurs for a flow that is oblique to the grid lines in case there is a non-zero gradient of the dependent variable in the direction normal to the flow.

- A combination of both the numerical scheme and the false diffusion.

- Or, it may be a real effect caused by the recirculation region pushing the jet into a different direction. 
An approximate expression for the false diffusion for a two-dimensional situation has been given by de Vahl Davis and Mallison, as reported by Patankar [5]:

$$
D_{1}=\frac{\rho u \Delta x \Delta y \sin 2 \theta}{4\left(\Delta y \sin ^{3} \theta+\Delta x \cos ^{3} \theta\right)},
$$

where $\Delta x$ and $\Delta y$ are the dimensions in the two directions in the two-dimensional grid lay-out, and $\theta$ represent the angle between the flow and the $x$ axis.

The false diffusion can be eliminated by using a finer grid, and by having situations where the flow direction is aligned with the grid. Since the inflow angle in the present computations is high, the false diffusion at the supply diffuser is very important, and may be considered the cause of the discrepancy between the numerical and the experimental results. In the case of the air flow rate of $3 \mathbf{A C H}$, the value of the real diffusion ( $\approx$ $0.00216 \mathrm{~m}^{2} / \mathrm{s}$ ) at the supply diffuser was found to be less than one third of the value of the false diffusion $\left(\approx 0.00777 \mathrm{~m}^{2} / \mathrm{s}\right)$ given by the above formula. This discrepancy may be eliminated by using more realistic supply boundary conditions. To investigate this further, detailed measurements of the flow characteristics in a small area surrounding the supply diffuser should be conducted rather than using only the measured values obtained at the supply diffuser opening. These measurements should be used in the numerical computations to predict the airflow pattern in the test room. The EXACT3 code would need to be modified to permit the use of these measurements, since they should be inputs at points slightly removed from the room boundaries. 


\section{Chapter 7}

\section{CONCLUSIONS AND RECOMMENDATIONS}

The primary objective in this thesis was to conduct an experimental investigation of the flow properties for a full scale room under isothermal ventilation conditions. The room was equipped with two commercial slot ceiling mounted diffusers. For this purpose, experimental facilities of the Building Performance Laboratory IRC (NRCC) were used for studying three-dimensional room airflows. The experimental results obtained are useful for evaluating existing scale and numerical models applied to room airflows. The main conclusions of the present thesis could be summarized as follows:

1. The instrumentations and the techniques used in this study proved to be very useful for studying the flow characteristics in full scale rooms.

2. The flow visualization results suggested that the flow at the mid-plane of the test room is two-dimensional. 
3. The presence of the partitions in the test room changed the air flow pattern in the test room.

4. The measuro' spatial velocity distribution and the flow visualization results were consistent in term. of revealing the air flow pattem at the mid-plane of the test room.

5. For design purposes, the supply air jet orientation (direction of the jet) used in this study should be avoided, since it may cause thermal discomfort in the regions where it is oriented, at least if used at the velocities as used in these tests.

6. Relatively high values of the turbulence intensity were measured in the test room, and especially at the central regions of the recirculation eddies.

7. The turbulence kinetic energy in the test room was found to be largest in the vicinity of the supply diffuser air jet, and was found to be negligibly small in the other parts of the test room.

8. Measurements of the contaminant concentrations in the test room showed that thorough mixing of the room air with the contaminants occurs within a few minutes after injection. Since the method of injection used in this study simulates a local source of contaminants as ma:' be encountered in offices, these measurements show the behavior of the contaminants in nccupied spaces for such circumstances.

9. From the contaminant concentration distributions, it was found that the higher the supply flow rate, the faster the mixing time of the contaminants with the room is, and the faster the decay of the contaminant concentration.

On the other hand, the preliminary investigation using the EXACT3 code showed that the steady state solution does not depend on the initial value of the dissipation rate of the turbulence kinetic energy, but the solution develops faster down stream of the supply diffuser for higher values of $\varepsilon$. 


\section{Chapter 7 Conclusions and Recommendations}

The discrepancies between the measured and the numerical results were attributed to the numerical scheme used in the code, and to the false diffusion in the numerical results since the incoming flow was oblique to the flow domain.

For future experimental studies to provide detailed measurements of the flow characteristics in a full scale room, for scale and numerical model evaluations, the following recommendations are made:

1. The traversing mechanism used in this experiment should be automated to allow more detailed measurements to be made in the test room.

2. The flow visualization techniques used in this study should be used to provide more information on the airflow patterns in other planes.

3. With these facilities a study should be conducted on the effect on the air flow distribution in the test room of the supply and return configuration, the presence of obstacles such as work stations and their location with respect to the supply and return diffusers. In addition, from these measurements. further guide lines should be developed for the designer of ventilation systems.

4. The measured data of the contaminant concentration distributions should be used for defining the ventilation effectiveness, and the evaluation of ventilation systems.

5. More detailed measurements of the flow characteristics in an enclosure surrounding the supply diffuser should be conducted. These measurements should be used in the numerical computations.

Finally, it is implied that the present experimental contribution and the further work suggested, when carried out, should be very useful for increasing the understanding of room air flow physics, and for improving the design of ventilation systems, so that they will be capable of providing acceptable indoor air quality. 


\section{REFERENCES}

1. DANTEC informations, "54N50 Low Velocity Flow Analyzer Mark II", Pub!. No. 5203E, Printed in Denmark, Octoiber 1985.

2. Evans R.G., Shaw C.Y., "A Multiposition Tracer Gas Sampling System for Building Air Movement Studies", Proceedings, AIVC Measurement Techniques Workshop, 21-23 March 1988, Koge Denmark.

3. Kurabuchi T., Fang J.B., Richard A. Grot, "A Numerical Method for Calculating Indoor Airflows using a Turbulence Model", NISTIR 89-4211, Gaithersburg, Maryland: U. S. Department of Commerce, National Institute of Standards and Technology, January 1990.

4. Anderson R., Hassani V., Kirkpatrick A., Knappmiller K., Hittle D., "Visualizing the Air Flow from Cold Air Ceiling Jets", ASHRAE Journal, May 1991.

5. Patankar S.V., "Numerical Heat Transfer anf Fluid Flow", Hemisphere Publishing Corporation, Washington D. C.., 1980.

6. Lage J.L., Bejan /.., Anderson R., "Efficiency of Transient Contaminant Removal from a Slot Ventilated Enclosure", Int. J. Heat Mass Transfer, Vol. 34, No. 10, pp. 2603-2615, 1991.

7. Jones W.P., Launder B.E., "The Prediction of Laminarization with a Two-equation Model of Turbulence", Int. J. Heat Mass Transfer, Vol. 15, pp. 301-314, 1972.

8. Heiselberg P., "Measurements of Test Case F (Forced convection, isothermal with contaminants)", Energy Conservation in Buildings and Community Systems, International Energy Agency, Annex 20, Sub-Task 1 report, September 1991. 
9. Chen Q., Moser A., Suter P., "Interpolation Theory and Influence of Boundary Conditions on Room Air Diffusion", Building and Environment, Vol. 26, No. 4, pp. 433-445, 1991.

10. Nottage B., Slaby J.G., Gojsza W.P., "A Smoke-Filament Technique for Experimental Research in Room Air Distribution". Trans. American Society of Heating and Ventilation Engineering, No. 1461, pp. 399-404, 1952.

11. Chen Q., Suter P., Moser A., "Influence of Air Supply Parameters on Indoor Air Diffusion", Building and Environment, Vol. 26, No. 4, pp. 417-431, 1991.

12. Rosten H.I., Spalding D.B., "The PHOENICS Reference Manual", CHAM TR/200, CHriM Ltd, London 1987.

13. Lam C. K. G., Bremhorst K., "A Modified Form of the $k-\varepsilon$ Model for Prediction Wall Turbulence", J. Fluids Engineering, ASME Trans., Vol. 103, pp. 456-460, 1981.

14. Nielsen P.V., Restivo A., Whitelaw J.H., "Buoyancy-Affected Flows in Ventilated Rooms", Numerical Heat Transfer, Vol. 2, pp. 115-127, 1979.

15. Chen Q., Moser A., Huber A., "Prediction of Buoyant, Turbulent Flow by a low Reynolds Number k-E Model", ASHRAE Trans., Vol. 96, No. 1, pp.564-573, $199($ ).

16. Andreas S., Wiss D., Metzen G., "Numerical Calculation of Room Air Currents and Comparison with LDA Measurements under Free and Forced Convection", SULZER Technical Review, january 1990.

17. Heiselberg P., Nielsen P.V., "Flow Conditions in a Mechanically Ventilated Room with a Convective Heat Source", 9 th AIVC Conference, Gent, Belgium, 12-15 September, 1988.

18. Awbi H.B., "Application of Computational Fluid Dynamics in Room Ventilation", Building and Environment, Vol. 24, No. 1, pp. 73-84, 1989. 
19. Awbi H.B., Nemri M.M., "Scale Effect in Room Airflow Studies", Energy and Buildings, Vol. 14, pp. 207-210, 1990.

20. Skovgaard M., Hyldgaard D.E., Nielsen P.V., "High and Low Reynolds Number Measurements in a Room with an Impinging Isothermal Jet", Energy Conservation in Buildings and Community Systems, International Energy Agency, Annex 20, Paper No. 12, ISSN 0902-7513 R9003, April 1990.

21. Nielsen P.V., Restivo A., Whitelaw J.H., "The Velocity Characteristics of Ventilated Rooms", Journal of Fluids Engineering, ASME trans., Vol. 100, pp. 291298, September 1978.

22. Gosman A.D., Pun W.M., Lecture notes for the course entitled "Calculation of Recirculating Flows", Imperial College, Heat Transfer Section, Report HTS/74/2, 1974.

23. Gosman A.D., Nielsen P.V., Restivo A., Whitelaw J.H., "The Flow Properties of Rooms with Small Ventilation Openings", J. Fluids Engineering, ASME trans., Vol. 102, pp. 316-323, September 1980.

24. Blum W., unpublished notes referred to by Gosman A.D. et al. [23].

25. Nielsen P.V., Moller A.T.A., "Measurements on Buoyant Jet Flows from a CeilingMounted Slot Diffuser", Energy Conservation in Buildings and Community Systems, International Energy Agency, Annex 20, Paper No. 6, ISSN $0902-7513$ R8832, 1988.

26. Nielsen P.V., "Specification of a Two-Dimensional Test Case", Energy Conservation in Buildings and Community Systems, International Energy Agency, Annex 20, Research Item No. 1.45, ISSN 0902-7513 R9040, November 1990.

27. ASHRAE Stancird 62-1989, "Ventilation for Acceptable Indoor Air Quality", ISSN 1041-2336, 1989. 
28. Fang J.B., Grot R.A., "Numerical Simulation of the Performance of Building Ventilation Systems", Preprint for ASHRAE Transactions, Vol. 96, 1990.

29. Ewert M., Renz U., Vogl N., Zeller M., "Definition of the Flow Parameters at the Room Inlet Device -Measurements and Calculations-". Air Movement and Ventilation Control Within Buildings, 12 th AIVC Conference, Ottawa, Canada, 2427 September, 1991.

30. Launder B.E., Spalding D.B., "The Numerical Computation of Turbulent Flow", Computer Methods in Applied Mechanics and Engineering, Vol. 3, pp. 269-289, 1974.

31. Nielsen P.V., "Prediction of Temperature and Velocity Distribution in an Air Conditioned Room", Proceedings of the Second Symposium on the Use of Computers for Environmental Engineering Related to Buildings, pp. 279-290, Paris, June 13-15, 1975.

32. Murakami D.E., Kato S., Suyama Y., "three-dimensional Numerical Simulation of Turbulent Airflow in a Ventilated Room by means of a Two-Equation Model". ASHRAE Transactions, Vol. 93, No. 1, pp. 621-642, 1987.

33. Kato S., Murakami D.E., "New Ventilation Efficiency Scales Based on Spatial Distribution of Contaminant Concentration Aided by Numerical Simulation", Preprint, ASHRAE Transactions, Vol. 94, No. 2, 1988.

34. Murakami D.E., Kato S., Suyama Y., "Numerical and Experimental Study on Turbulent Diffusion Fields in Conventional Flow Type Clean Rooms", Preprint, ASHRAE Transactions, Vol. 94, No. 2, 1988.

35. Rydberg J., Norback P., "Air Distribution and Draft", ASHRAE Rescarch Report No. 1362, ASHRAE Transactions, Vol. 55, pp. 225-240, 1949.

36. Koestel A., Tuve G.L., "Performance and Evaluation of Room Air Distribution Systems", ASHRAE Research Report No. 1553, ASHRAE Transactions, Vol. 61. pp. 533-550, 1955. 
37. Gosman A.D., Pun W.M., Runchal A. K., Spalding D. B., Wolfshtein M., "Heat and Mass Transfer in Recirculating Flows", Academic Press, London, 1969.

38. Miller P. L., Nevins R. G., "Room Air Distribution with an Air Distributing Ceiling Parts", ASHRAE Transactions, Vol. 75, No. 1, pp. 118-131, 1969.

39. Murakami S., Kato S., "Numerical and Experimental Study on Room Airflow -- 3D Predictions using the k-e Turbulence Model", Building and Environment, Vol. 24. No. 1, pp. 85-97, 1989.

40. Heikkinen J., "Modeling of a Supply Air Terminal for Room Air Flow Simulation", Air Movement and Ventilation Control Within Buildings, 12 th AIVC Conference. Ottawa, Canada, 24-27 September, 1991.

41. CREARE Inc., "FLUENT, a General Purpose Computer Program for Modeling Fluid Flow, Heat transfer and Combustion", Hanover NH, Seminar Notes, 1987.

42. Lemaire A.D., "User Manual WISH", TNO - Insitute of Applied Physics, Delft, 1989.

43. Lamers A.P.G.G., van de Velde R., "Air Flow Patterns in Ventilated Rooms", Phoenics Journal, Vol. 2, No. 2, pp. 219-238, 1989.

44. Markatos N.C., Malin M.R., Cox G., "Mathematical Modelling of BuoyancyInduced Smoke Flow in Enclosures", Int. J. Heat Mass Transfer, Vol. 25, pp. 63-75, 1982.

45. Jackman P.J., "Air Movement in Rooms with Ceiling-Mounted Difîusers", BSRIA Laboratory Report No. 81, 1973.

46. Sandberg M., Sjöberg M., "The Use of Moments for Assessing Air Quality", Building and Environment, Vol. 18, pp. J81-197, 1987. 
47. Davidson L., Olsson E., "Calculation of Age and Local Purging Flow R" $\mathbf{r}^{+*}$ in Rooms", Building and Environment, Vol. 22, No. 2, pp. 111-127, 1987.

48. Rosten H.I., Spalding D.B., "The PHOENICS-84 Reference Handbook", CHAM TR/100, 1985.

49. Gosman A.D., Ideriah F.J.K., "TEACH-T: A General Computer Program for TwoDimensional, Turbulent, Recirculating Flows", Dept. of Mechanical Engineering. Imperial College, London 1976.

50. Davidson L., "One-Equation Turbuience Models in Flows Near Walls", Rept. 86/1 2nd ed., Dept. of Applied Thermodynamics and Fluid Mechanics, Chalmers Univ. of Tech., Gö teborg 1986.

51. Carpenter G.A., Moulsley L.J., "A Visualization Technique for Studying Air Movement in Large Enclosures Over a Wide Range of Ventilation Rates", Journal of the Institution of Heating and Ventilating Engineers, Vol. 39, pp. 279-287, 1972.

52. Moulsley L.J., Boothroyd D.N., "A Device for Producing Small Bubbles for Use in the Visualization of Air Movement", Journal of Agricultural Engineering Research. Vol. 16, pp. 364-367, 1971.

53. Anon, "Bubbles Show the Way Air Moves", New Scientist, Vol. 43, p. 590, 1969.

54. Cox C.W.J., Ham Ph.J., Koppers J.M., van Schijndel L. L. M., "Temperature Efficiency, Air Change Efficiency and Ventilation Efficiency in an Office Room with Displacement Ventilation", C113 W67 Symposium on Energy, Moisture and Climate in Buildings, Rotterdam, The Netherlands, 3-6 September, 1990.

55. Zhang J.S., Christianson L.L., Riskowski G.L., "Regional Airflow Characteristics in a Mechanically Ventilated Room Under Non-Isothermal Conditions". Preprint, ASHRAE Transactions, Vol. 95, No. 2, 1989. 
56. Zhang J., "Fundamental Study of Two Dimensional Room Ventilation Flows Under Isothermal and Non-Lsothermal Conditions", Phd. Thesis, University of Illinois at Urbana-Champaign, 1991.

57. James R., Ahart P.E., Randall S. Helm, "A Test System to Measure Air Distribution and Comfort in an Open Plan Office", ASHRAE Journal, October 1989.

58. Cariton-Foss J.A., "Office Ventilation", ASHRAE Journal, September 1988.

59. Anderson R., "Determination of Ventilation Efficiency Based Upon Short Term Tests", Effective Ventilation, 9 th AIVC Conference, Gent, Belgium, 12-15 September, 1988.

60. Enai M., Shaw C.Y., Reardon J.T.,"On the Multiple Tracer Gas Techniques for Measuring Interzonal Airflows in Buildings", Preprint, ASHRAE Transactions, Vol. 96, No. $1,1990$.

61. Enai M., Shaw C.Y., Reardon J.T., Magee R.J., "Multiple Tracer Gas Techniques for Measuring Interzonal Airflows for Three Interconnected Spaces", Preprint, ASHRAE Transactions, Vol. 96, No. 1, 1990.

62. Bubble Generator Manual, Sage Action Inc., Ithaca, N.Y.

63. CRC Handbook of Chemistry and Physics, WEAST 52ad Editions, 1971-1972.

64. Soultogiannis A.A., "Numerical Simulation of Ventilation Air Movement in Offices", Ms. Thesis, University of Carleton at Ottawa-Ontario, Canada, 1990.

65. Skovgaard M., Lemaire A.D., "Representation of boundary conditions at supply opening BASIC MODEL", Technical Note on Research Item no 1.11, February 7, 1990. 


\section{TABLES}




\begin{tabular}{|c|c|c|c|c|}
\hline Test & Volume Flow & Test & \multicolumn{2}{|c|}{ Flow Obstacles } \\
\cline { 4 - 5 } Name & Rate (ACH)* & Conditions & Height & Floor Gap \\
\hline T01 & 3.0 & Isothermal & - & - \\
T02 & 1.5 & Isothermal & - & - \\
T03 & 3.0 & Isothermal & $6.5 \mathrm{ft}(1.981 \mathrm{~m})$ & $6.0 "(0.152 \mathrm{~m})$ \\
T04 & 3.0 & Isothermal & $6.5 \mathrm{ft}(1.981 \mathrm{~m})$ & $0.0^{\prime \prime}$ \\
T05 & 3.0 & Isothermal & $5.5 \mathrm{ft}(1.676 \mathrm{~m})$ & $6.0 "(0.152 \mathrm{~m})$ \\
T06 & 3.0 & Isothermal & $5.5 \mathrm{ft}(1.676 \mathrm{~m})$ & $0.0 "$ \\
\hline
\end{tabular}

$(\mathrm{ACH})^{*}$ : Air Changes per Hour

Table 5.1: Summary of the Experimental Tests Conducted 


\begin{tabular}{|c|c|c|}
\hline REFERENCE & FORMULA USED & PARAMETERS USED \\
\hline $\begin{array}{l}\text { 1. M. Skovgaard/ } \\
\text { A. D. Lemaire (1990) }\end{array}$ & $\varepsilon_{\text {in }}=C^{\frac{3}{4}} \mu \frac{k_{i} 2^{\frac{3}{2}}}{l}=10 U^{3}{ }_{i=} \frac{I^{3} U}{D_{h}}$ & $\begin{array}{l}\mathrm{D}_{\mathrm{h}}: \text { hydraulic diameter, } \\
\mathrm{C} \mu=0.09, \\
\ell=0.03 \mathrm{D}_{\mathrm{h}}, \\
\mathrm{K}_{\mathrm{iz}}=\frac{3}{2} \mathrm{I}^{2}{ }_{\mathrm{v}} \mathrm{U}^{2} \mathrm{in} .\end{array}$ \\
\hline $\begin{array}{l}\text { 2. Shuzo Murakami/ } \\
\text { Shinsuke Kato (1989) }\end{array}$ & $\varepsilon_{i s}=C_{\mu} \frac{k_{0}^{\frac{3}{2}}}{l_{0}}$ & $\begin{array}{l}\ell_{0}=0.33 \\
k_{0}=0.005\end{array}$ \\
\hline 3. H. B. Awbi (1989) & $\varepsilon_{\text {in }}=\frac{k_{\text {in }}^{\frac{3}{2}}}{\lambda H}$ & $\begin{array}{l}H: \text { Room height, } \\
\lambda=0.005 \\
\mathrm{~K}_{\mathrm{in}}=\frac{3}{2} \mathrm{I}^{2}{ }_{\mathrm{u}} \mathrm{U}^{2} \mathrm{is} .\end{array}$ \\
\hline $\begin{array}{l}\text { 4. A. P. G. G. Lamers/ } \\
\text { R. van de Velde (1989) }\end{array}$ & $\varepsilon_{\text {in }}=C_{\mu} \frac{k^{\frac{3}{2}}}{l_{i n}}$ & $\begin{array}{l}\ell \text { is }=0.1 \frac{h}{2} \\
h: \text { Height of the inlet slot } \\
\text { diffuser. }\end{array}$ \\
\hline $\begin{array}{l}\text { 5. T. Kurabuchi/ } \\
\text { J. B. Fang/ } \\
\text { Richard A. Grot (1990) }\end{array}$ & $\varepsilon_{i s}=C_{\mu} \frac{k_{\text {in }^{2}}^{\frac{3}{2}}}{\ell}$ & $\begin{array}{l}\mathrm{K}_{\mathrm{i}}=0.01-0.03 \mathrm{U}_{\mathrm{ip}}{ }^{2}, \\
\ell=0.05-0.25 \mathrm{~L}, \\
\mathrm{~L}_{\mathrm{o}}: \text { Representative length } \\
\text { scale of the intake. }\end{array}$ \\
\hline 6. P. V. Nielsen (1990) & $\varepsilon_{\text {in }}=\frac{k^{\frac{3}{2}} \text { is }}{l_{0}}$ & $\begin{array}{l}l_{0}=0.1 \mathrm{~h}, \\
\mathrm{~h}: \text { Height of the inlet slot } \\
\text { diffuser. }\end{array}$ \\
\hline
\end{tabular}

Table 5.2: Some of the various correlations used to specify the dissipation rate of the turbulence kinetic energy $(\varepsilon)$ at the supply diffuser. 


\begin{tabular}{|c|c|c|c|c|c|}
\hline $\begin{array}{l}\text { Test } \\
\text { Name }\end{array}$ & $\begin{array}{c}\text { Room } \\
\text { Average } \\
\text { Temperature } \\
\left({ }^{\circ} \mathrm{C}\right)\end{array}$ & $\begin{array}{c}\Delta \mathrm{T} \text { (eupply-Reum) } \\
\left({ }^{\circ} \mathrm{C}\right)\end{array}$ & $\begin{array}{c}\Delta \mathrm{T} \text { (oupply-Room) } \\
\left({ }^{\circ} \mathrm{C}\right)\end{array}$ & $\begin{array}{c}\text { Ar } \\
\times 10^{3}\end{array}$ & $\begin{array}{c}\text { Correction } \\
\text { Factor } \xi\end{array}$ \\
\hline $\begin{array}{c}\text { T01 } \\
\text { T02 } \\
\text { T03 } \\
\text { T04 } \\
\text { T05 } \\
\text { T06 } \\
\text { T01S* }\end{array}$ & $\begin{array}{l}22.19 \\
22.14 \\
22.15 \\
22.32 \\
22.28 \\
22.45 \\
22.70\end{array}$ & $\begin{array}{c}0.05 \\
-0.01 \\
0.18 \\
0.15 \\
0.04 \\
0.11 \\
-0.05\end{array}$ & $\begin{array}{c}-0.24 \\
-0.43 \\
-0.51 \\
-0.47 \\
-0.24 \\
-0.65 \\
0.00\end{array}$ & $\begin{array}{c}-4.370 \\
-8.582 \\
-0.929 \\
-0.856 \\
-0.437 \\
-1.183 \\
0.000\end{array}$ & $\begin{array}{l}1.054 \\
1.050 \\
1.054 \\
1.082 \\
1.082 \\
1.061 \\
1.061\end{array}$ \\
\hline
\end{tabular}

* : denote the flow visualization using smoke for the test case T01.

Table 6.1.a: Flow visualization test conditions.

\begin{tabular}{|c|c|c|c|c|c|c|}
\hline $\begin{array}{c}\text { Test } \\
\text { Name }\end{array}$ & $\begin{array}{c}\Delta \mathbf{P}_{\text {uupply }} \\
\text { Measured } \\
\text { inches of } \\
\mathbf{H}_{2} \mathbf{O}\end{array}$ & $\begin{array}{c}\Delta \mathbf{P}_{\text {wupply }} \\
\text { Set } \\
\text { inches of } \\
\mathbf{H}_{2} \mathbf{O}\end{array}$ & $\begin{array}{c}\Delta \mathbf{P}_{\text {ream }} \\
\text { Measured } \\
\text { incnes of } \\
\mathbf{H}_{2} \mathbf{O}\end{array}$ & $\begin{array}{c}\Delta \mathbf{P}_{\text {recurm }} \\
\text { Set } \\
\text { inches of } \\
\mathbf{H}_{2} \mathbf{O}\end{array}$ & $\begin{array}{c}\text { \% Error } \\
\text { Supply }\end{array}$ & $\begin{array}{c}\text { \%o Error } \\
\text { Return }\end{array}$ \\
\hline T01 & 0.289 & 0.287 & 0.278 & 0.277 & 0.57 & 0.36 \\
T02 & 0.073 & 0.071 & 0.070 & 0.068 & 2.82 & 2.94 \\
T03 & 0.289 & 0.287 & 0.279 & 0.277 & 0.56 & 0.72 \\
T04 & 0.292 & 0.290 & 0.282 & 0.280 & 0.69 & 0.71 \\
T05 & 0.292 & 0.290 & 0.284 & 0.280 & 0.67 & 1.43 \\
T06 & 0.295 & 0.289 & 0.281 & 0.279 & 2.09 & 0.72 \\
T01S & 0.295 & 0.289 & 0.283 & 0.279 & 193 & 1.43 \\
\hline
\end{tabular}

Table 6.1.b: Comparison between the set point and the measured flow rates through the supply and the return orifice plates during the flow visualization. 


\begin{tabular}{|c|c|c|c|c|c|}
\hline $\begin{array}{c}\text { Test } \\
\text { Name }\end{array}$ & $\begin{array}{c}\text { Room } \\
\text { Average } \\
\text { Temperature } \\
\left({ }^{\circ} \mathrm{C}\right)\end{array}$ & $\begin{array}{c}\Delta \mathrm{T}_{\text {(uupply-Rewm) }} \\
\left({ }^{\circ} \mathrm{C}\right)\end{array}$ & $\begin{array}{c}\Delta \mathrm{T}_{\text {(uvpply-Room) }} \\
\left({ }^{\circ} \mathrm{C}\right)\end{array}$ & $\begin{array}{c}\mathrm{Ar} \\
\times 10^{3}\end{array}$ & $\begin{array}{c}\text { Correction } \\
\text { Factor } \xi\end{array}$ \\
\hline T01 & 22.38 & 0.05 & -0.43 & -0.783 & 1.082 \\
T02 & 22.26 & -0.01 & -0.54 & -3.470 & 1.082 \\
T03 & 22.05 & 0.18 & -0.41 & -0.747 & 1.087 \\
T04 & 22.32 & 0.15 & -0.47 & -0.856 & 1.086 \\
T05 & 22.53 & 0.04 & -0.49 & -0.892 & 1.049 \\
T06 & 22.29 & 0.11 & -0.49 & -0.892 & 1.078 \\
\hline
\end{tabular}

Table 6.1.c: Velocity, temperature, turbulence intensity, and turbulent kinetic energy measurements test conditions.

\begin{tabular}{|c|c|c|c|c|c|c|}
\hline $\begin{array}{c}\text { Test } \\
\text { Name }\end{array}$ & $\begin{array}{c}\Delta \mathbf{P}_{\text {supply }} \\
\text { Measured } \\
\text { inches of } \\
\mathbf{H}_{2} \mathbf{O}\end{array}$ & $\begin{array}{c}\Delta \mathbf{P}_{\text {supply }} \\
\text { Set } \\
\text { inches of } \\
\mathbf{H}_{2} \mathbf{O}\end{array}$ & $\begin{array}{c}\Delta \mathbf{P}_{\text {retum }} \\
\text { Measured } \\
\text { inches of } \\
\mathbf{H}_{2} \mathbf{O}\end{array}$ & $\begin{array}{c}\Delta \mathbf{P}_{\text {ictum }} \\
\text { Set } \\
\text { inches of } \\
\mathbf{H}_{2} \mathbf{O}\end{array}$ & $\begin{array}{c}\text { \% Error } \\
\text { Supply }\end{array}$ & $\begin{array}{c}\text { \% Error } \\
\text { Return }\end{array}$ \\
\hline T01 & $\mathbf{0 . 2 9 6}$ & $\mathbf{0 . 2 9 2}$ & $\mathbf{0 . 2 8 7}$ & $\mathbf{0 . 2 8 2}$ & 1.33 & 1.77 \\
T02 & $\mathbf{0 . 0 7 3}$ & $\mathbf{0 . 0 7 2}$ & $\mathbf{0 . 0 7 1}$ & $\mathbf{0 . 0 7 0}$ & $\mathbf{0 . 8 6}$ & 1.43 \\
T03 & 0.293 & 0.291 & 0.284 & 0.281 & 0.77 & 1.07 \\
T04 & 0.300 & 0.291 & 0.285 & 0.281 & 3.09 & 1.42 \\
T05 & 0.288 & 0.284 & 0.278 & 0.274 & 1.41 & 1.46 \\
T06 & 0.295 & 0.292 & 0.285 & 0.282 & 1.03 & 1.06 \\
\hline
\end{tabular}

Table 6.1.d: Comparison between the set point and the measured flow rates through the supply and the return orifice plates during the measurements of the velocity, the temperature, and the turbulence intensity. 

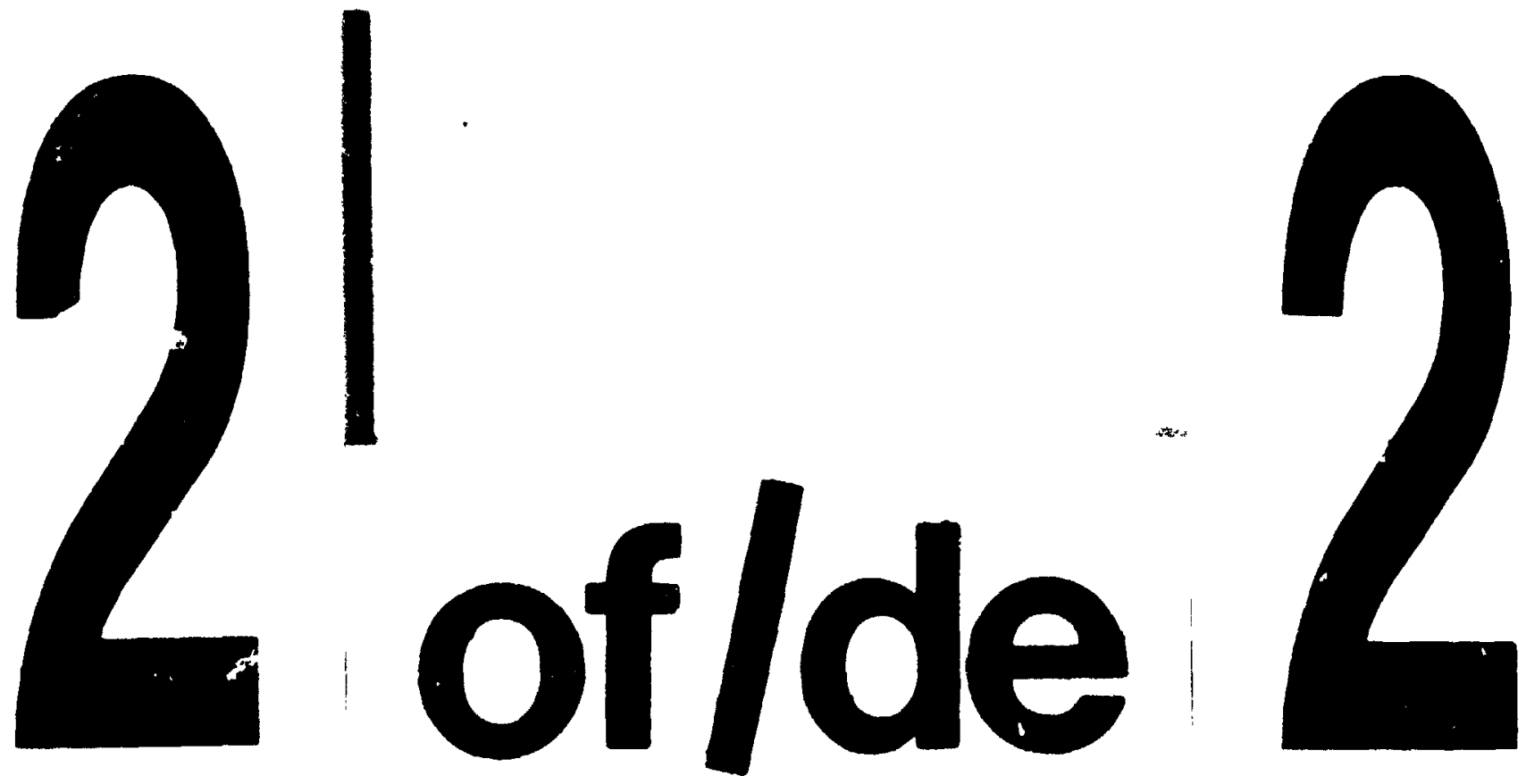

PM-1 31/2"X4" PHOTOGRAPHIC MICROCOPY TARGET NES 10104 ANSI/ISO \#2 EOUNALENT

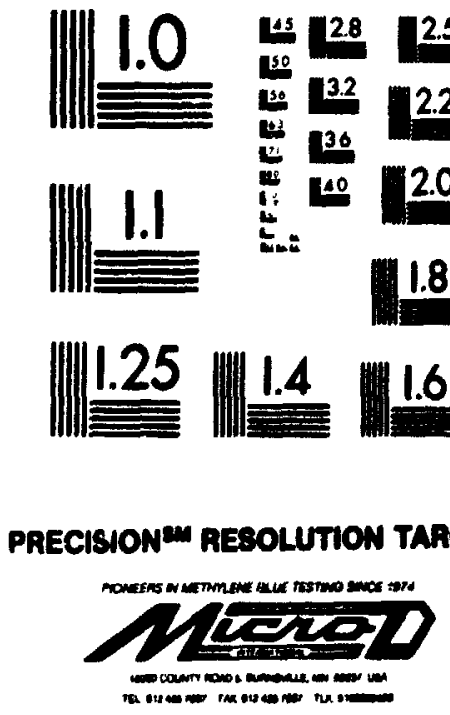




\begin{tabular}{|c|c|c|c|c|c|}
\hline $\begin{array}{c}\text { Test } \\
\text { Name }\end{array}$ & $\begin{array}{c}\text { Room } \\
\text { Average } \\
\text { Temperature } \\
\left({ }^{\circ} \mathrm{C}\right)\end{array}$ & $\Delta \mathrm{T}_{\text {(supply-Reum) }}$ & $\Delta \mathrm{T}_{\text {(supply-Room) }}$ & $\begin{array}{c}\text { Ar } \\
\left.\times 10^{3} \mathrm{C}\right)\end{array}$ & $\begin{array}{c}\text { Correction } \\
\text { Factor } \xi\end{array}$ \\
\hline T01 & 22.30 & -0.07 & -0.02 & -0.036 & 1.071 \\
T02 & 22.23 & 0.01 & -0.04 & -0.257 & 1.055 \\
T03 & 21.56 & 0.17 & 0.27 & 0.493 & 1.102 \\
T04 & 21.40 & 0.26 & 0.38 & 0.694 & 1.104 \\
T05 & 21.62 & 0.14 & 0.20 & 0.365 & 1.071 \\
T06 & 21.74 & 0.08 & 0.17 & 0.310 & 1.071 \\
\hline
\end{tabular}

Table 6.1.e: Contaminant concentration measurements test conditions.

\begin{tabular}{|c|c|c|c|c|c|c|}
\hline $\begin{array}{c}\text { Test } \\
\text { Name }\end{array}$ & $\begin{array}{c}\Delta \mathbf{P}_{\text {supply }} \\
\text { Measured } \\
\text { inches of } \\
\mathbf{H}_{2} \mathbf{O}\end{array}$ & $\begin{array}{c}\Delta \mathbf{P}_{\text {supply }} \\
\text { Set } \\
\text { inches of } \\
\mathbf{H}_{2} \mathbf{O}\end{array}$ & $\begin{array}{c}\Delta \mathbf{P}_{\text {rewm }} \\
\text { Measured } \\
\text { inches of } \\
\mathbf{H}_{2} \mathbf{O}\end{array}$ & $\begin{array}{c}\Delta \mathbf{P}_{\text {retum }} \\
\text { Set } \\
\text { inches of } \\
\mathbf{H}_{2} \mathbf{O}\end{array}$ & $\begin{array}{c}\text { \% Error } \\
\text { Supply }\end{array}$ & $\begin{array}{c}\text { \% Error } \\
\text { Return }\end{array}$ \\
\hline T01 & 0.291 & 0.290 & 0.285 & 0.280 & 0.21 & 1.75 \\
T02 & 0.070 & 0.072 & 0.069 & 0.070 & 2.86 & 1.43 \\
T03 & 0.300 & 0.295 & 0.286 & 0.285 & 1.69 & 0.35 \\
T04 & 0.301 & 0.295 & 0.286 & 0.285 & 2.03 & 0.35 \\
T05 & 0.293 & 0.289 & 0.283 & 0.279 & 1.38 & 1.43 \\
T06 & 0.295 & 0.289 & 0.284 & 0.279 & 2.07 & 1.79 \\
\hline
\end{tabular}

Table 6.1.f: Compari son between the set point and the measured flow rates through the supply and the return orifice plates during the contaminant concentration measurements. 


\begin{tabular}{|c|c|c|c|c|c|c|}
\hline \multirow{2}{*}{ Location } & \multicolumn{6}{|c|}{ U/Ud } \\
\hline & T01 & T02 & T03 & T04 & T05 & T06 \\
\cline { 2 - 7 } & 0.0377 & 0.0417 & 0.0377 & 0.0380 & 0.0370 & 0.0376 \\
Frame A & 0.0196 & 0.0361 & 0.0169 & 0.0148 & 0.0169 & 0.0149 \\
Frame B & $0.028:$ & 0.0387 & 0.0273 & 0.0265 & 0.0268 & 0.0262 \\
Room & 0.028 &
\end{tabular}

Table 6.2: Average non-dimensional velocity in the test room.

\begin{tabular}{|c|c|c|c|c|c|c|}
\hline \multirow{2}{*}{$\mathrm{X} / \mathrm{H}^{*}$} & \multicolumn{6}{|c|}{ Average Temperature $\left({ }^{\circ} \mathrm{C}\right)$ in a Horizontal Line } \\
\hline & T01 & T02 & T03 & T04 & T05 & T06 \\
\hline & 22.06 & 21.93 & 21.78 & 21.99 & 22.18 & 22.01 \\
0.166 & 22.26 & 22.20 & 21.97 & 22.18 & 22.41 & 22.19 \\
0.277 & 22.45 & 22.31 & 22.15 & 22.29 & 22.60 & 22.36 \\
0.395 & 22.65 & 22.52 & 22.32 & 22.61 & 22.78 & 22.53 \\
0.499 & 22.67 & 22.57 & 22.35 & 22.63 & 22.83 & 22.67 \\
0.610 & 22.21 & 22.13 & 21.89 & 22.13 & 22.42 & 22.11 \\
0.720 & 22.18 & 22.05 & 21.82 & 22.06 & 22.37 & 22.03 \\
0.832 & 22.67 & 22.53 & 22.40 & 22.69 & 22.88 & 22.63 \\
0.945 & 22.29 & 22.07 & 21.80 & 22.17 & 22.31 & 22.12 \\
\hline
\end{tabular}

$\mathrm{X} / \mathrm{H}^{*}$ : is the vertical position, with $\mathrm{X}=0$ at the ceiling.

Table 6.3: Vertical temperature distribution in the test room.

\begin{tabular}{|c|c|c|c|c|c|c|}
\hline & T01 & T02 & T03 & T04 & T05 & T06 \\
\cline { 2 - 7 } & & & & & & \\
$\begin{array}{c}\text { Mixing } \\
\text { Time } \\
\text { (minutes) }\end{array}$ & 5.85 & 11.0 & 8.03 & 8.49 & 7.11 & 7.31 \\
\hline
\end{tabular}

Table 6.4: Mixing time in the test room. 
FIGURES 


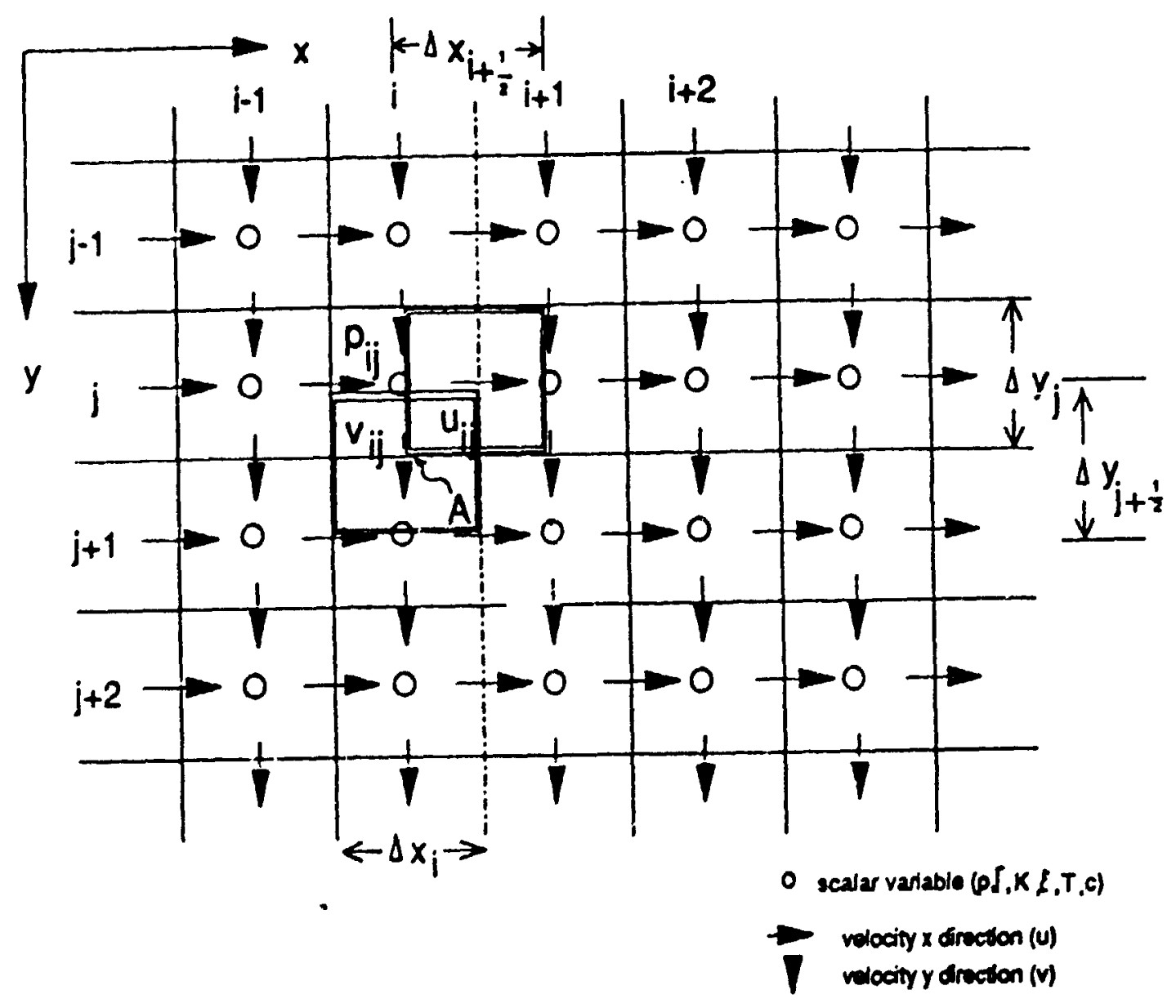

Figure 3.1: Staggered mesh system (Reference 3). 


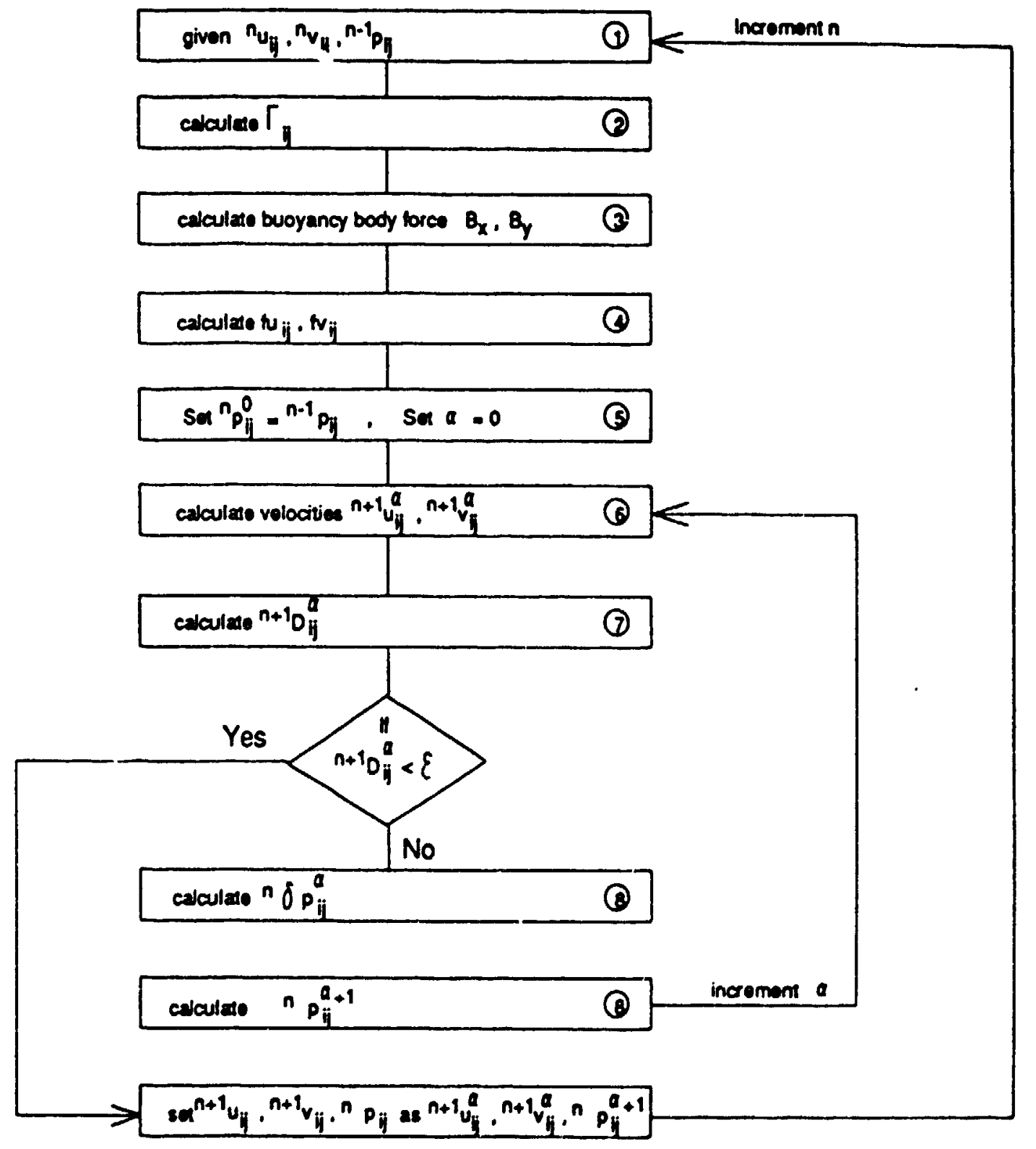

Figure 3.2: Solution procedure for the momentum equations (Reference 3). 


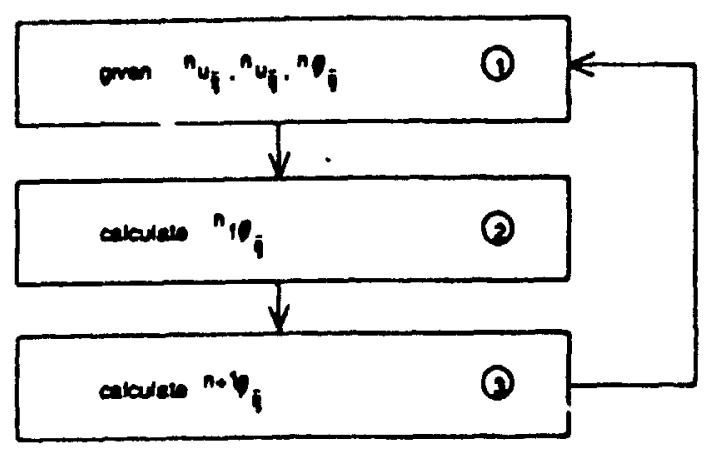

Figure 3.3: Solution procedure for the scalar equations (Reference 3).

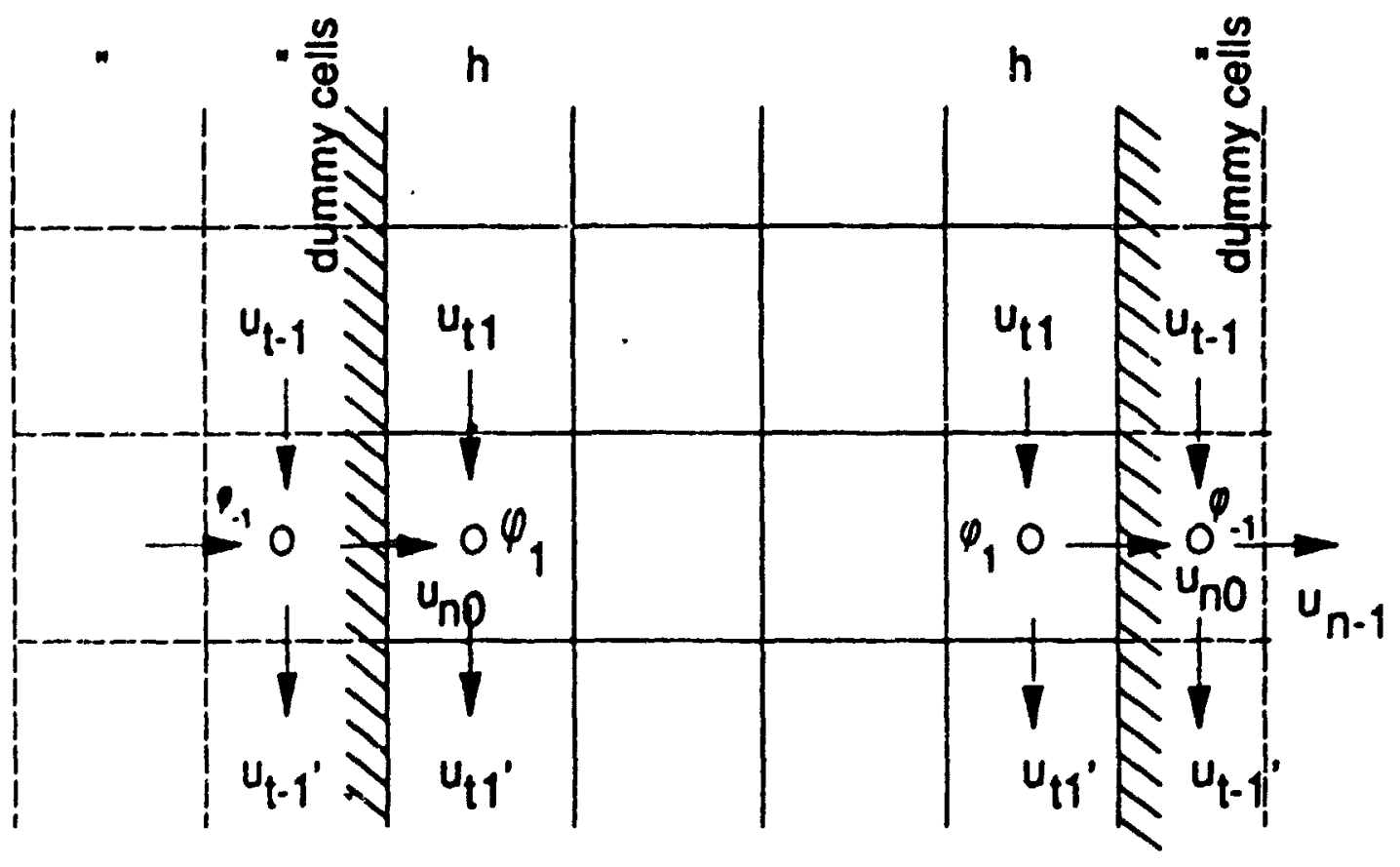

Figure 3.4: Mesh layout near boundary (Reference 3). 


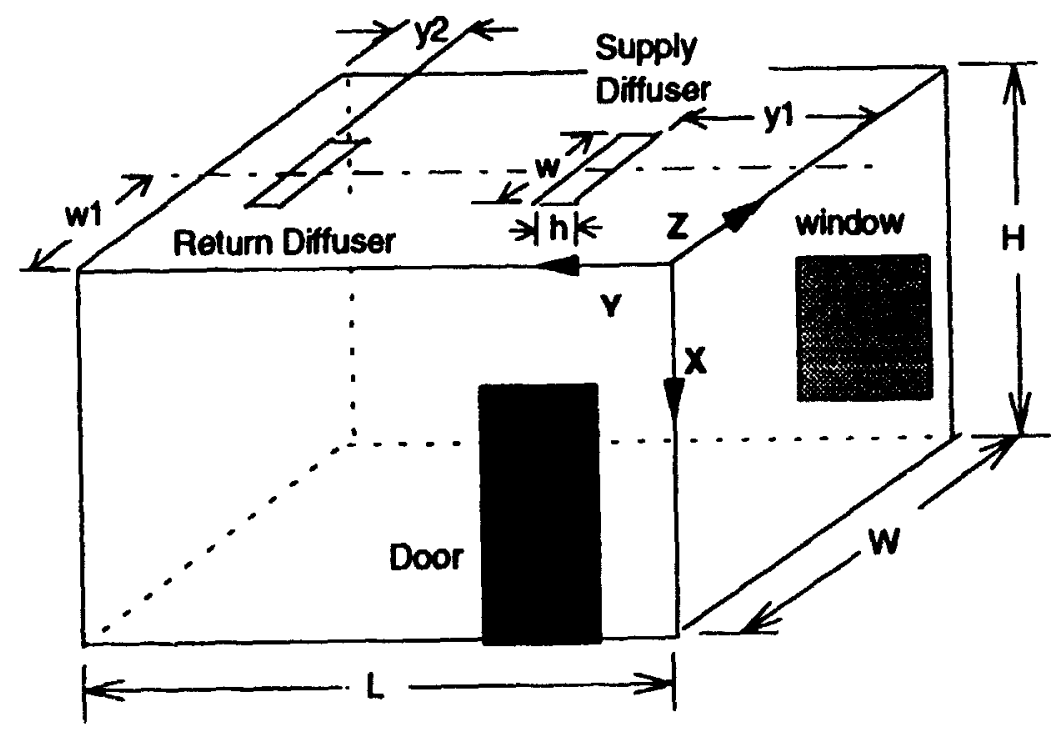

Figure 4.1: Test room facility and dimensions, $L=4.75 \mathrm{~m}, \mathrm{H}=2.87 \mathrm{~m}$, $\mathrm{W}=4.87 \mathrm{~m}, \mathrm{w}=1.016 \mathrm{~m}, \mathrm{~h}=0.0127 \mathrm{~m}, \mathrm{yl}=2.141 \mathrm{~m}$, $y 2=0.806 \mathrm{~m}, w 1=2.435 \mathrm{~m}$. 


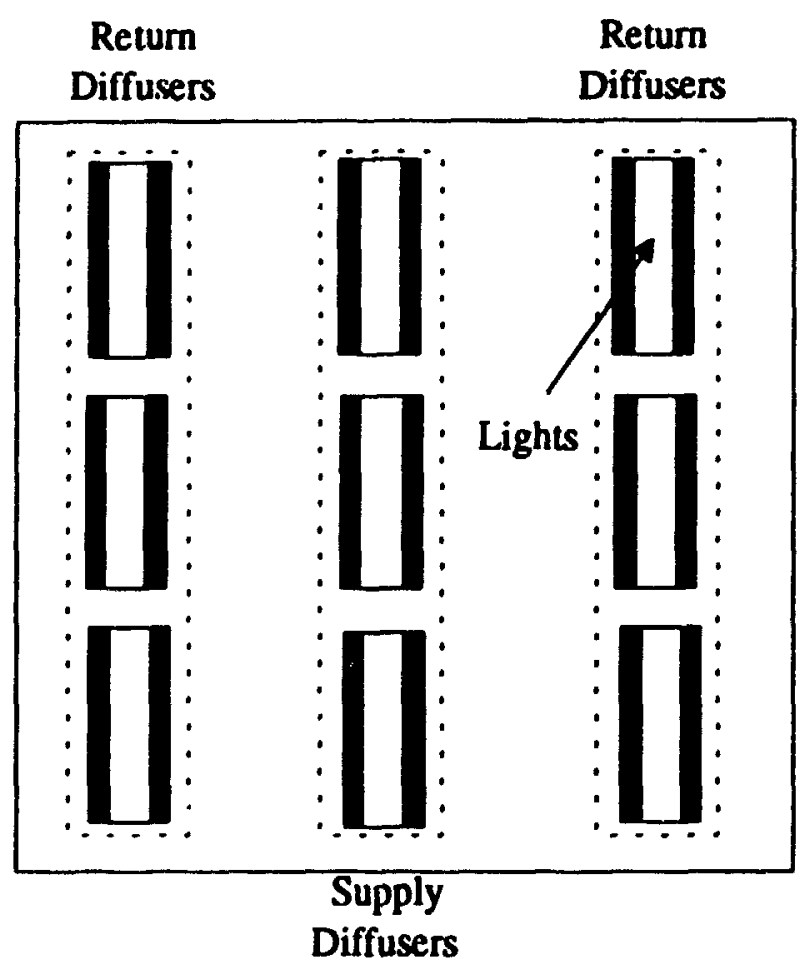

Figure 4.2: Locations of the ceiling-mounted diffusers. 


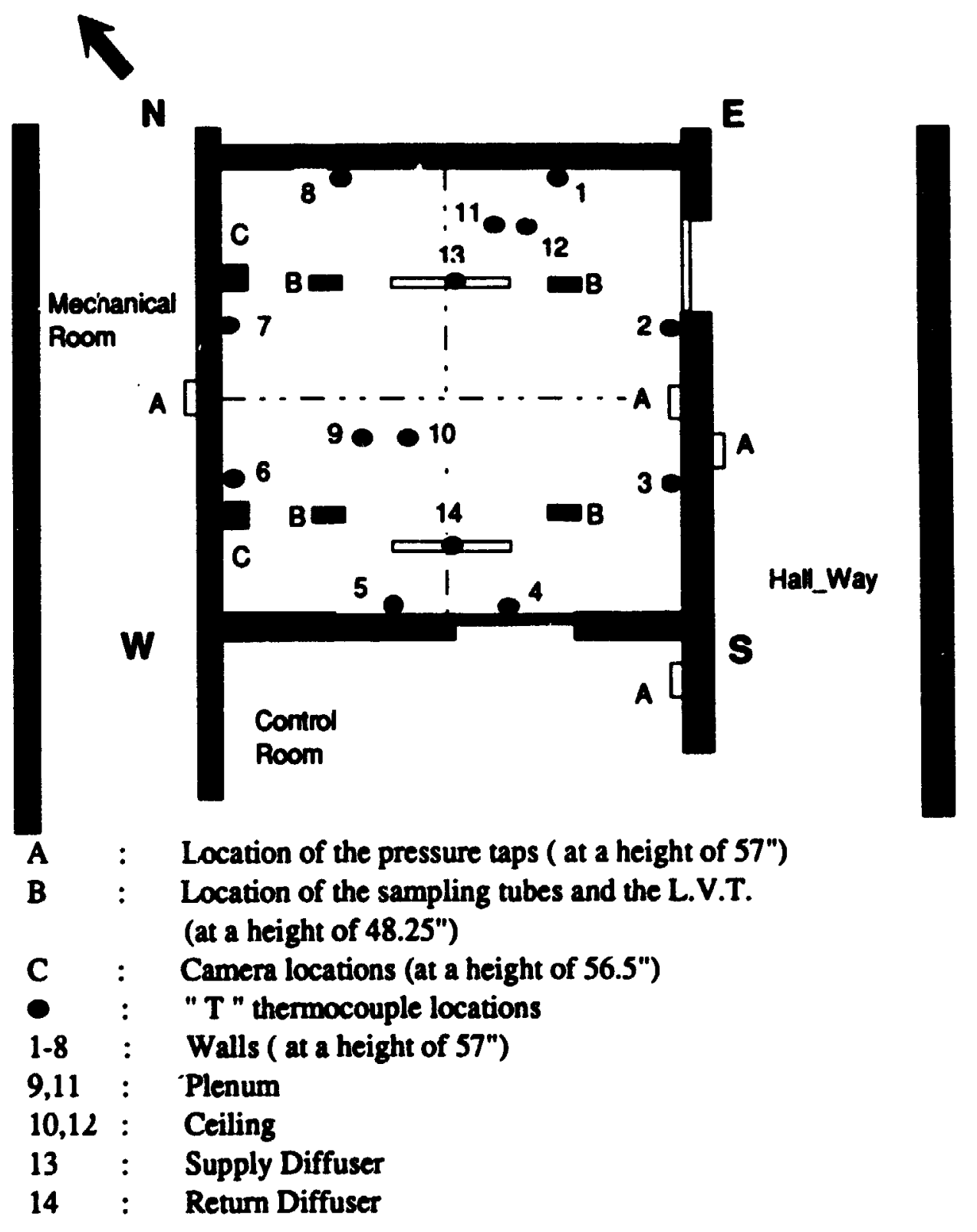

Figure 4.3: Sampling locations for the velocity, temperature, and contaminant measurements. 


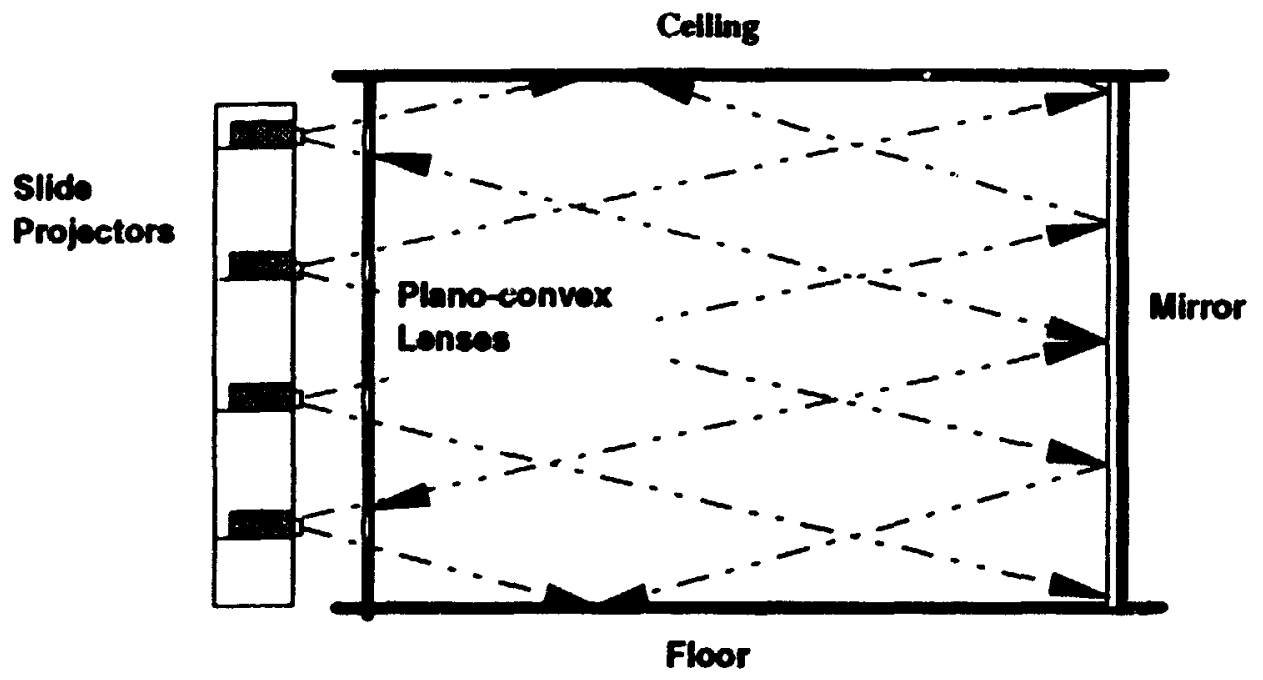

Figure 4.4. Light sheet system. 


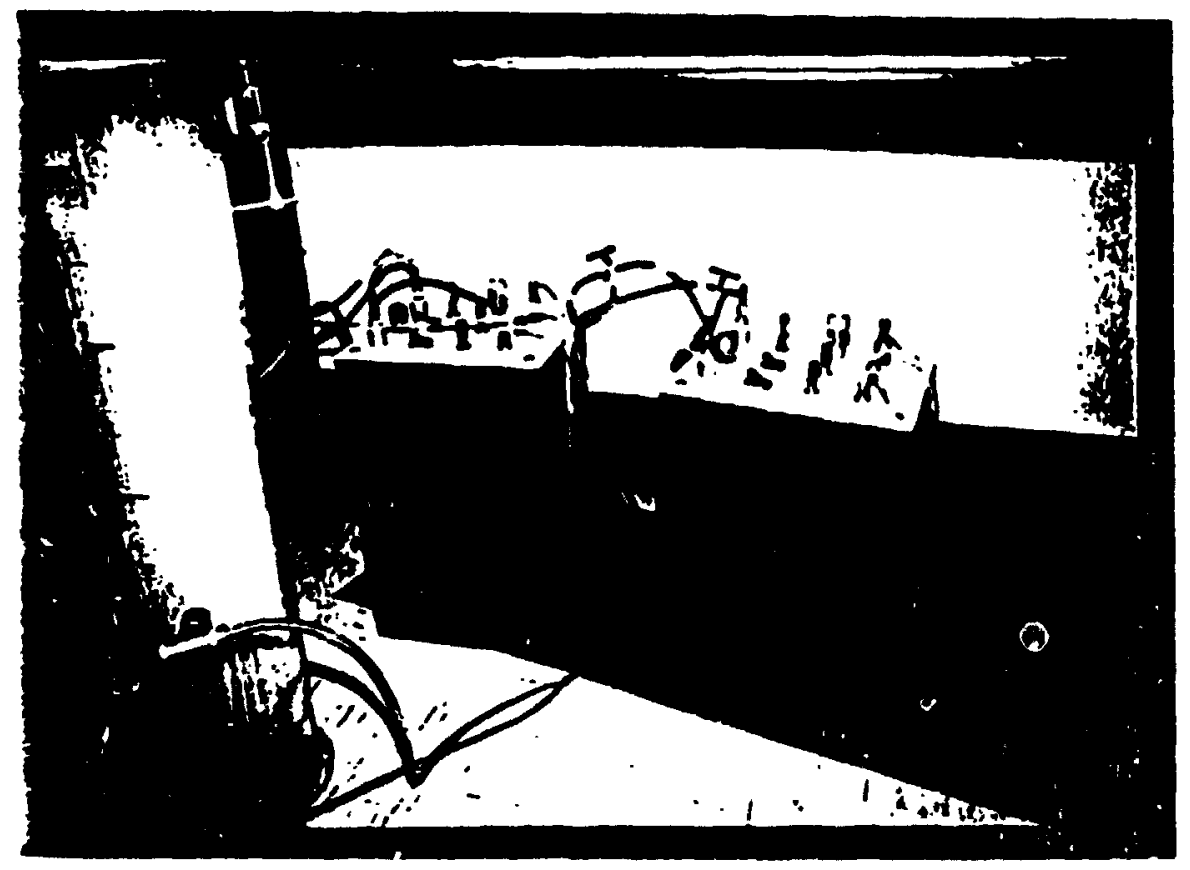

Figure 4.5: SAI bubble gerierators. 


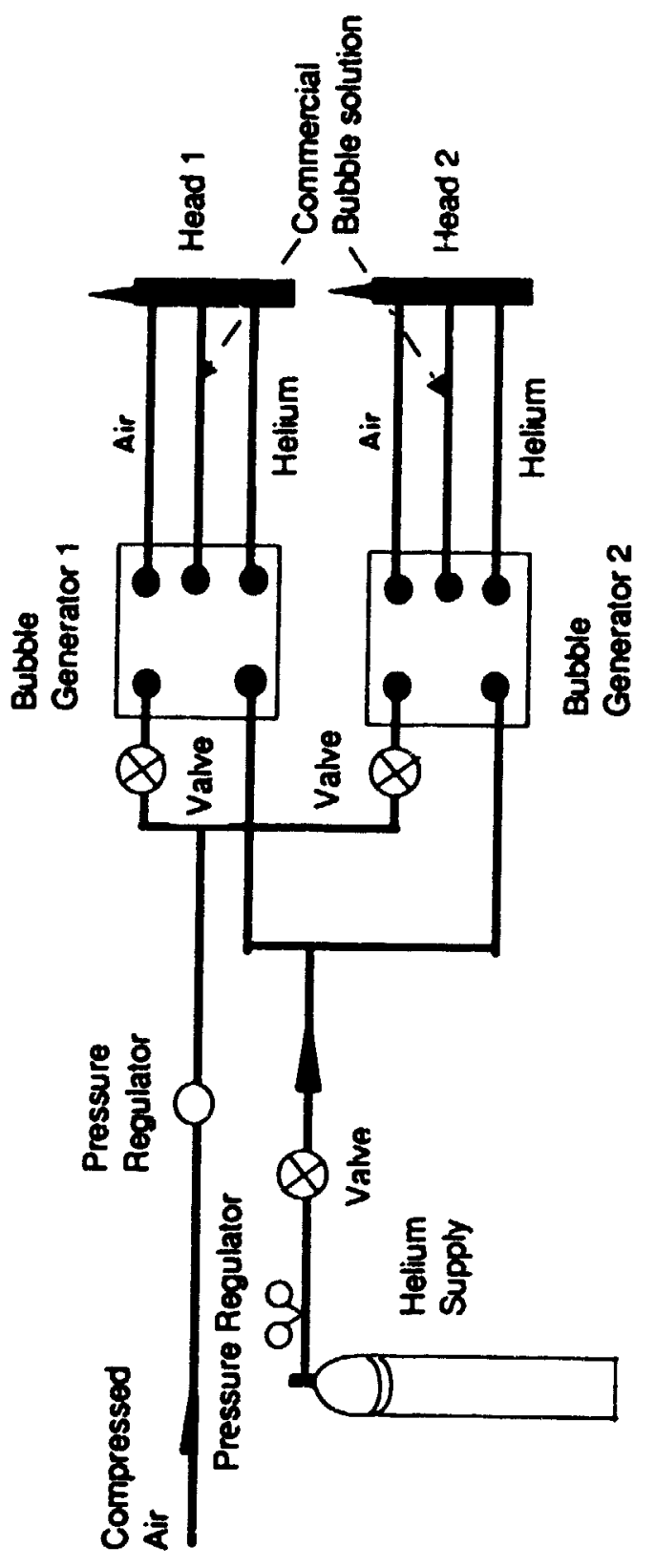

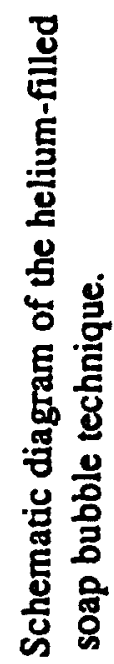

官 


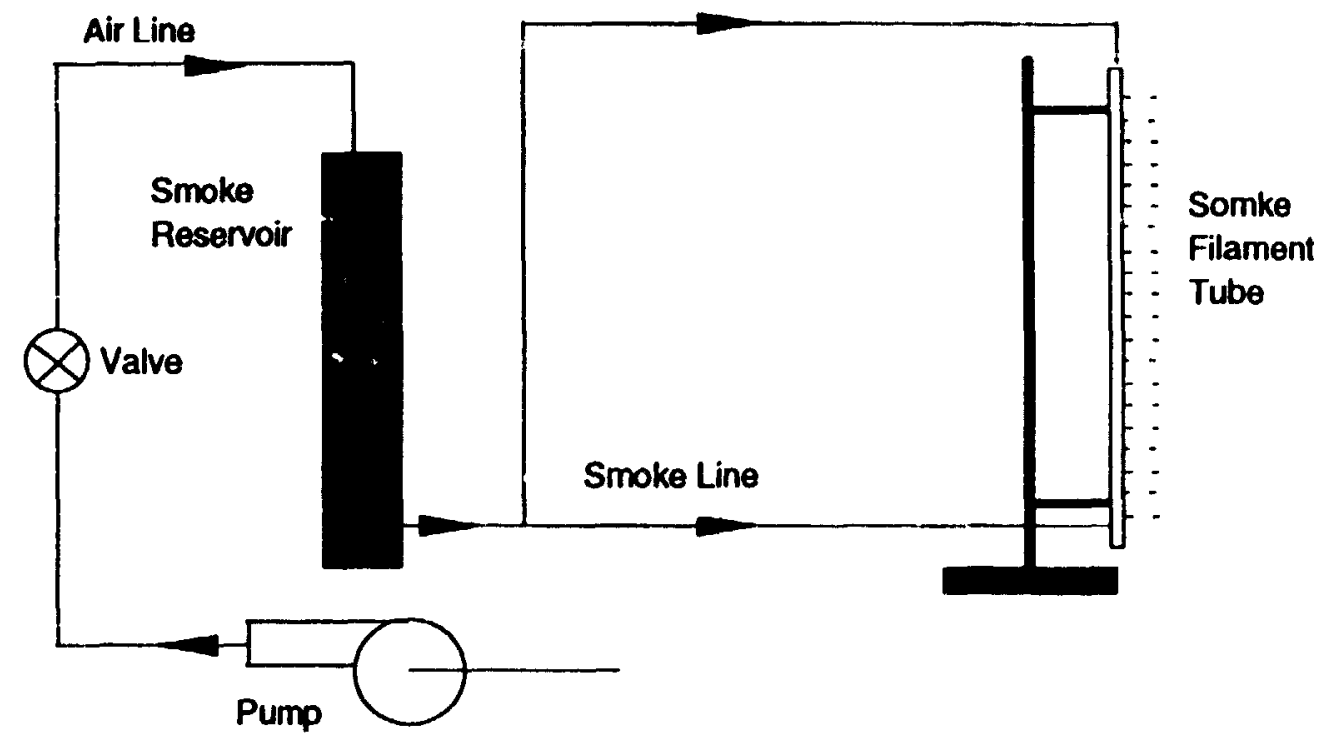

Figure 4.7: Schematic diagram of the smoke filament technique. 


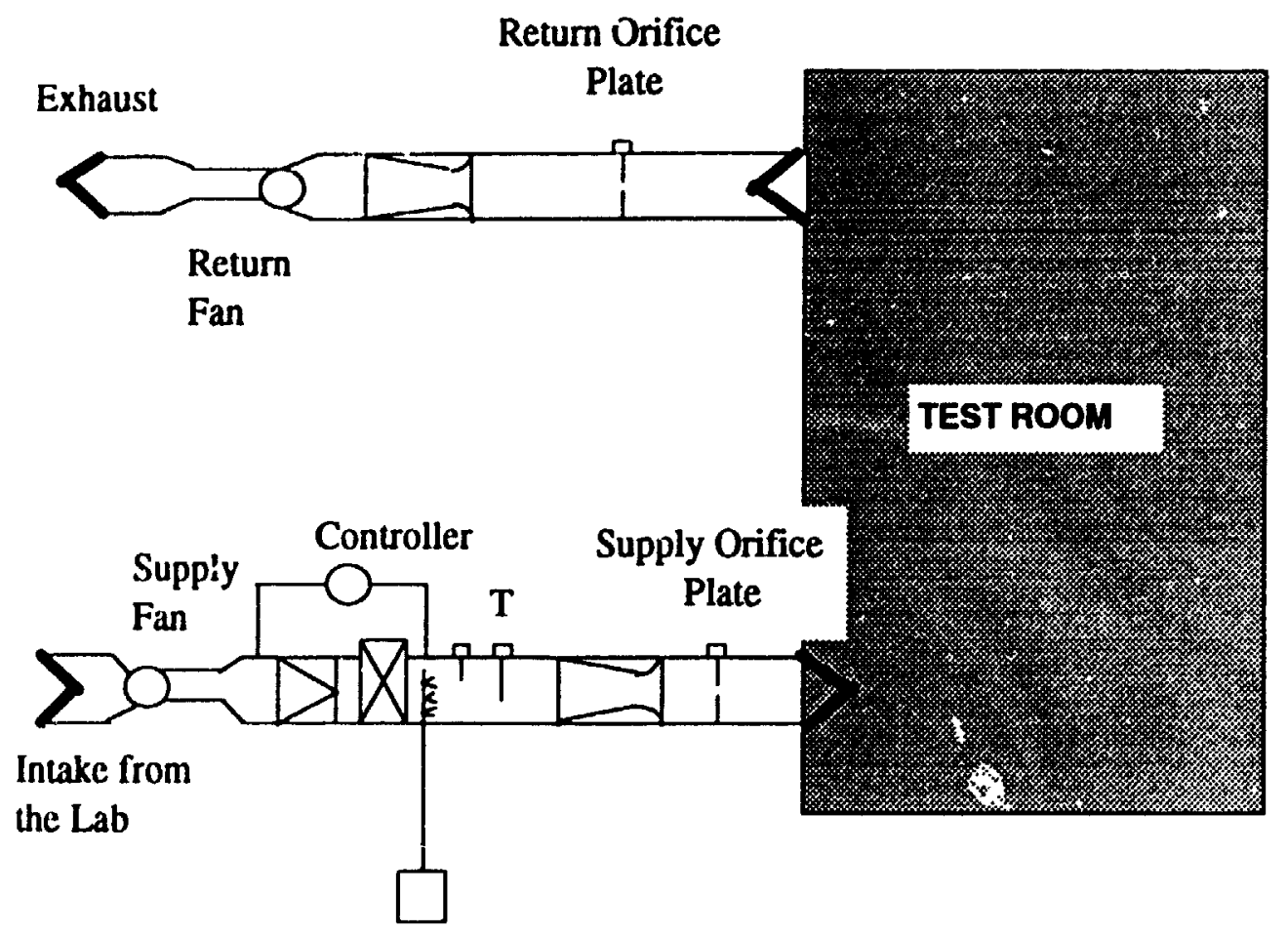

Figure 4.8: Test room HVAC system. 


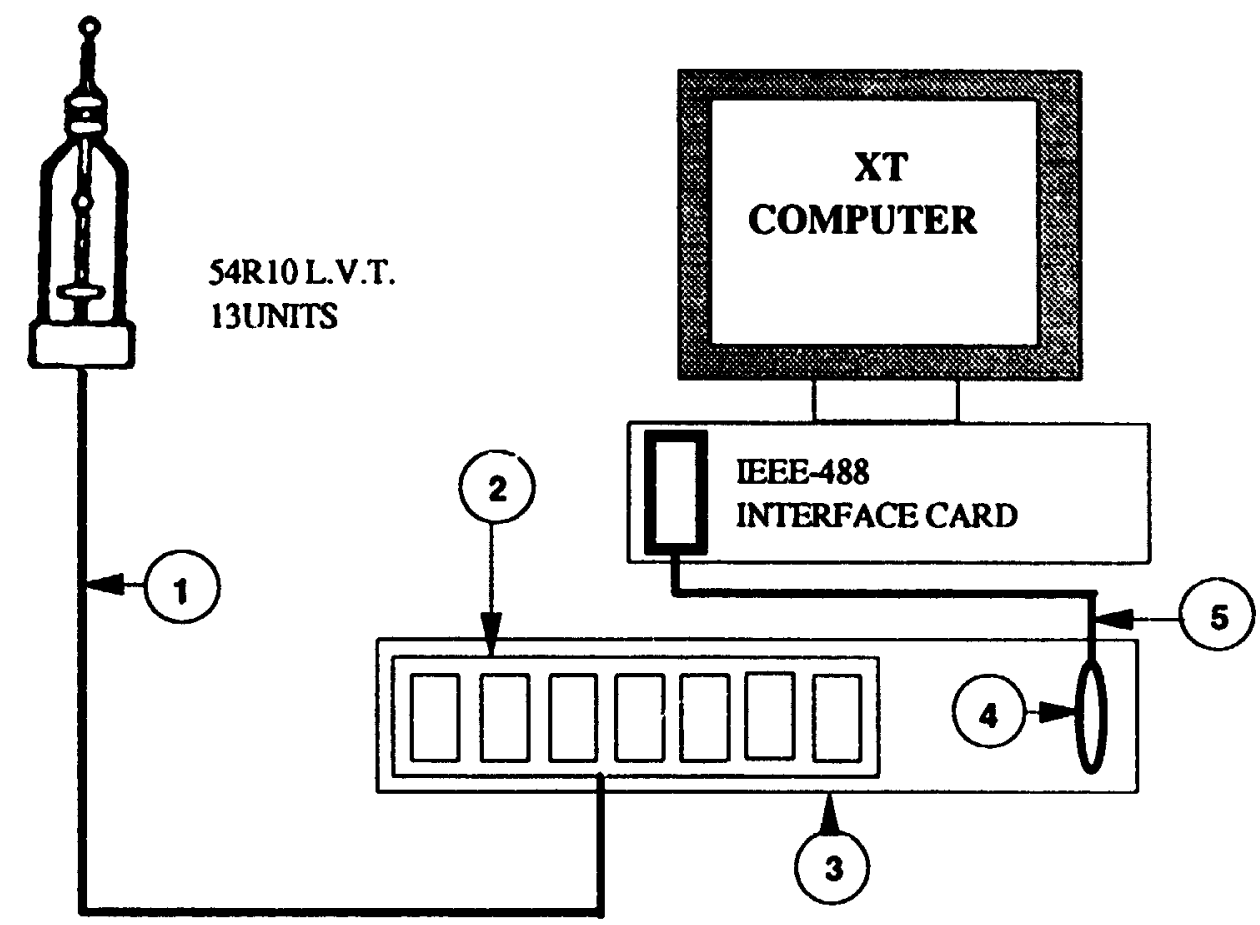

1. CONNECTION CABLE (13 UNITS)

2. $54 N 21$ INPUT MODULE

3. $54 \mathrm{~N} 10$ Multiflow Analyzer (M.F.A)

4. IEEE-488 I/O

5. IEEE CABLE

Figure 4.9: Velocity, temperature, turbulence intensity measuring system. 
a)

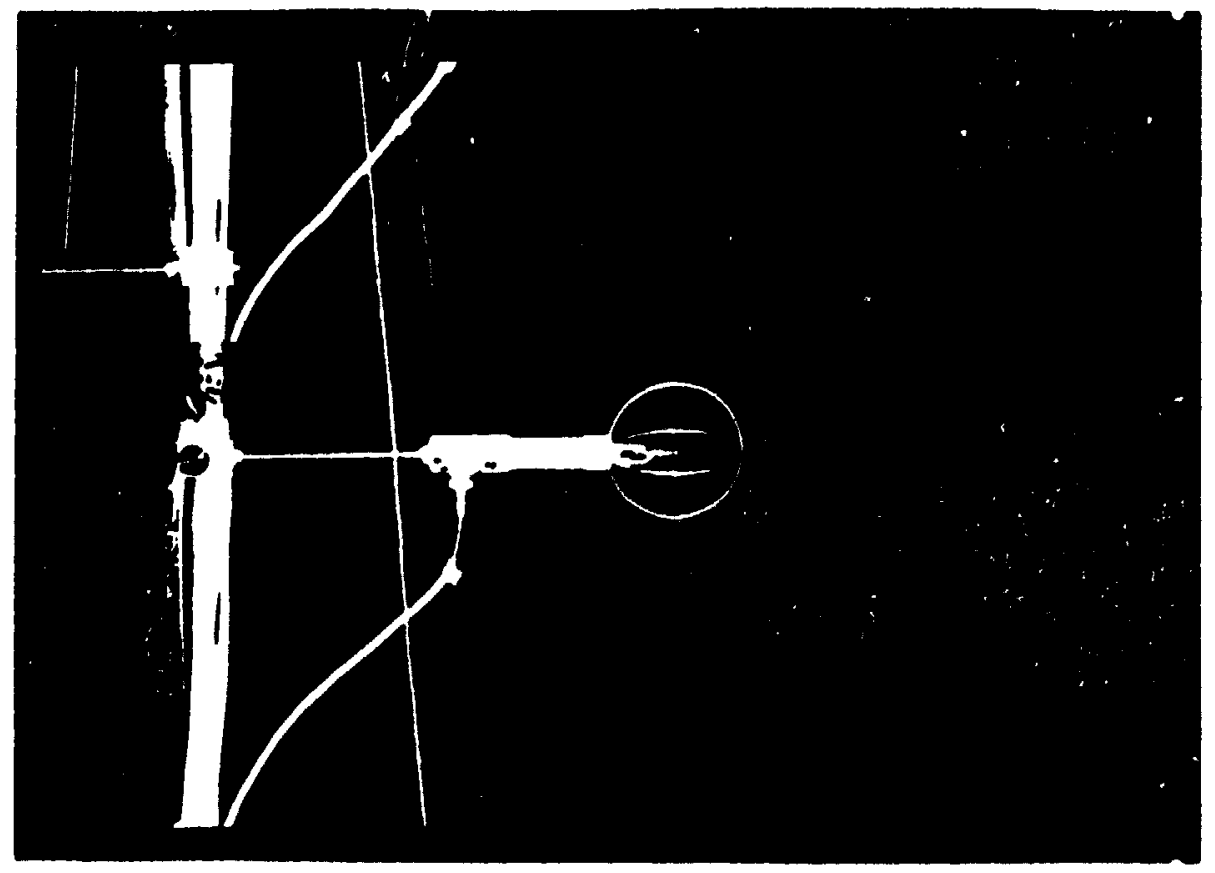

b)

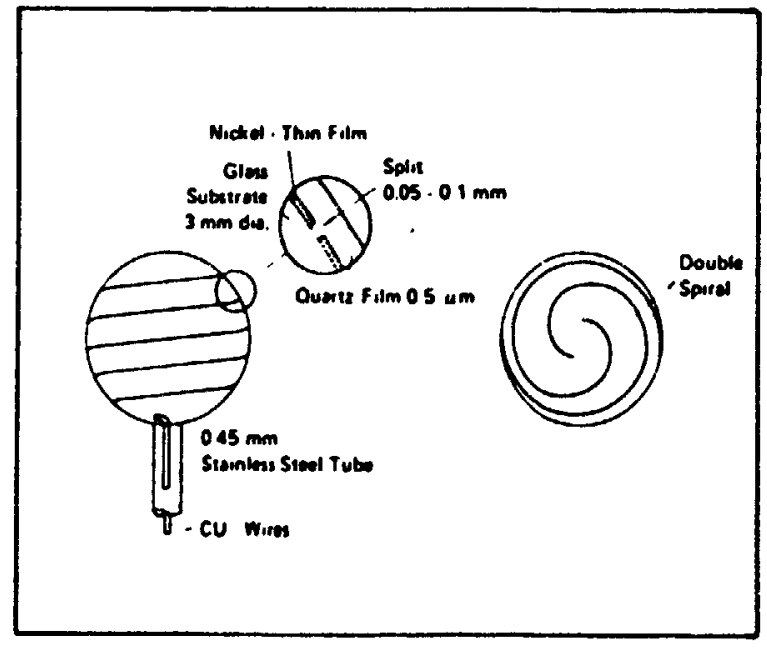

Figure 4.10: Low Velocity Transducer 54R10. 


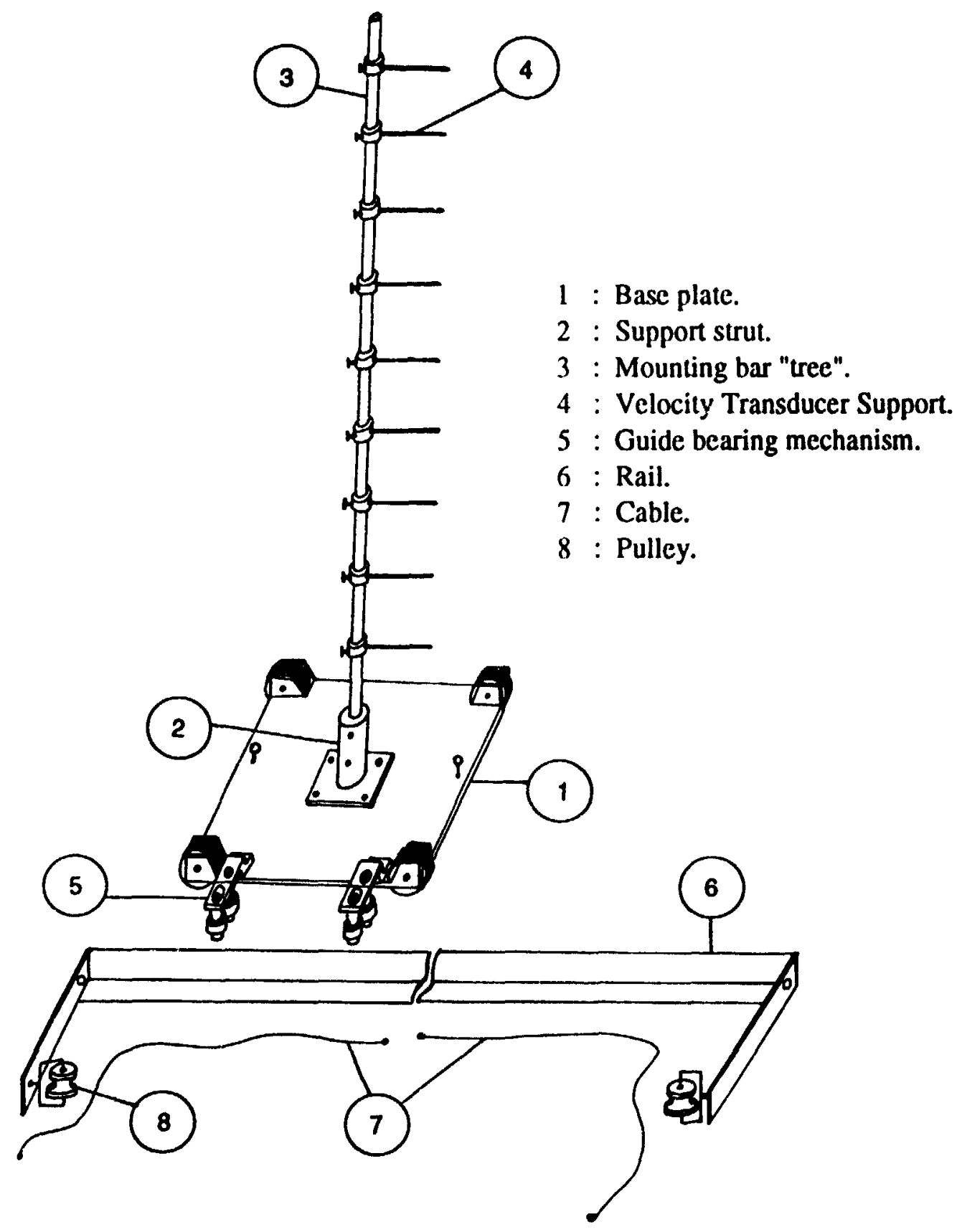

Figure 4.11: Traversing mechanism. 

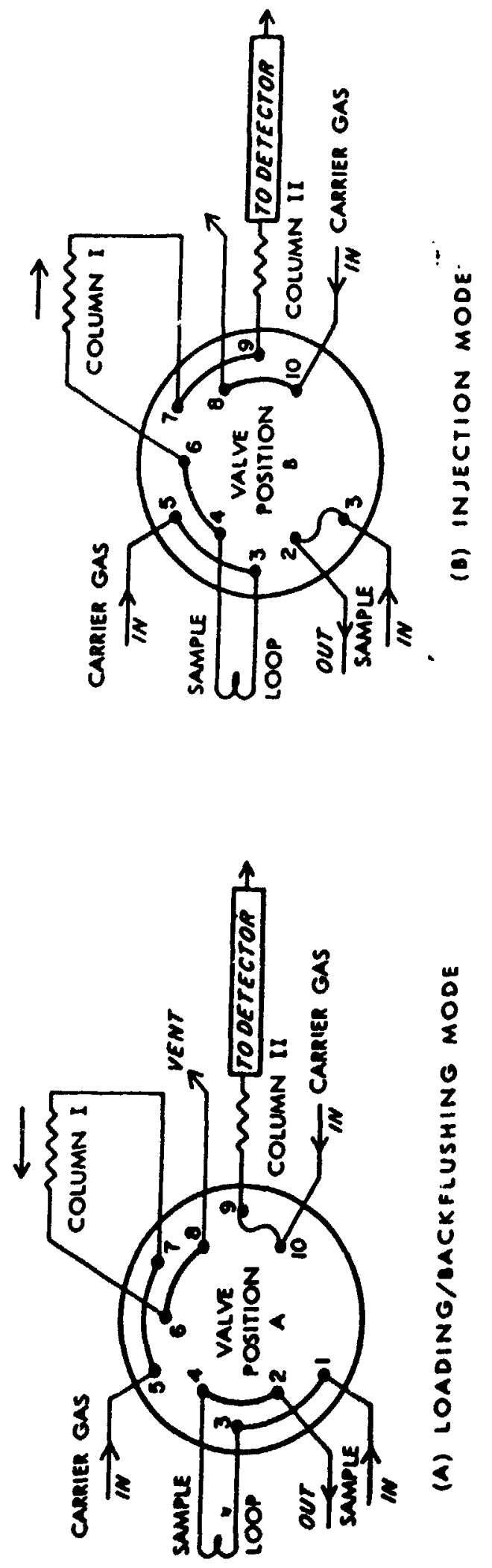

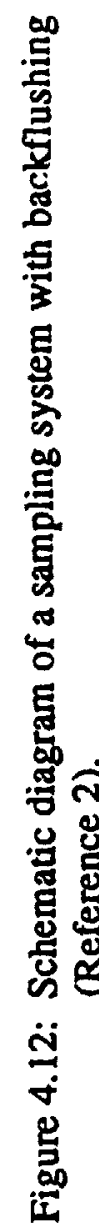




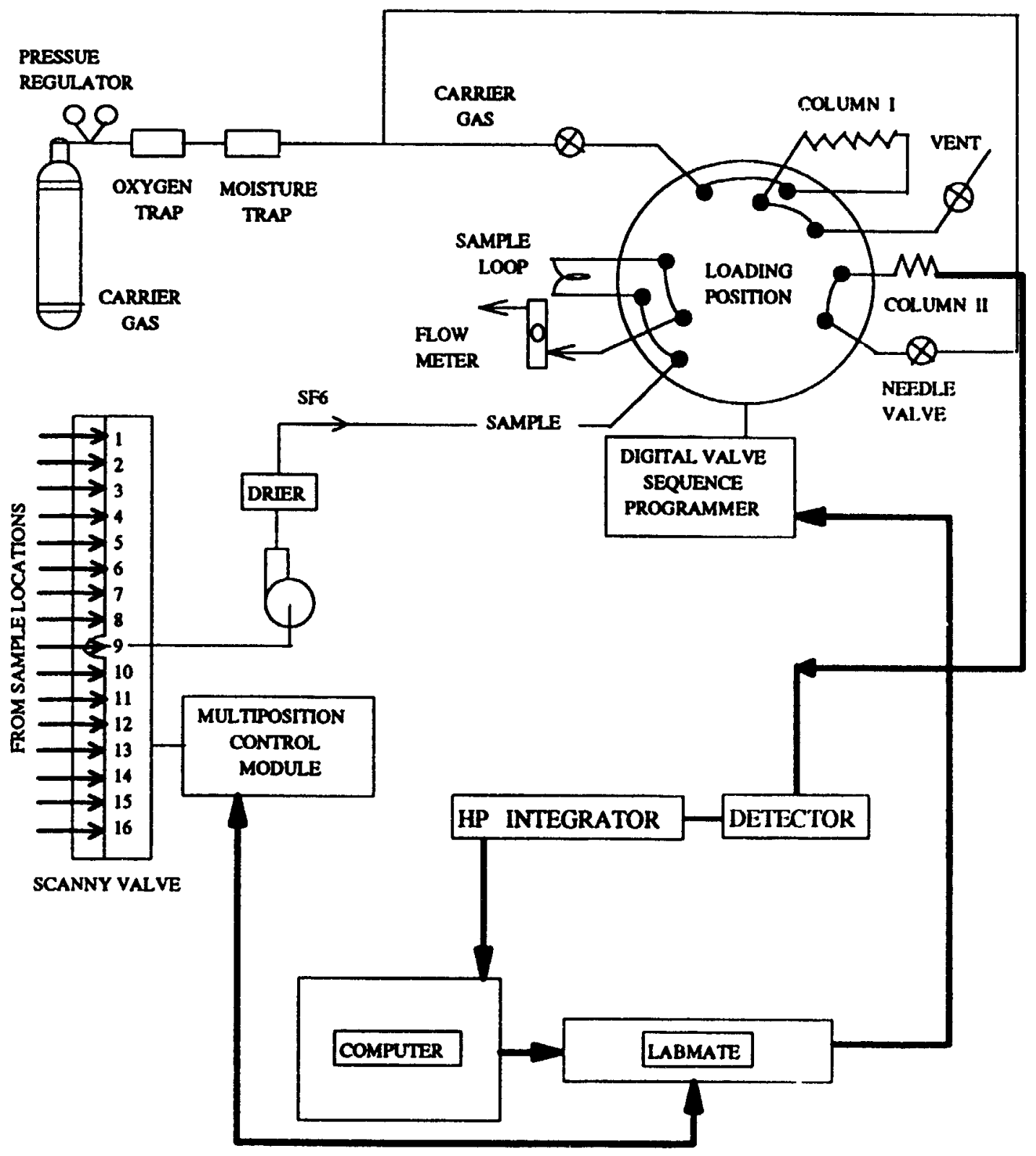

Figure 4.13.a: System I for contaminant concentration measurements 


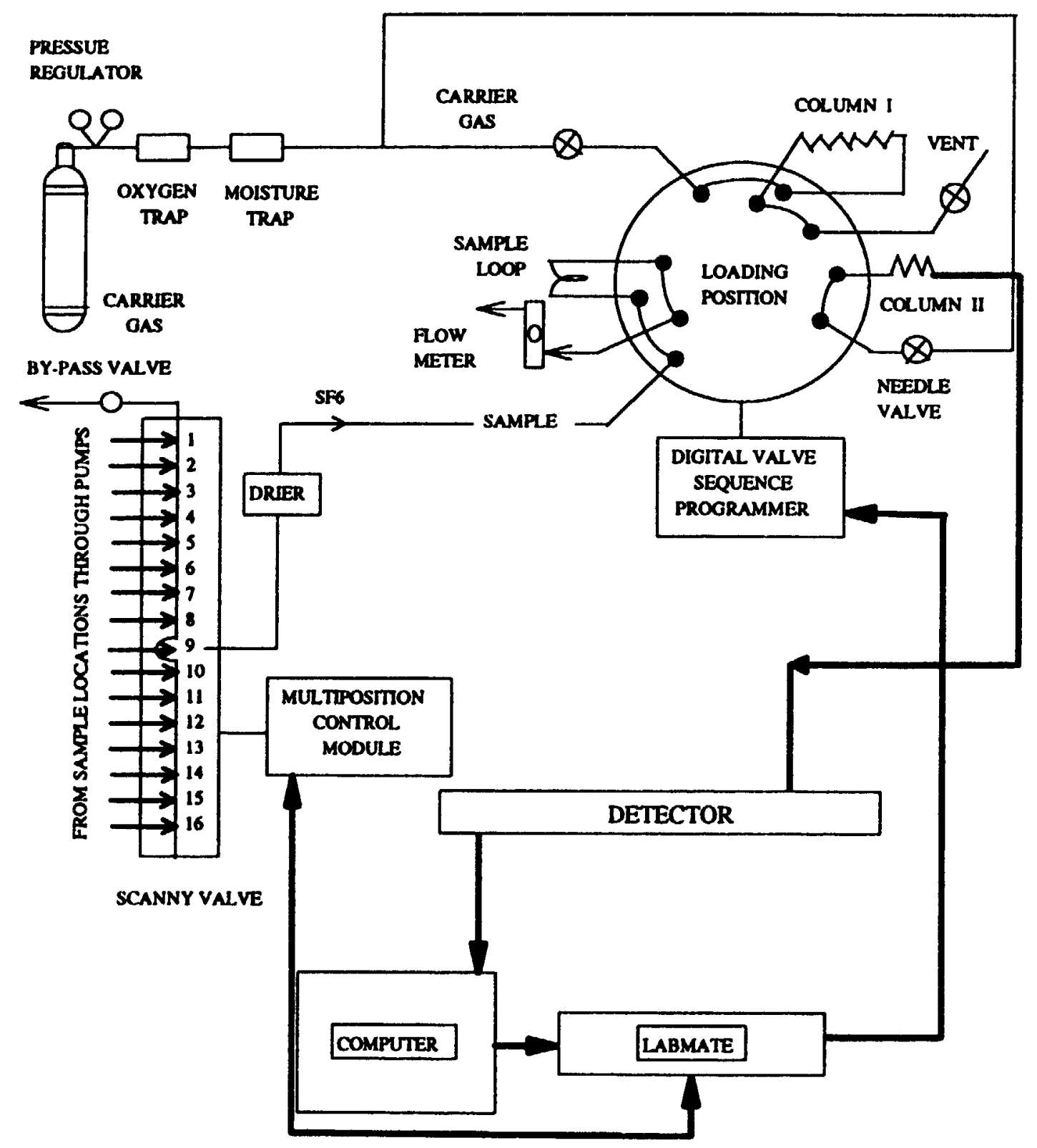

Figure 4.13.b: System II for contaminant concentration measurements. 


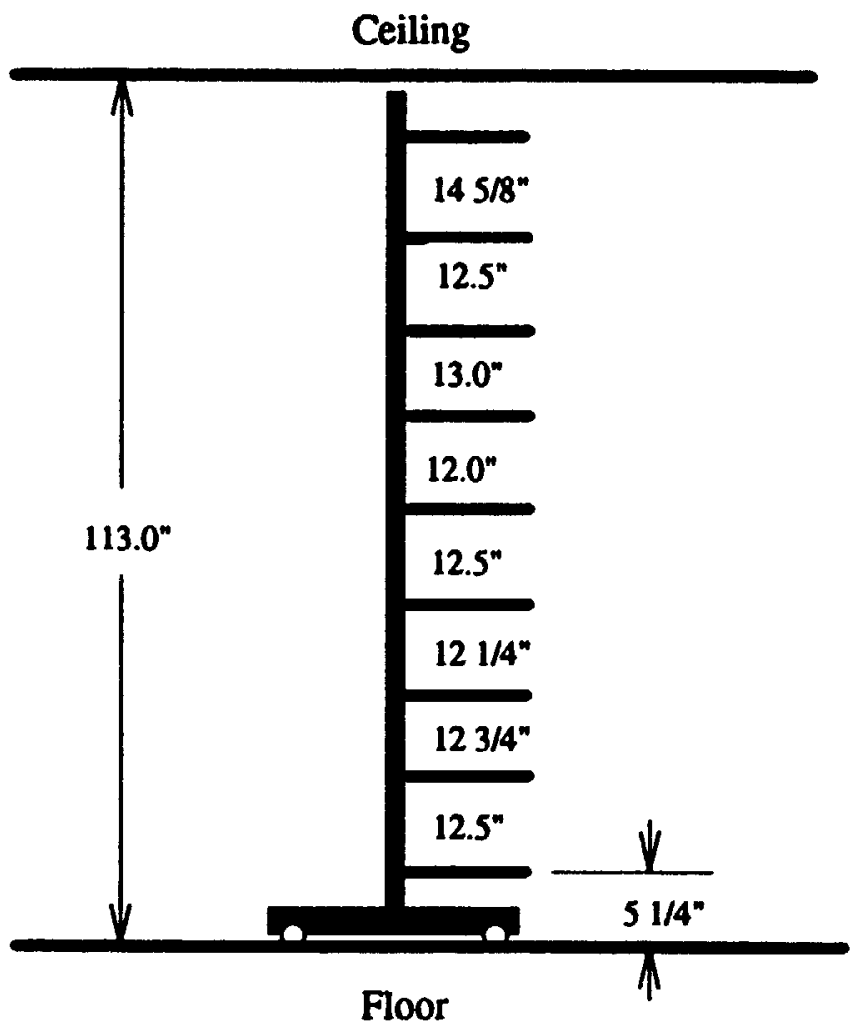

Figure 4.14: Vertical distribution of the contaminant concentration sampling tubes. 


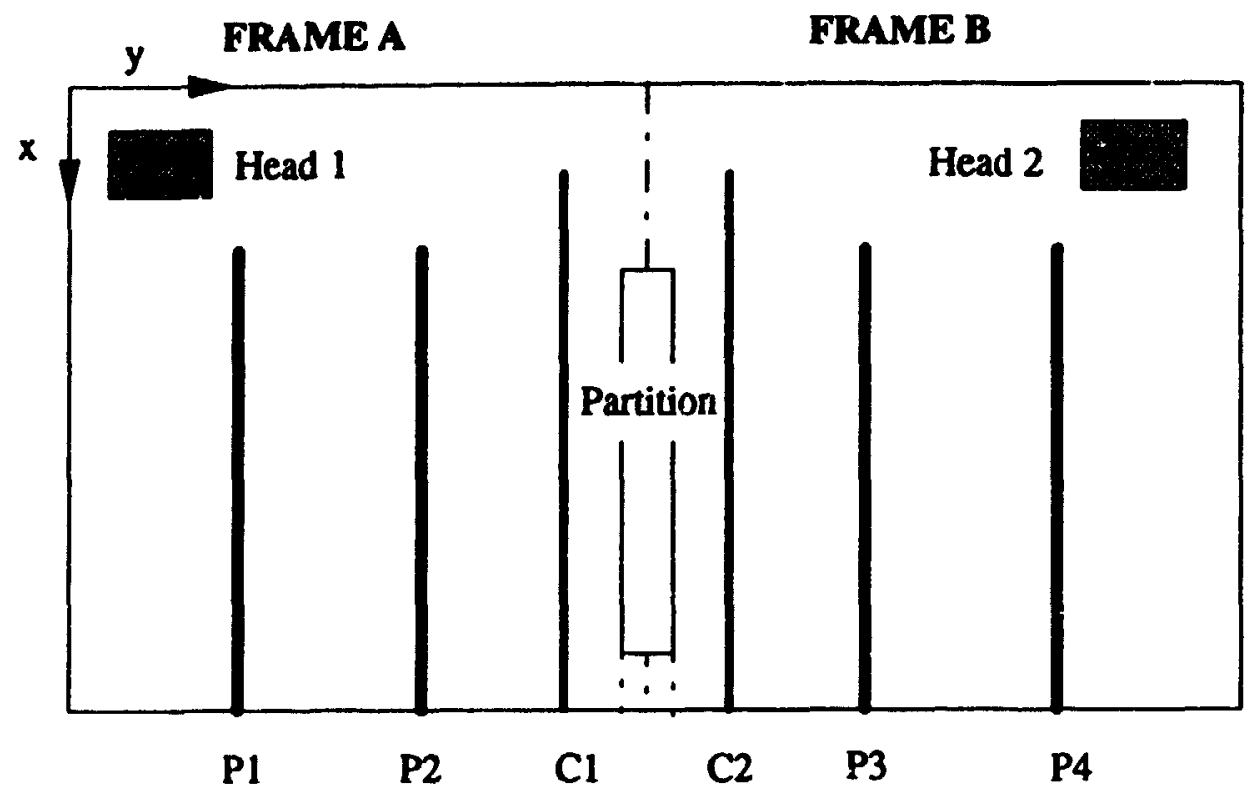

P1, P2, P3, P4: The four different positions for the smoke test at $\mathrm{Y} / \mathrm{L}=0.156$, $0.284,0.667,0.836$ respectively.

C1, C2 : Sampling locations of the "tree", when using the partitions at $Y /=0,411$, 0.582 respectively.

Figure 5.1: Smoke tube, bubble generator heads, and sampling tree positions. 


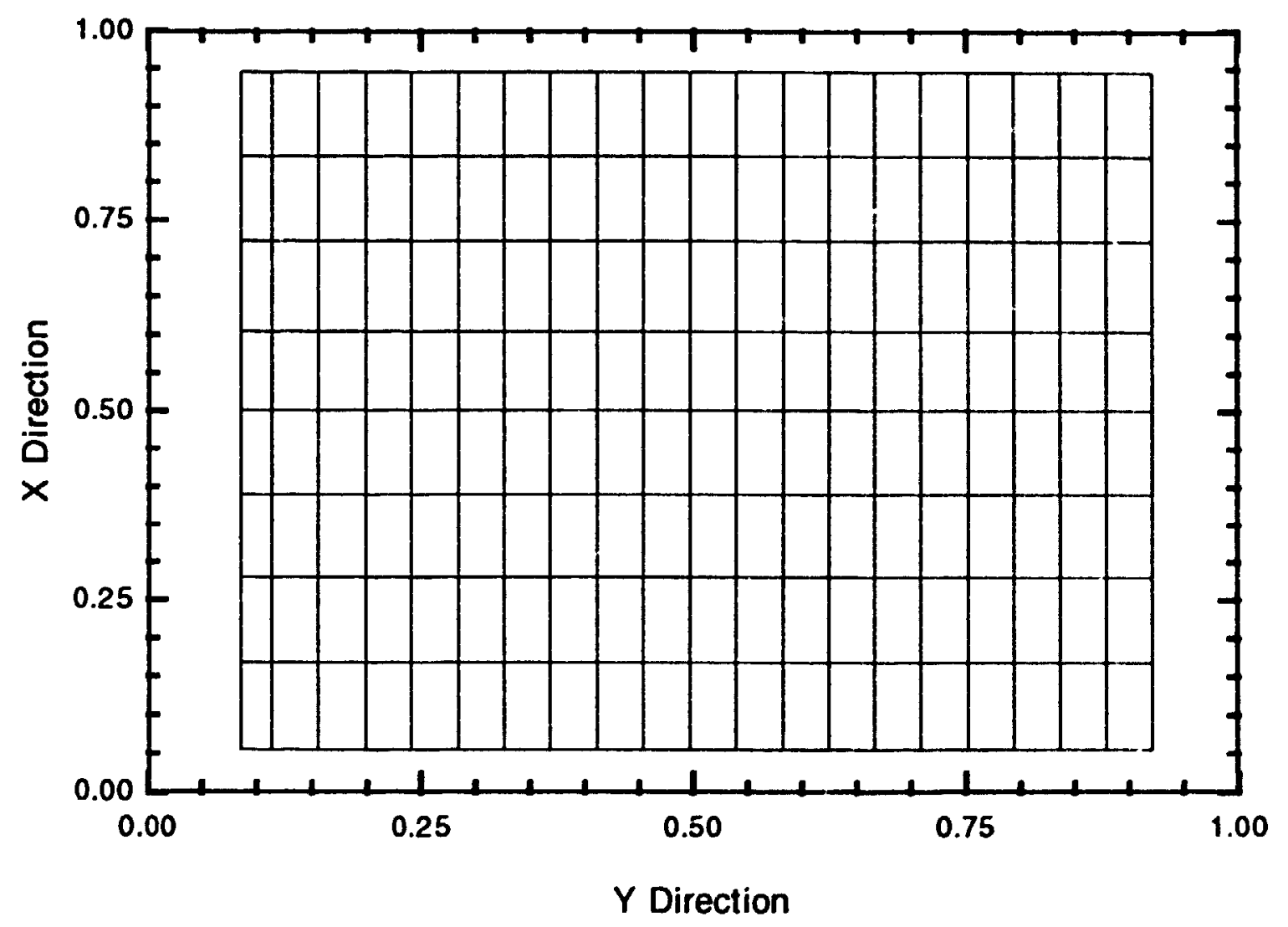

Figure 5.2: Experimental Grid ( $9 \times 21$ ) Points 

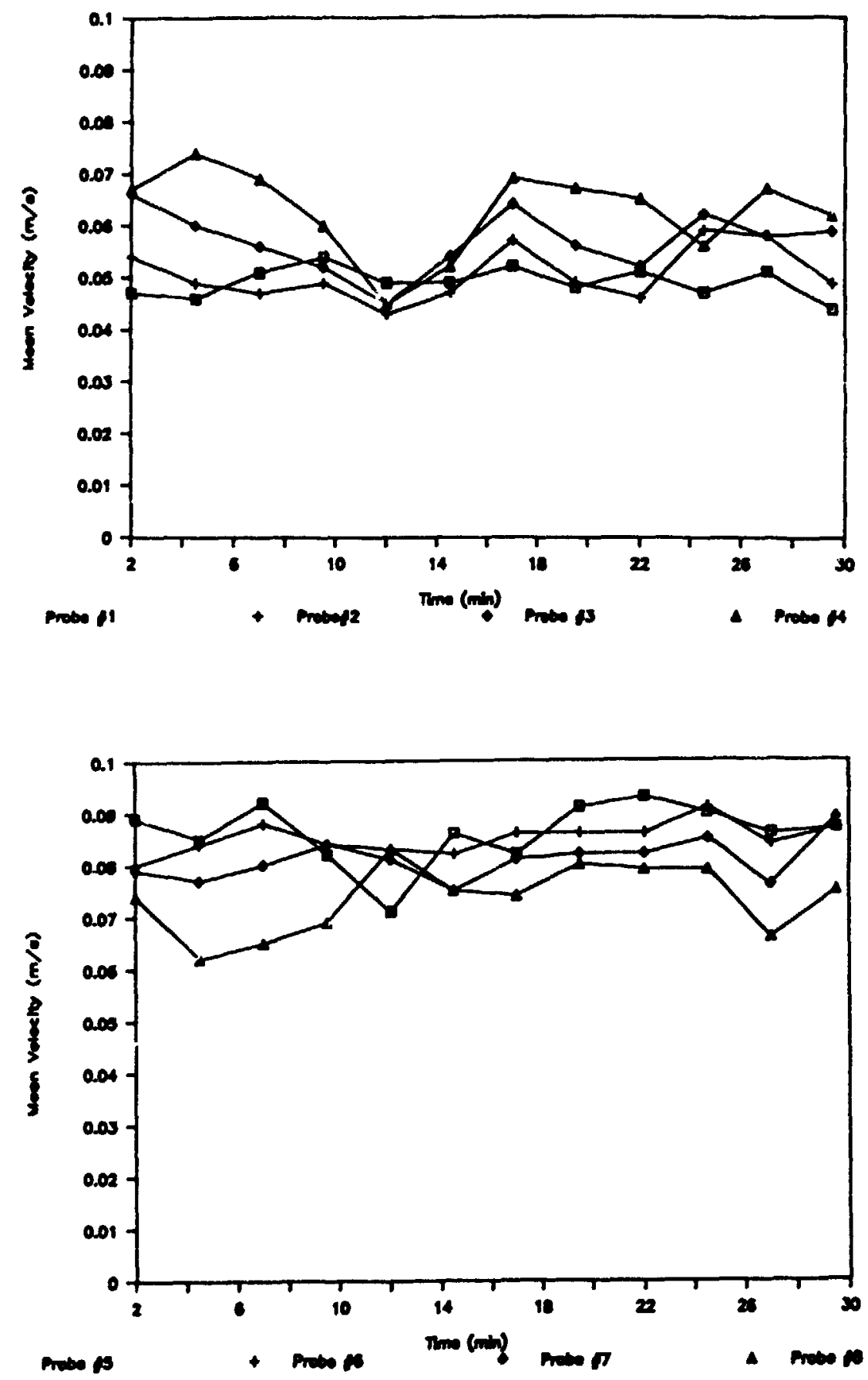

Figure 5.3.a: Effect of the integration time on the measured mean velocity, $\mathrm{IT}=2$ minutes. 

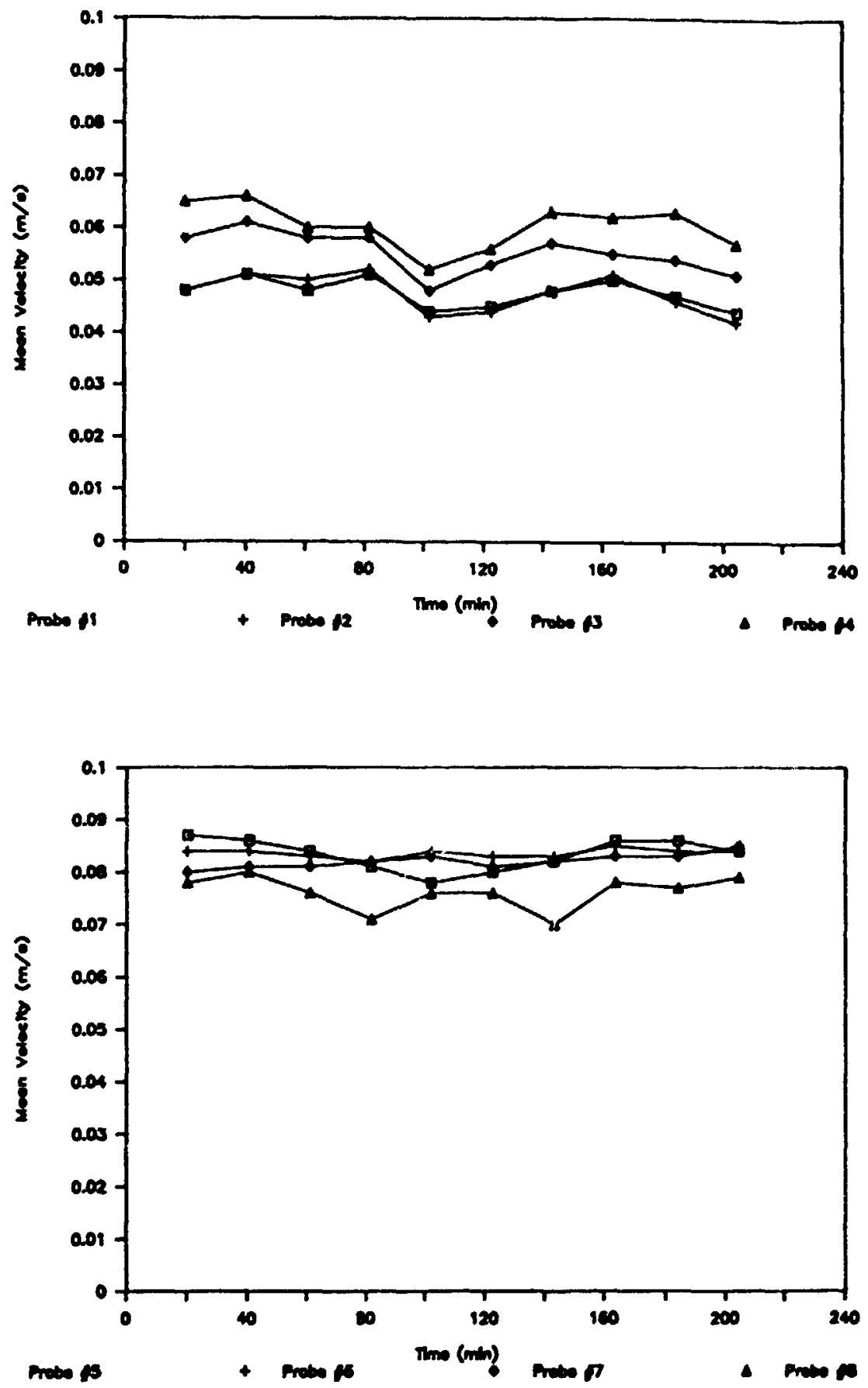

Figure 5.3.b: Effect of the integration time on the measured mean velocity, $I T=20$ minutes. 
a)

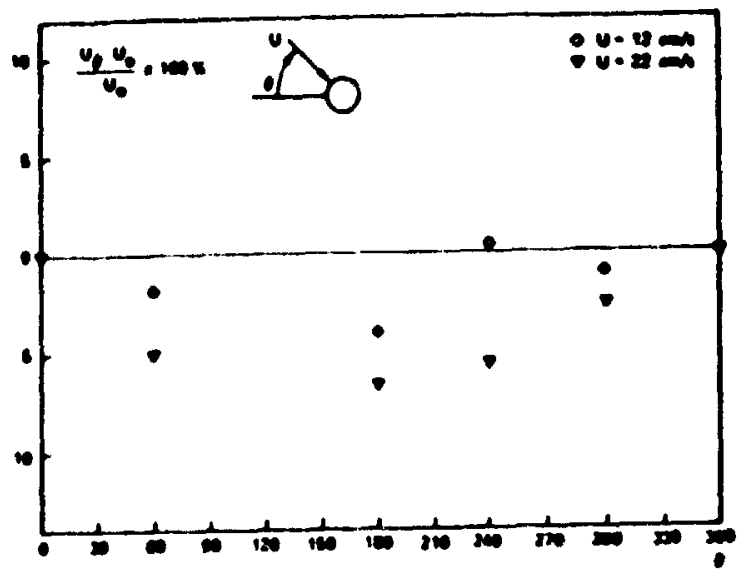

b)

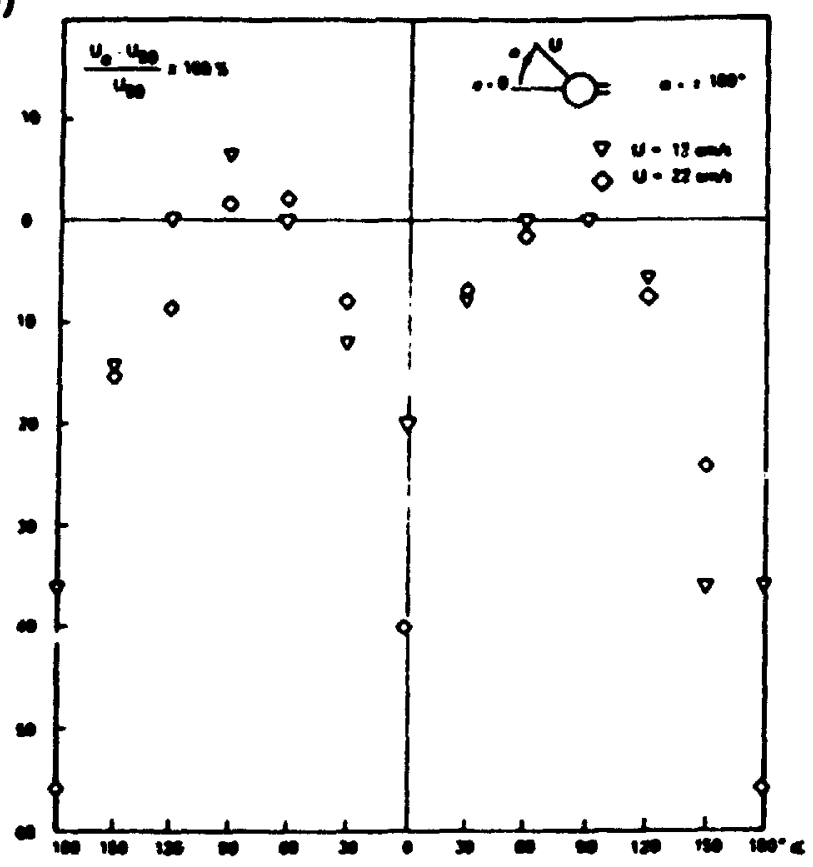

Figure 5.4: Variation of the velocity with a) the roll angle, and b) the yaw angle (From reference 1).

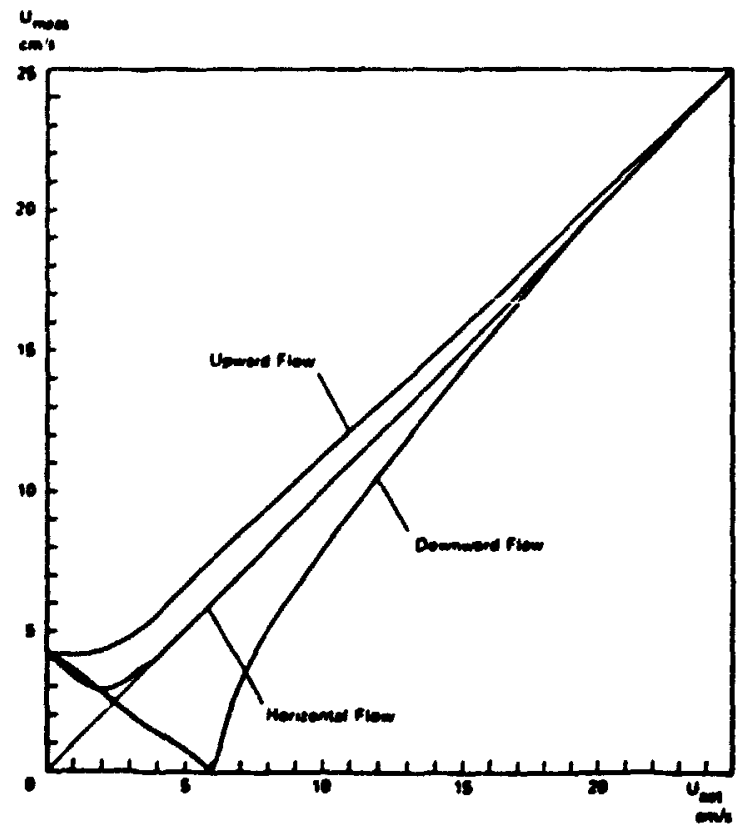

Figure 5.5: Influence of natural convection at low velocities (Reference 1). 


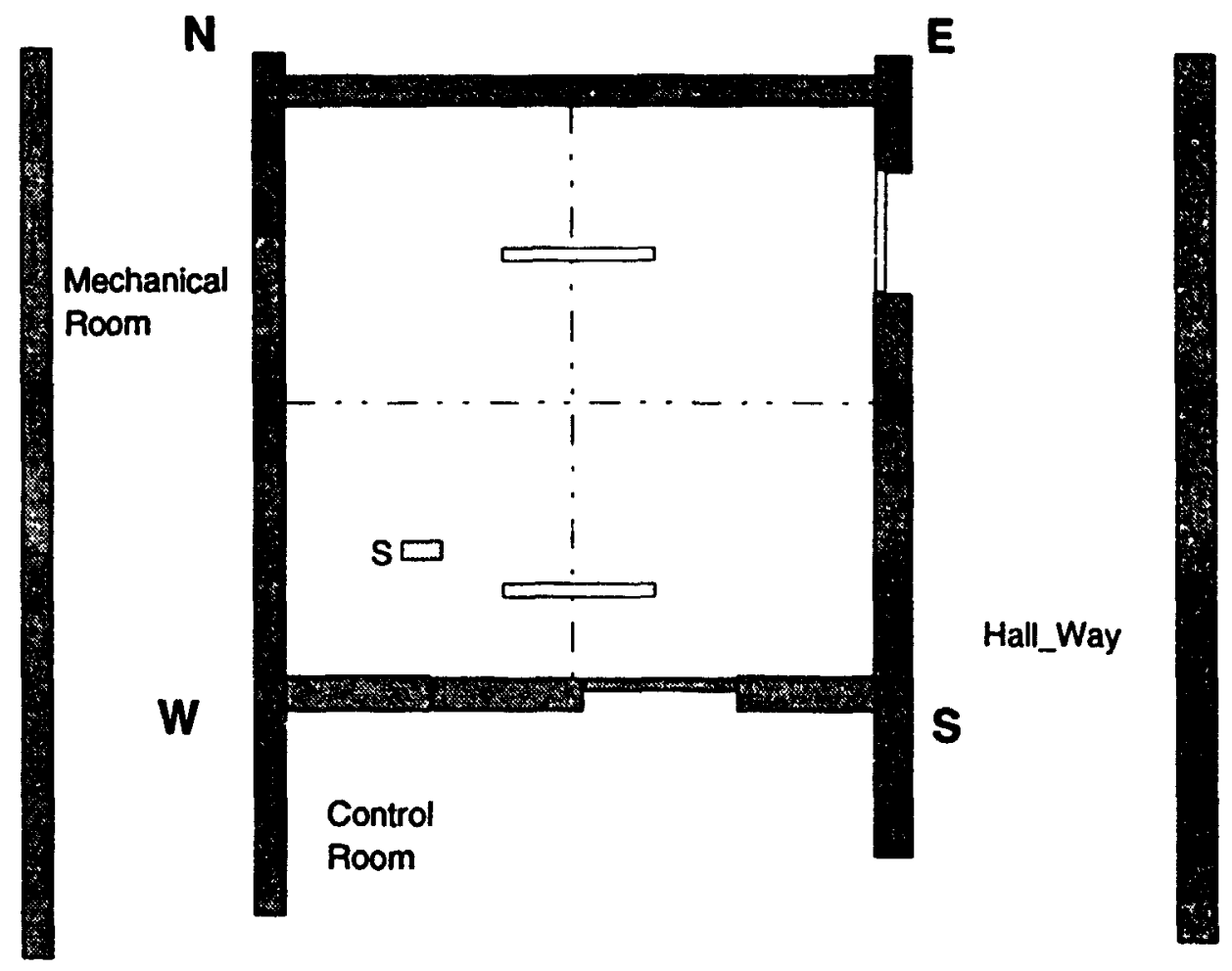

S : Contaminant source Location,

(at a height of 48.25")

Figure 5.6: Contaminant source location. 


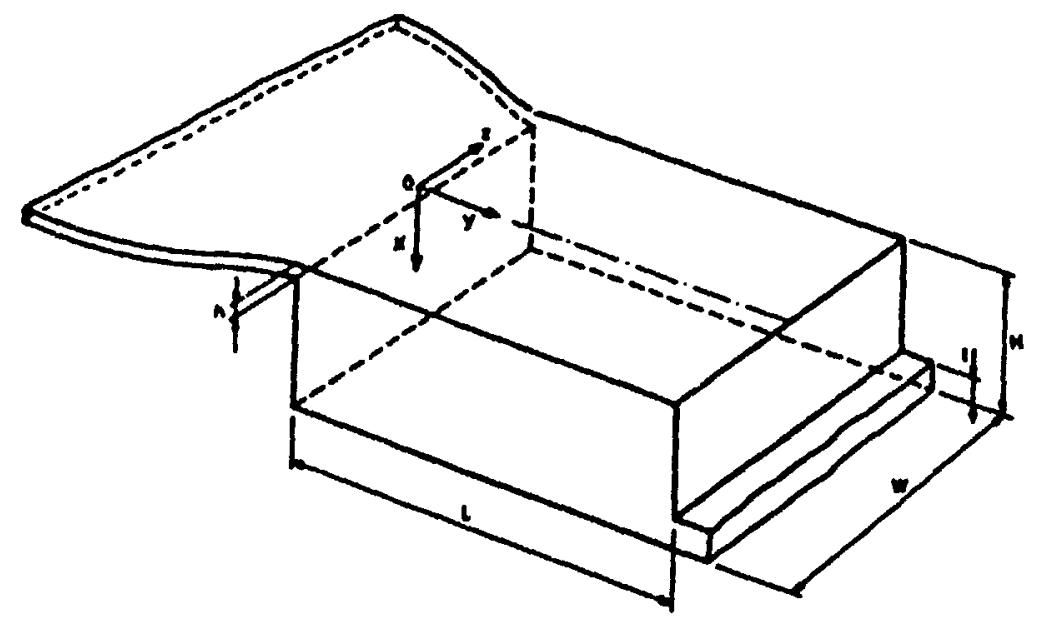

Figure 5.7: Geometry and dimensions of the test model used by Nielsen [26], $H=3.0 \mathrm{~m}, \mathrm{~L}=9.0 \mathrm{~m}$, $\mathrm{h}=0.168 \mathrm{~m}$, and $\mathrm{t}=0.48 \mathrm{~m}$. 
-)

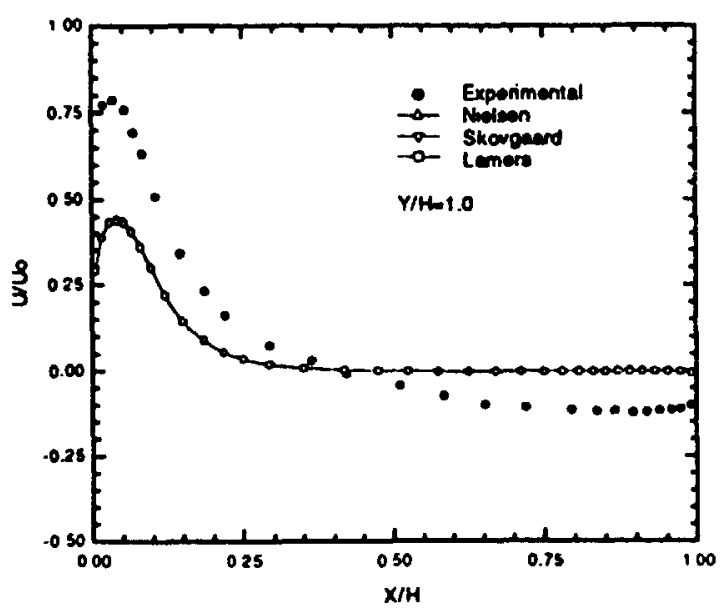

c)

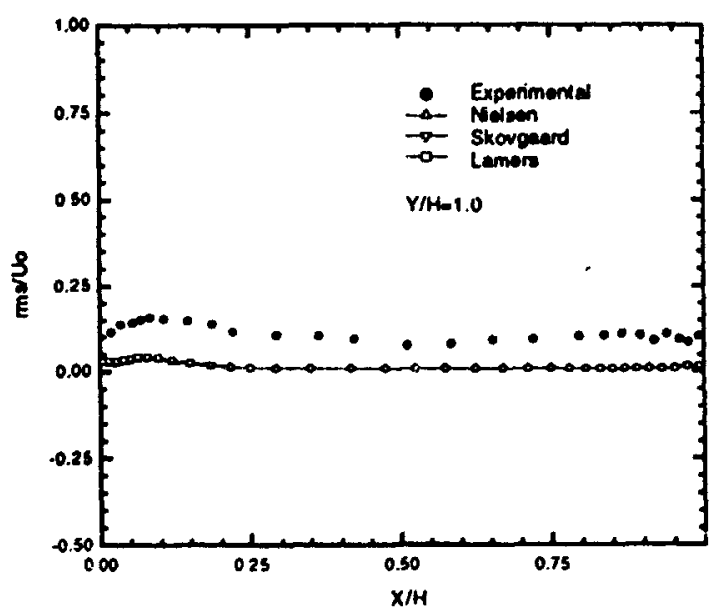

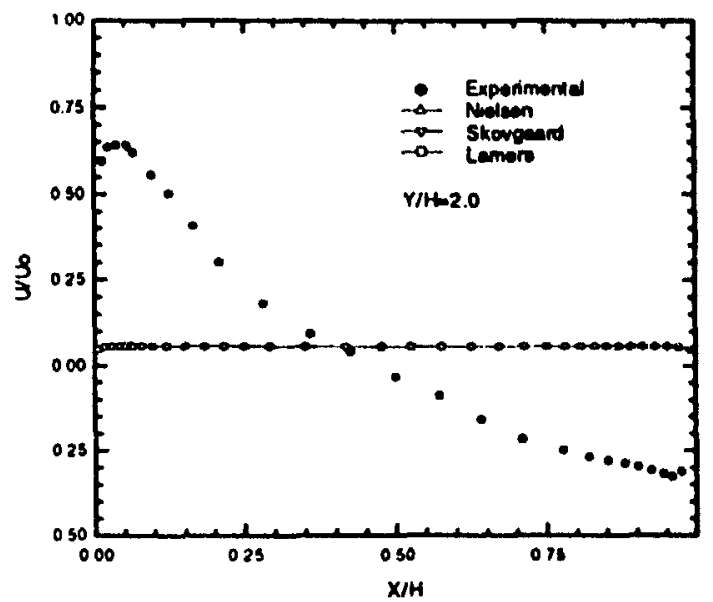

d)

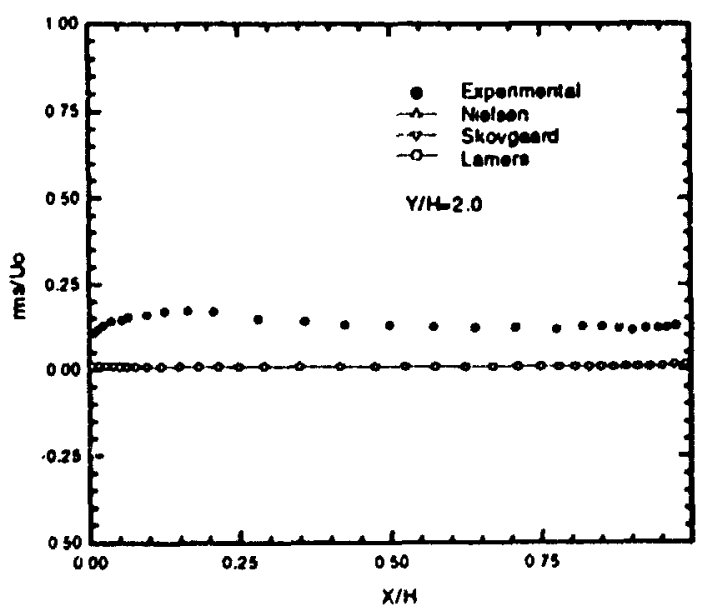

Figure 5.8: Velocity and turbulence kinetic energy distribution at an early stage (4000 time step iterations), a) and c) at $\mathrm{Y} / \mathrm{H}=1.0, \mathrm{~b}$ ) and $\mathrm{e}$ ) at $\mathrm{Y} / \mathrm{H}=2.0$. 
$\bullet$

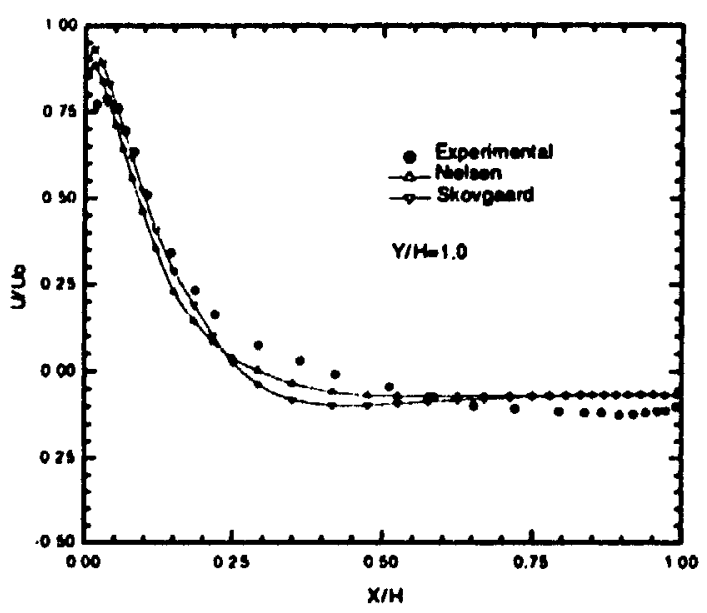

c)

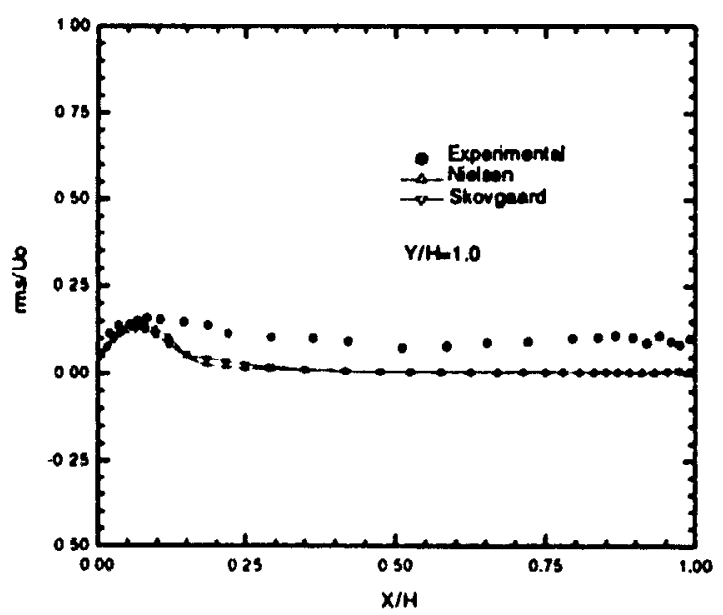

b)

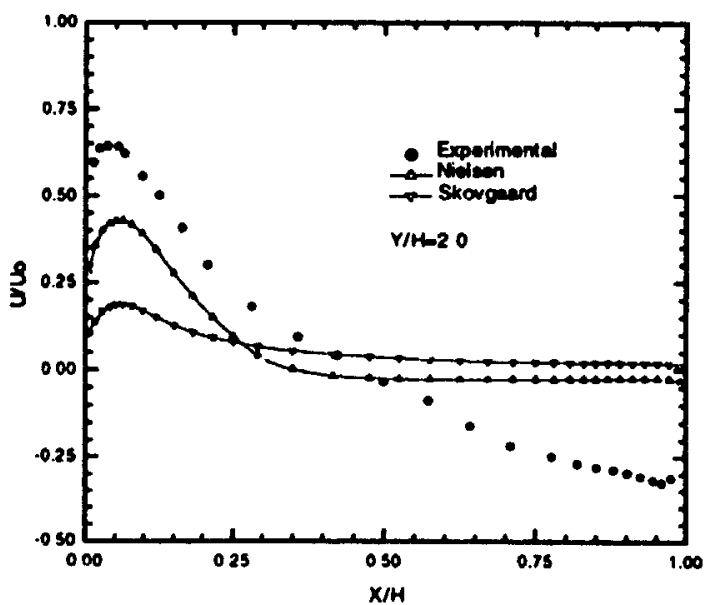

d)

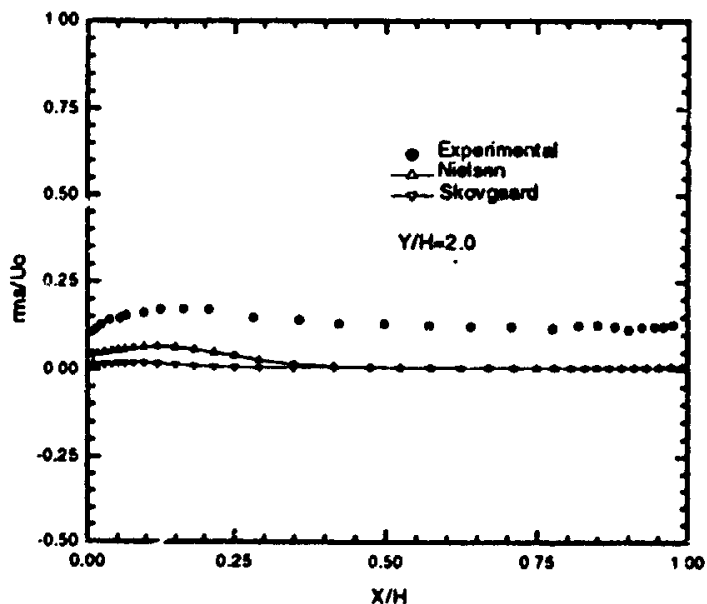

Figure 5.9: Velocity and turbulence kinetic energy distribution at an intermediate stage ( 8000 time step iterations), a) and c) at $\mathrm{Y} / \mathrm{H}=1.0, \mathrm{~b}$ ) and $\mathrm{e}$ ) at $\mathrm{Y} / \mathrm{H}=2.0$. 
a)

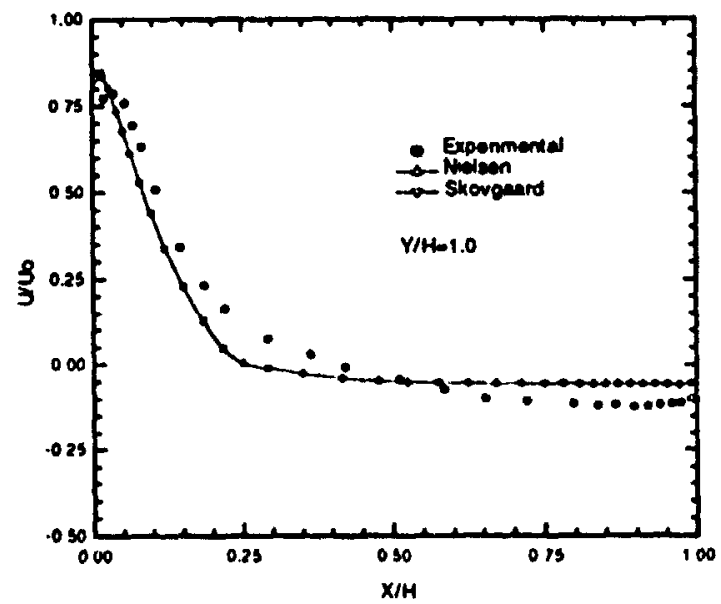

c)

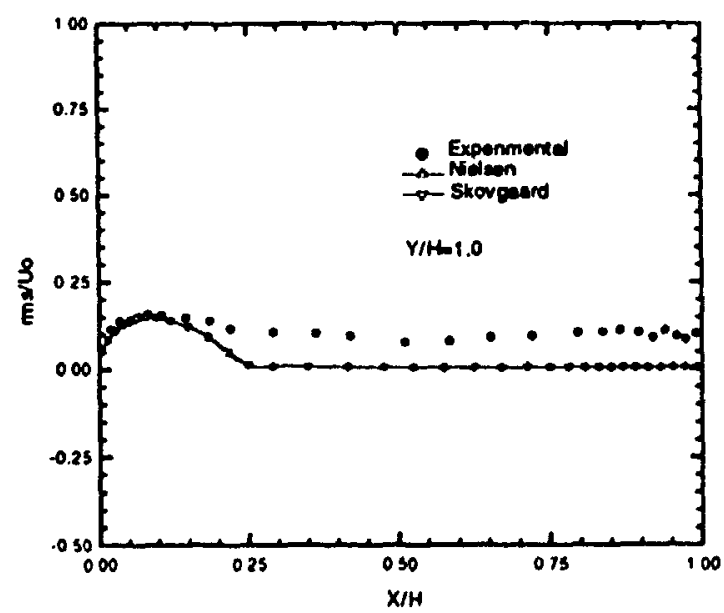

b)

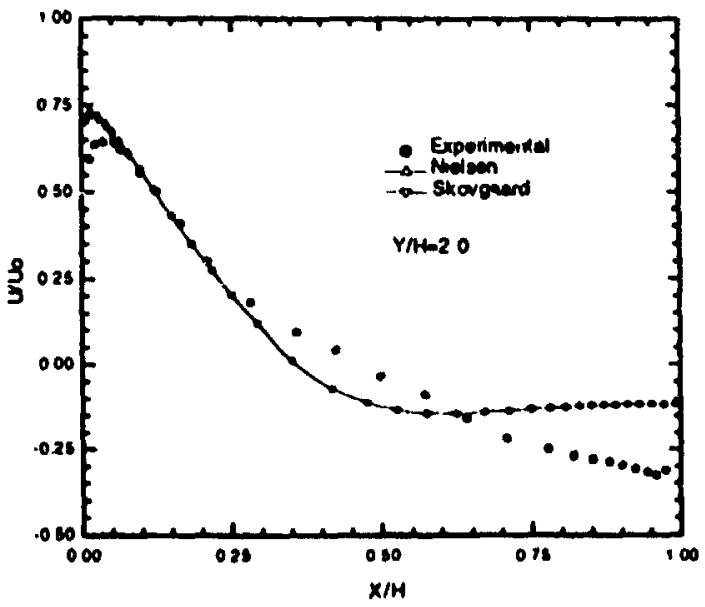

9)

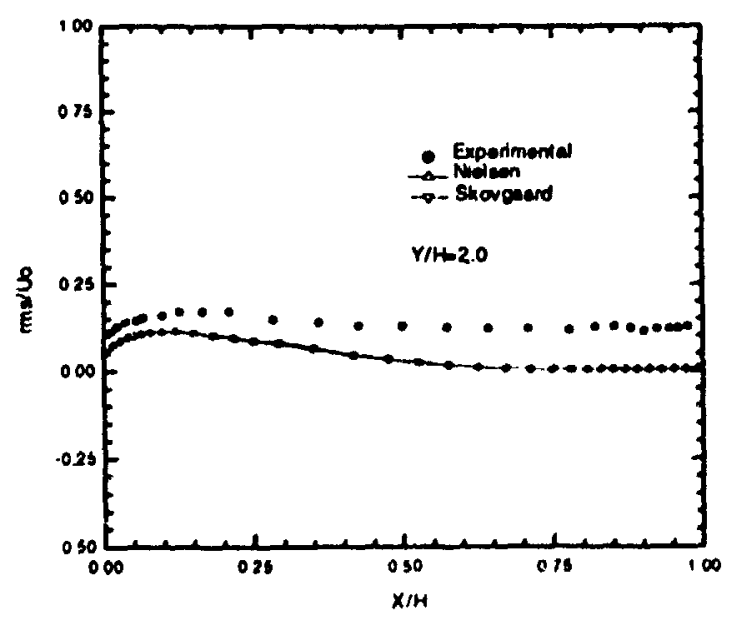

Figure 5.10: Velocity and turbulence kinetic energy distribution at the steady state stage (13000 time step iterations), a) and c) at $\mathrm{Y} / \mathrm{H}=1.0, \mathrm{~b}$ ) and $\mathrm{e}$ ) at $\mathrm{Y} / \mathrm{H}=2.0$. 

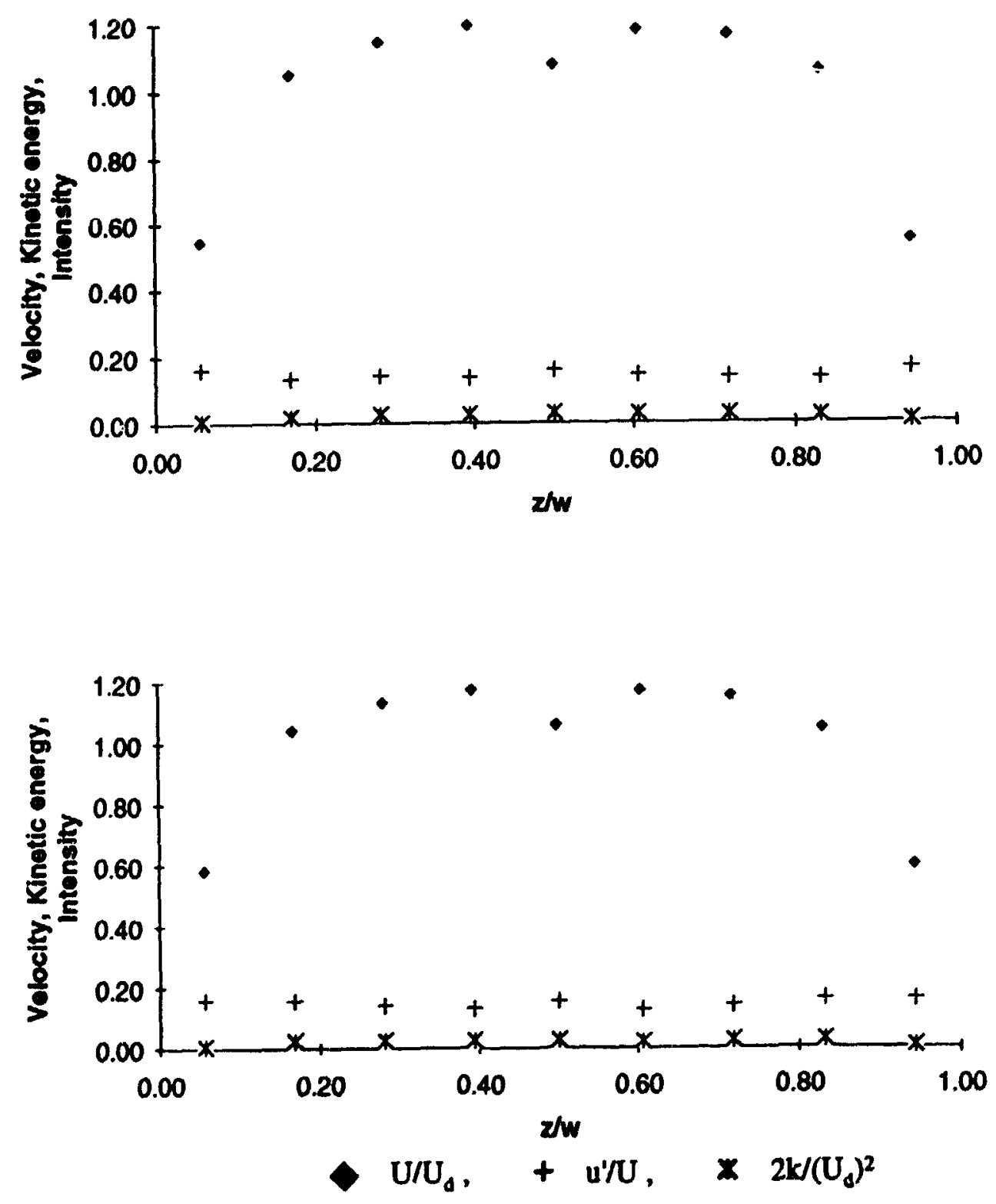

Figure 5.11.a: Velocity $\left(U_{d}\right)$, Turbulence kinetic energy $\left(2 k /\left(U_{d}\right)^{2}\right)$, and Turbulence intensity $\left(\mathrm{TI}=\left(\mathrm{u}^{\prime} / \mathrm{U}\right)\right)$ along the supply diffuser for a) $1.5 \mathrm{ACH}$, and b) $3 \mathrm{ACH}$. 


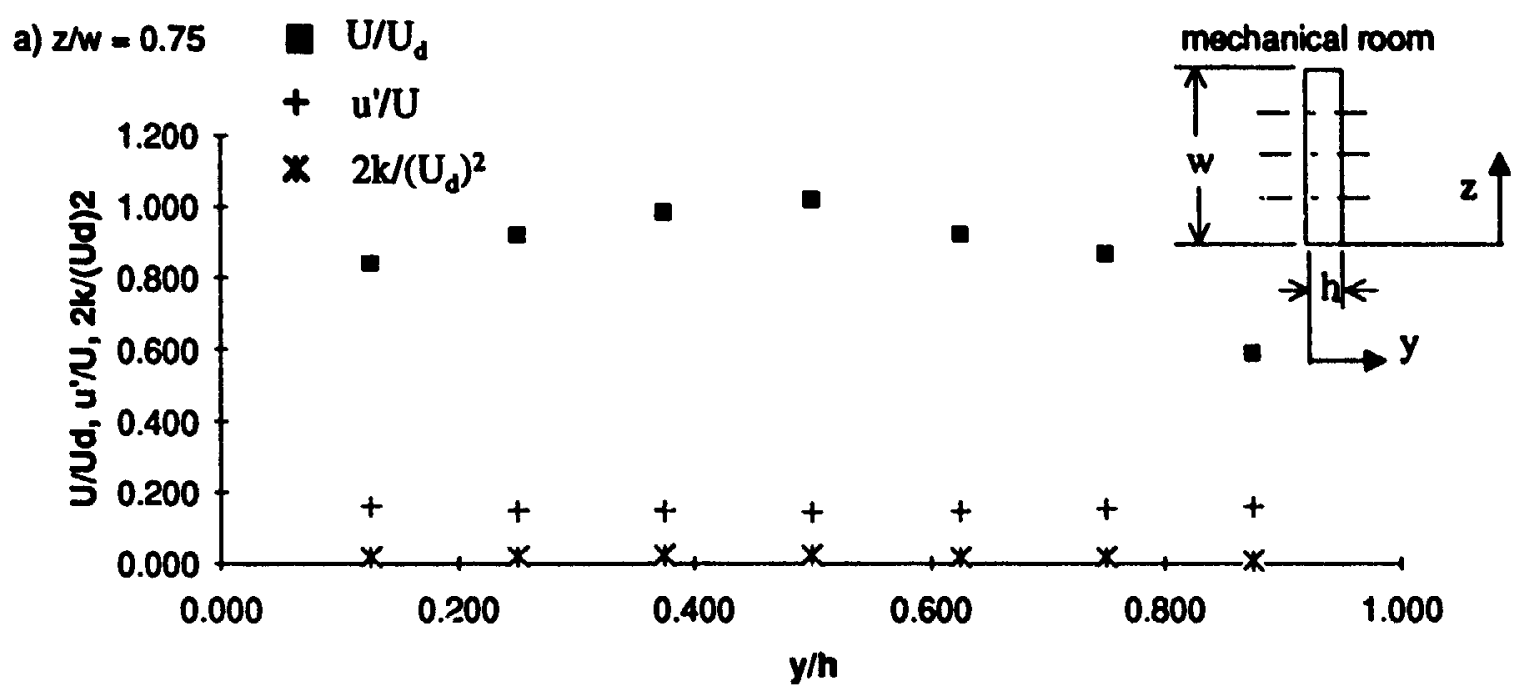

b) $z / w=0.50$

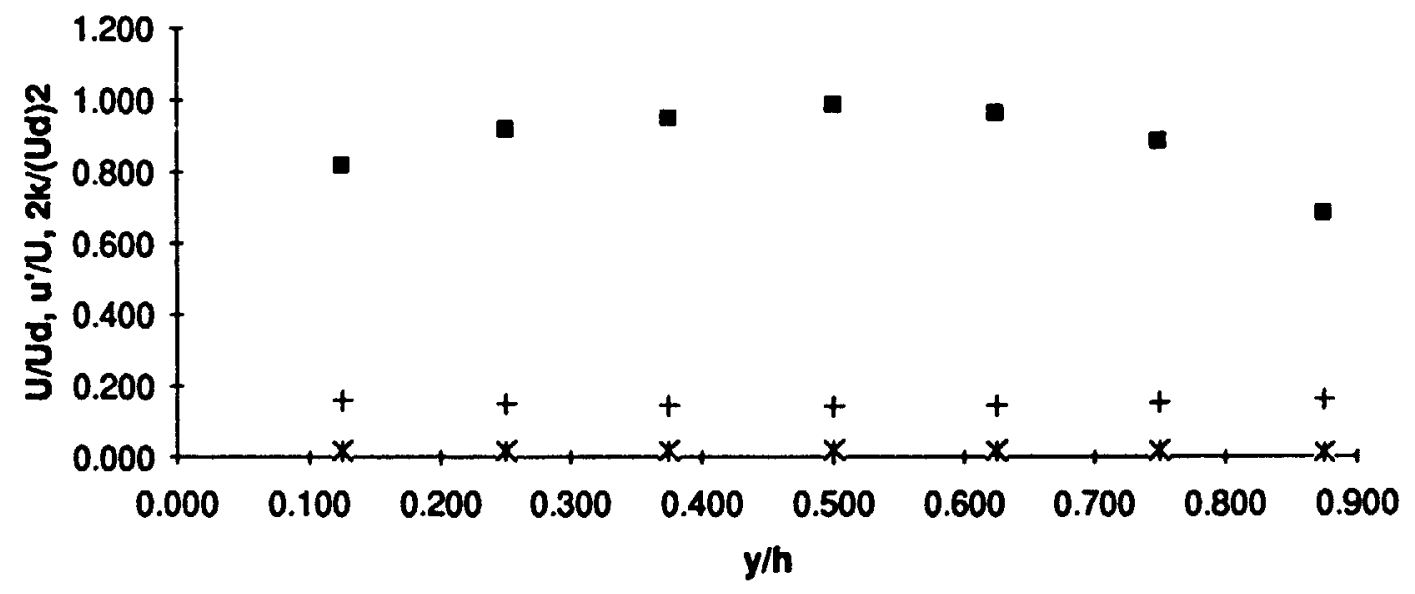

c) $z / w=0.25$

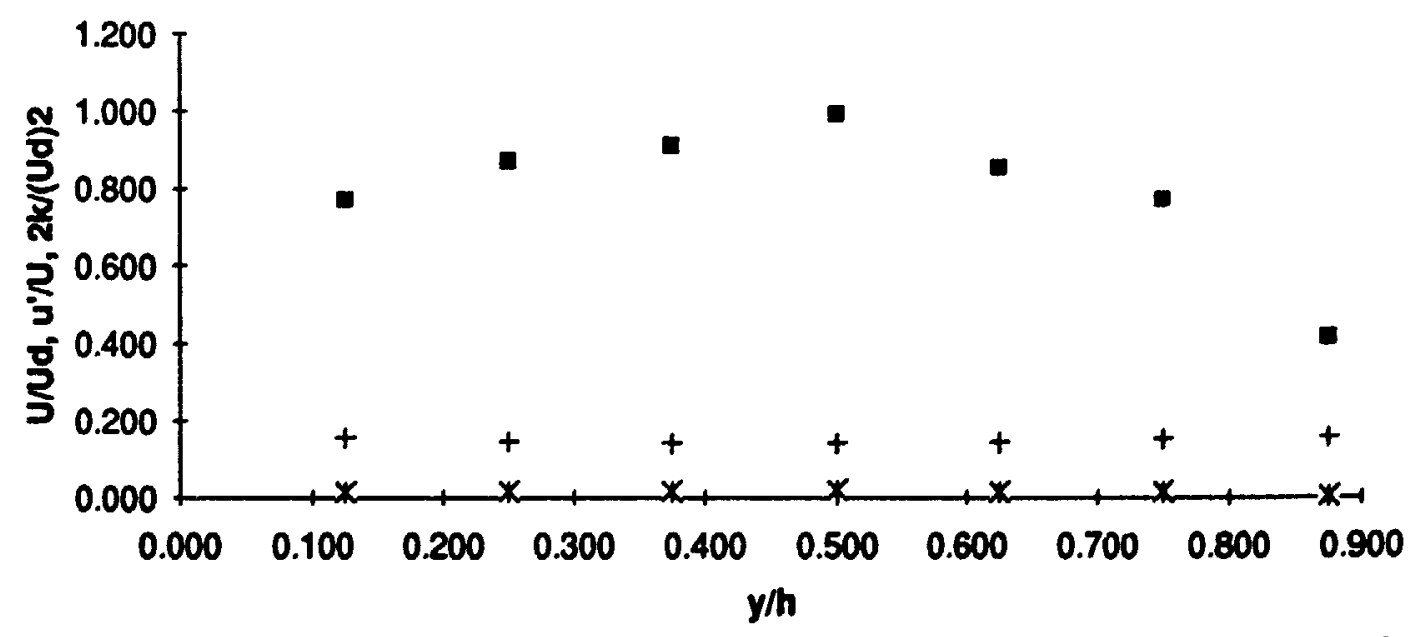

Figure 5.11.b: Velocity $\left(U_{\lrcorner}\right)$, Turbulence kinetic energy $\left(2 \mathrm{k} /\left(\mathrm{U}_{\mathcal{L}}\right)^{2}\right)$, and Turbulence intensity $\left(\mathrm{TI}=\left(\mathrm{u}^{\prime} / \mathrm{N}\right)\right)$ across the supply diffuser for $\left.3 \mathrm{ACH}(\mathrm{a}), \mathrm{b}\right)$, and c)), and for $1.5 \mathrm{ACH}(d), e)$, and f)). 
d) $z / w=0.75$

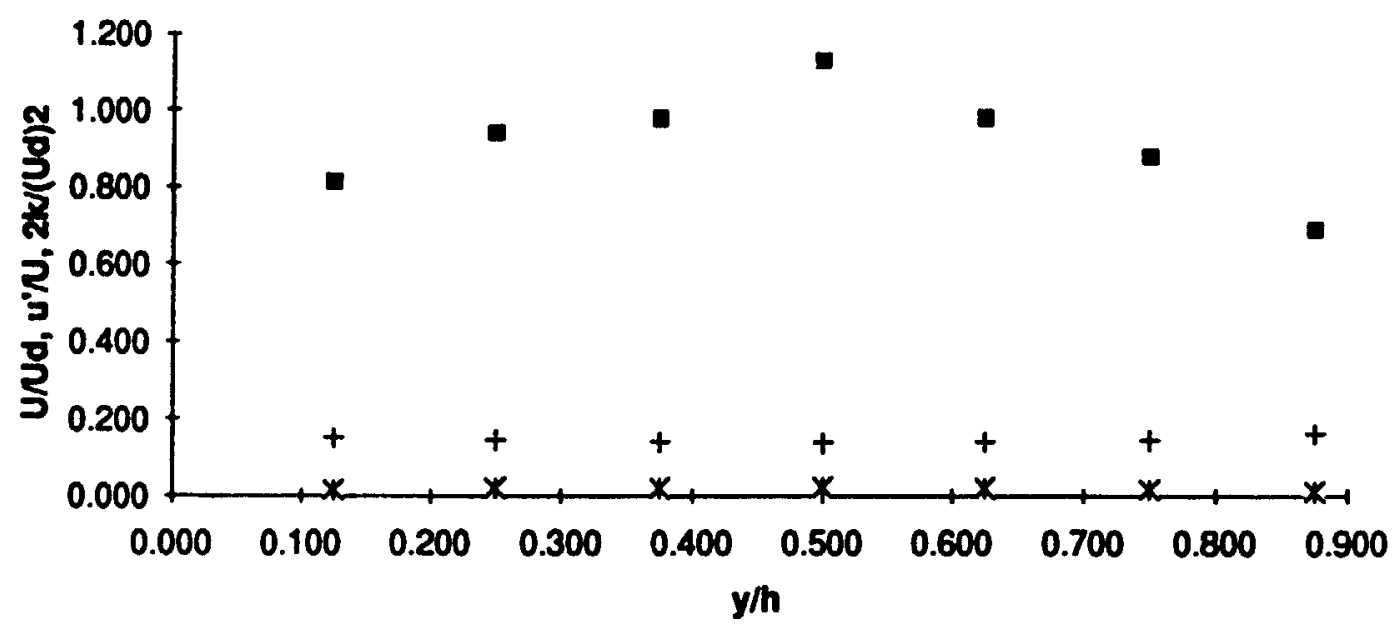

e) $z / w=0.50$

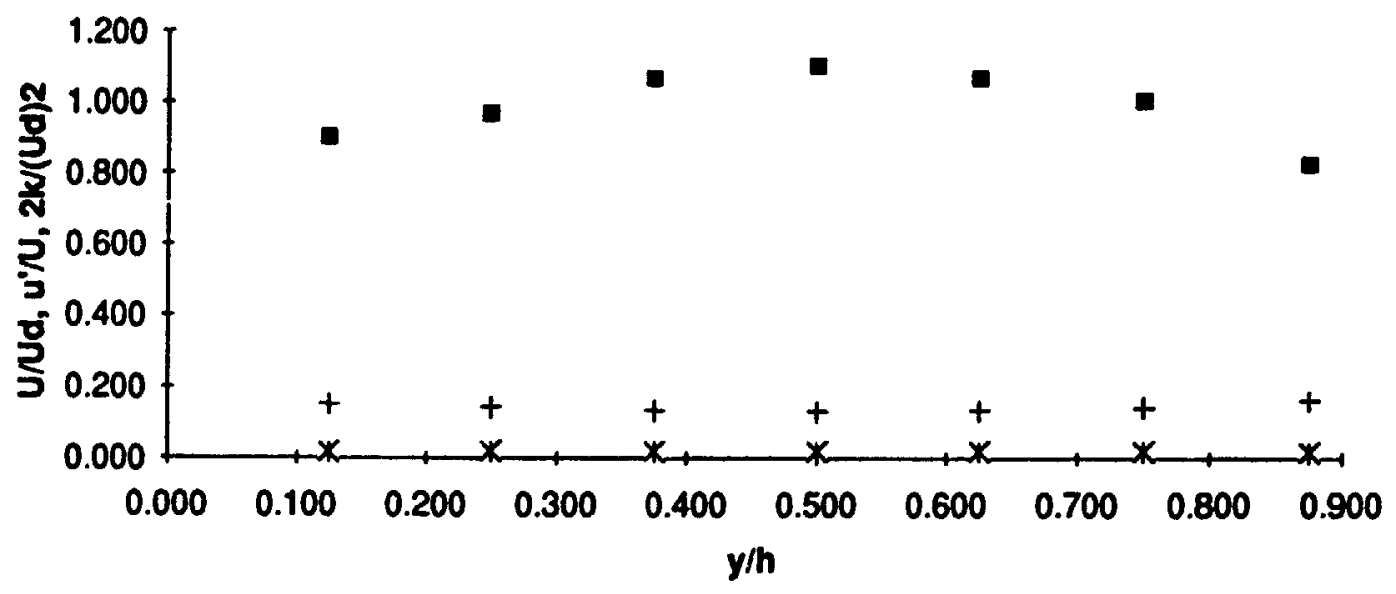

f) $z / w=0.25$

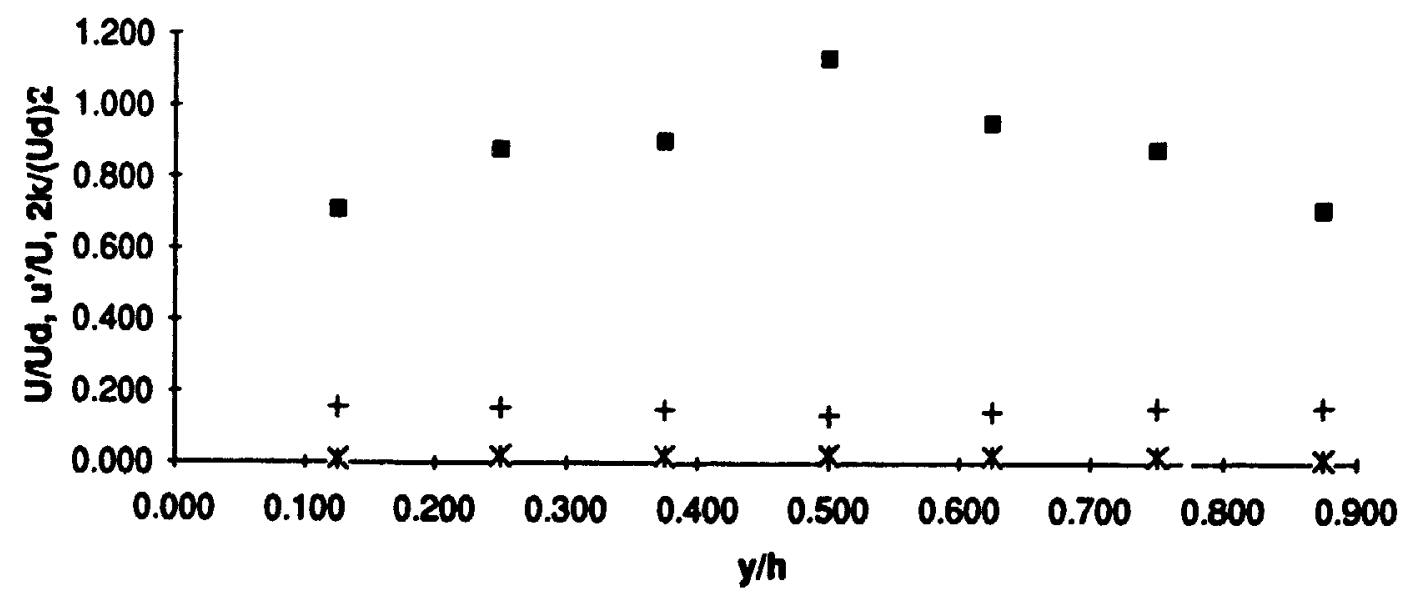

Figure 5.11.b: (cont.) 
Frame A

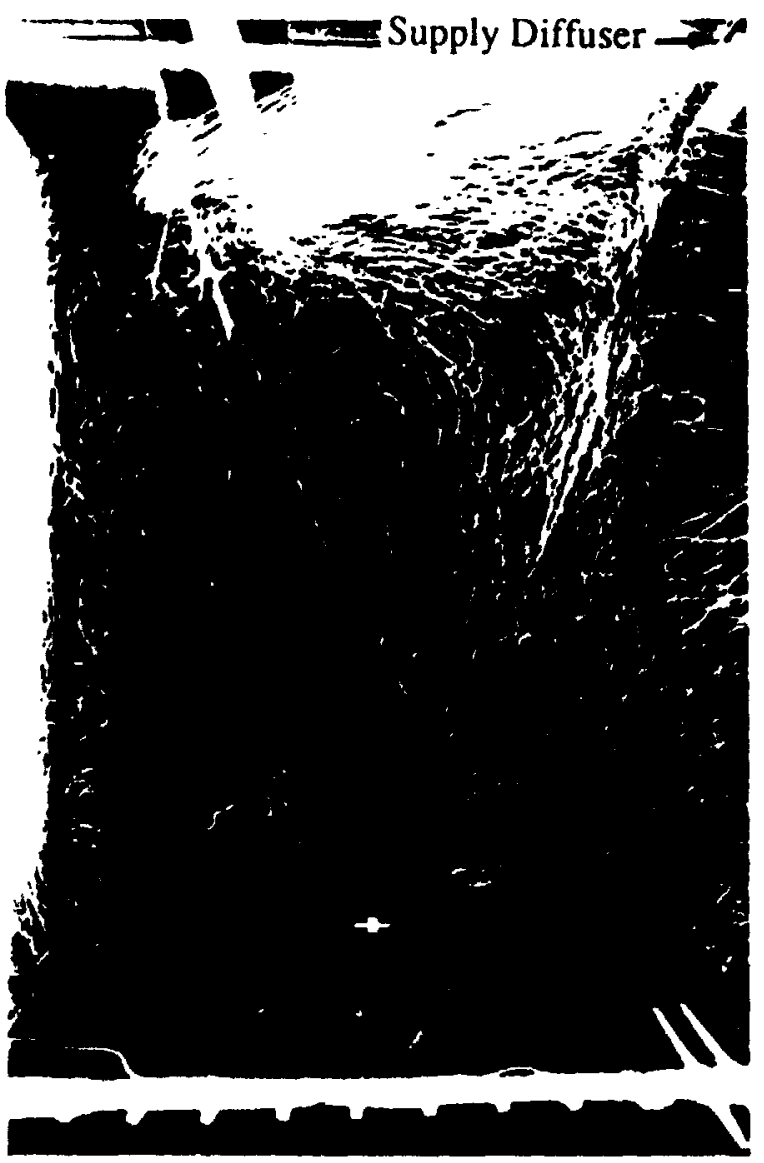

Fratluk B

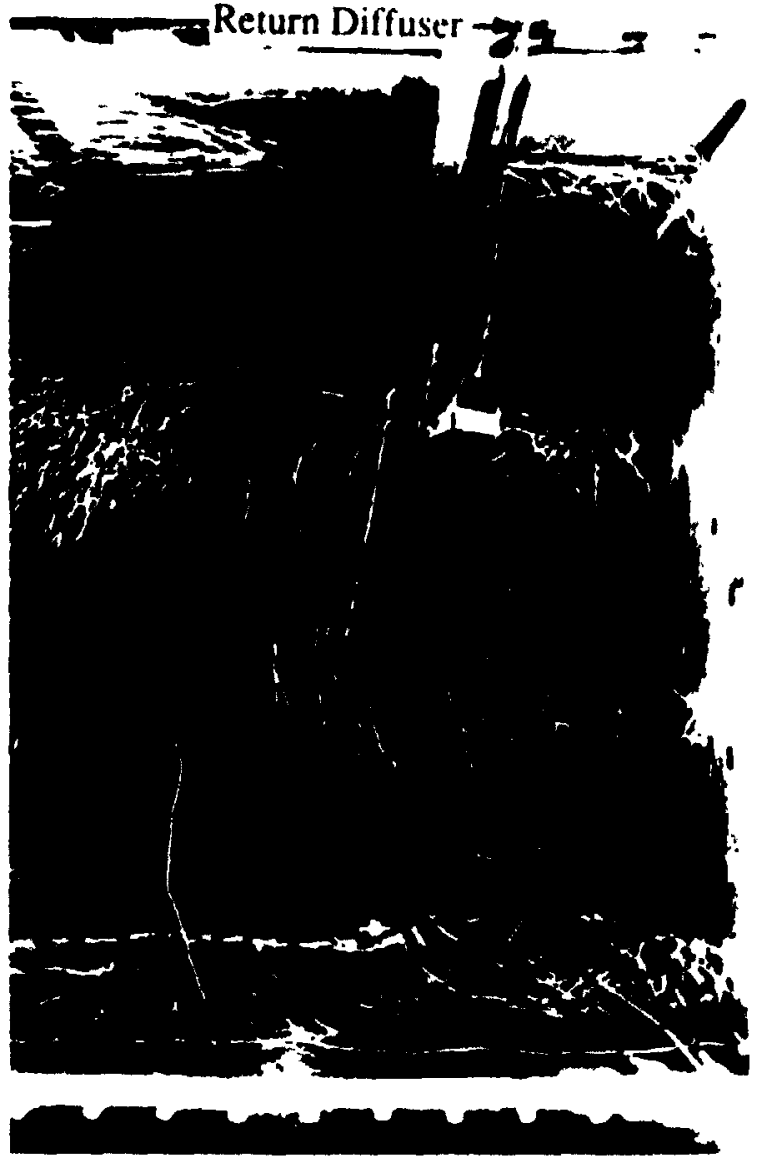

Figure 6.1.a: Flow visualization using bubbles in the mid-plane of the test room, Toll. 

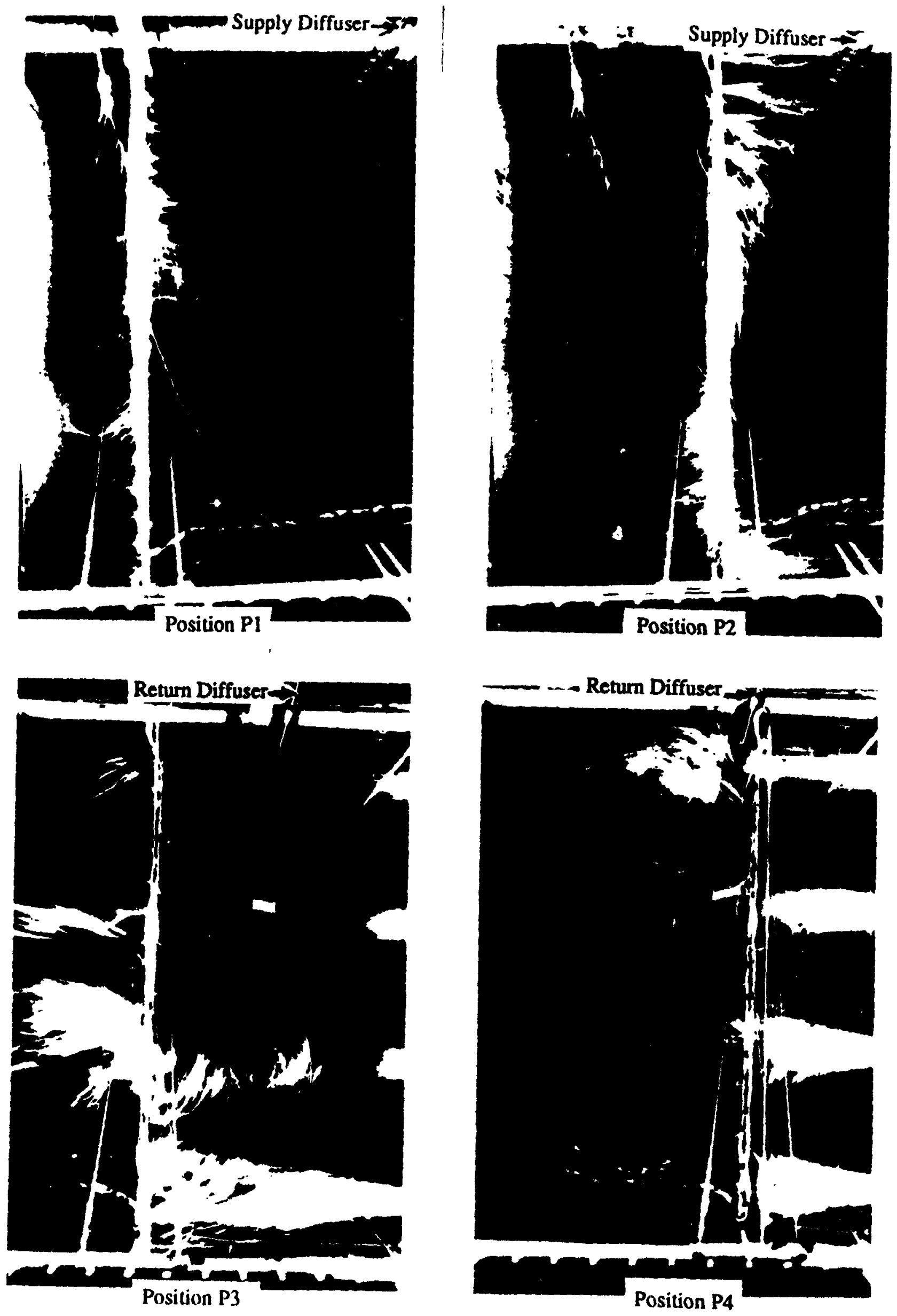

Figure 6.1.b: Flow visualization using smoke in the mid-plane of the test room, T01. 
Frame A

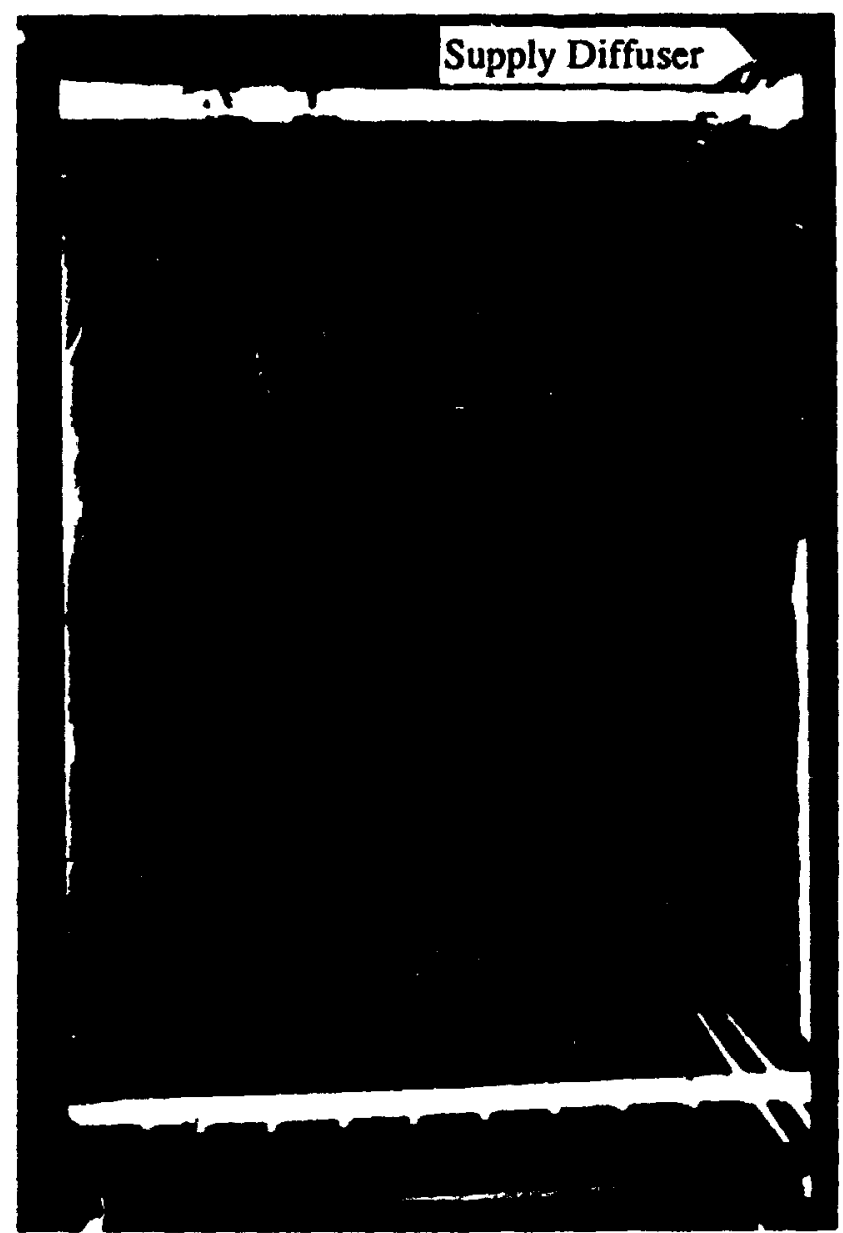

Fiallite 13

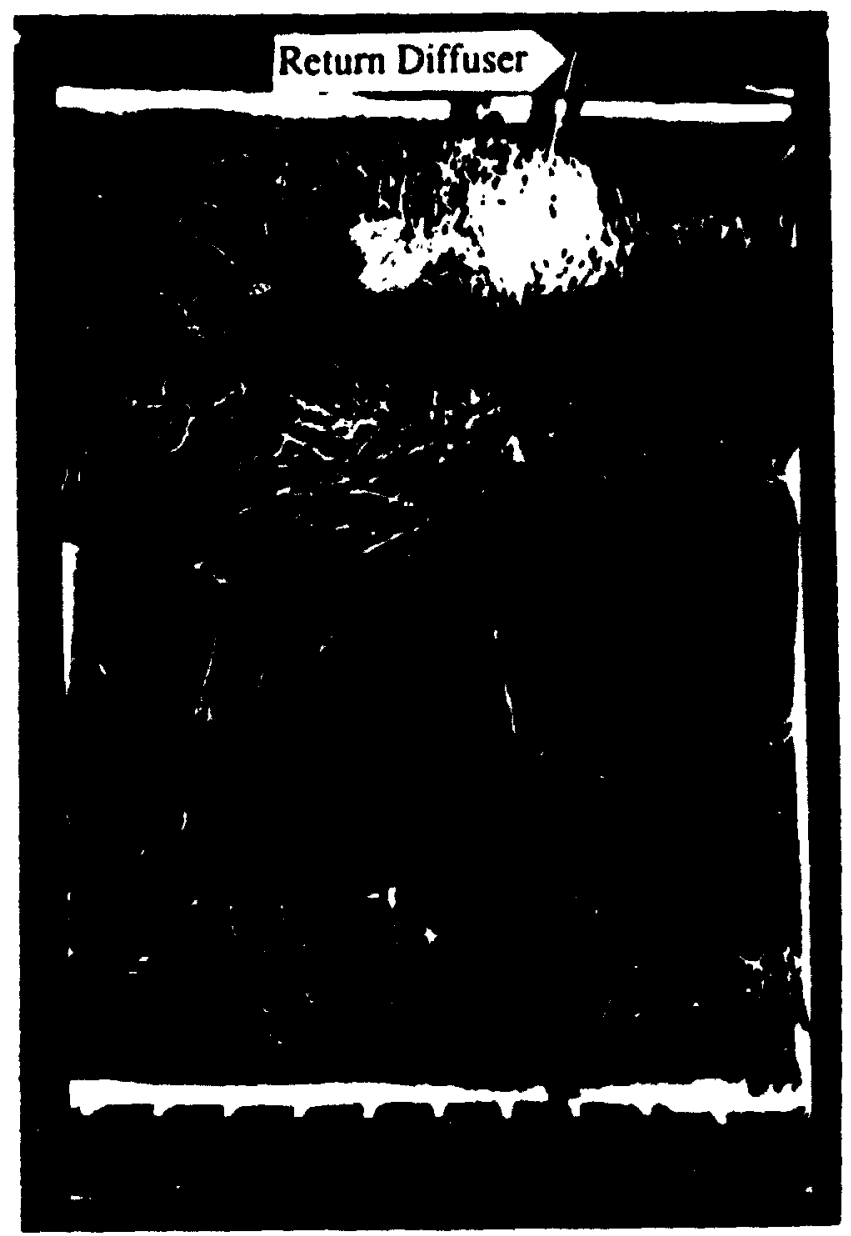

Figure 6.1.c: Flow visualization using bubbles in the mid-planc of the test room, T0.5, partition height $=5.5 \mathrm{ft}$, gapl $=6.0$ inches, partition localed in lloc center of the room. 
Iramle: $A$

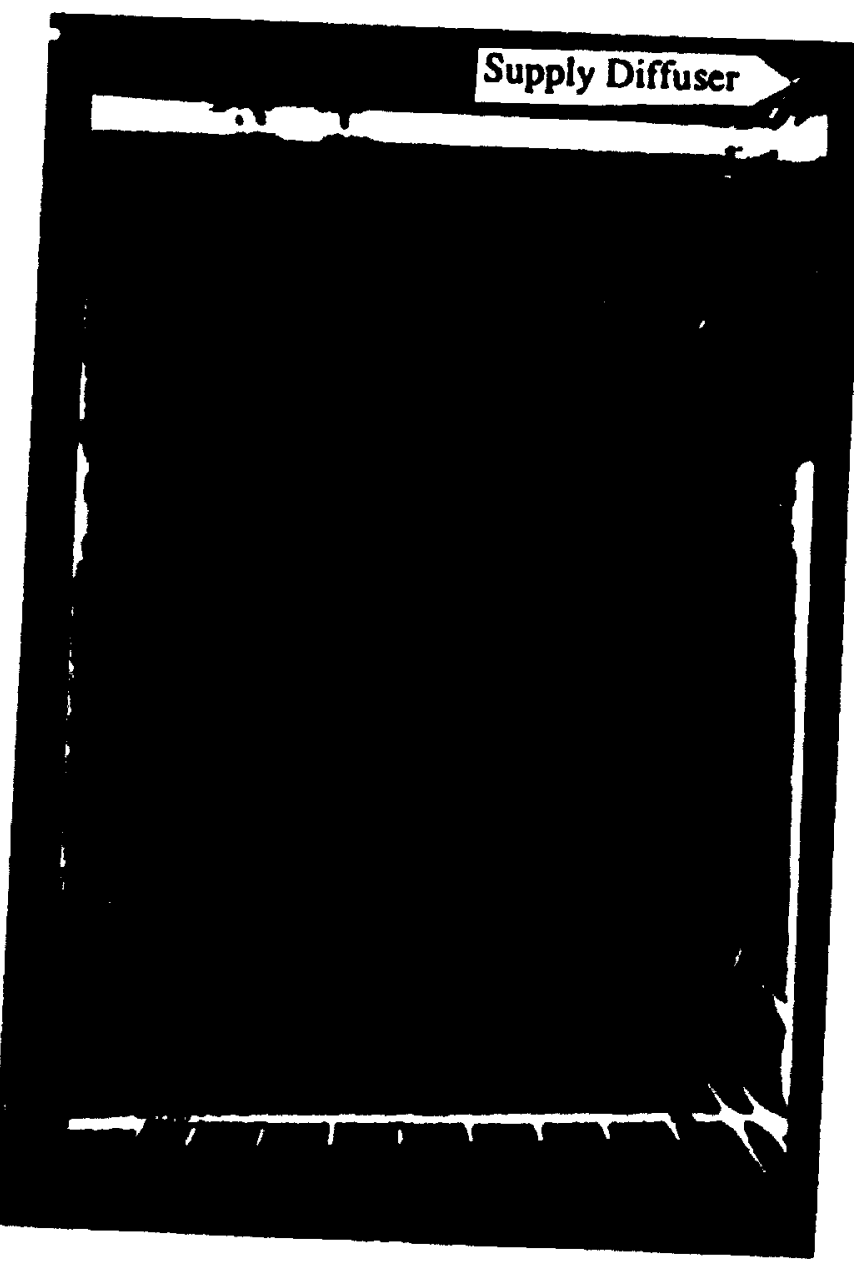
lägure 6.l.d: Flow visualization using bubbles in the mid-plane of the test room, Tu4,
partition height $=0.5 \mathrm{ht}$. gap $=0.0$ inclues, partition locate', in the center
of the ronm.
Frame B

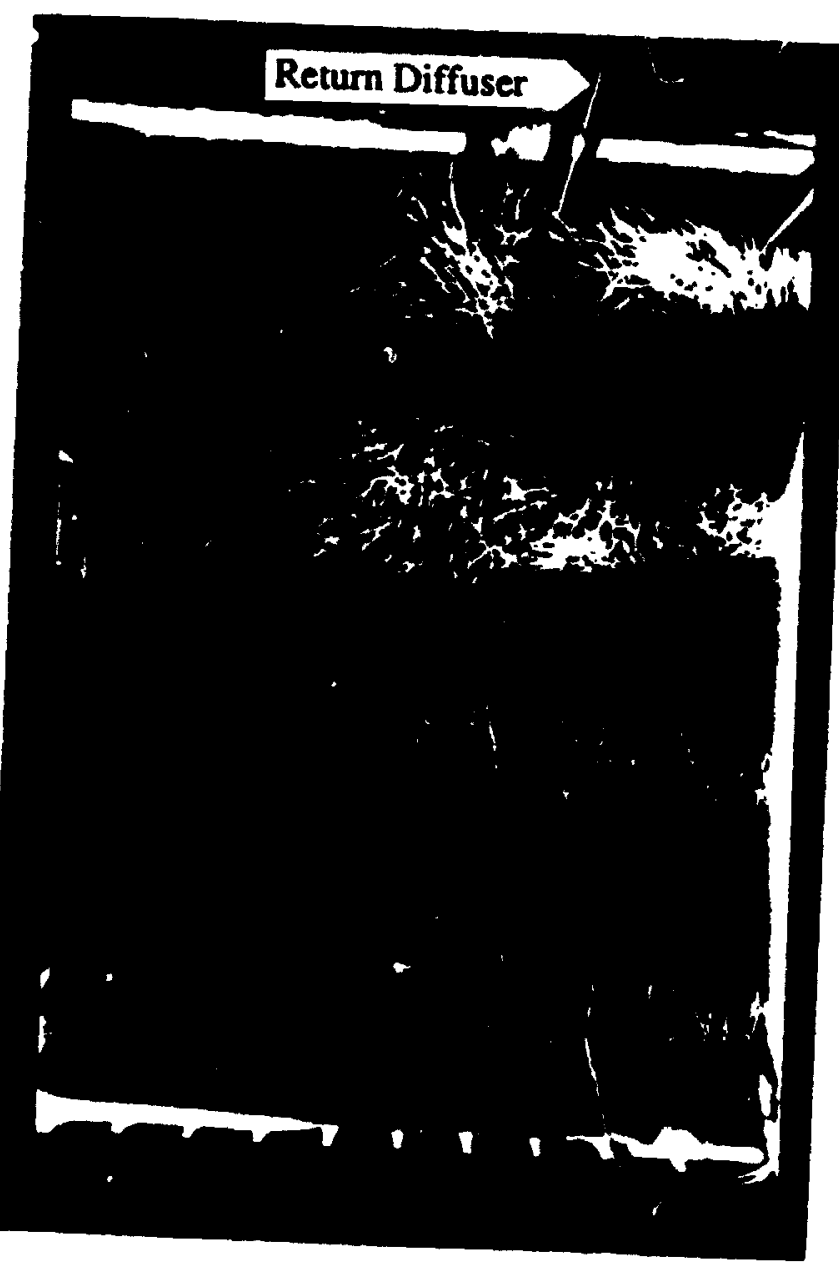




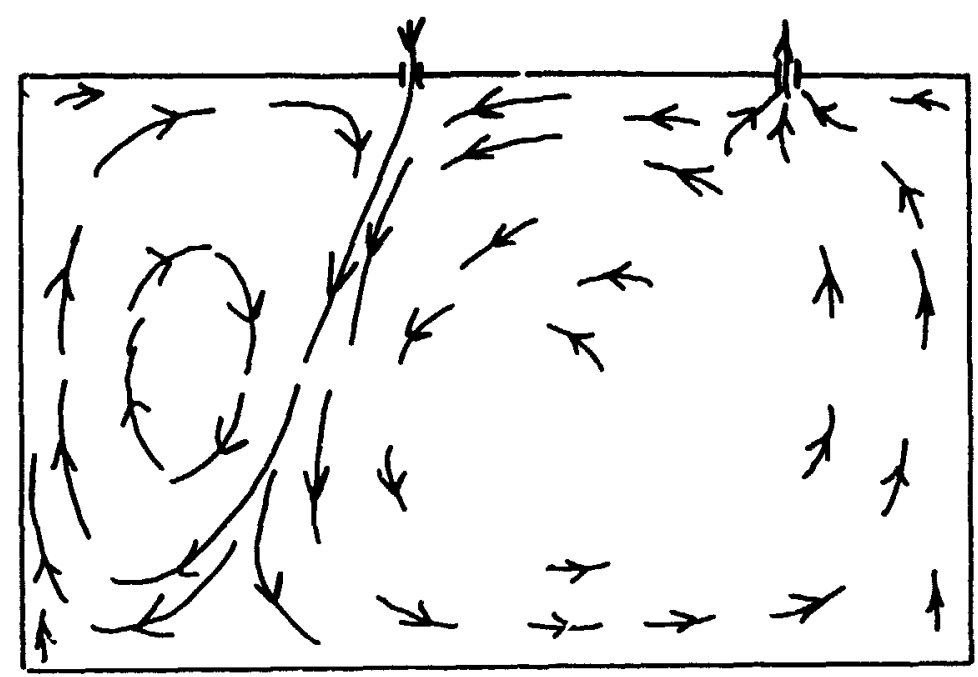

test T01

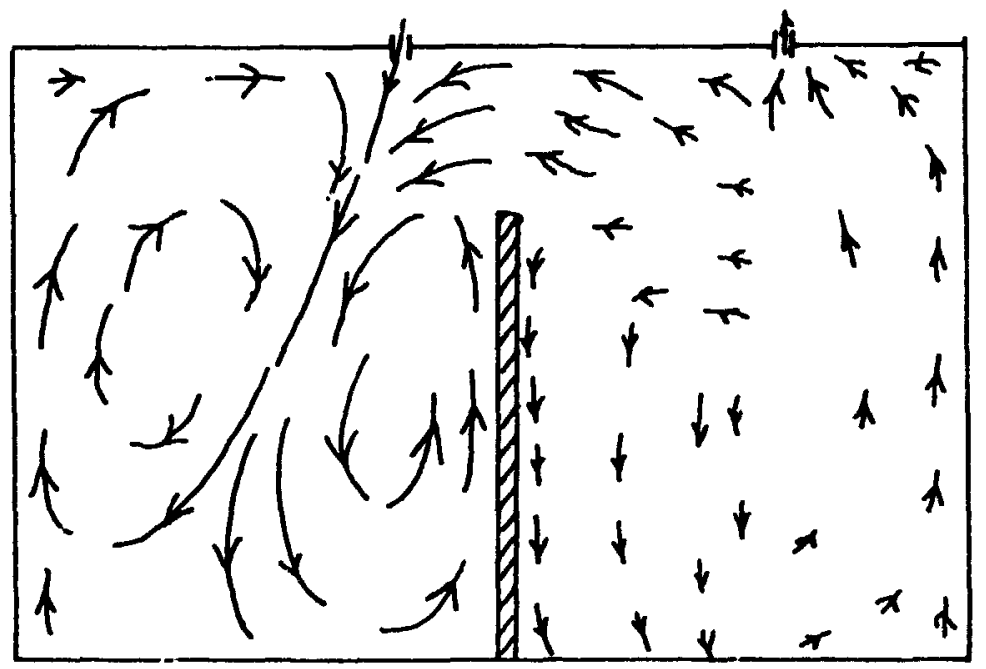

test T04

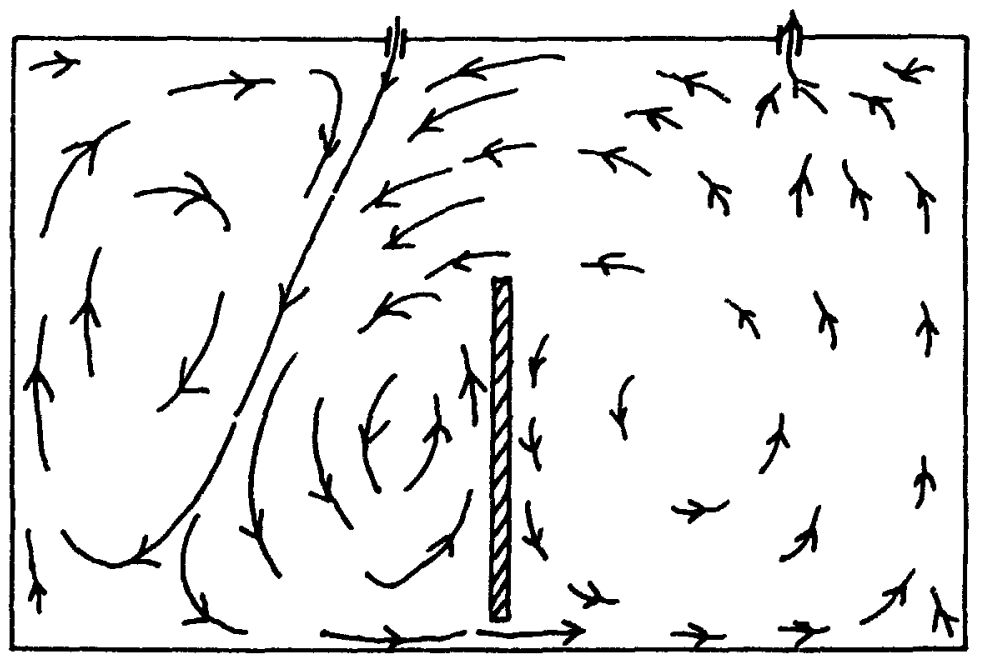

test T05

Figure 6.1.e: Qualitative sketches of observations of the air flow pattern in the mid-plane of the test room, for test T01, lest T04, and test T05 


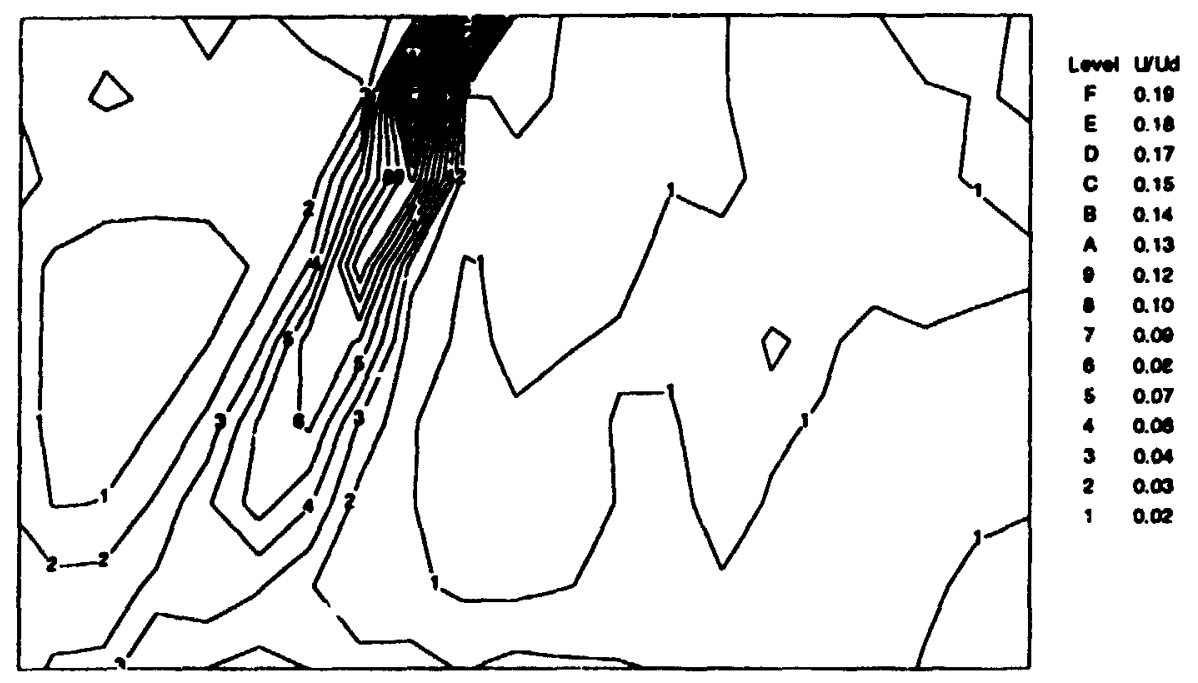

a) Tost T01, Ud $=4.302 \mathrm{~m} / \mathrm{s}, \quad \xi=1.082$

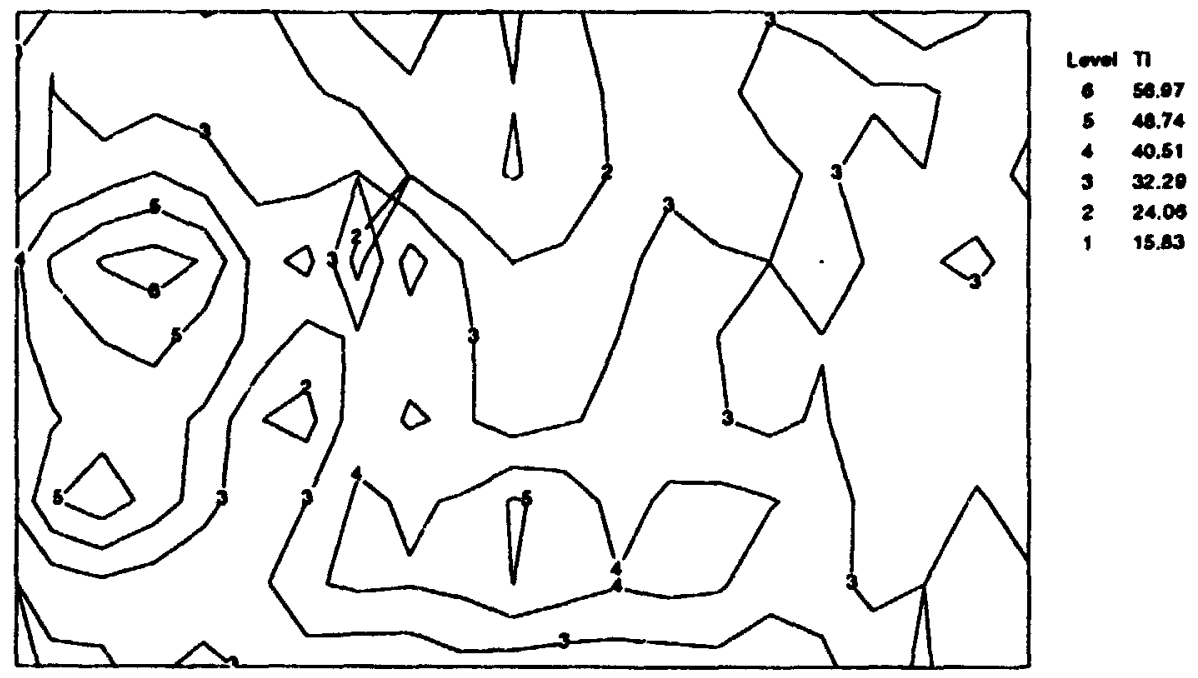

b) Test T01, $\xi=1.082$

Figure 6.2: Spatial distribution of a) the velocity, and $b$ ) the turbulence intensity in the mid plane of the test room, for test $\mathrm{T} 01$. 


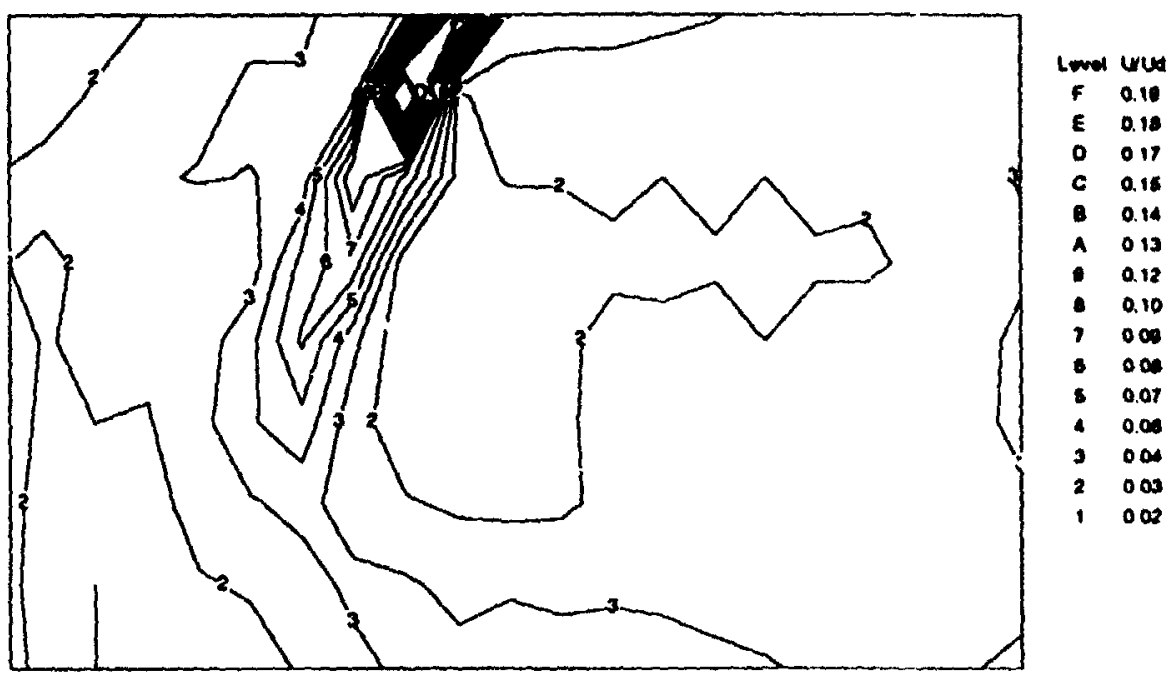

a) Test T02, ud $=2.291 \mathrm{~m} / \mathrm{s}, \quad \xi=1.082$

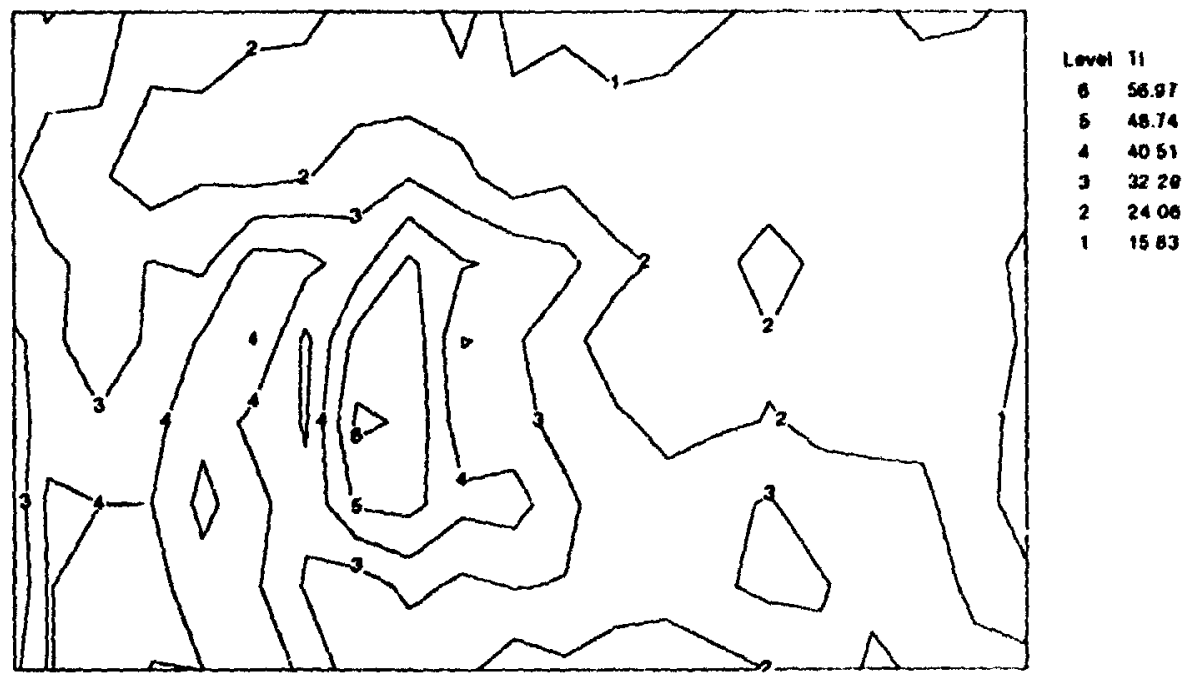

b) Test T02, $\xi=1.082$

Figure 6.3: Spatial distribution of a) the velocity, and b) the turbulence intensity in the mid plane of the test room, for test T02. 


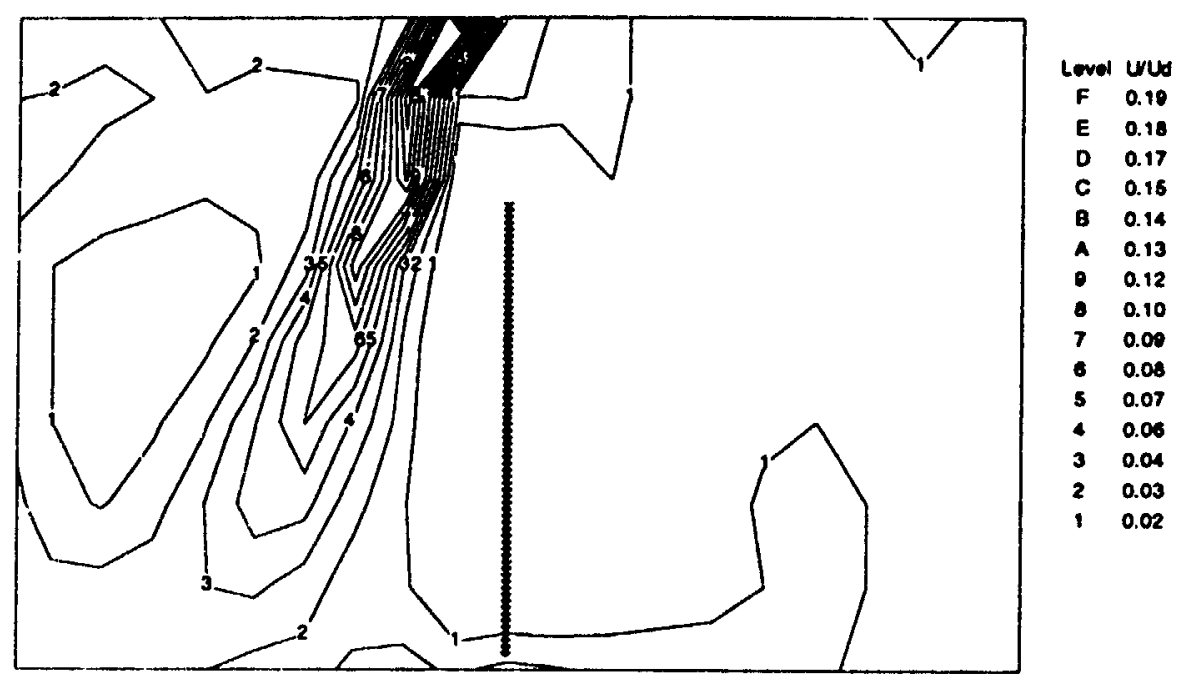

a) Test T03, Ud $=4.302 \mathrm{~m} / \mathrm{s}, \quad \xi=1.087$

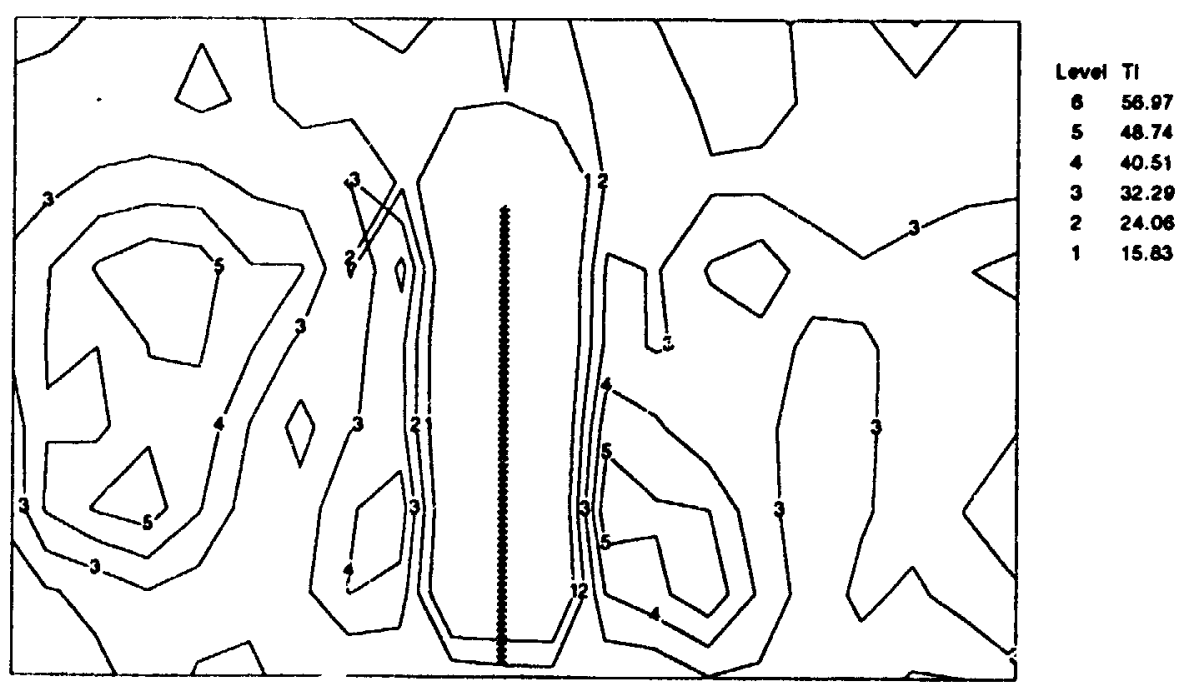

b) Test T03, $\xi=1.087$

Figure 6.4: Spatial distribution of a) the velocity, and b) the turbulence intensity in the mid plar.e of the test room, for test T03. 


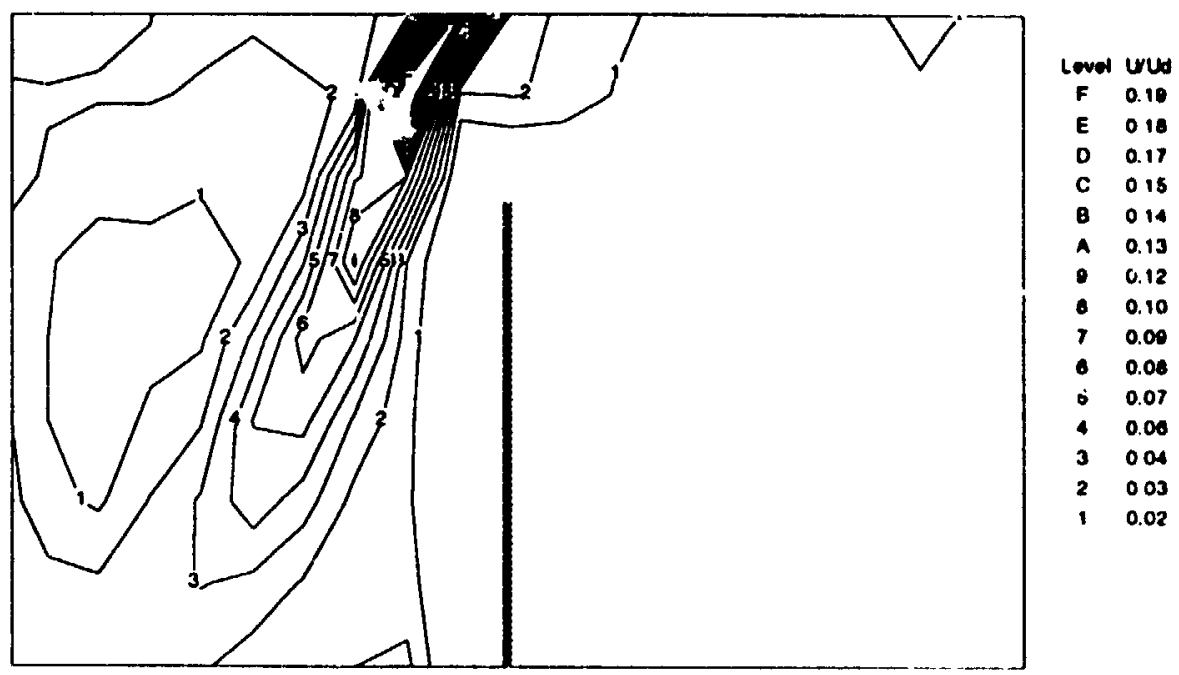

a) Test T04, Ud $=4.302 \mathrm{~m} / \mathrm{s}, \quad \xi=1.086$

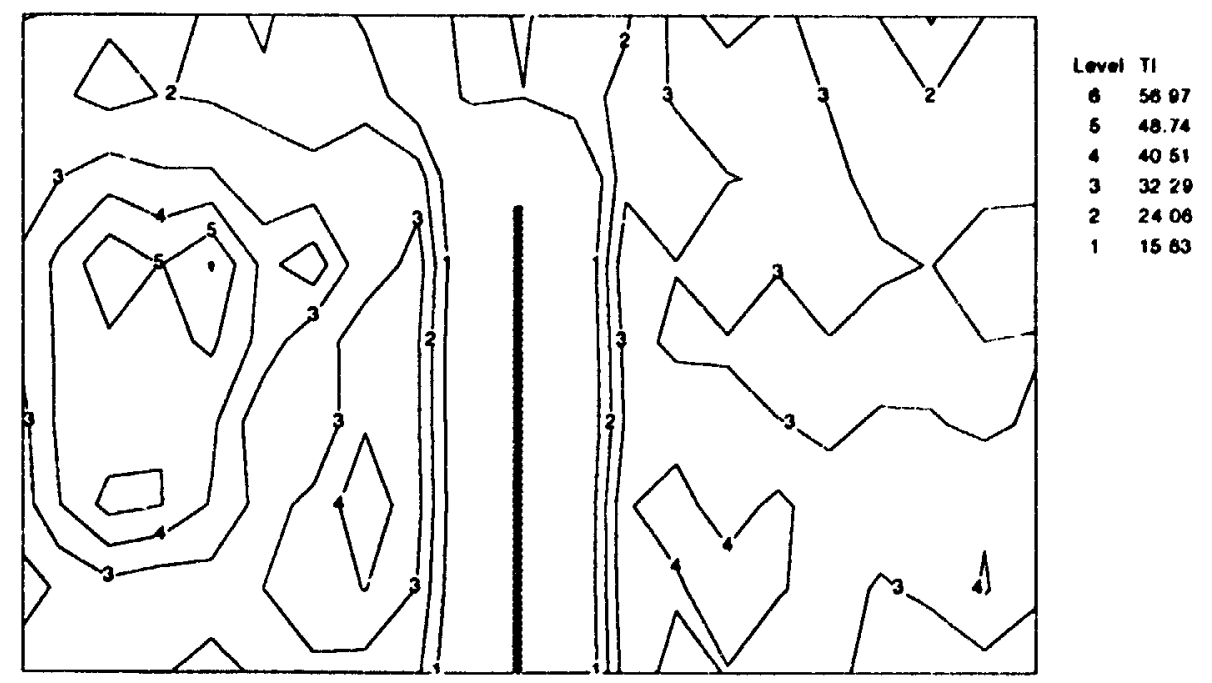

b) Test T04, $\xi=1.086$

Figure 6.5: Spatial distribution of a) the velocity, and b) the turbulence intensity in the mid plane of the test room, for test T04. 


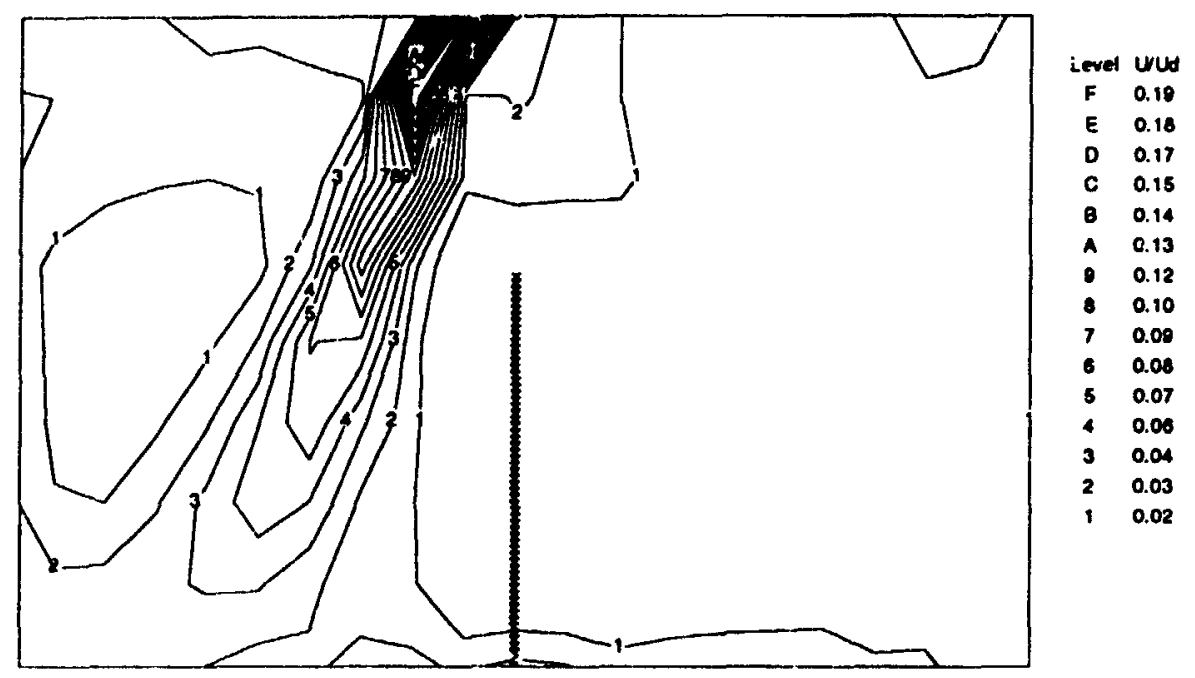

a) Test T05, Ud $=4.302 \mathrm{~m} / \mathrm{s}, \quad \xi=1.049$

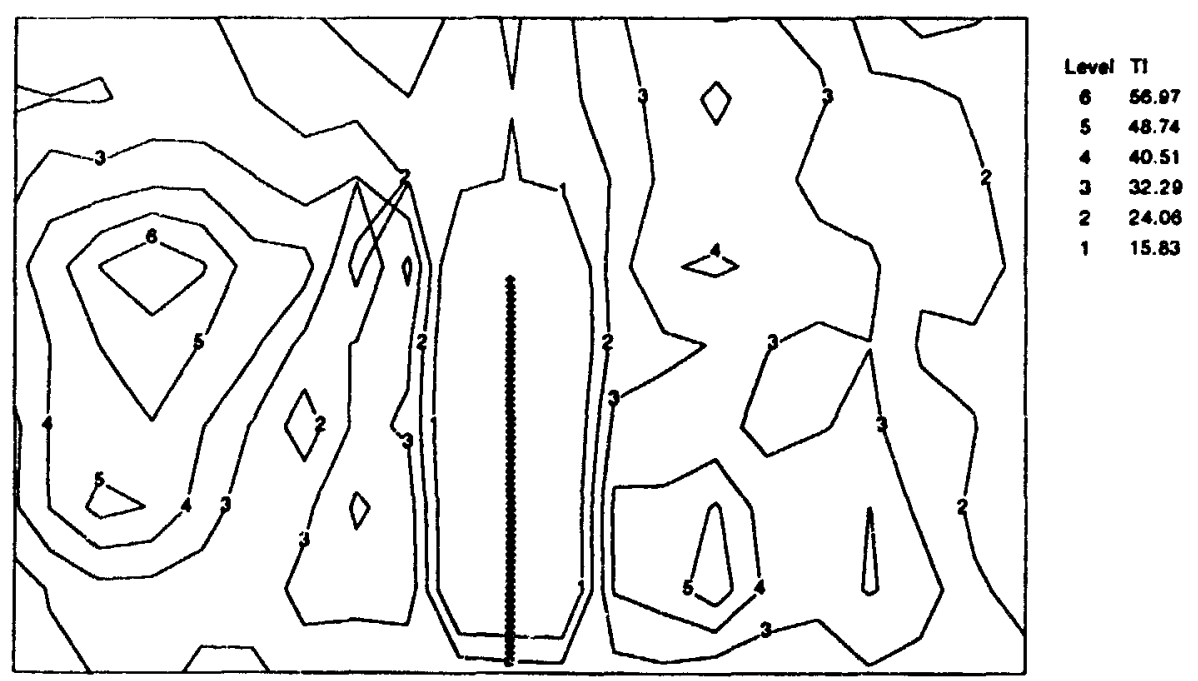

b) Test T05, $\xi=1.049$

Figure 6.6: Spatial uistribution of a) the velocity, and b) the turbulence intensity in the mid plane of the test room, for test T05. 


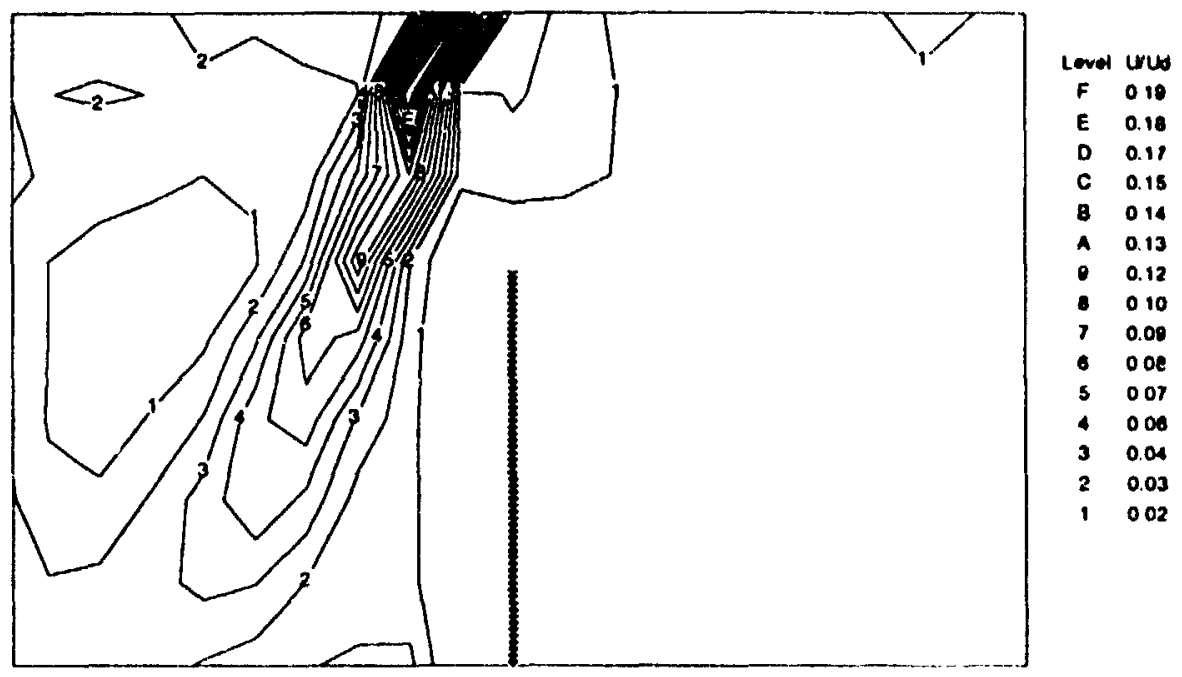

a) Test T06, Ud $=4.302 \mathrm{~m} / \mathrm{s}, \quad \xi=1.078$

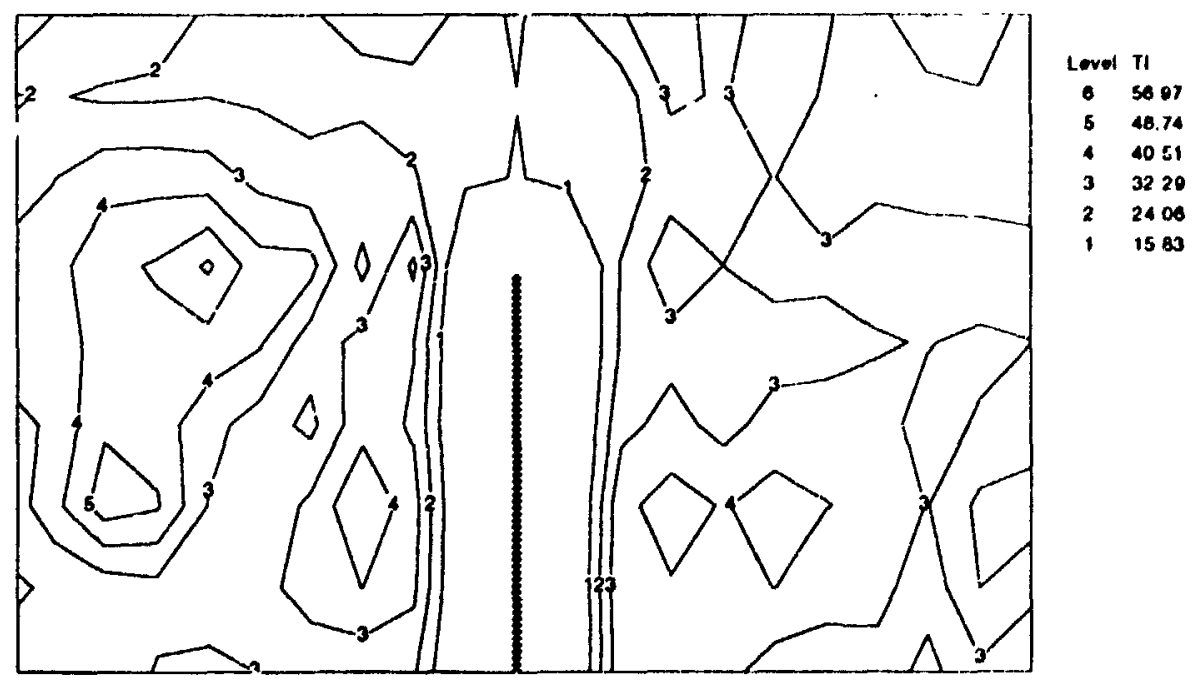

b) Test T06, $\xi=1.078$

Figure 6.7: Spatial distribution of a) the velocity, and b) the turbulence intensity in the mid plane of the test room, for test T06. 


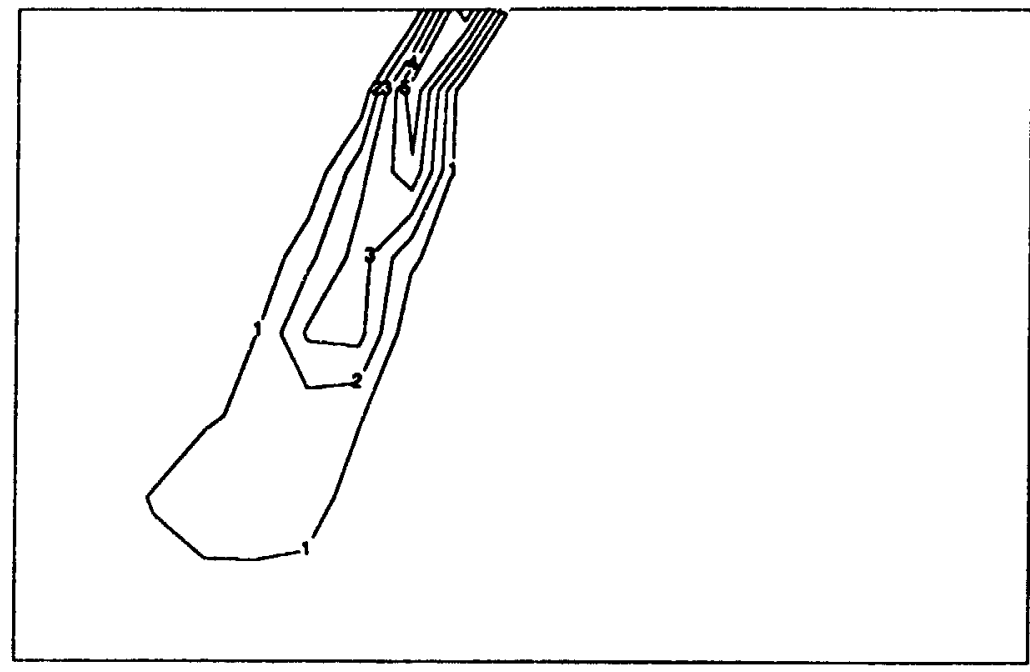

$\begin{array}{cc}\text { Level } & 2 \text { wud } \\ 6 & 1.24 \\ 5 & 1.04 \\ 4 & 0.03 \\ 3 & 0.63 \\ 2 & 0.42 \\ 1 & 0.22\end{array}$

a) Tost T01, $\xi=1.082$
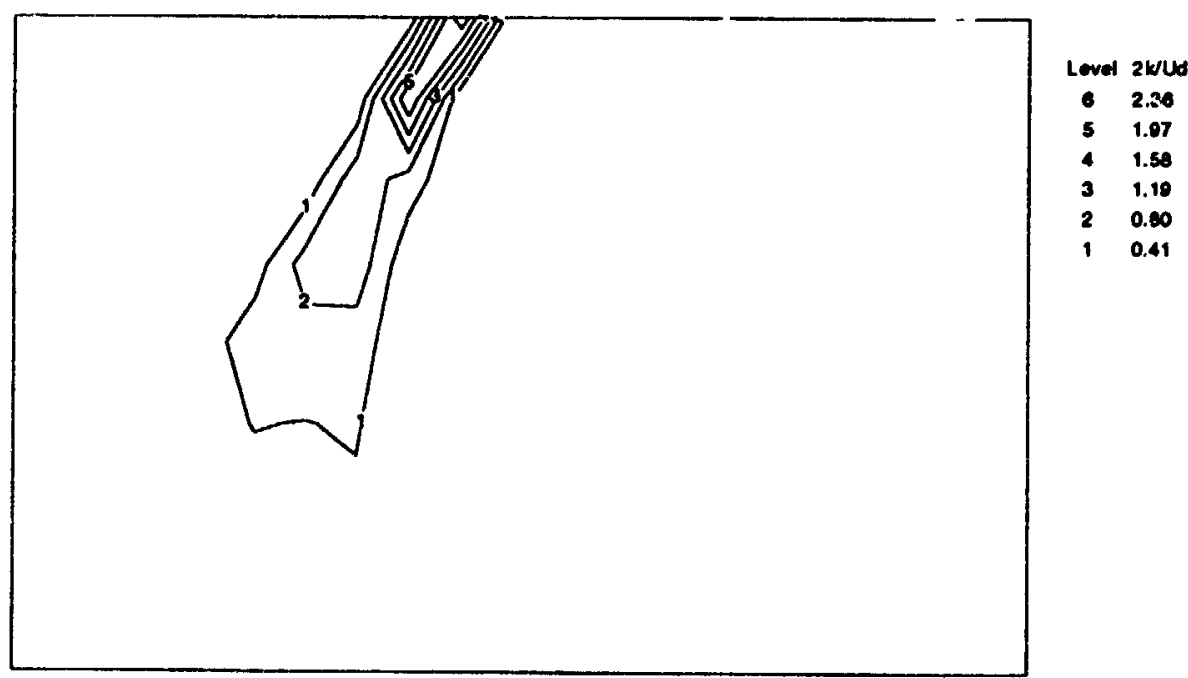

b) Test T02, $\xi=1.082$

Figure 6.8: Spatial distribution of the turbulent kinetic energy in the mid-plane of the test room for the tests a) T01, b) T02, c) T03, d) T04, e) T05, and f) T06. 


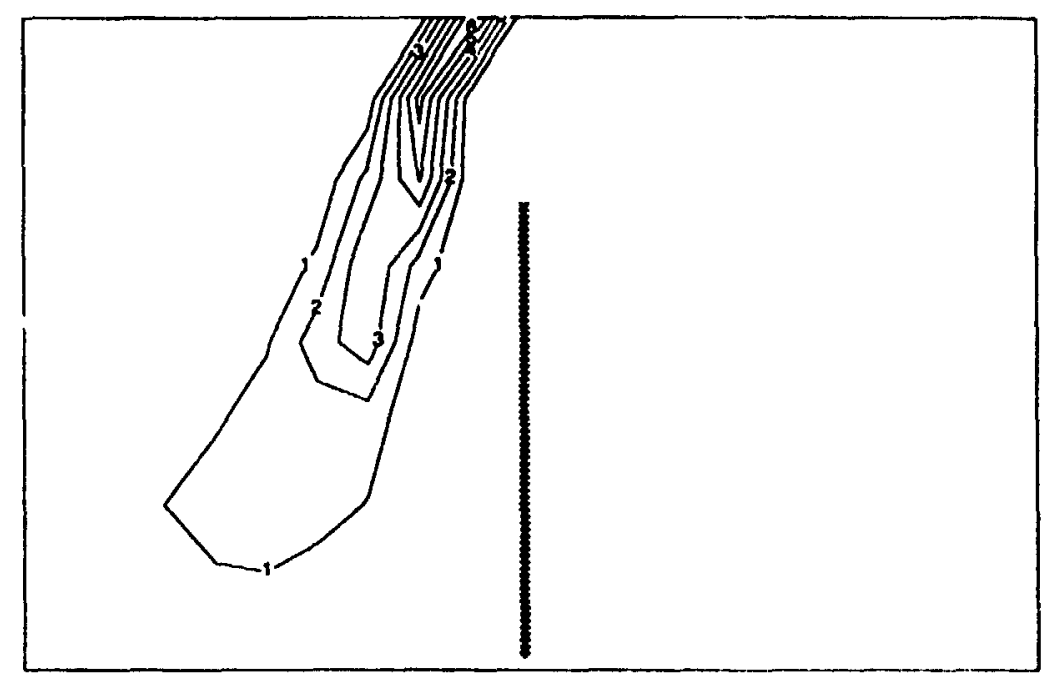

$\begin{array}{cc}\text { Lovel Rtus } \\ 6 & 125 \\ 5 & 1.04 \\ 4 & 0.03 \\ 3 & 063 \\ 2 & 0.42 \\ 1 & 021\end{array}$

c) Test T03, $\xi=1.087$

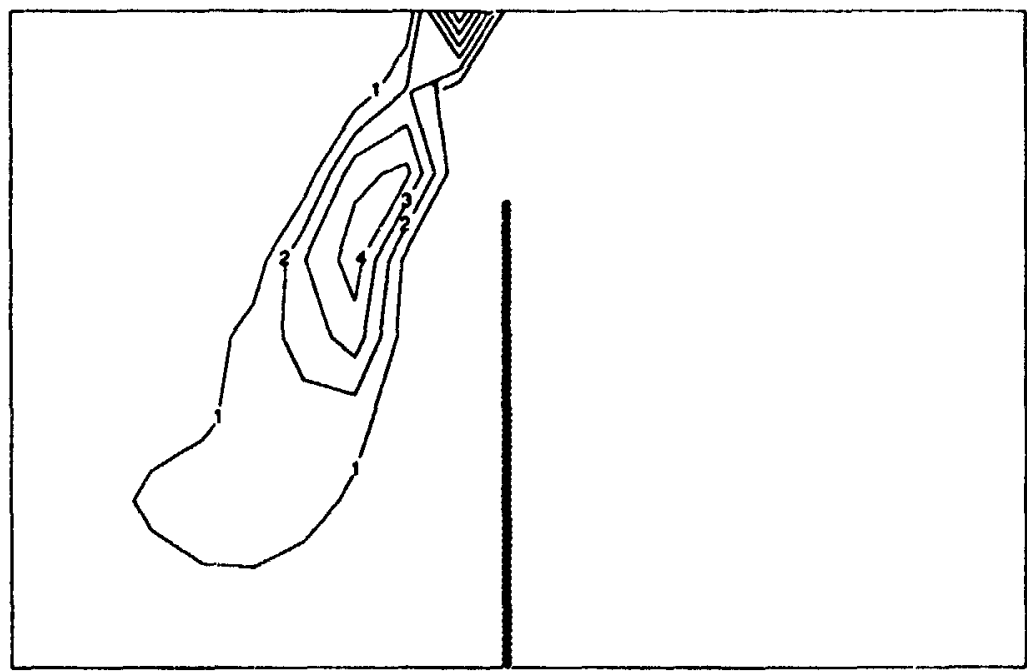

Level 2 wud

- 126

104
$4 \quad 083$

0.3

30.63

$\begin{array}{ll}2 & 0.22 \\ 1 & 0.21\end{array}$

d) Test T04, $\xi=1.086$

Figure 6.8: (cont. ) 


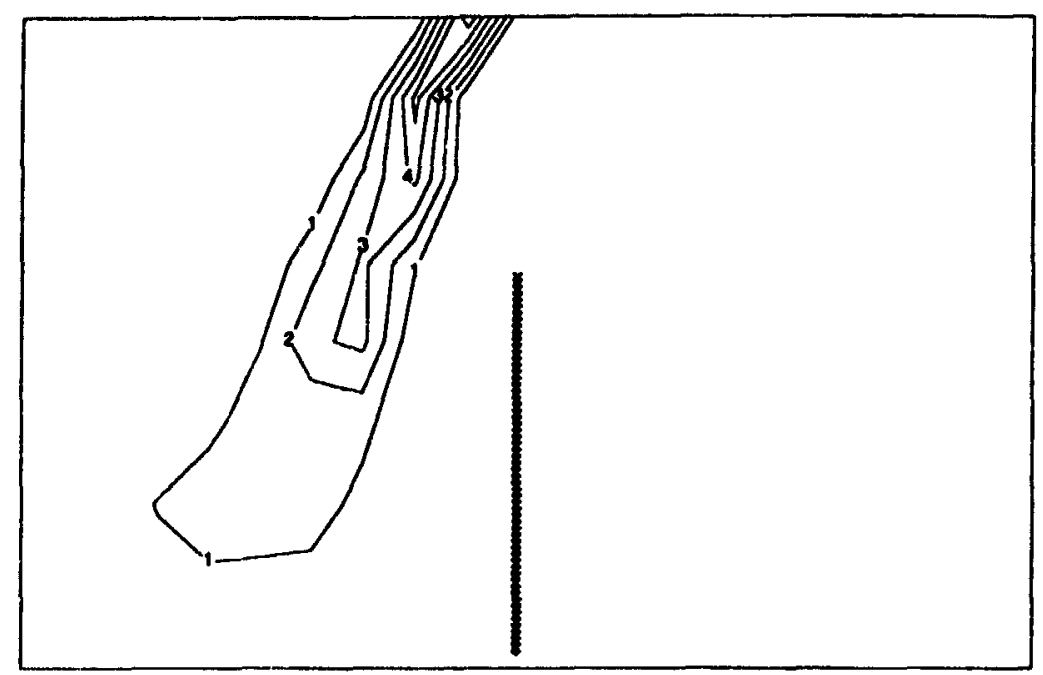

$\begin{array}{cc}\text { Level } & 2 \mathrm{~W} / \mathrm{us} \\ 6 & 1.26 \\ 5 & 1.04 \\ 4 & 0.23 \\ 3 & 0.63 \\ 2 & 0.42 \\ 1 & 0.21\end{array}$

0) Test T05, $\xi=1.049$

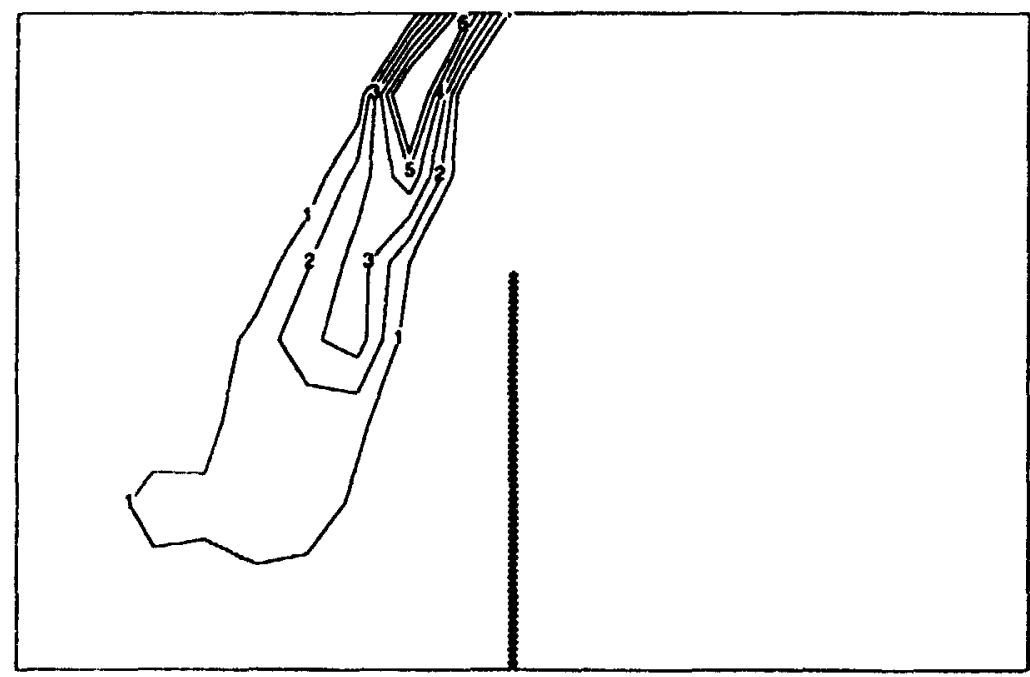

$\begin{array}{cl}\text { Level } & 2 \text { Wus } \\ 6 & 1.25 \\ 5 & 1.04 \\ 4 & 0.83 \\ 3 & 0.63 \\ 2 & 0.42 \\ 1 & 0.21\end{array}$

1) Test T06, $\xi=1.078$

Figure 6.8: (cont) 


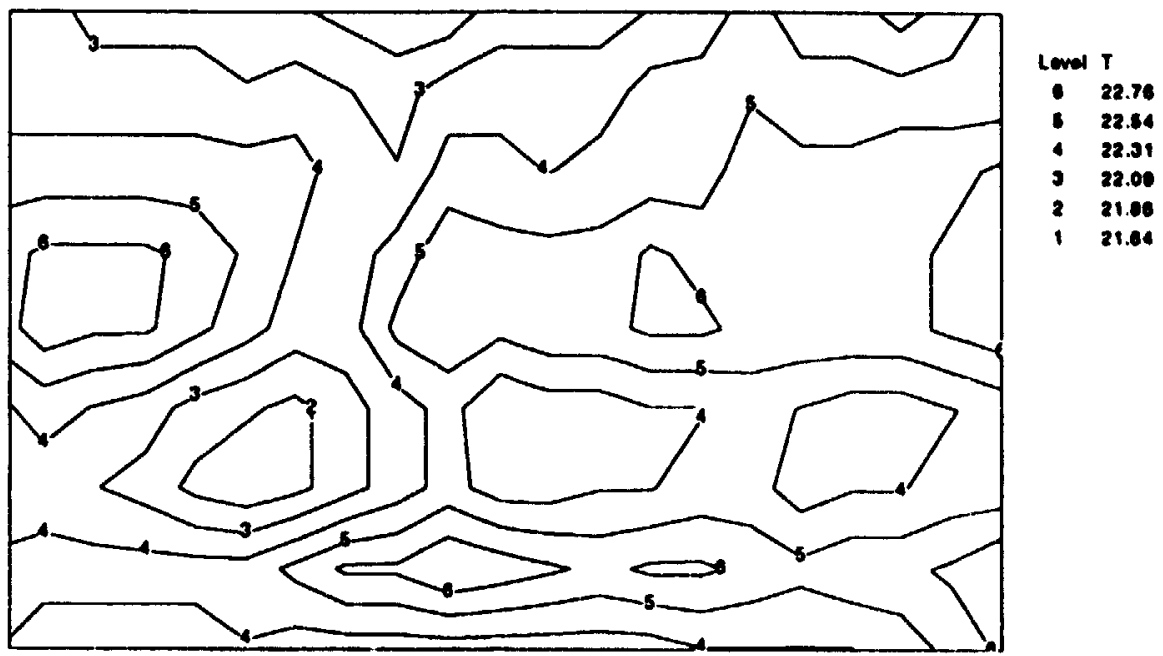

a) Test T01, $\xi=1.082$

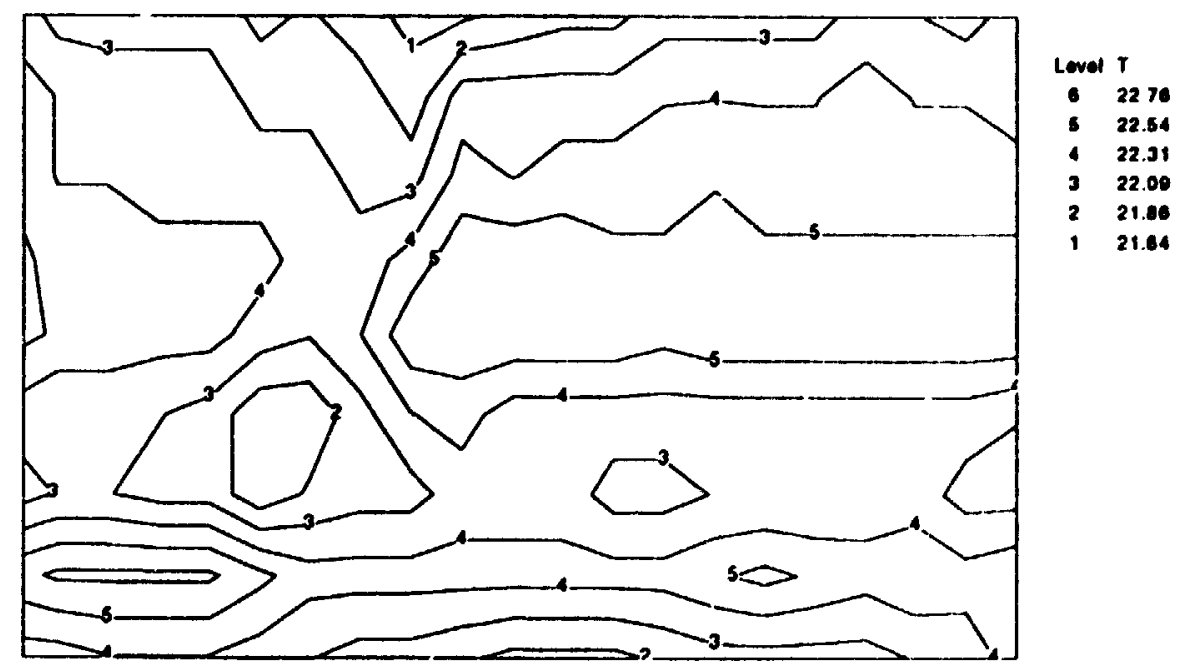

b) Test T02, $\xi=1.082$

Figure 6.9: Spatial distribution of the temperature in the mid-plane of the test room for the tests a) T01, b) T02, c) T03, d) T04, e) T05, and f) T06. 


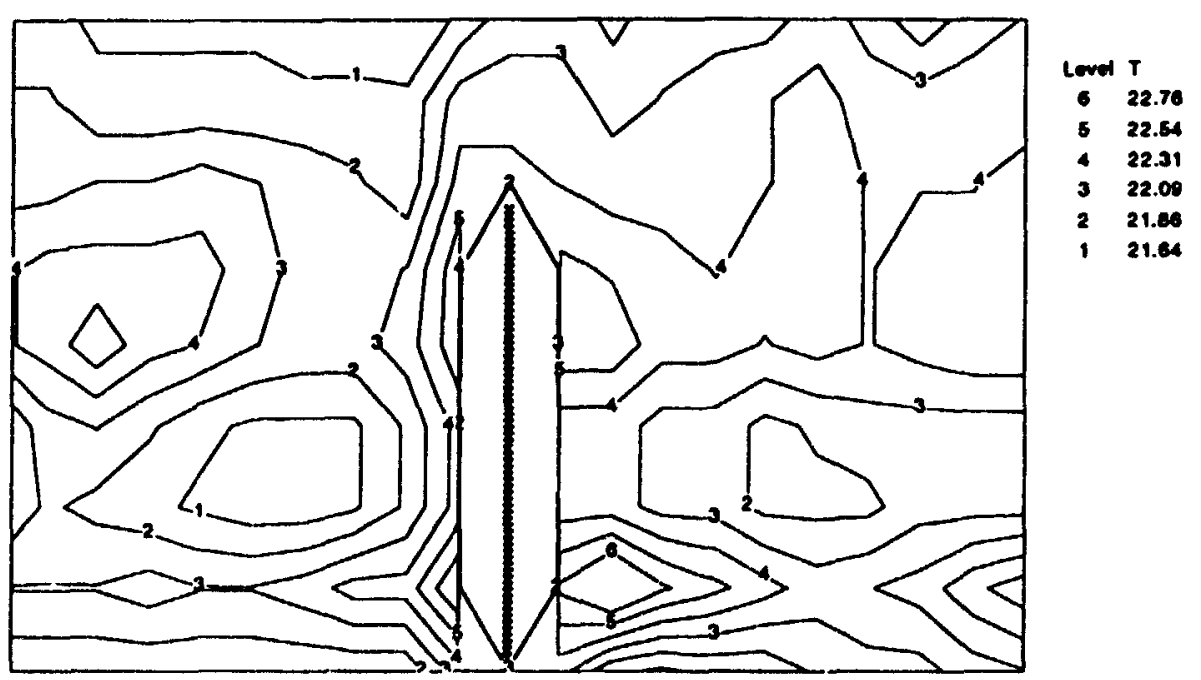

c) Test T03, $\xi=1.087$

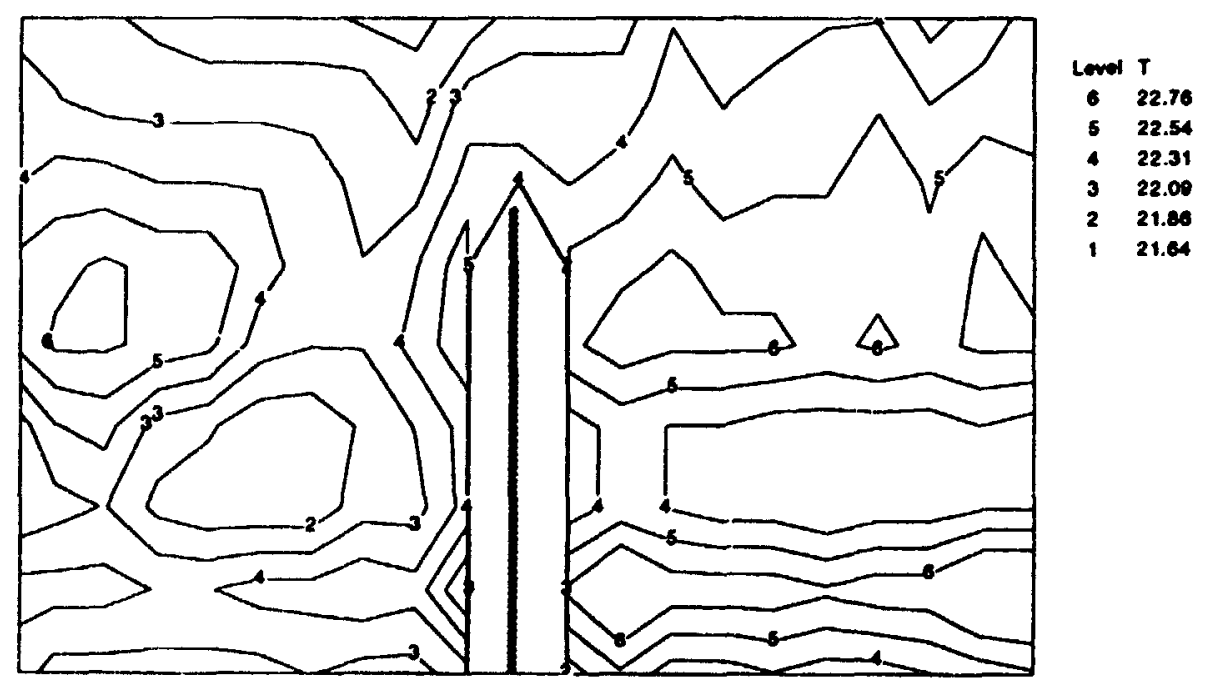

d) Test T04, $\xi=1.086$

Figure 6.9: (cont.) 


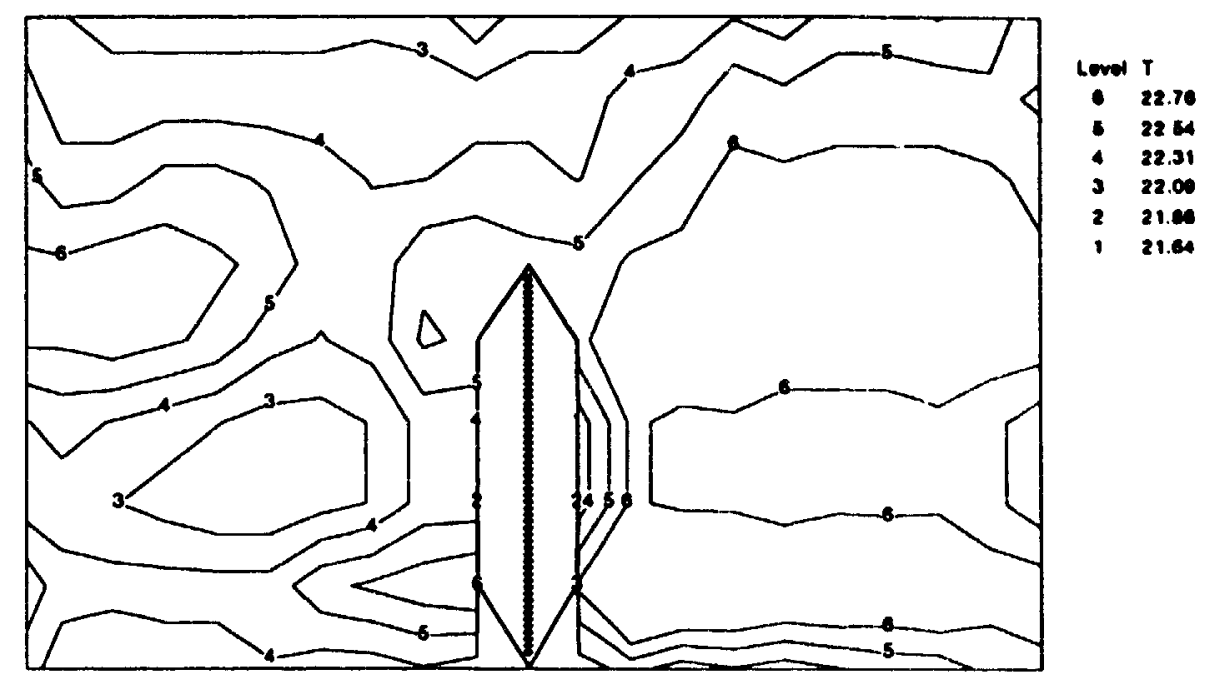

e) Test T05, $\xi=1.049$

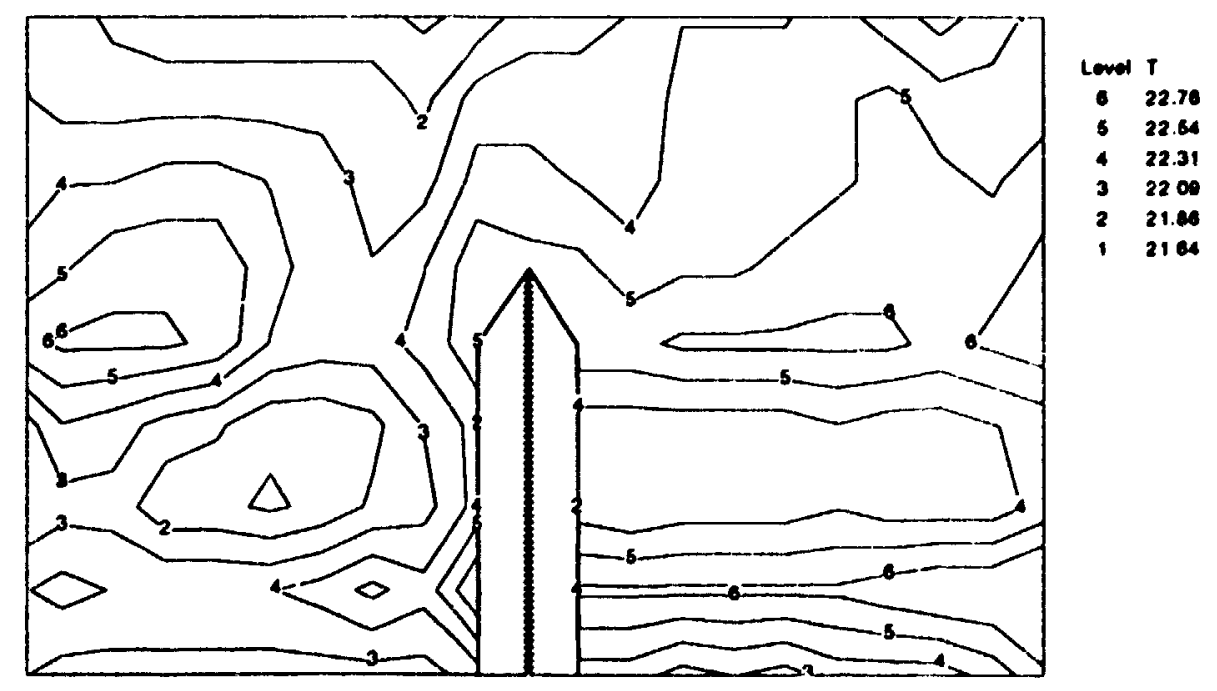

f) Test TO6, $\xi=1.078$

Figure 6.9: (cont.) 


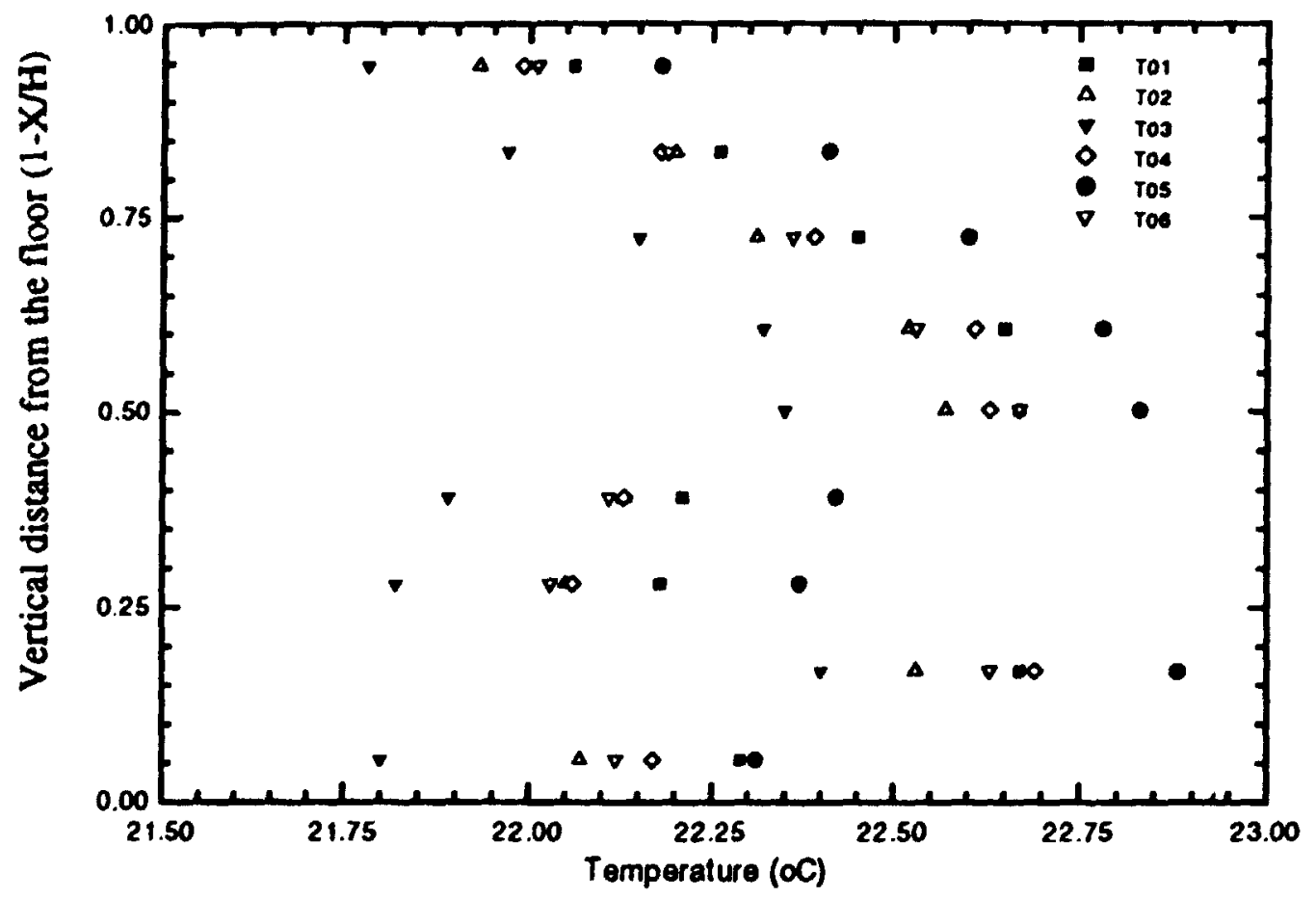

Figure 6.10: Vertical distribution of the average temperature, measured on a horizontal line in the mid-plane of the test room for the tests a) TO1, b) $\mathrm{TO2}$, c) $\mathrm{TO3}, \mathrm{d}) \mathrm{TO4}, \mathrm{e}) \mathrm{TOS}$, and f) $\mathrm{TO6}$. 


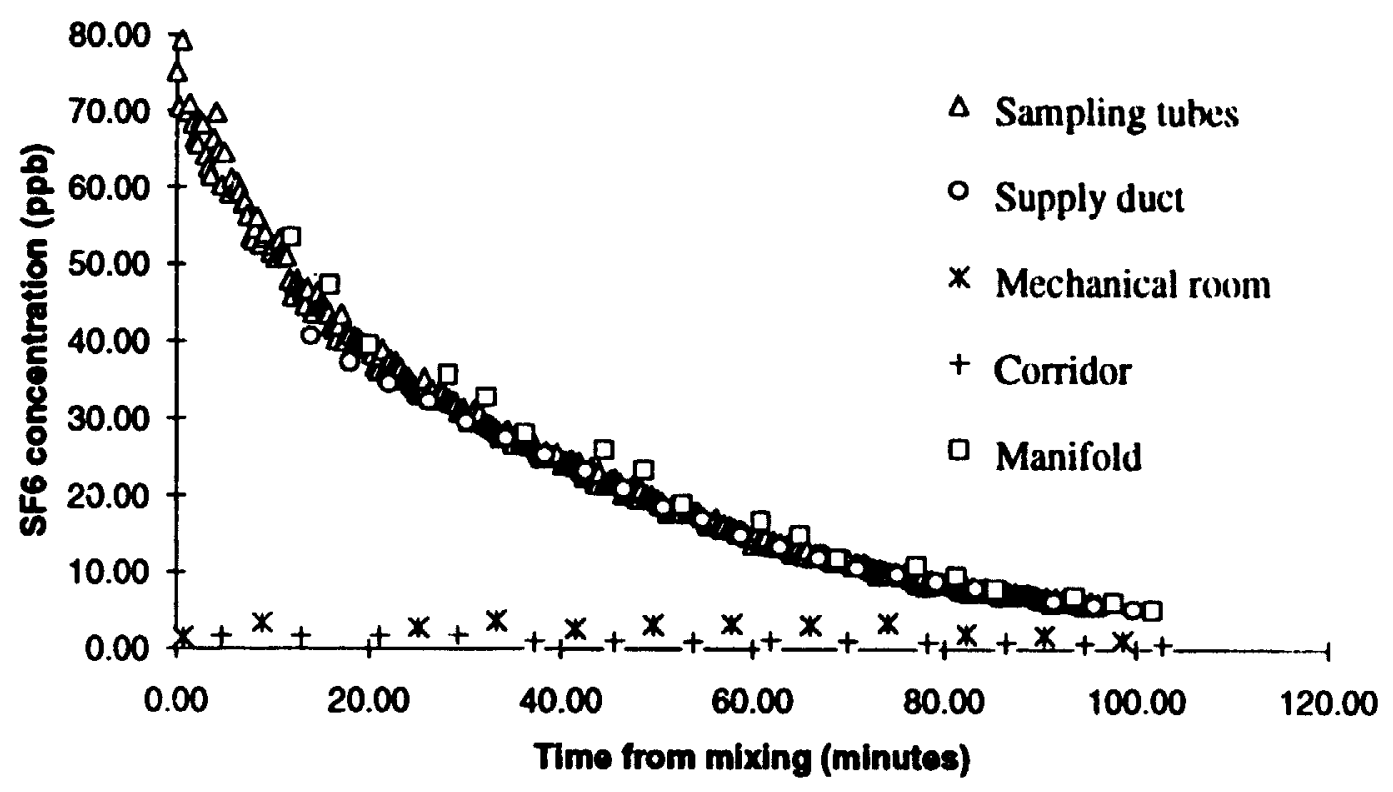

Figure 6.11: Contaminant concentration distribution in the test room for test T01 (3 ACH).

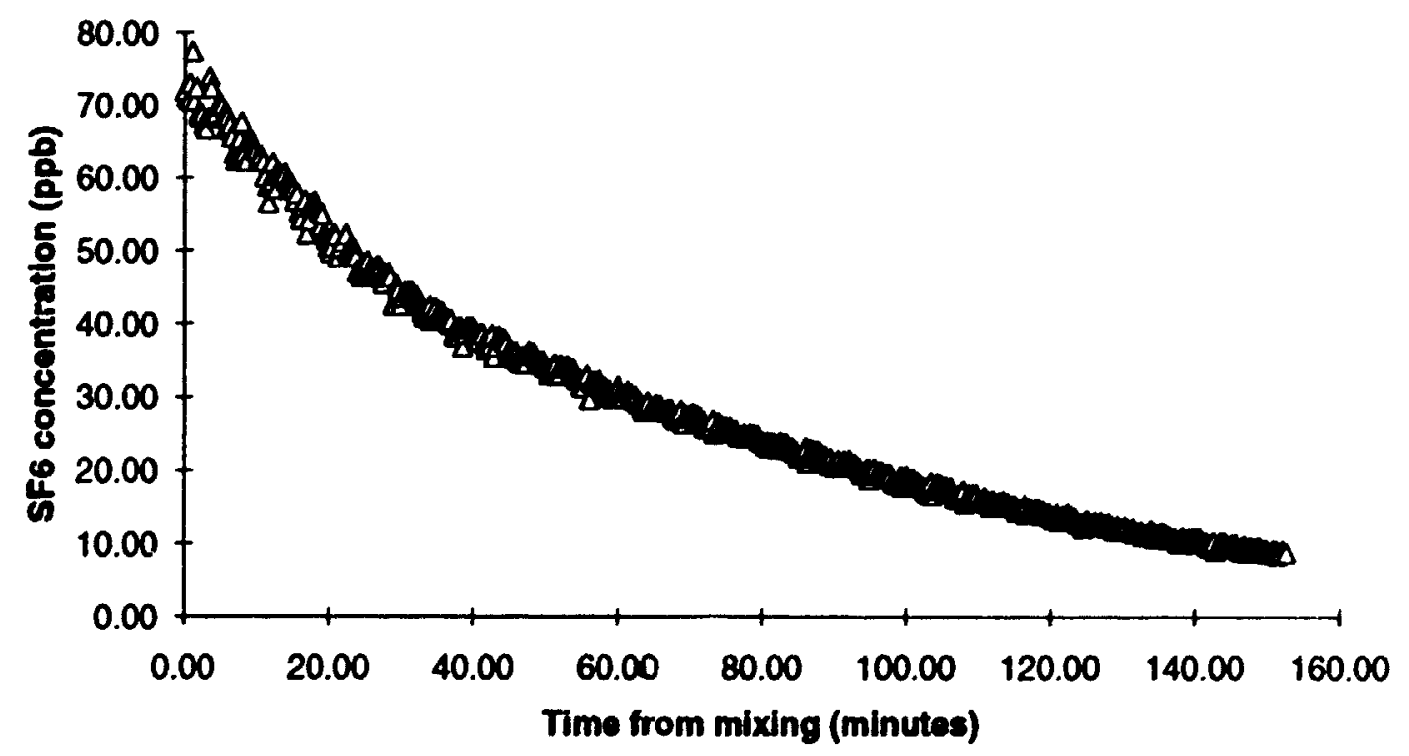

Figure 6.12: Contaminant concentration distribution in the test room for test T02 (1.5 ACH). 


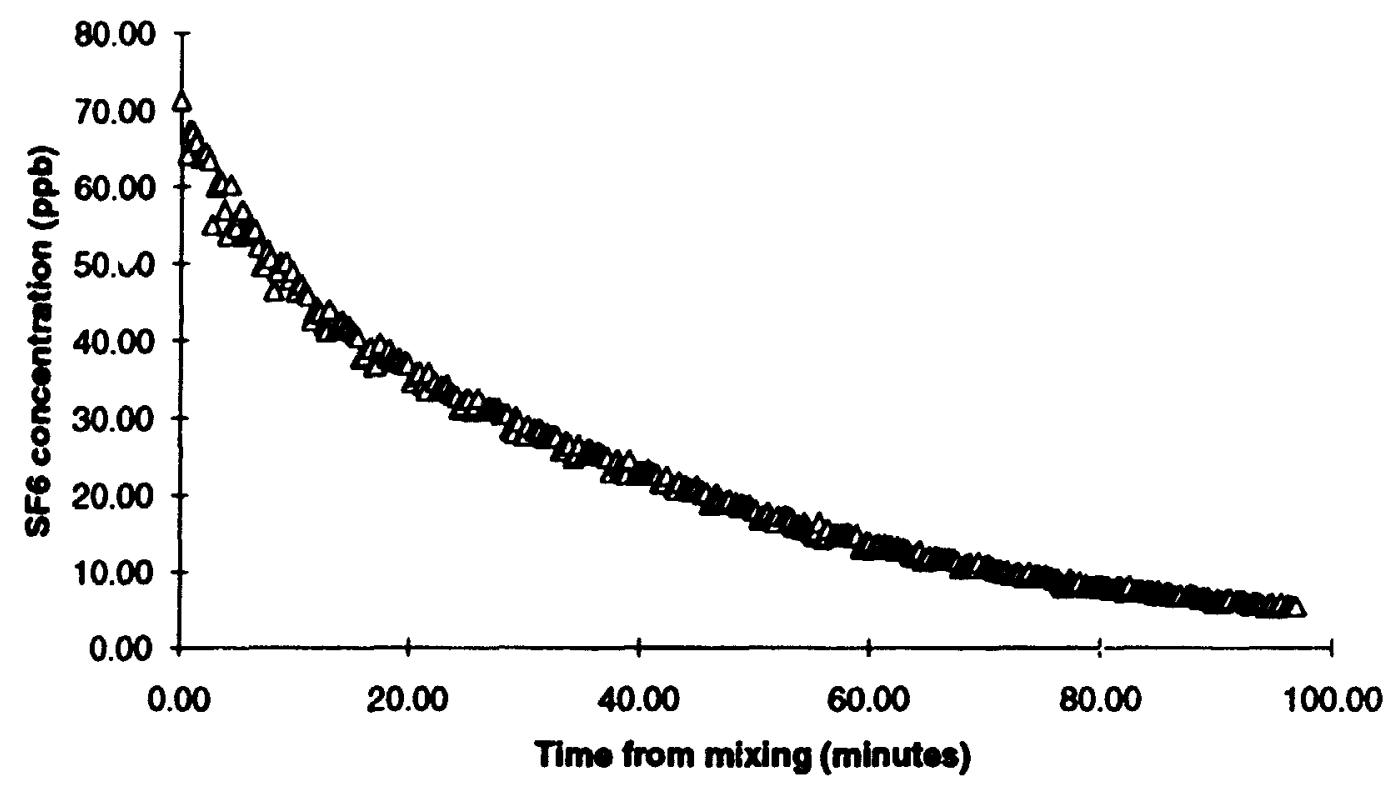

Figure 6.13: Contaminant concentration distribution in the test room for test T03, partition height $=6.5 \mathrm{ft}$, gap $=6.0$ inches, partition located in the center of the room.

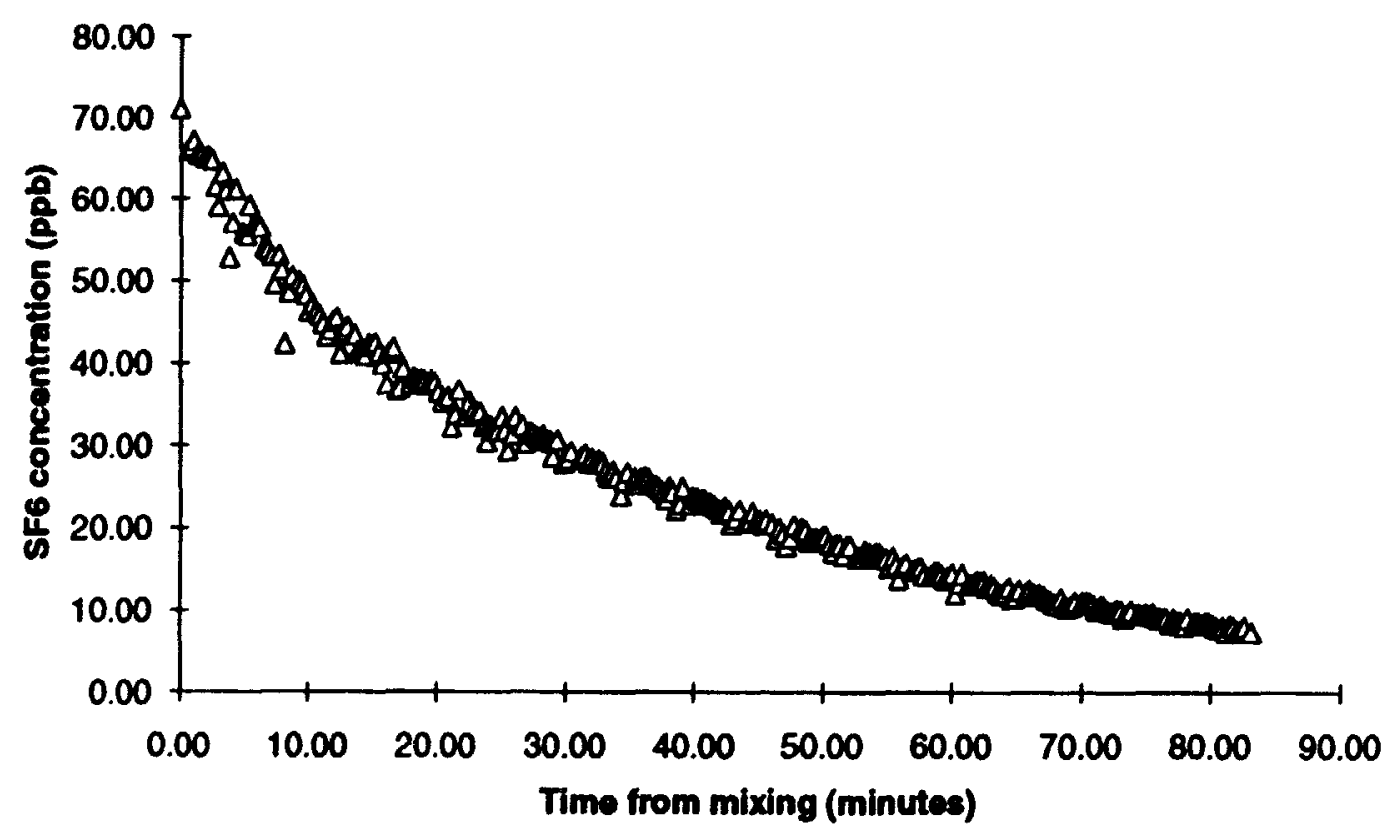

Figure 6.14: Contaminant concentration distribution in the test room for test T04, partition height $=6.5 \mathrm{ft}$, gap $=0.0$ inches, partition located in the center of the room. 


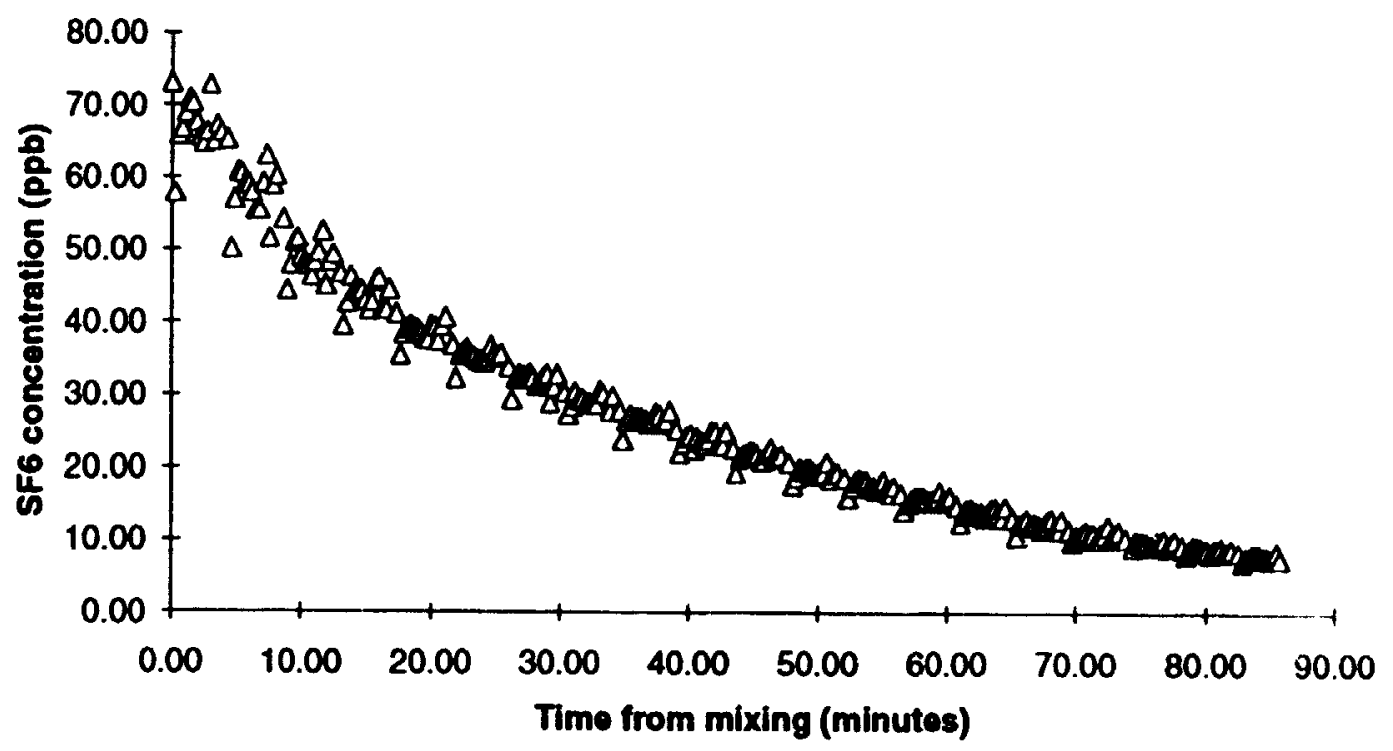

Figure 6.15.a: Contaminant concentration distribution in the test room for test T05, position $\mathrm{Cl}$, partition height $=5.5 \mathrm{ft}$, gap $=6.0$ inct.es, partition located in the center of the room.

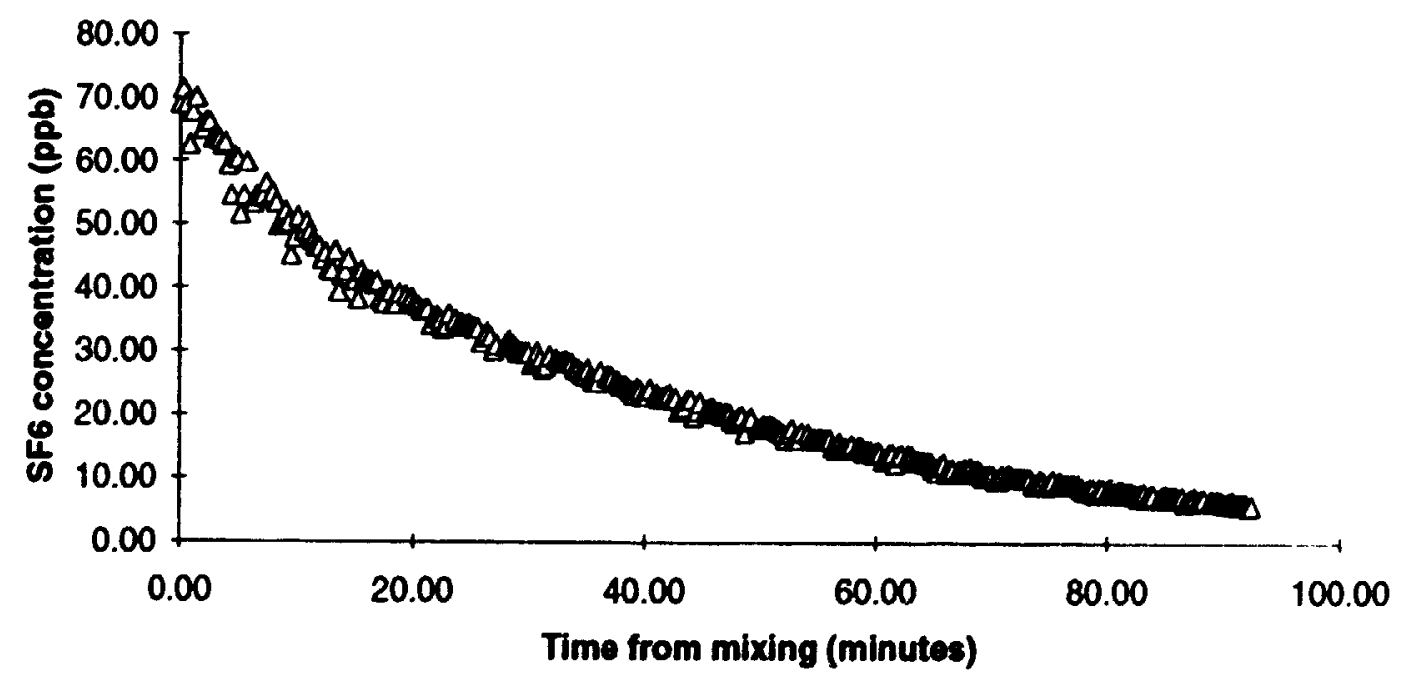

Figure 6.15.b: Contaminant concentration distribution in the test room for test T05, position C2, partition height $=5.5 \mathrm{ft}, \mathrm{g}: \mathrm{p}=6.0$ inches, partition located in the certer of the room. 


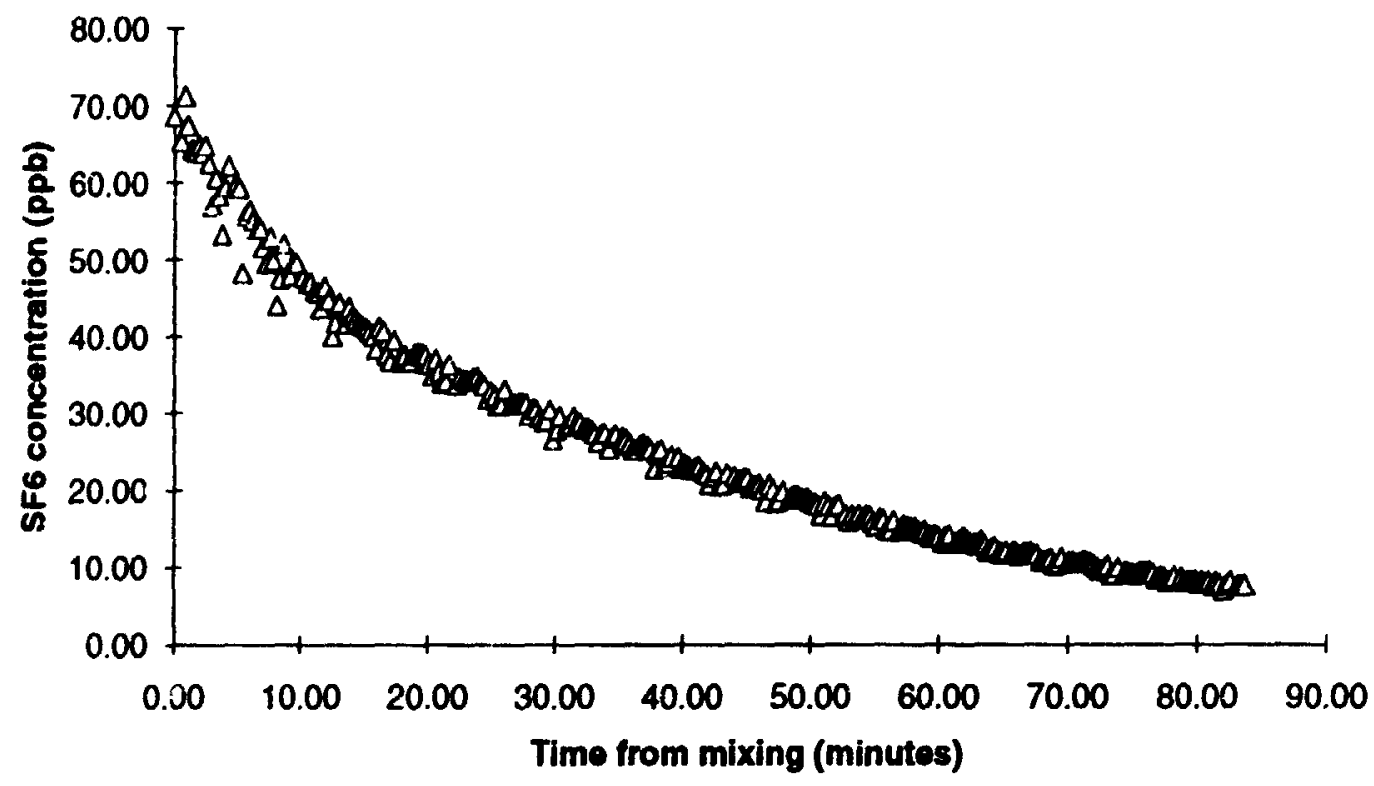

Figure 6.16: Contaminant concentration distribution in the test room for test T06, partition height $=5.5 \mathrm{ft}, \mathrm{gap}=0.0$ inches, partition located in the center of the room. 

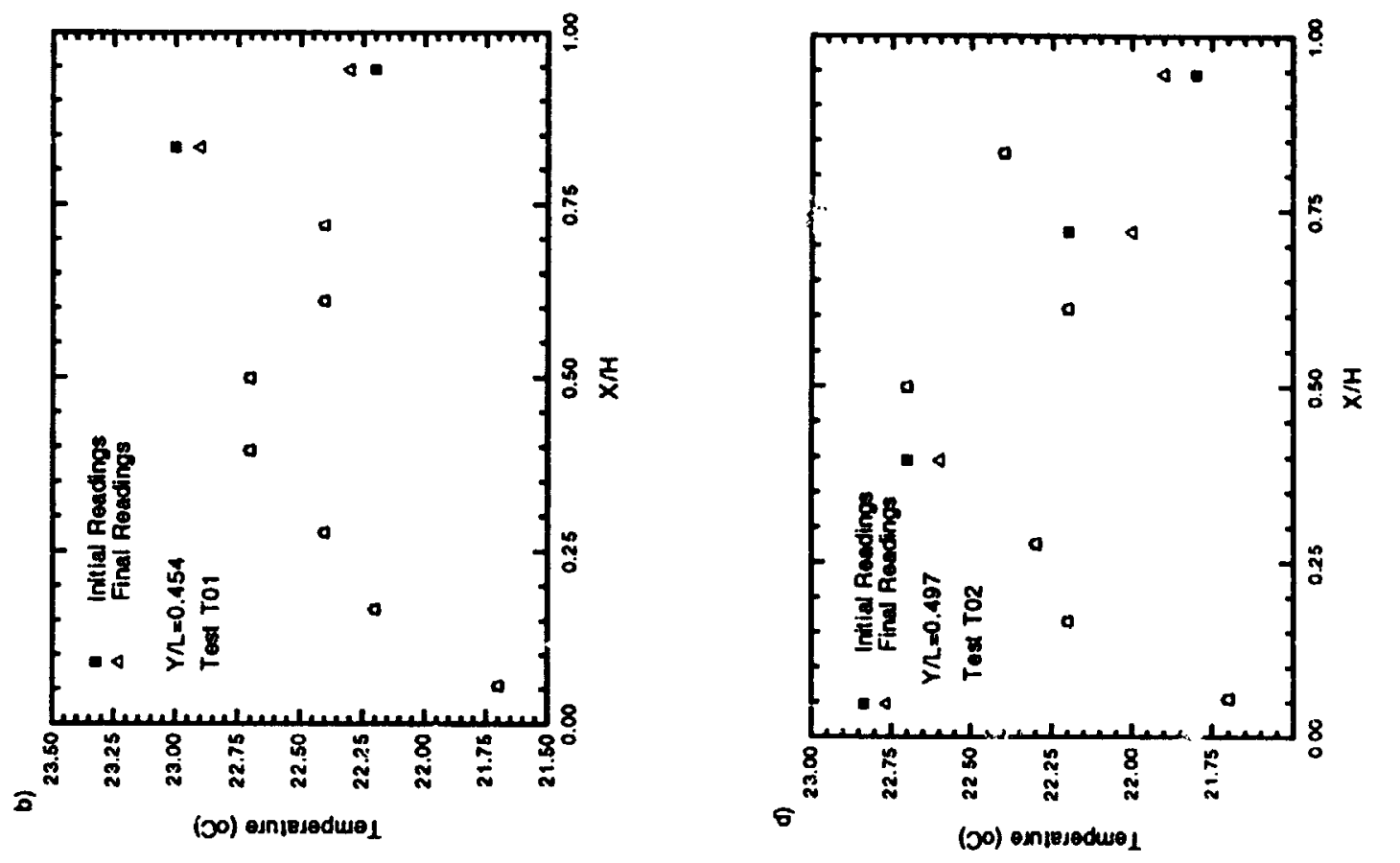

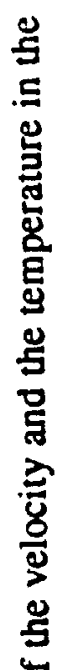
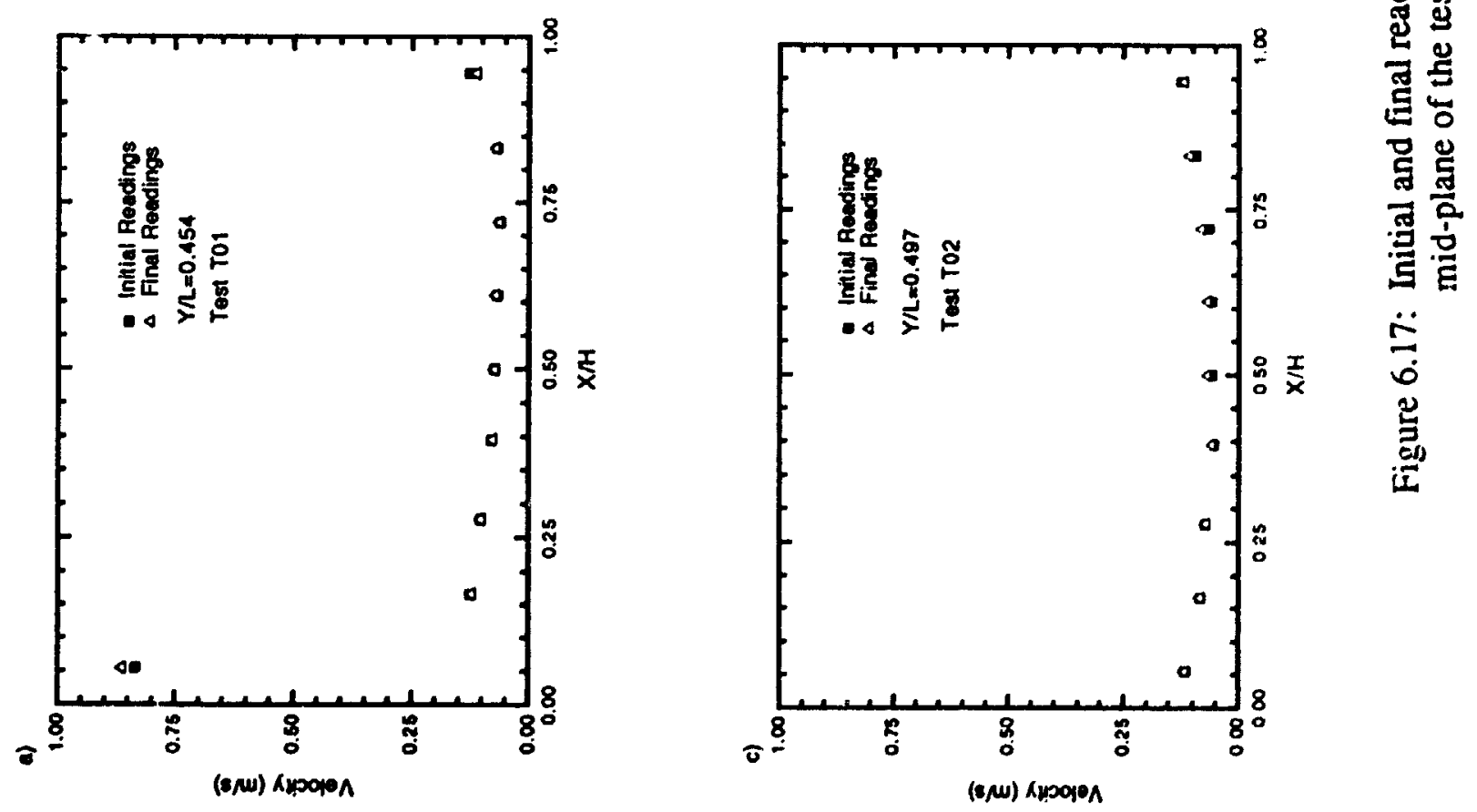

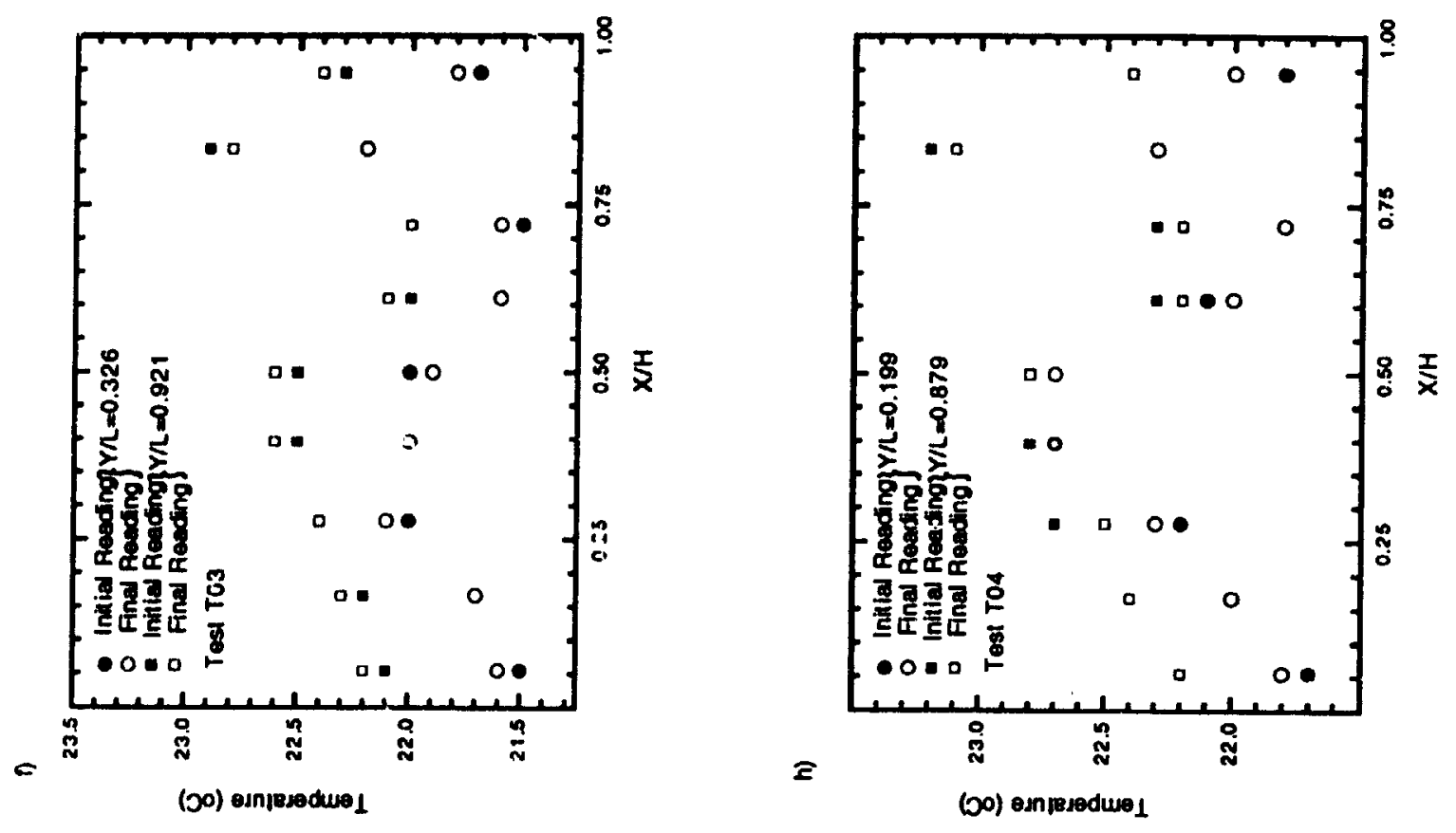

3
3
0
0
0
0
0
5
0
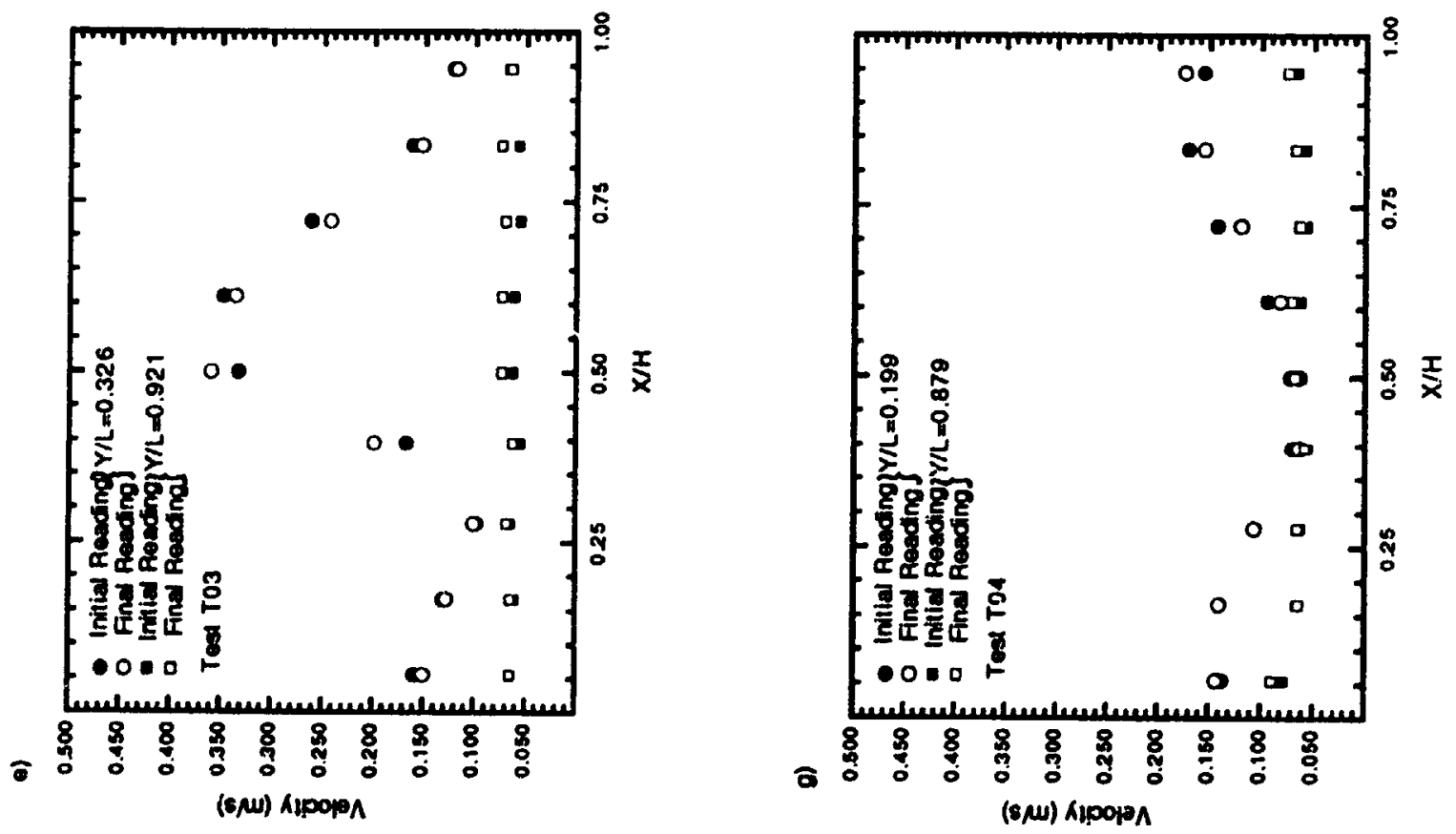


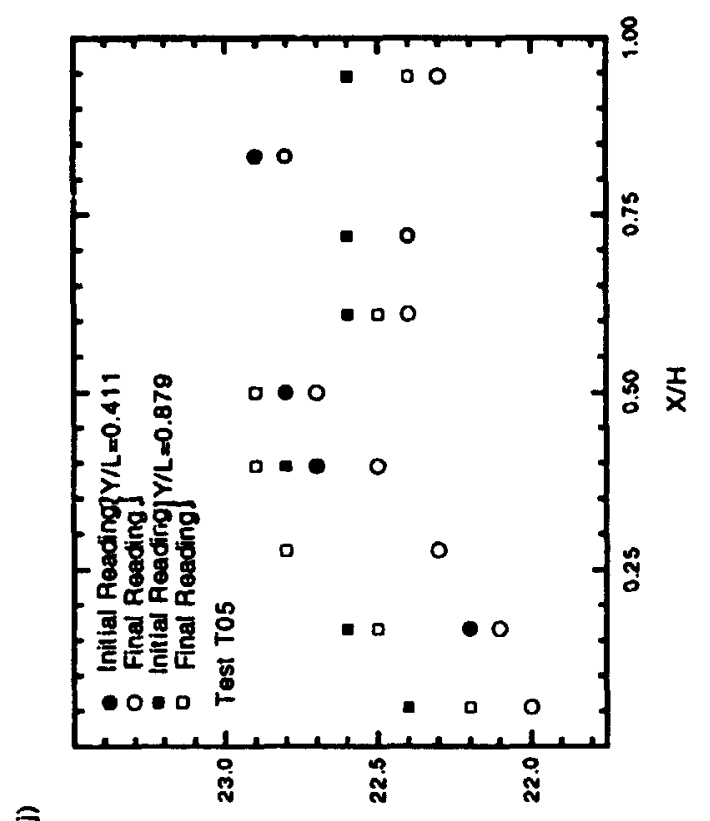

(D) eunjejedue I

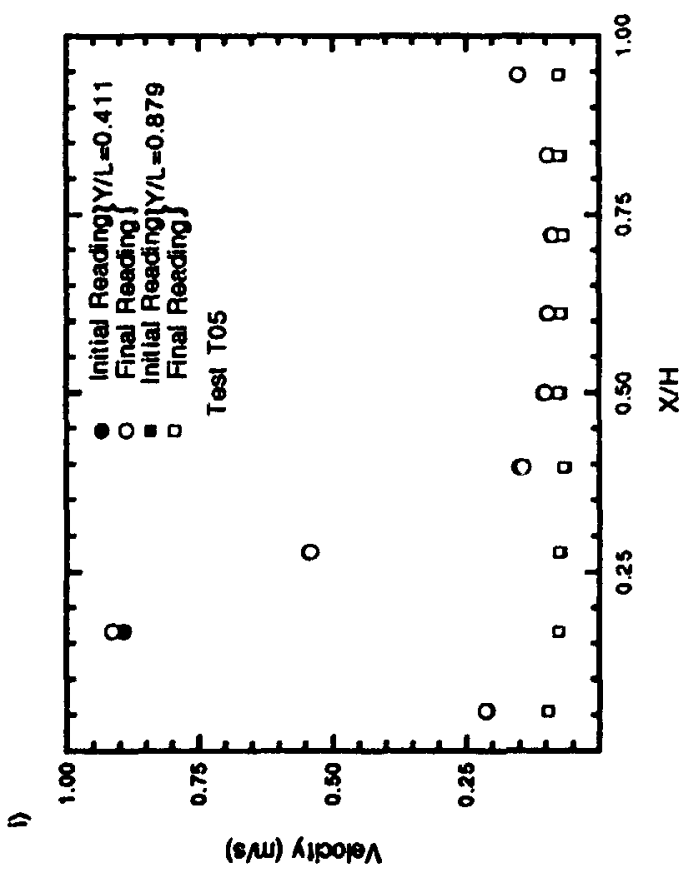

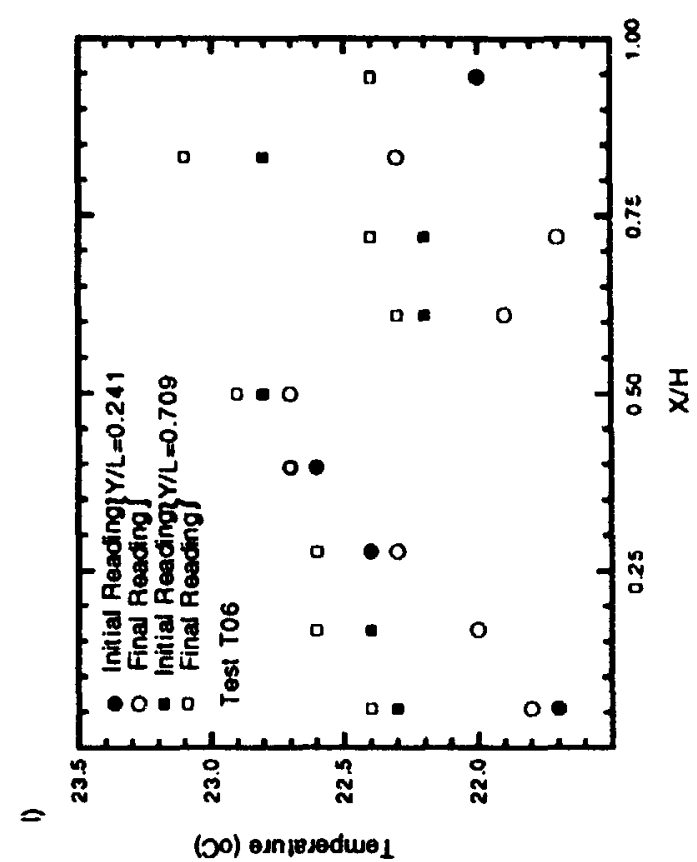

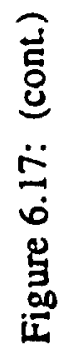

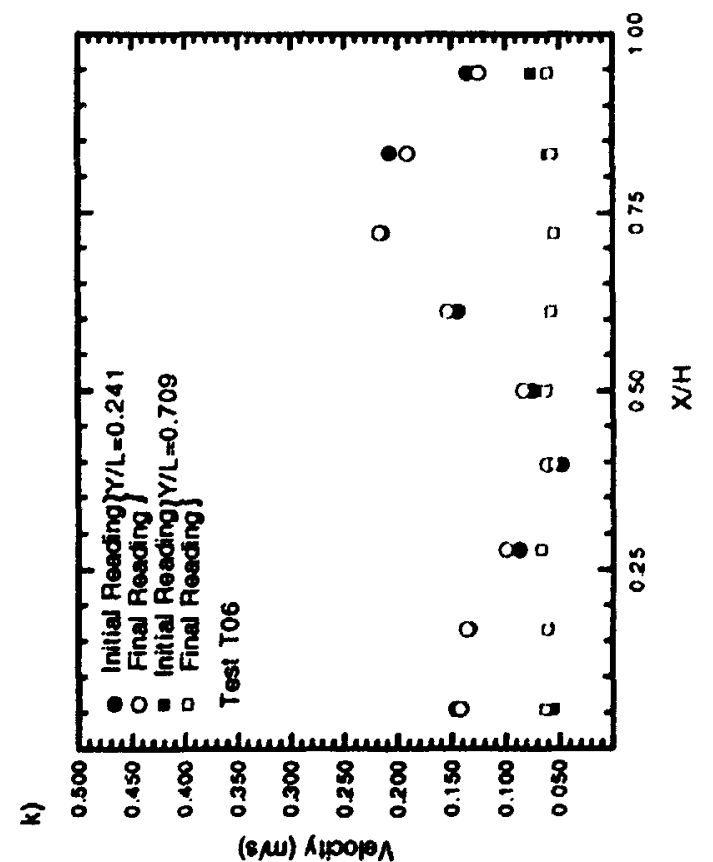




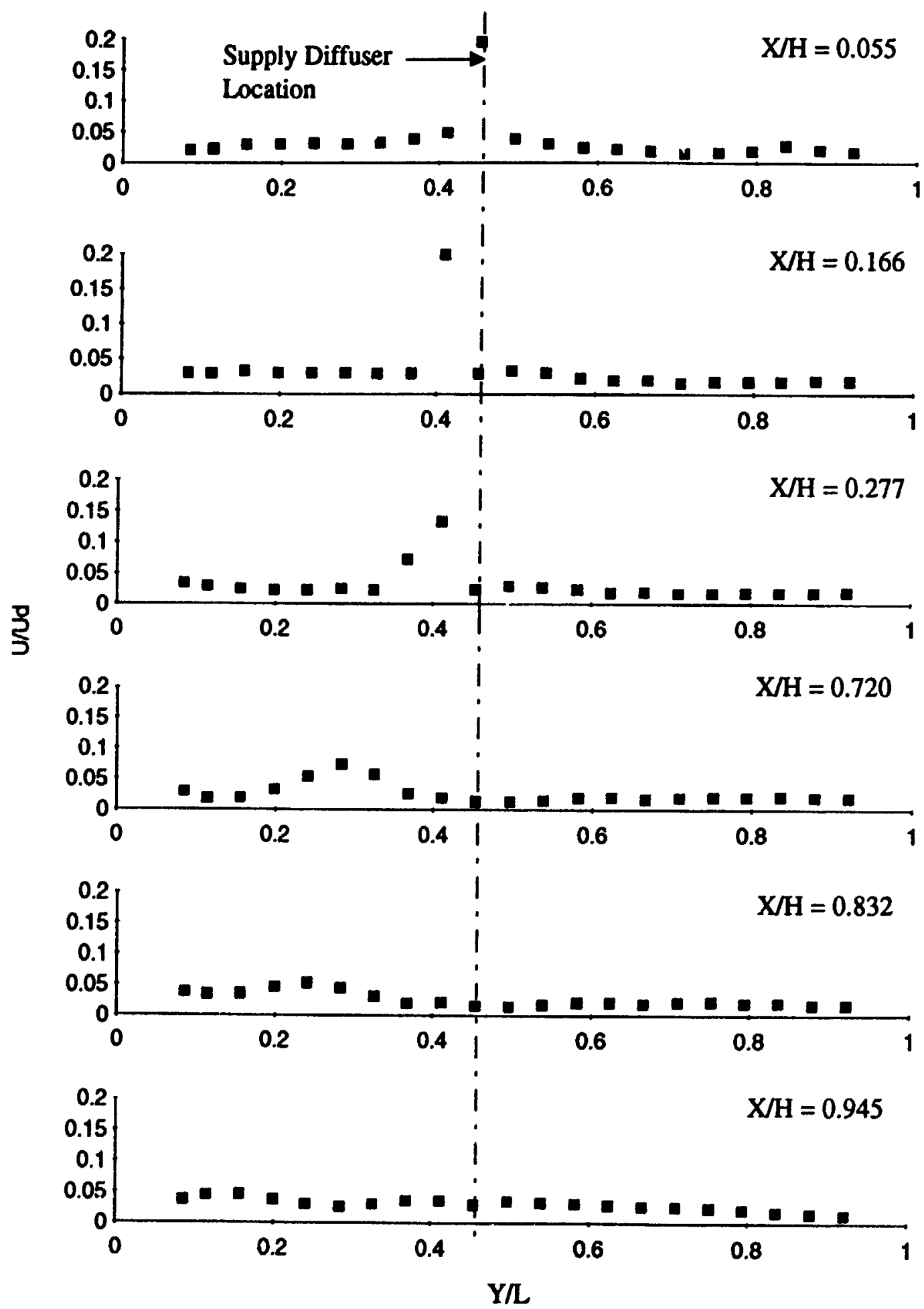

Figure 6.18: Typical horizontal distribution of the velocity in the symmetric plane of the test room. 
a)

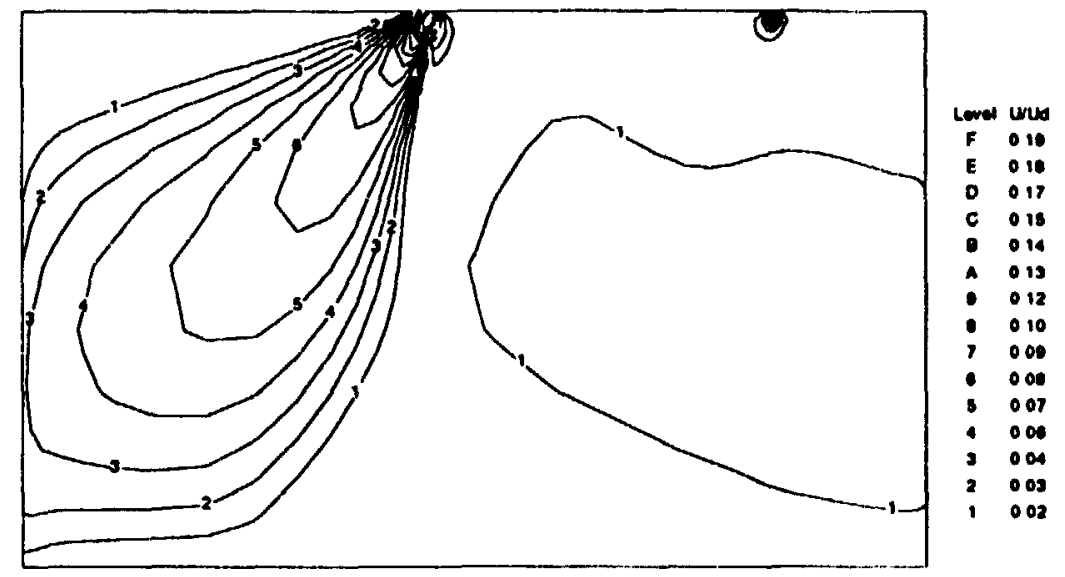

b) $\stackrel{0.5 \mathrm{~m} / \mathrm{s}}{\longrightarrow}$

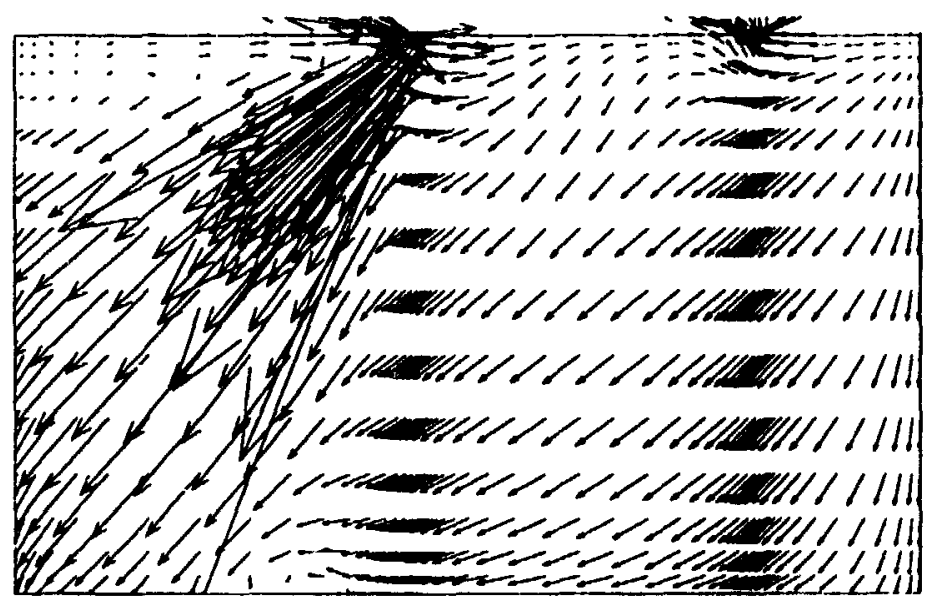

Figure 6.19: Predicted a) velocity contour, and b) velocity vector distributions in the mid-plane of the test room, for test T01, inflow angle $=16^{\circ}$. 
a)

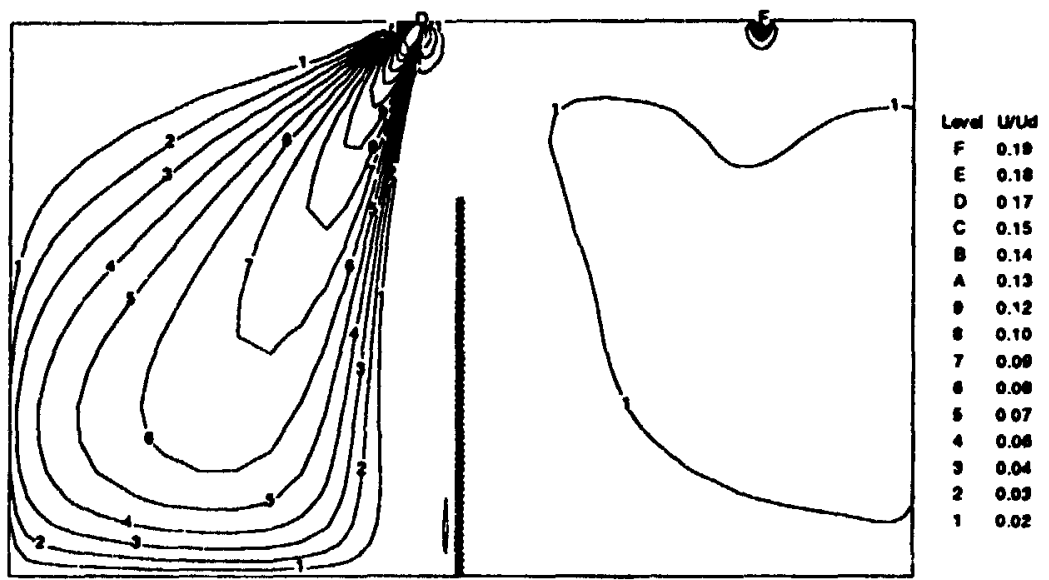

b) $\stackrel{0.5 \mathrm{~m} / \mathrm{s}}{\longrightarrow}$

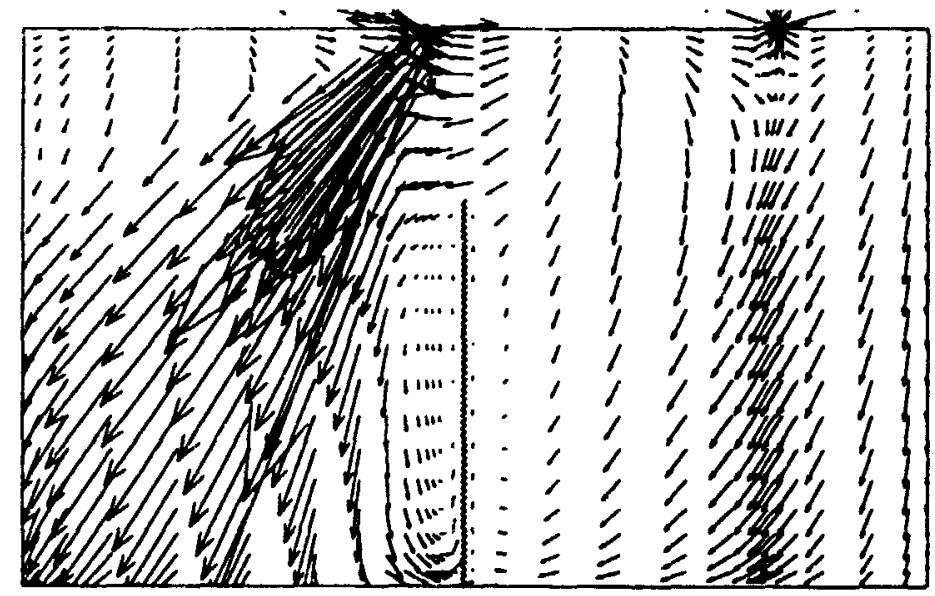

Figure 6.20: Predicted a) velocity contour, and b) velocity vector distributions in the mid-plane of the test room, for test T04, inflow angle $=16^{\circ}$. 
a)

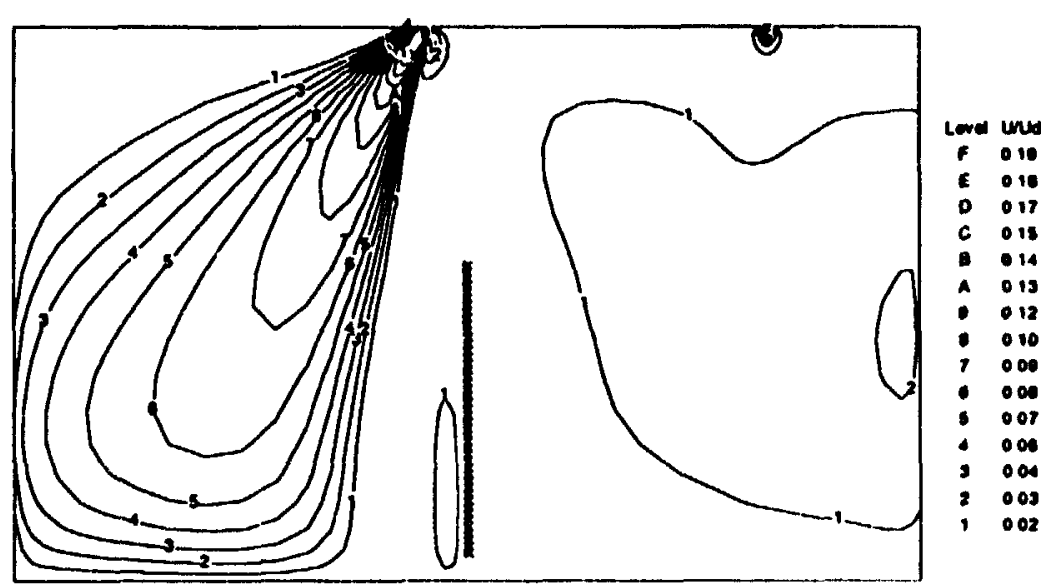

b) $0.5 \mathrm{~m} / \mathrm{s}$

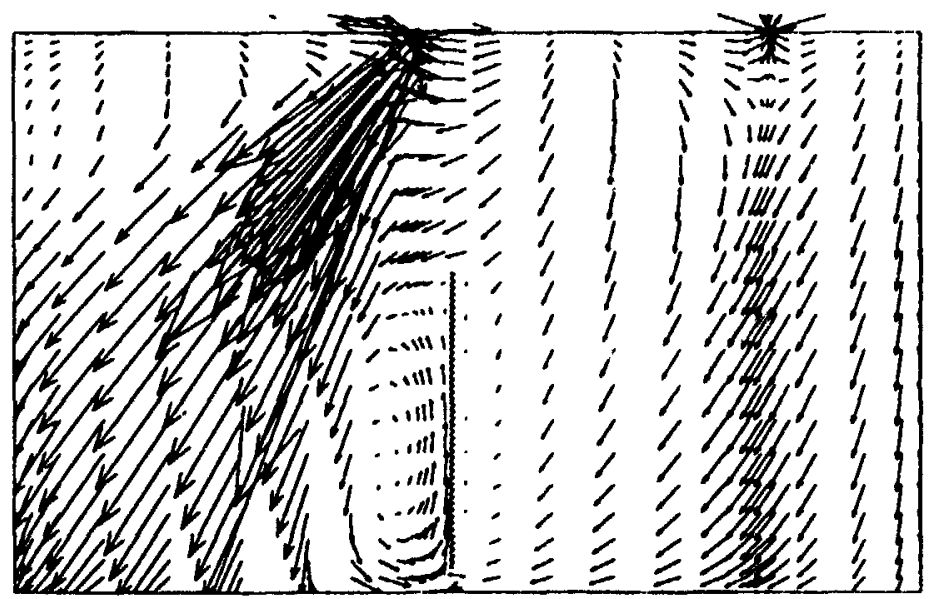

Figure 6.21: Predicted a) velocity contour, and b) velocity vector distributions in the mid-plane of the test room, for test T05, inflow angle $=16^{\circ}$. 

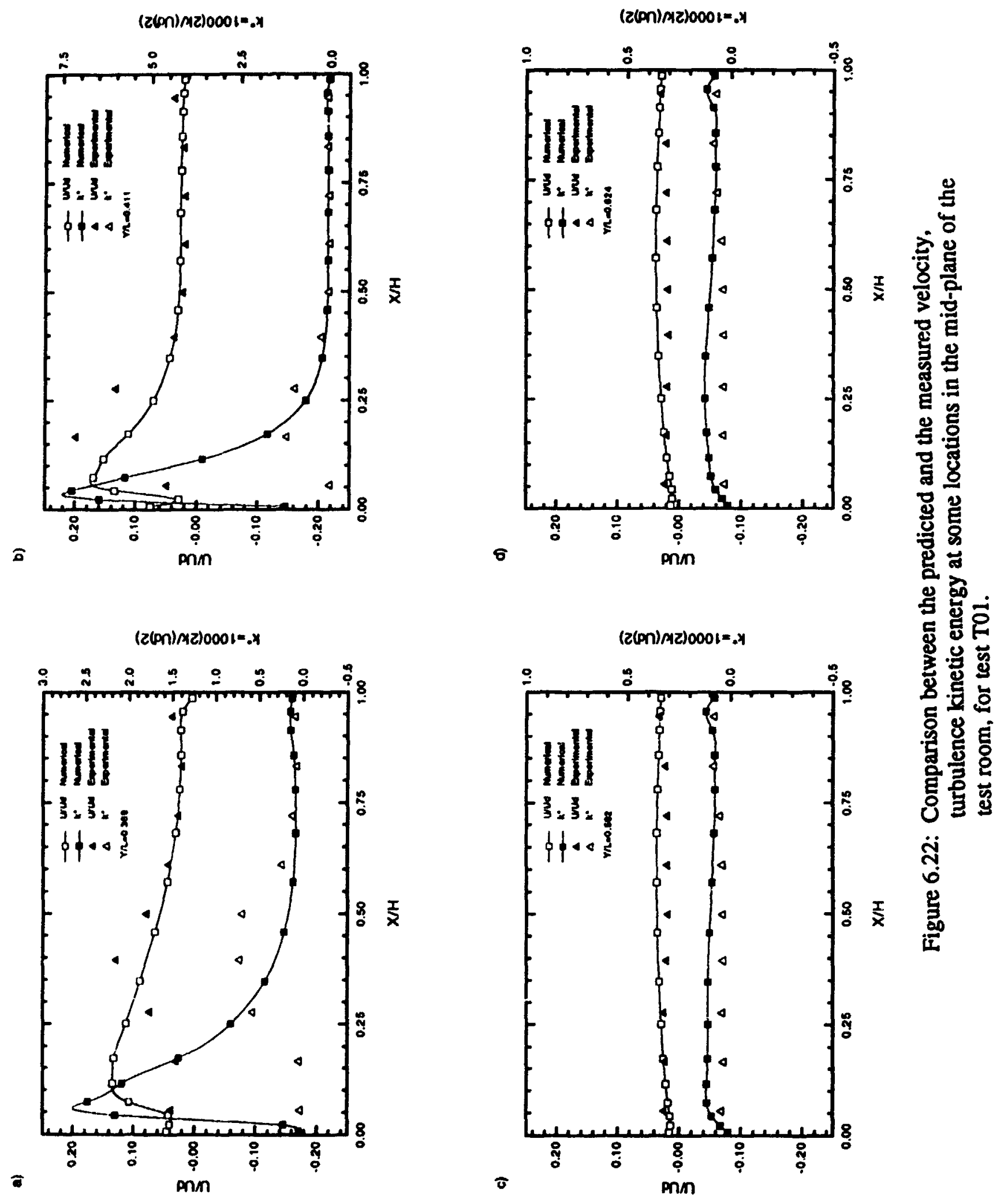

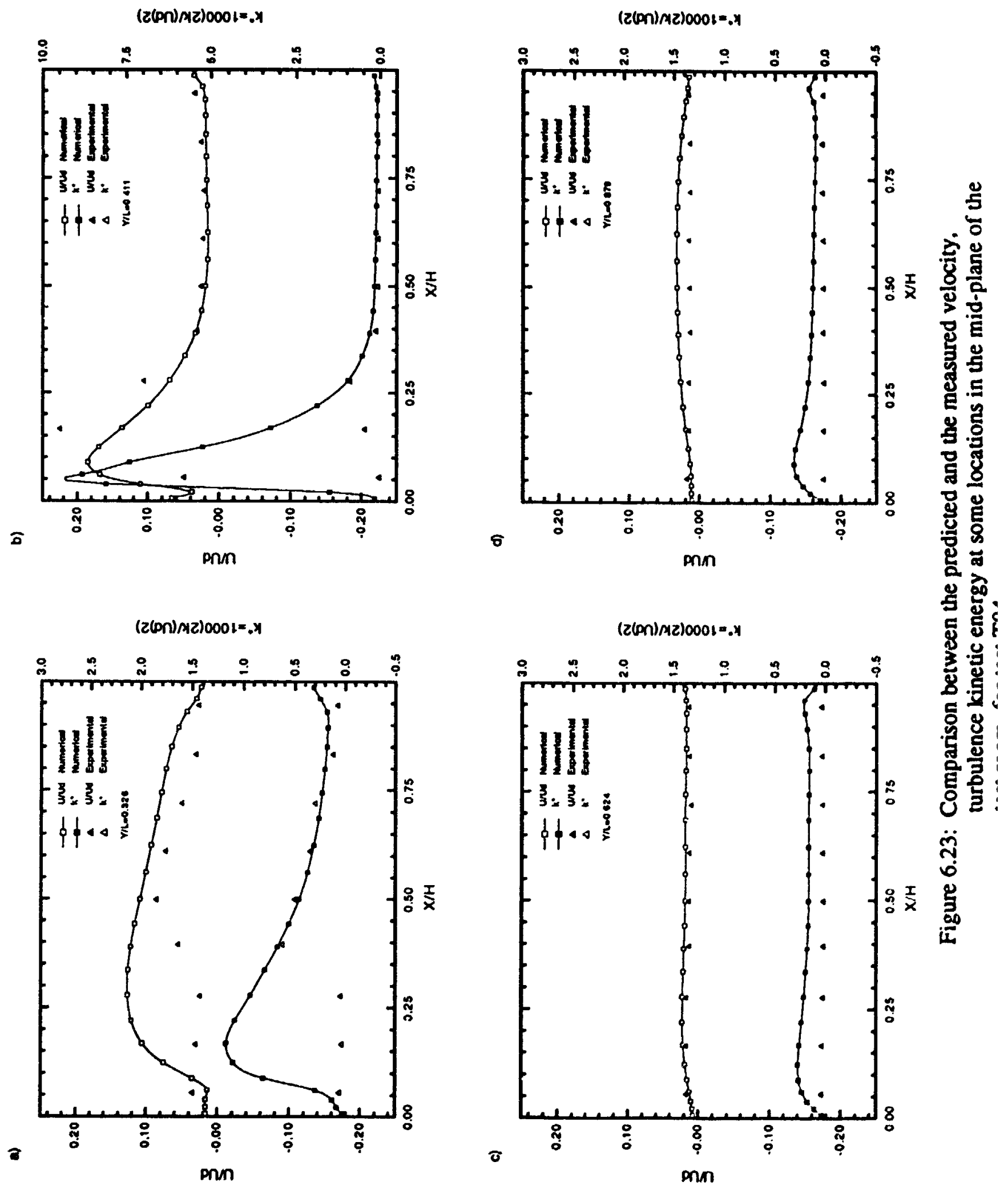

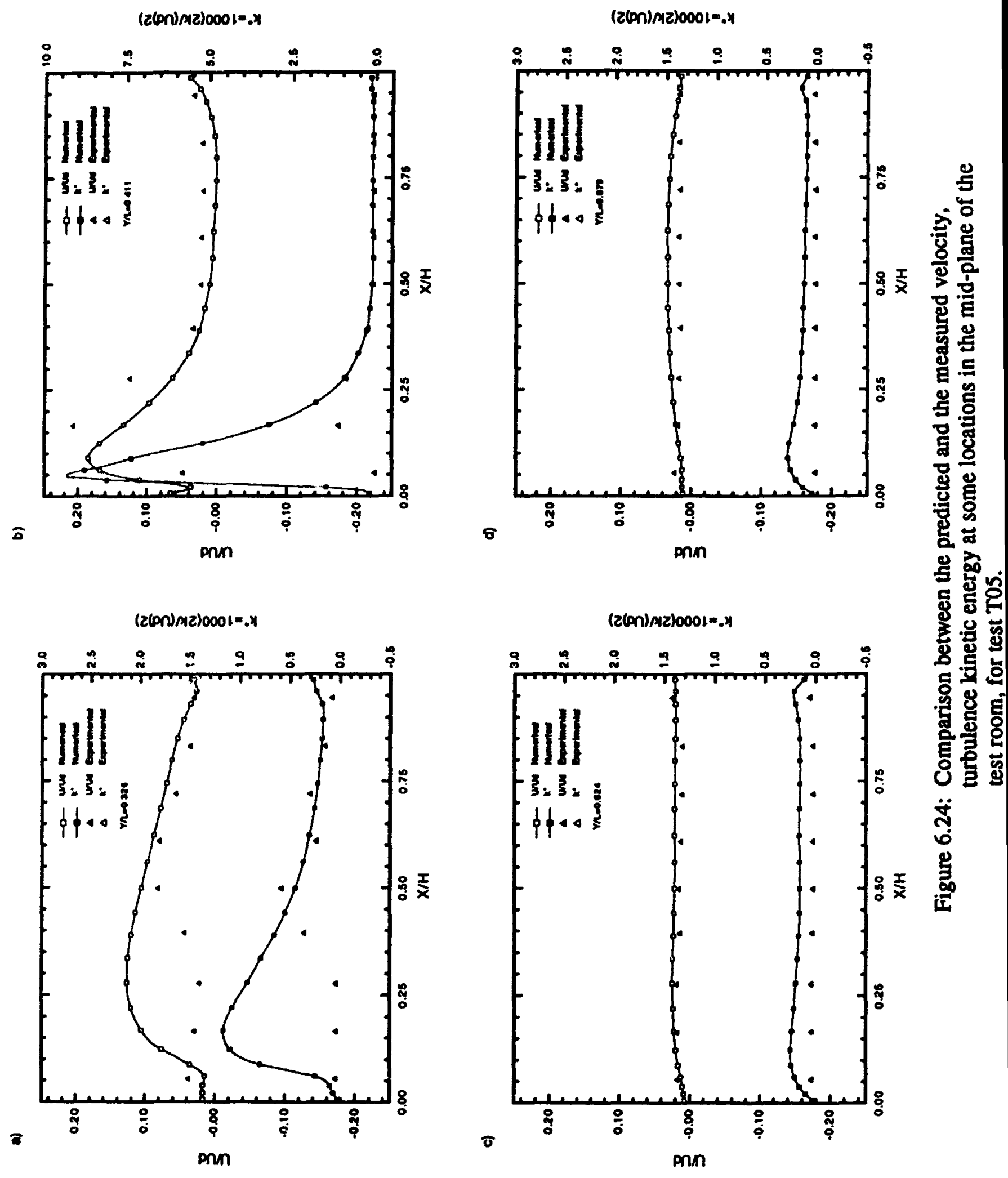
a)

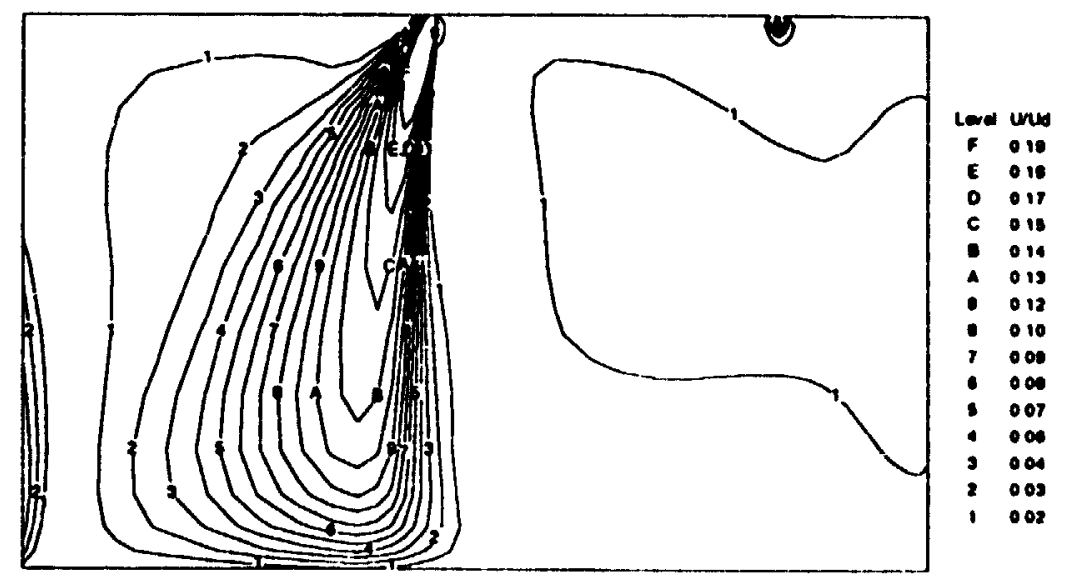

b)

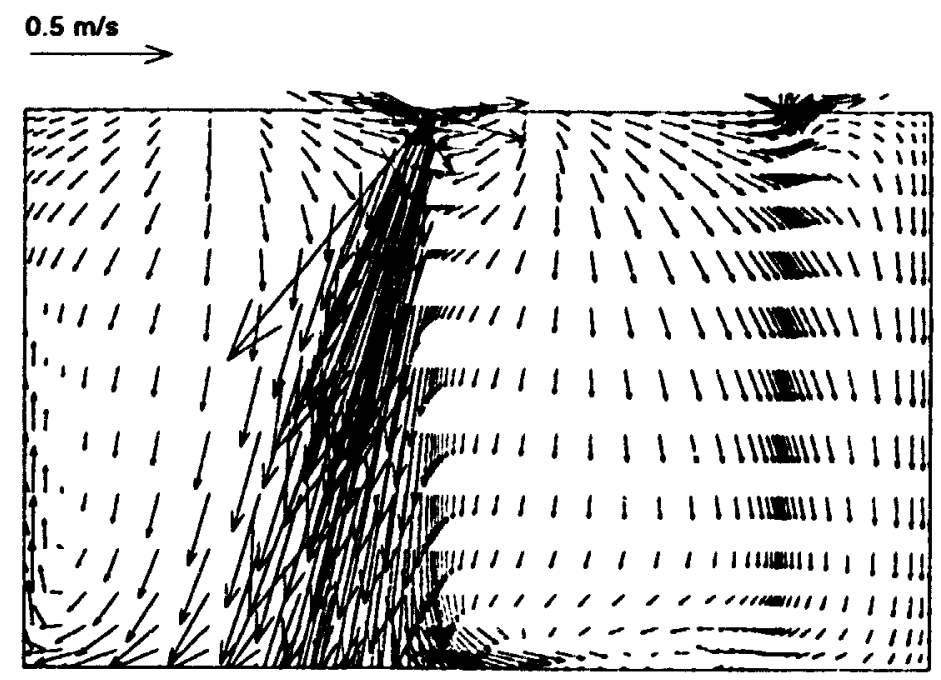

Figure 6.25: Predicted a) velocity contour, and b) velocity vector distributions in the mid-plane of the test room, for test T01, inflow angle $=11^{\circ}$. 
a)

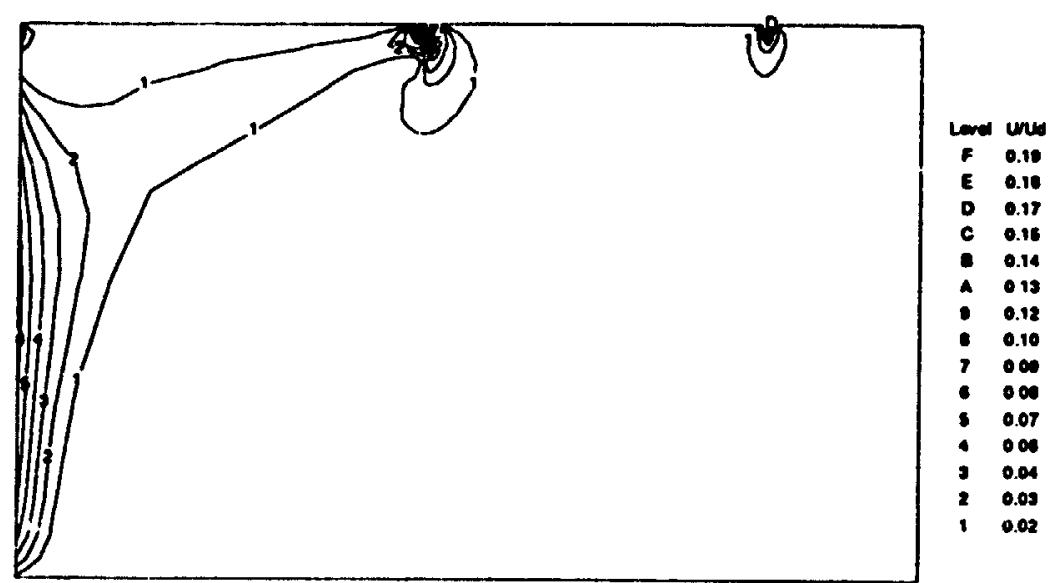

b) $\stackrel{0.5 \mathrm{~m} / \mathrm{s}}{\longrightarrow}$

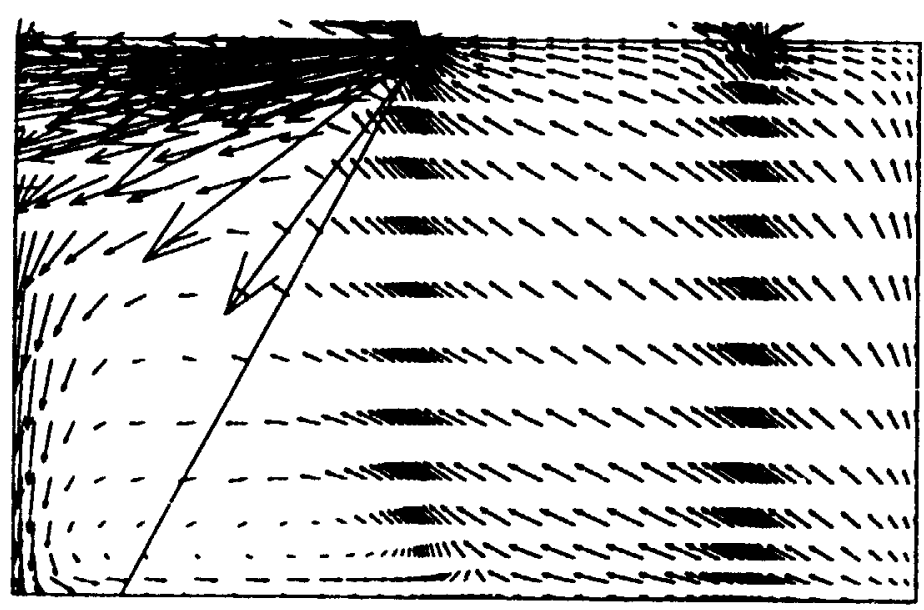

Figure 6.26: Predicted a) velocity contour, and b) velocity vector distributions in the mid-plane of the test room, for test T01, inflow angle $=22^{\circ}$. 
a)

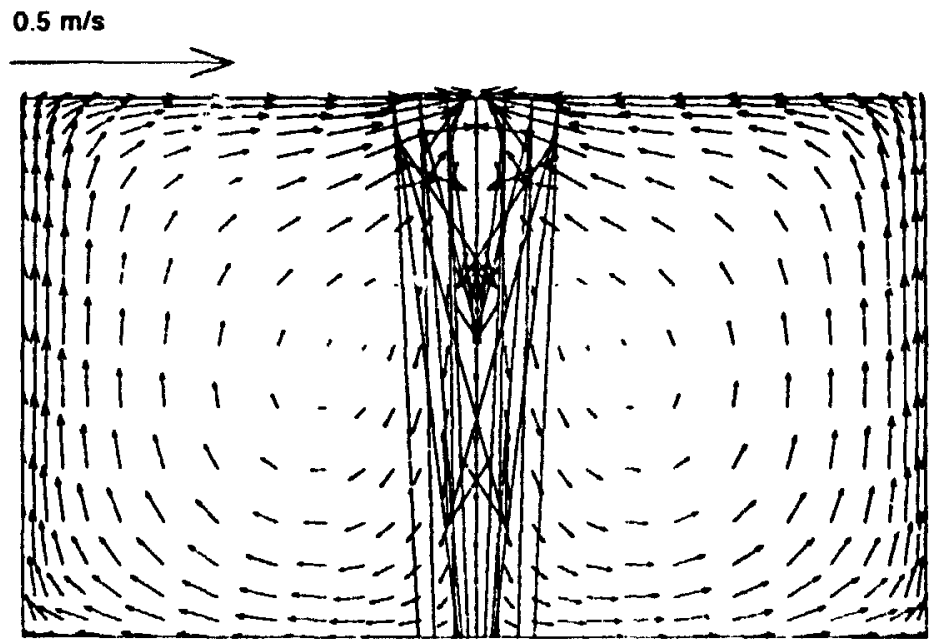

b)

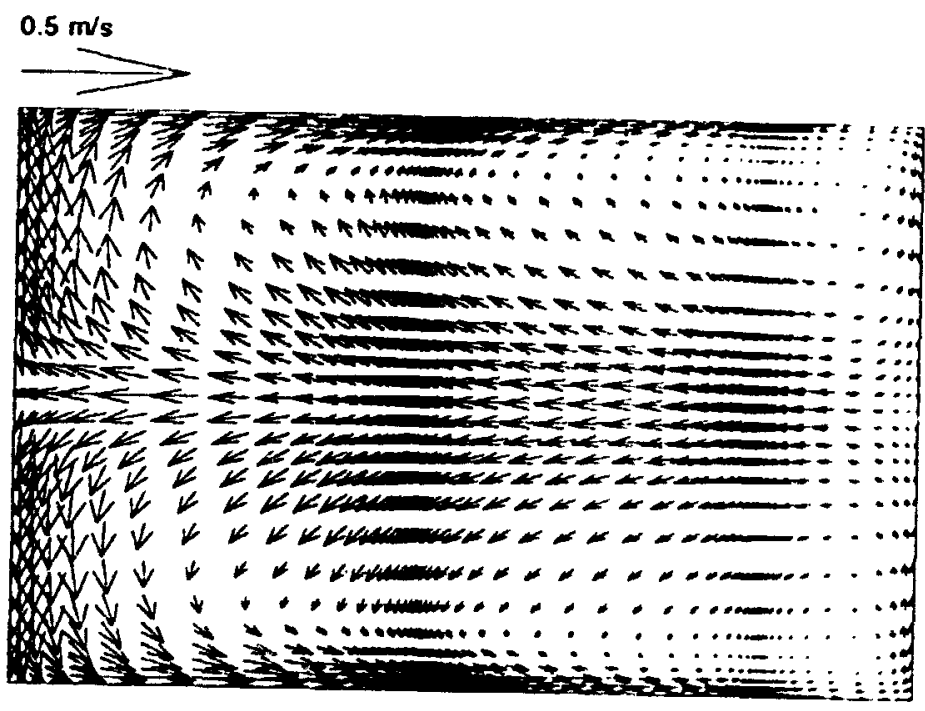

Figure 6.27: Predicted air flow pattern for test T01 in a) a plane containing the supply diffuser ( $Y / L=0.452)$, and $b$ ) a plane parallel to the supply diffuser $(\mathrm{X} / \mathrm{H}=0.856)$. 


\section{APPENDIX A}

\section{DEFINITIONS}

\section{Air Diffusion Performance Index (ADPD:}

The ADPI is commonly used to specify the performance of an air diffuser system, and is defined as the percentage of the locations in the occupied zone that meet acceptable limits of effective draft temperatures between $-1.7^{\circ} \mathrm{C}$ and $+1.1^{\circ} \mathrm{C}$ and a local air velocity of less than $(1.35 \mathrm{~m} / \mathrm{s}$.

Effective draft temperature ( $\Phi$ ): is given by the following equation [28]:

$$
\left.\Phi=i T_{x}-T_{c}\right)-8.0\left(V_{x}-0.15\right) \text {, }
$$

where $T_{x}$ : is the local air temperature,

$T_{c}:$ is the room average temperature,

$V_{x}$ : is the local air velocity in $\mathrm{m} / \mathrm{s}$.

\section{Local Purging Flow Rate:}

It is defined as the local net flow rate al which air is supplied, from the supply air opening, to an arbitrary point within the room.

\section{Local Mean age (Mean Age of Air), (or Age of Air):}

The locial mean age at an arbitrary point is the time that has elapsed, on average, since the molecules passing this point entered the room. 


\section{Ventilation Effectiveness Performance Index (VEPI):}

If "c" designates an effective pollutant concentration for a given position and time in a space, VEPI is then defined as the percentage of points for which "c" lies in the air quality comfort zone.

\section{Box Method:}

Boundary conditions are given at the surface of an imaginary box around the diffuser.

\section{Simplified slit:}

Replacing the complicated diffuser with a simple opening which has the same effective area. 

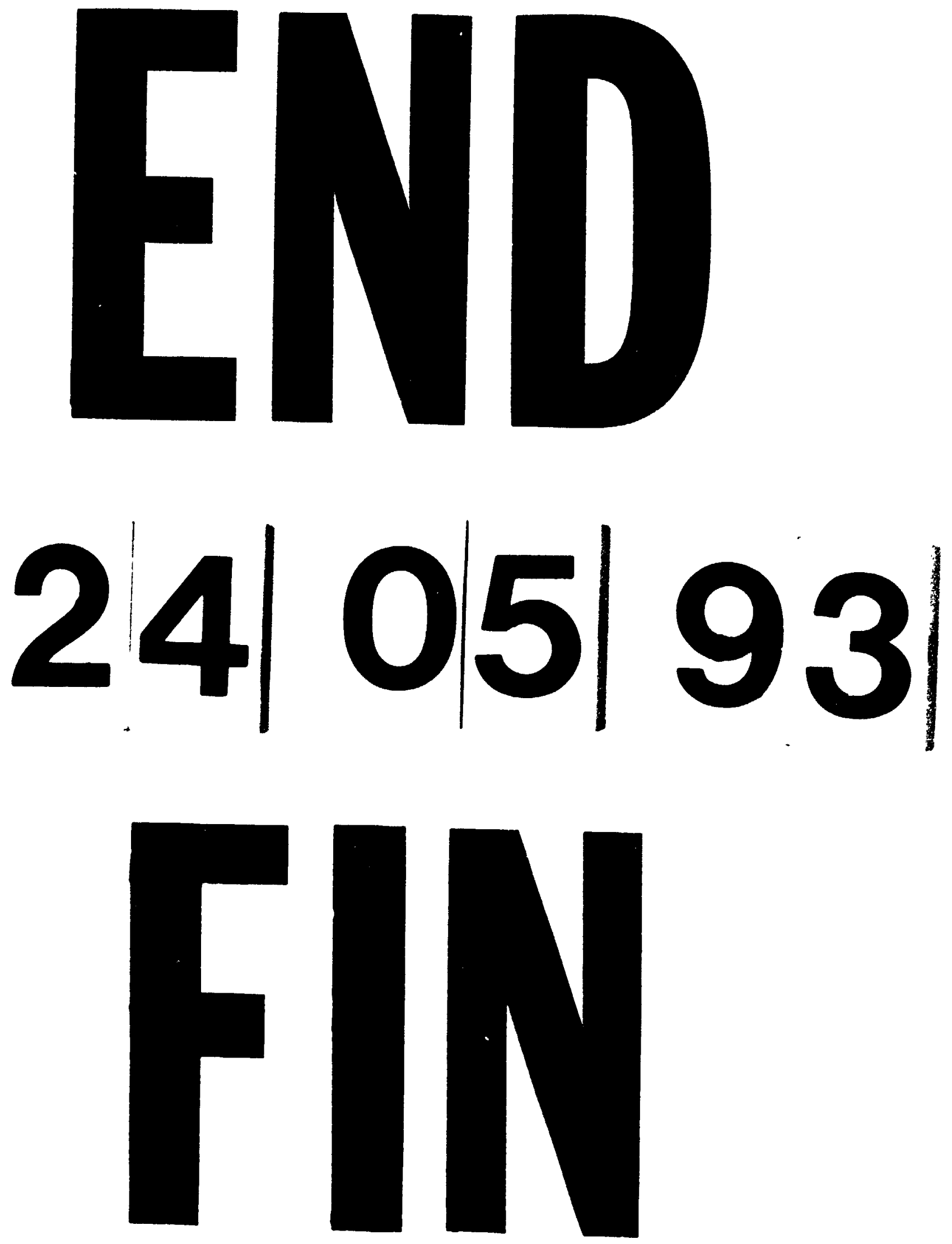